\title{
VARIABILIDADE ESPACIAL DO ÍNDICE DE CONE CORRELACIONADA COM MAPAS DE PRODUTIVIDADE
}

\author{
RAYMUNDO LEITE DA SILVA JÚNIOR \\ Engenheiro Agrônomo
}

Orientador: Prof. Dr. JOSÉ PAULO MOLIN

\begin{abstract}
Dissertação apresentada à Escola Superior de Agricultura "Luiz de Queiroz", Universidade de São Paulo, para obtenção do título de Mestre em Agronomia, Área de Concentração: Máquinas Agrícolas.
\end{abstract}

$$
\begin{gathered}
\text { P I R A C I C A B A } \\
\text { Estado de São Paulo - Brasil } \\
\text { Março - } 2001
\end{gathered}
$$




\section{ERRATA}

Autor: Raymundo Leite da Silva Júnior

Título: Variabilidade espacial do índice de cone correlacionada com mapas de produtividade.

$\begin{array}{lll}\text { p. } & \text { item } & \text { linha } \\ 90 \text { a } 93 & 4.5 & \text { figuras 39 a 45 } \\ 100 \text { a } 103 & 4.7 & \text { figuras 54 a } 60 \\ 107 & 5 & \text { primeira }\end{array}$

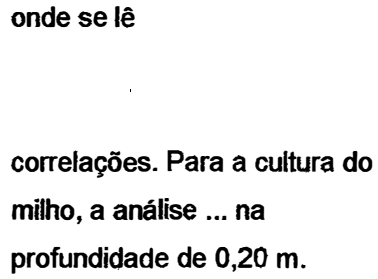

onde se lê correlações. Para a cultura do milho, a análise ... na profundidade de $0,20 \mathrm{~m}$.

leia-se

desconsiderar as retas ajustadas

desconsiderar as retas ajustadas correlações, porém, com baixos coeficientes de determinação. No entanto, houve uma tendência de diminuição da produtividade tanto do milho como da soja com o aumento do indice de cone, especialmente nas profundidades de 0,10 a $0,20 \mathrm{~m}$. 
Dados Internacionais de Catalogação na Publicação (CIP)

DIVISÃO DE BIBLIOTECA E DOCUMENTAÇÃO - Campus "Luiz de Oueiroz"/USP

\section{Silva Júnior, Raymundo Leite da}

Variabilidade especial do índice de cone correlacionada com mapas de produtividade / Raymundo Leite da Silva. Júnior. -- Piracicaba, 2001.

132 p. : il.

Dissertação (mestrado) - - Escola Superior de Agricultura Luiz de Queiroz, 2001. Bibliografia.

1.Compactação do solo 2. Equipamento agrícola 3. GPS 4. Mapeamento do solo 5. Penetrômetro 6. Profundidade 7. Relação solo-água 8. Resistência à penetração 9. SIG 10. Variabilidade espacial I. Titulo

CDD 631.4 
A Deus, a minha esposa Karla, aos meus filhos André, Rebeca e Ester, e aos meus pais, que deste mundo já partiram. 


\section{AGRADECIMENTOS}

Ao Criador do Céu, da Terra, da Água e do Mar, e de tudo que neles há; Deus-Jesus.

Ao Prof. Dr. José Paulo Molin, como orientador, pela oportunidade de poder realizar este trabalho e partilhar do seu conhecimento, podendo contar com seu incentivo, apoio e amizade.

A todos os Professores do Departamento de Engenharia Rural, pela enorme contribuição ao meu enriquecimento intelectual e profissional.

A todos os técnicos, operadores de máquinas e mecânicos do Departamento de Engenharia Rural, pelo apoio durante a realização deste trabalho.

A todos os funcionários da Faculdade de Zootecnia e de Engenharia de Alimentos da Universidade de São Paulo em Pirassununga, pelo apoio durante a realização deste trabalho.

A todos os funcionários do Centro de Tecnologia da Fundação $A B C$, em Castro, Paraná, pelo apoio durante a realização deste trabalho.

À jornalista Ana Paula da Silva, pelas revisões e correções feitas neste trabalho.

A todos os colegas e amigos, pelo apoio e amizade durante o período que passamos juntos no Curso de Máquinas Agrícolas. 


\section{SUMÁRIO}

Página

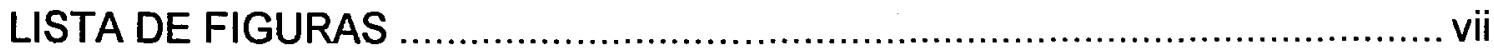

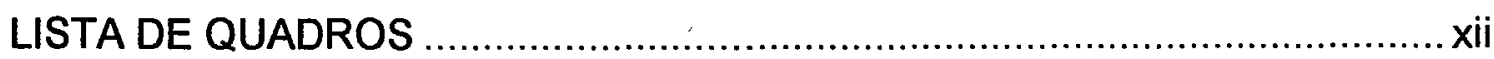

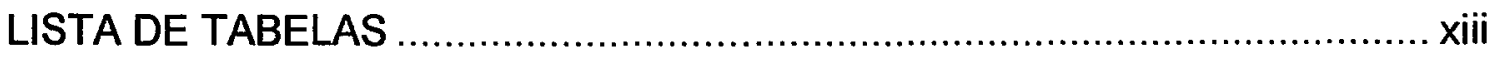

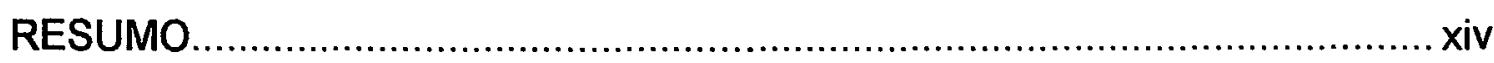



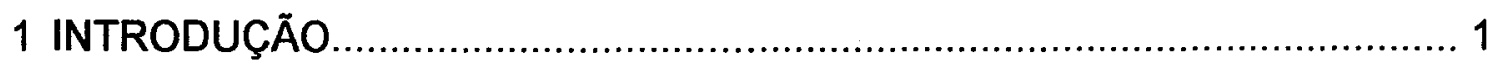

2 REVISÄO BIBLIOGRÁFICA .......................................................... 4

2.1 A compactação do solo e a resistência à penetração............................. 4

2.2. Origens e principais causas da resistência do solo ................................ 6

2.3 A resistência do solo à penetração e suas implicações........................... 8

2.4 Métodos para determinação da resistência do solo à penetração............. 9

2.5 Penetrômetros ............................................................................. 11

2.5.1 Tipos de penetrômetros de cone manuais.......................................... 15

2.5.1.1 Penetrômetros de cone manuais de mola ....................................... 16

2.5.1.2 Penetrômetros de cone manuais de impacto .................................. 16

2.5.1.3 Penetrômetros de cone manuais com traçadores gráficos................. 17

2.5.1.4 Penetrômetros de cone manuais elétricos e eletrônicos ................... 18

2.5.2 Penetrômetros de cone mecânicos ................................................... 19

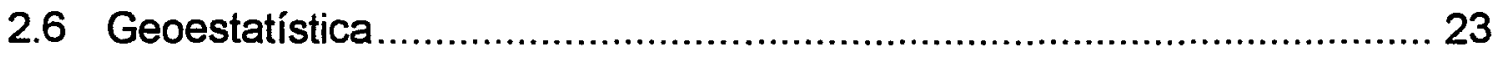

2.7 Modelagem probabilística e estacionaridade..................................... 24

2.7.1 Descrição e modelagem da variabilidade espacial ............................. 26

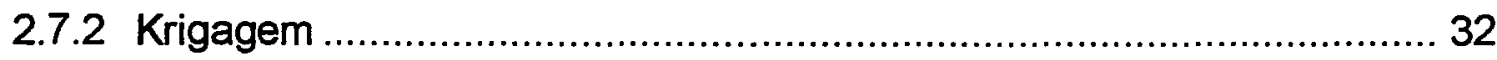

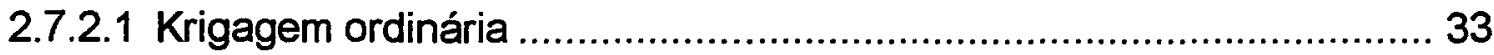

2.8 Sistema de Posicionamento Global - GPS..................................... 37

2.9 Sistema de Informação Geográfica - SIG .......................................... 39

2.10 Mapas de produtividade.................................................................. 40

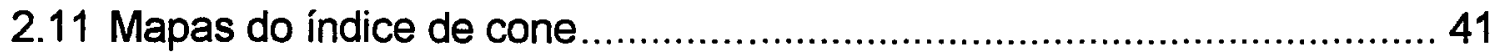




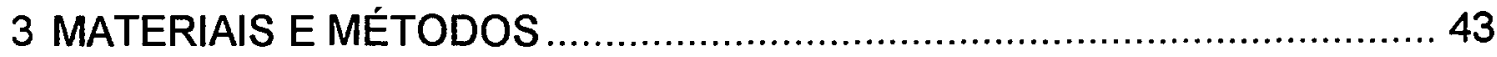

3.1 Caracterização das áreas experimentais ........................................... 43

3.2 Caracterização do penetrômetro........................................................ 44

3.2.1 Sistema de aquisição de dados .................................................... 47

3.3 Sistema de Posicionamento Global - GPS ....................................... 48

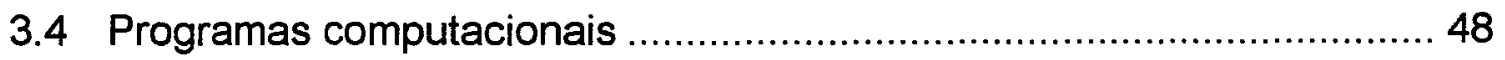

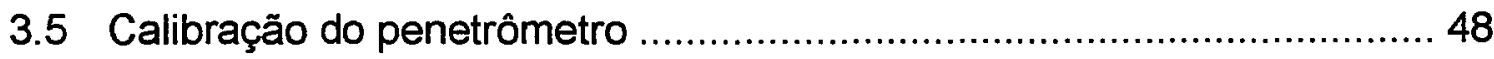

3.6 Caracterização das grades amostrais do indice de cone e do teor

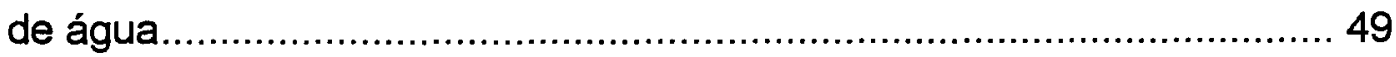

3.7 Coleta de dados do índice de cone e do teor de água ........................ 52

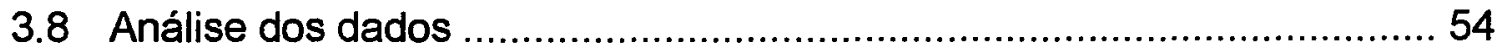

3.8.1 Análise estatística descritiva............................................................. 54

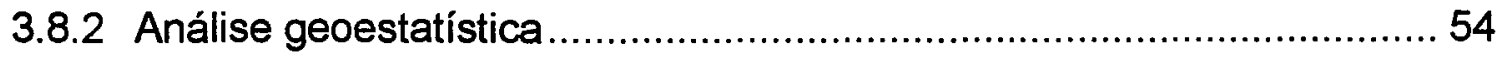

3.9 Geração dos mapas do indice de cone ................................................. 55

3.10 Geração dos mapas de produtividade .................................................. 56

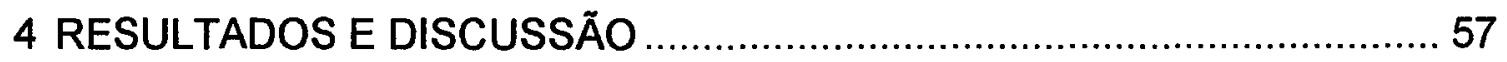



4.2 Análise estatística descritiva dos dados de campo.............................. 59

4.2.1 Análise estatística descritiva dos dados da área de Pirassununga ...... 59

4.2.2 Análise estatística descritiva dos dados da área de Castro................. 67

4.3 Análise geoestatística dos dados .....................................................69

4.3.1 Análise geoestatística dos dados da área de Pirassununga ................ 70

4.3.2 Análise geoestatística dos dados da área de Castro.......................... 76

4.4 Mapas do indice de cone da área de Pirassununga ............................. 78

4.5 Análises de correlação entre produtividade e índice de cone da

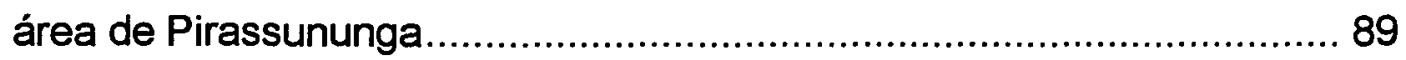

4.6 Mapas do índice de cone da área de Castro ...................................... 94

4.7 Análises de correlação entre produtividade e indice de cone da

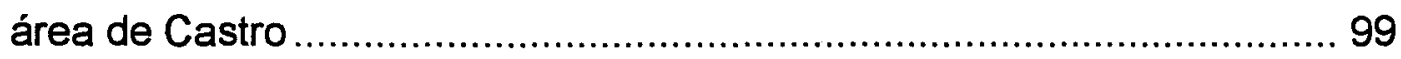

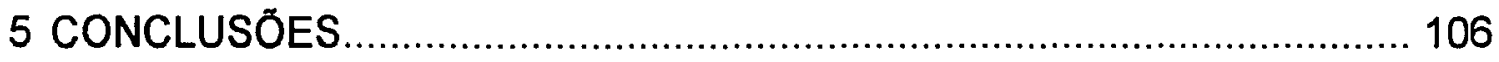




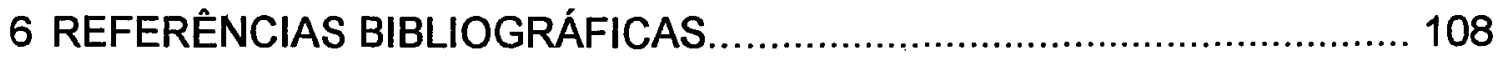

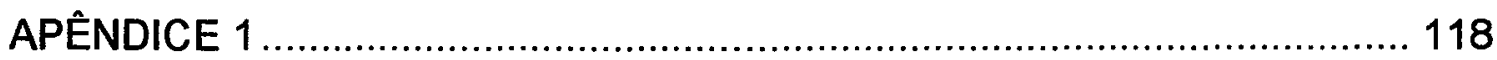

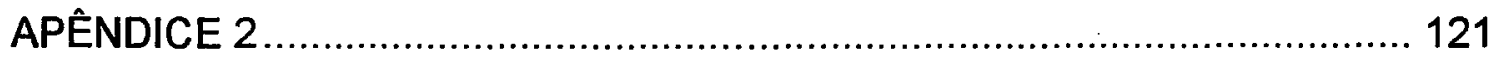

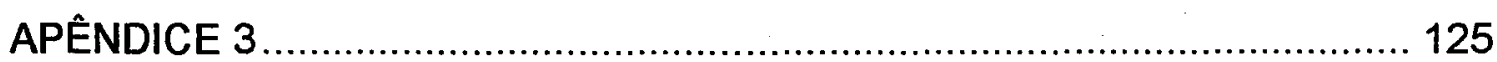




\section{LISTA DE FIGURAS}

Página

1 Curva de compressão do solo como meio de determinar o valor da pressão de pré-consolidação .................................................................... 5

2 Constituição básica dos penetrômetros de cone....................................... 14

3 Representação da associação das variáveis em pontos distintos em função da distância que as separa.................................................... 27

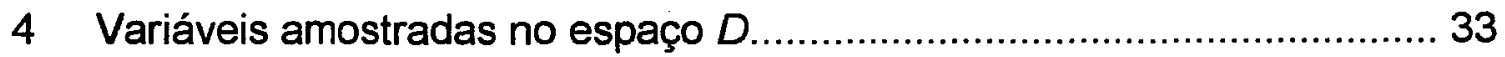

$5 a$ e 5b Diferentes configurações de vizinhança .......................................... 34

6 Penetrômetro utilizado no trabalho mostrando as partes constituintes mais importantes (a). Penetrômetro em funcionamento no campo (b)

7 Grade amostral sistemática da área de Pirassununga mostrando os pontos onde foram coletados os dados do indice de cone e do teor de água

8 Grade amostral sistemática da área de Castro mostrando os pontos onde foram coletados os dados do índice de cone e do teor de água

9 Grade amostral sistemática da área de Pirassununga mostrando os 150 pontos onde foram coletados os dados do índice de cone e do teor de água, após a irrigação pelo sistema de pivô central

10 Curva de calibração da célula de carga utilizada para medir a força de penetração no penetrômetro.

11 Curva de calibração do sonar utilizado para medir a profundidade de penetração no penetrômetro. 58

12 Gráfico de distribuição de frequência dos dados do índice de cone da área de Pirassununga 
13 Gráfico do índice de cone, relacionado com a profundidade, representando a média de todos os pontos da área de Pirassununga

14 Gráfico de distribuição de frequência dos dados do índice de cone dos 150 pontos antes da irrigação pelo pivô central da área de Pirassununga

15 Gráfico de distribuição de frequência dos dados do índice de cone dos 150 pontos após a irrigação pelo pivô central da área de Pirassununga

16 Gráfico do índice de cone, relacionado com a profundidade, representando a média dos 150 pontos antes da irrigação pelo pivô central da área de Pirassununga 65

17 Gráfico do índice de cone, relacionado com a profundidade, representando a média dos 150 pontos após a irrigação pelo pivô central da área de Pirassununga 66

18 Gráfico de distribuição de frequência dos dados do índice de cone da área de Castro

19 Gráfico do índice de cone, relacionado com a profundidade, representando a média de todos os pontos da área de Castro 69

20 Semivariogramas experimentais mostrando os modelos ajustados para os dados do índice de cone de todas as profundidades da área de Pirassununga 70

21 Semivariogramas experimentais mostrando os modelos ajustados para os dados do índice de cone de todas as profundidades dos 150 pontos antes da irrigação pelo pivô central da área de Pirassununga

22 Semivariogramas experimentais mostrando os modelos ajustados para os dados do índice de cone de todas as profundidades dos 150 pontos após a irrigação pelo pivô central da área de Pirassununga 
23 Semivariogramas experimentais mostrando os modelos ajustados para os dados do índice de cone de todas as profundidades da área de Castro. 76

24 Mapa do índice de cone da profundidade de 0,10 $\mathrm{m}$ da área de Pirassununga 78

25 Mapa do índice de cone da profundidade de $0,15 \mathrm{~m}$ da área de Pirassununga 78

26 Mapa do índice de cone da profundidade de $0,20 \mathrm{~m}$ da área de Pirassununga 79

27 Mapa do índice de cone da profundidade de 0,25 $\mathrm{m}$ da área de Pirassununga 79

28 Mapa do índice de cone da profundidade de $0,30 \mathrm{~m}$ da área de Pirassununga 80

29 Mapa do índice de cone da profundidade de $0,35 \mathrm{~m}$ da área de Pirassununga 80

30 Mapa do indice de cone da profundidade de $0,40 \mathrm{~m}$ da área de Pirassununga 81

31 Mapa do índice de cone da profundidade de $0,10 \mathrm{~m}$ dos 150 pontos antes (a) e após (b) a irrigação pelo pivô central da área de Pirassununga 82

32 Mapa do índice de cone da profundidade de $0,15 \mathrm{~m}$ dos 150 pontos antes (a) e após (b) a irrigação pelo pivô central da área de Pirassununga 83

33 Mapa do índice de cone da profundidade de $0,20 \mathrm{~m}$ dos 150 pontos antes (a) e após (b) a irrigação pelo pivô central da área de Pirassununga 84

34 Mapa do índice de cone da profundidade de $0,25 \mathrm{~m}$ dos 150 pontos antes (a) e após (b) a irrigação pelo pivô central da área de Pirassununga 
35 Mapa do índice de cone da profundidade de $0,30 \mathrm{~m}$ dos 150 pontos antes (a) e após (b) a irrigação pelo pivô central da área de Pirassununga 86

36 Mapa do índice de cone da profundidade de 0,35 m dos 150 pontos antes (a) e após (b) a irrigação pelo pivô central da área de Pirassununga 87

37 Mapa do indice de cone da profundidade de $0,40 \mathrm{~m}$ dos 150 pontos antes (a) e após (b) a irrigação pelo pivô central da área de Pirassununga 88

38 Mapa de produtividade do milho, safra 1999, da área de Pirassununga 89

39 Relação entre produtividade do milho $e$ índice de cone da profundidade de $0,10 \mathrm{~m}$ da área de Pirassununga

40 Relação entre produtividade do milho e índice de cone da profundidade de $0,15 \mathrm{~m}$ da área de Pirassununga

41 Relação entre produtividade do milho $e$ índice de cone da profundidade de $0,20 \mathrm{~m}$ da área de Pirassununga

42 Relação entre produtividade do milho $e$ indice de cone da profundidade de $0,25 \mathrm{~m}$ da área de Pirassununga

43 Relação entre produtividade do milho $e$ indice de cone da profundidade de $0,30 \mathrm{~m}$ da área de Pirassununga

44 Relação entre produtividade do milho $e$ índice de cone da profundidade de 0,35 $\mathrm{m}$ da área de Pirassununga

45 Relação entre produtividade do milho $e$ índice de cone da profundidade de $0,40 \mathrm{~m}$ da área de Pirassununga

46 Mapa do índice de cone da profundidade de 0,10 $\mathrm{m}$ da área de Castro 95

47 Mapa do índice de cone da profundidade de $0,15 \mathrm{~m}$ da área de Castro 
48 Mapa do índice de cone da profundidade de $0,20 \mathrm{~m}$ da área de Castro 96

49 Mapa do índice de cone da profundidade de $0,25 \mathrm{~m}$ da área de Castro 96

50 Mapa do índice de cone da profundidade de $0,30 \mathrm{~m}$ da área de Castro

51 Mapa do índice de cone da profundidade de $0,35 \mathrm{~m}$ da área de Castro

52 Mapa do índice de cone da profundidade de $0,40 \mathrm{~m}$ da área de Castro 98

53 Mapas de produtividade da soja, safra 1999 (a), e do milho, safra 2000 (b), da área de Castro 99

54 Relação entre produtividade da soja e do milho e índice de cone da profundidade de $0,10 \mathrm{~m}$ da área de Castro 100

55 Relação entre produtividade da soja e do milho e índice de cone da profundidade de $0,15 \mathrm{~m}$ da área de Castro

56 Relação entre produtividade da soja e do milho e índice de cone da profundidade de $0,20 \mathrm{~m}$ da área de Castro.

57 Relação entre produtividade da soja e do milho e índice de cone da profundidade de 0,25 $\mathrm{m}$ da área de Castro.

58 Relação entre produtividade da soja e do milho e índice de cone da profundidade de $0,30 \mathrm{~m}$ da área de Castro. 102

59 Relação entre produtividade da soja e do milho e índice de cone da profundidade de $0,35 \mathrm{~m}$ da área de Castro. 103

60 Relação entre produtividade da soja e do milho e índice de cone da profundidade de $0,40 \mathrm{~m}$ da área de Castro. 


\section{LISTA DE QUADROS}

Página

1 Métodos laboratoriais para a determinação da resistência do solo à penetração 


\section{LISTA DE TABELAS}

Página

1 Momentos estatísticos dados do índice de cone e valores do teor de água da área de Pirassununga

2 Momentos estatísticos dos dados do índice de cone e valores do teor de água dos 150 pontos antes da irrigação pelo pivô central da área de Pirassununga

3 Momentos estatísticos dos dados do índice de cone e valores do teor de água dos 150 pontos após a irrigação pelo pivô central da área de Pirassununga

4 Momentos estatísticos dos dados do índice de cone e valores do teor de água da área de Castro

5 Parâmetros e modelos dos semivariogramas ajustados e o efeito pepita expresso como a porcentagem do patamar da área de Pirassununga

6 Parâmetros e modelos dos semivariogramas ajustados e o efeito pepita expresso como a porcentagem do patamar dos 150 pontos antes da irrigação pelo pivô central da área de Pirassununga.

7 Parâmetros e modelos dos semivariogramas ajustados e o efeito pepita expresso como a porcentagem do patamar dos 150 pontos após a irrigação pelo pivô central da área de Pirassununga

8 Parâmetros e modelos dos semivariogramas ajustados e o efeito pepita expresso como a porcentagem do patamar da área de Castro 


\title{
VARIABILIDADE ESPACIAL DO ÍNDICE DE CONE CORRELACIONADA COM MAPAS DE PRODUTIVIDADE
}

\author{
Autor: Raymundo Leite da Silva Júnior \\ Orientador: Prof. Dr. José Paulo Molin
}

\section{RESUMO}

Este trabalho teve como objetivo explorar a variabilidade espacial do índice de cone, através de análises geoestatísticas, e correlacioná-la com mapas de produtividade. Duas áreas com sistema de semeadura direta foram utilizadas no experimento, uma no município de Pirassununga, SP, e a outra no município de Castro, PR. Mapas do indice de cone das profundidades de 0,10; 0,$15 ; 0,20 ; 0,25 ; 0,30 ; 0,35$ e $0,40 \mathrm{~m}$ foram gerados e correlacionados com mapas de produtividade. Para tanto, foi utilizado um penetrômetro de cone hidráulico-eletrônico, posicionado por DGPS (Sistema de Posicionamento Global Diferencial), com correção diferencial em tempo real via satélite, sendo as informações processadas por um programa de Sistema de Informação Geográfica (SIG). Todas as profundidades analisadas apresentaram estrutura de dependência espacial nas duas áreas. Observou-se o efeito do teor de água do solo sobre o índice de cone. A análise de regressão entre as produtividades $\mathrm{e} \mathrm{o}$ índice de cone apresentou baixos coeficientes de determinação. $\mathrm{Na}$ área de Castro houve tendência de redução da produtividade do milho e da soja com o aumento do índice de cone em todas as profundidades. Os mapas do índice de cone do solo, gerados através do sistema penetrômetro de cone hidráulicoeletrônico, GPS, SIG e programas computacionais geoestatísticos, mostraram 
a variabilidade do índice de cone existente entre as regiões representadas pelos diversos pontos amostrais levantados. 


\section{SPACIAL VARIABILITY OF CONE INDEX CORRELATED WITH YIELD MAPS}

Author: Raymundo Leite da Silva Júnior Adviser: Prof. Dr. José Paulo Molin

\section{SUMMARY}

The objective of this work was to explore the spatial variability of cone index using geostatistical analysis and to correlate it with yield maps. The work was carried out in two areas located in Pirassununga, SP, and in Castro, PR. Cone index maps of the depths 0,$10 ; 0,15 ; 0,20 ; 0,25 ; 0,30 ; 0,35$ and $0,40 \mathrm{~m}$ were developed and correlated with yield maps. A hydraulic-electronic cone penetrometer was used, linked to a DGPS (Deferential Global Positioning System) satellite real-time corrected, with the data controlled by a GIS (Geographic Information System). All depths showed spatial structure in both areas. Water content of the soil affected the cone index. The regression analysis between yield and cone index showed low determination coefficients, there was a tendency of yield loss on corn and soybeans as the cone index increased in all depths at the Castro area. The cone index maps of the soil, developed by hydraulic-electronic cone penetrometer, GPS, GIS and geostatistic software, showed the different plots of the regions. 


\section{INTRODUÇÃO}

A compactação do solo tem sido um dos grandes problemas da agricultura moderna. Seus efeitos têm causado expressivas perdas econômicas nas principais atividades agrícolas, além de contribuírem para a degradação do meio ambiente.

A intensificação do uso de máquinas agrícolas, nas várias etapas do processo de produção, é a principal responsável pela compactação do solo. Por dificultar o crescimento das raizes, a troca catiônica e a absorção dos nutrientes pela planta, ela reduz a produção e limita a produtividade.

Muitos esforços têm sido feitos no sentido de minimizar os efeitos prejudiciais causados pela compactação do solo na agricultura, com ênfase ao estudo de rodados especiais que trafegam em áreas de produção, especificamente pelo aumento da área de contato rodado-solo, visando à melhor distribuição da massa dos veículos. Outro aspecto importante refere-se à diminuição da relação massa/potência dos tratores agrícolas, como resultado do aperfeiçoamento de seus projetos de construção mecânica e do desenvolvimento de novos tipos de materiais utilizados em suas fabricações. Verifica-se, portanto, uma tendência ao aperfeiçoamento dos dispositivos de tração e dos rodados das máquinas e equipamentos agrícolas que trabalham em áreas de produção. 
O solo não é um meio homogêneo e não se pode tratá-lo como tal. Com os atuais recursos tecnológicos existentes já é possível considerar sua heterogeneidade. As análises estatísticas clássicas, que tratam o solo como um meio homogêneo, estão sendo substituídas por análises espaciais, as quais consideram correlações entre observações vizinhas. Isto só está sendo possível graças aos poderosos recursos computacionais de análise e de modelagem, que somente agora estão se tornando disponíveis à ciência agronômica.

O estudo da variabilidade espacial e temporal da compactação do solo pode contribuir para a agricultura de precisão, possibilitando um melhor conhecimento das áreas e dos fatores de produção que venha auxiliar nas tomadas de decisões e no gerenciamento das operações e manejos localizados.

Em estudos das relações solo-máquina-planta, uma das alternativas para se caracterizar fisicamente o solo é a medida da resistência à penetração, comumente avaliada através do índice de cone por ser de fácil e rápida determinação. Trata-se de um parâmetro dependente de determinadas condições sob as quais ocorre a ruptura do solo (cisalhamento, atrito, compressão) na zona de ação da ponta cônica dos aparelhos denominados penetrômetros.

A resistência do solo à penetração, particularmente de solos com camadas adensadas ("hardpans"), pode influenciar significativamente a produção das culturas. Por isso, o desenvolvimento de sensores, procedimentos de campo, análise de dados e técnicas para produzir mapas da resistência do solo à penetração são importantes nas operações de manejo localizado. Os mapas da resistência à penetração e os mapas de produtividade podem ser correlacionados visando à obtenção de possíveis interações entre esses dois fatores. Os mapas da resistência à penetração do solo poderão se tornar fontes de informação-base a ser incluída nos sistemas de informações geográficas de manejo localizado. 
Mas, para se fazer mapas, é importante entender a natureza da variabilidade espacial de um parâmetro físico a fim de se determinar como mapear esse parâmetro. Os aspectos mais importantes são a quantidade de dados requerida e o espaçamento desses dados, para que o parâmetro seja adequadamente mapeado. A questão fundamental é definir se 0 parâmetro físico sob consideração é contínuo no espaço e qual é a natureza da variabilidade espacial da função.

Este estudo tem como objetivo explorar a variabilidade espacial do índice de cone, através de análises geoestatísticas, e sua relação com o teor de água do solo. Propõe-se a geração de mapas da resistência do solo à penetração, através do índice de cone, a partir de amostras georreferenciadas, correlacionando-os com os mapas de produtividade. Para tanto, é utilizado um penetrômetro de cone hidráulico-eletrônico, acoplado ao sistema de três pontos do trator, posicionado por DGPS (Sistema de Posicionamento Global Diferencial), com correção diferencial em tempo real via satélite, sendo as informações processadas por um programa de Sistema de Informação Geográfica - SIG. 


\section{REVISÃO BIBLIOGRÁFICA}

\subsection{A compactação do solo e a resistência à penetração}

A compactação do solo é um processo de adensamento em que a porosidade e a permeabilidade são reduzidas, a resistência é aumentada e muitas mudanças são provocadas na estrutura do solo e em várias caracteristicas de seu comportamento (Soane \& Ouwerkerk, 1994).

Hartge \& Horn $(1991)^{1}$, citados por Horn \& Lebert (1994), Kézdi (1974) e Bradford \& Gupta (1986), fazem diferenciaçōes entre os vários termos usados para definir a compactação do solo:

- as forças aplicadas ao solo devem estar relacionadas a uma área para fornecer informações a respeito da resistência ou a deformação do solo;

- o processo que descreve o aumento da massa do solo por unidade de volume, devido a cargas aplicadas externamente ou a mudanças na pressão interna da água, é definido como compressão. Cargas externas estáticas ou dinâmicas podem ser aplicadas em formas de vibração, rolagem, pisoteio, enquanto que forças internas por unidade de área

\footnotetext{
${ }^{1}$ HARTGE, K. H.; HORN, R. Einführung in die bodenphysik. Stuttgart, Germany: Enke, 1991. $303 p$.
} 
podem ser a pressão ou a sucção da água causada por um gradiente hidráulico;

- a resistência contra a diminuição do volume quando o solo é submetido a uma carga mecânica é definida como compressibilidade e pode ser descrita pela curva de compressão do solo;

- a diferença entre a densidade inicial e a densidade máxima pela qual um solo pode ser compactado por uma determinada quantidade de energia em um conteúdo definido de água é definida como compactabilidade;

- a resistência do volume de solo não perturbado ou de um material de solo completamente homogeneizado com um determinado potencial mátrico da água é quantificada pelo valor da pressão de préconsolidação, que pode ser definida como o valor da pressão no ponto de transição entre a curva de compressão secundária e a reta de compressão virgem, como pode ser visto na Figura 1.
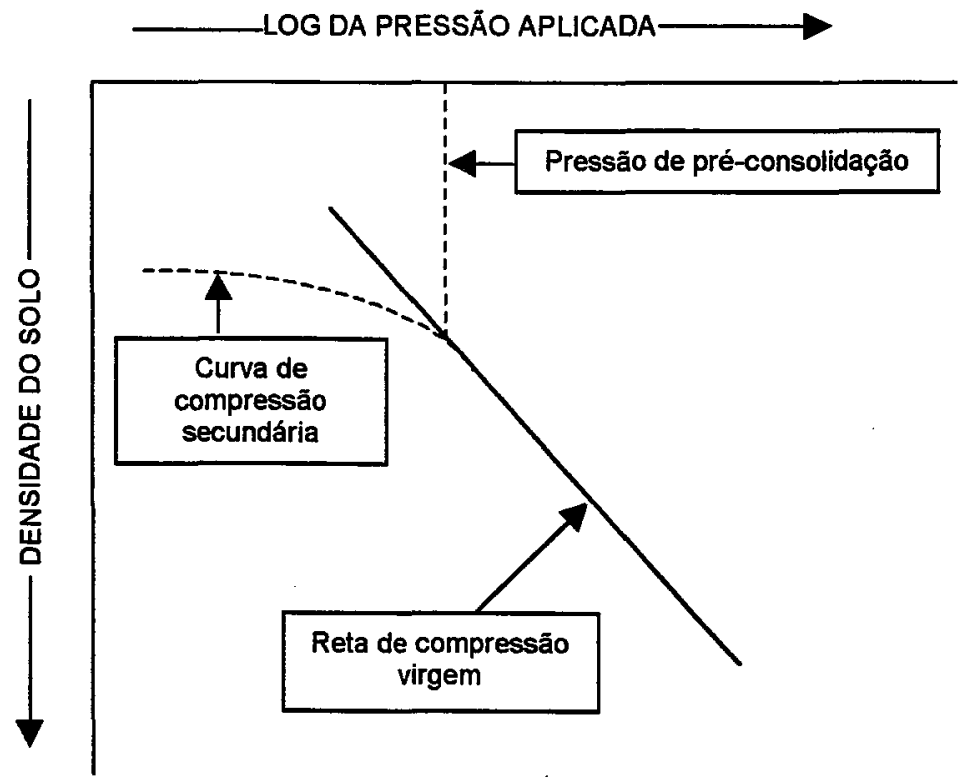

Figura 1 - Curva de compressão do solo como meio de determinar o valor da pressão de pré-consolidação (Lebert \& Horn, 1991). 
A curva de compressão secundária representa os niveis de pressões experimentadas pelo solo no passado, com deformações pequenas, elásticas e recuperáveis; enquanto a reta de compressão virgem representa as primeiras pressões aplicadas ao solo, com deformações plásticas e não recuperáveis. A pressão de pré-consolidação representa a maior pressão que o solo já suportou no passado e reflete o tipo de manejo utilizado. Portanto, para que não ocorra compactação adicional, o solo deve ser cultivado ou trafegado com valores de pressão próximos à região da curva de compressão secundária (Dias Júnior \& Pierce, 1996).

A medida da resistência do solo à penetração serve para identificar o estado de compacidade do solo. Dependendo do tipo e forma do instrumento utilizado, pode ocorrer corte ou separação, fratura por cisalhamento, fratura por atrito, por compressão ou mesmo fratura plástica, ou qualquer combinação destas, quando o mesmo é forçado no solo. Os modelos matemáticos utilizados para representar o comportamento durante a penetração no solo geralmente são de dois tipos: 1) a força requerida para causar penetração em termos de uma magnitude ou área utilizada; 2) a energia requerida para causar penetração. O comportamento é descrito expressando-se a resistência à penetração a uma dada profundidade (Balastreire, 1987).

\subsection{Origens e principais causas da resistência do solo}

A deformação do solo pode ocorrer quando partículas elementares são capazes de se separar e se mover uma em relação à outra. Tais movimentos são restringidos pelas fricçōes partículas-partículas e por vínculos interpartículas. Quanto mais denso o solo e quanto mais intrincado o arranjo das partículas, maiores são as forças de fricção, as quais, em conjunto com a pressão de sobrecarga, são as principais responsáveis pela resistência do material granular seco (Bradford et al., 1971). 
Os tipos de vínculos envolvidos na resistência do solo incluem as forças de coesão, que ocorrem devido aos meniscos de poros de água, e vínculos da fase sólida nos contatos partícula-partícula, como aqueles de mineral-mineral e mineral-orgânico-mineral. Minerais argilosos e compostos orgânicos, em virtude dos seus tamanhos, áreas específicas e propriedades de superfície, atuam como agentes cimentantes entre as partículas grosseiras, como silte e areia (Guérif, 1988).

A intensidade da resistência à penetração das raízes varia largamente dentro do perfil do solo. Independentemente do efeito da distribuição do conteúdo de água, a distribuição da resistência no perfil depende da distribuição dos elementos estruturais, como os agregados ou grânulos, e das zonas compactadas ou fragmentadas (O'Sullivan et al., 1987; Billot \& Marionneau, 1988).

Como proposto por Monnier et al. (1973) e por Fiès \& Stengel (1981), a resistência natural do solo à penetração das raízes pode ser analisada de acordo com a partição do espaço poroso em dois tipos: 1) o espaço poroso textural, que ocorre devido principalmente ao estado de empacotamento das partículas elementares; 2) o espaço poroso estrutural, o qual resulta do arranjo dos elementos estruturais criados pelo preparo do solo, e/ou clima, e/ou atividades biológicas.

A distribuição dos rastros dos rodados sobre o campo e o teor de água no momento das operações agricolas (semeadura; controle de ervas, pragas e doenças; aplicação de fertilizantes e colheita) são os principais responsáveis pela distribuição da resistência do solo à penetração das raizes no campo. As práticas de preparo do solo e as condições climáticas influenciam a distribuição da resistência dentro do perfil do solo (Manichon, 1988).

Soane et al. (1981a e b) sugerem a redução da média da pressão de contato dos pneus dos veículos sobre os solos de valores menores que 0,2 MPa para valores menores que 0,1 MPa. 


\subsection{A resistência do solo à penetração e suas implicações}

Para que as raízes das plantas possam se movimentar e crescer entre as partículas do solo, elas precisam desenvolver forças capazes de vencer a resistência mecânica do solo à sua penetração. É possível que esta resistência exceda a capacidade da planta, restringindo parcialmente ou totalmente o crescimento de suas raízes, causando alterações no seu metabolismo (Gill, 1961).

Em qualquer densidade do solo, a resistência mecânica à penetração da raiz está inversamente relacionada com o teor de água. Quando os solos estão molhados, as condições de aeração na ponta da raiz exercem controle maior sobre a penetração do que a resistência do solo. Em contraste, quando os solos estão ressecados, a impedância mecânica aumenta e o crescimento da raiz é limitado pela resistência do solo à penetração ( Raney \& Edminster, 1961).

Valores da resistência à penetração podem ser usados para caracterizar os solos em termos de habilidade de crescimento das culturas, resistência à penetração das raízes e à emergência das sementes (Taylor \& Gardner, 1963).

Taylor \& Ratliff (1969) encontraram que a taxa de elongação, a porcentagem de penetração e a concentração da raiz de algodão diminuem continuamente à medida que a impedância mecânica do solo aumenta de 0 a 3,2 MPa.

Vepraskas \& Miner (1986), em experimentos sobre o crescimento do tabaco em solos de textura grosseira na Carolina do Norte, Estados Unidos, encontraram camadas compactadas com valores de 2,8 a 3,2 $\mathrm{MPa}$ como resultantes do preparo do solo.

Dexter (1986), em estudos sobre a profundidade ideal da semeadura para evitar os deslocamentos laterais dos agregados, concluiu que no subsolo a resistência do penetrômetro não deveria exceder a 0,4 $\mathrm{MPa}$ para as plantas com eixo seminal simples e a $3,0 \mathrm{MPa}$ para as plantas com quatro eixos seminais. 
Miller (1987) afirma que a penetração das raizes pode ser reduzida se a resistência do solo atingir valores da ordem de $3,0 \mathrm{MPa}$, o que pode resultar em decréscimo no suprimento de água e nutrientes para as plantas.

Valores de índice de cone de 0,2 MPa foram sugeridos por Dick (1987) e Torres \& Villegas (1993) como normais para solos cultivados com cana-deaçúcar.

Klein et al. (1998) observaram que pequenas variações na condição de umidade do solo proporcionam variações acentuadas da resistência à penetração. Eles constataram que a determinação da resistência à penetração não é recomendável quando o solo se encontra próximo à sua capacidade de campo.

Perumpral (1987) menciona que a resistência do cone à penetração depende de vários fatores, tais como: a área da projeção do cone, o teor de água no solo e a velocidade de penetração da haste que compõe o penetrômetro.

\subsection{Métodos para determinação da resistência do solo à penetração}

Os métodos utilizados para medir a resistência do solo à penetração das raízes podem ser divididos em aqueles sob condições laboratoriais e os in-situ. O Quadro 1 apresenta os testes laboratoriais mais comuns utilizados para medir a resistência do solo à penetração.

Os métodos sob condições in-situ envolvem aqueles que utilizam sensores para medir as pressões e tensões no perfil do solo e os que utilizam os aparelhos conhecidos como penetrômetros de cone.

0 método que mede as pressões e tensões utiliza sensores com propriedades de deformação diferentes daqueles do material do solo e são instalados através de escavações em profundidade do perfil sem que a estrutura original do solo seja perturbada. Os sensores são constituídos por

transdutores com princípios pneumáticos, hidráulicos ou potenciométricos. Por 
esse método, é possível medir a intensidade da resistência, a pressão de atenuação e a deformação do solo (Horn \& Lebert, 1994).

Quadro 1. Métodos laboratoriais para a determinação da resistência do solo à penetração (extraído de Horn \& Lebert, 1994).

\begin{tabular}{|c|c|c|c|}
\hline Método & Parâmetro & Obtido do(a) & Condiçōes do solo \\
\hline $\begin{array}{l}\text { Teste de estabilidade de } \\
\text { agregados }^{1}\end{array}$ & comprimento $(\mathrm{cm})$ & & - agregados individuais \\
\hline Teste de Atterberg $^{1}$ & conteúdo de água $\left(\%, w / w^{*}\right)$ & & - solo homogeneizado \\
\hline Teste de proctor ${ }^{1}$ & $\begin{array}{c}\text { conteúdo de água }\left(\%, w / w^{*}\right) \\
\text { densidade }\left(\mathrm{Mg} \cdot \mathrm{m}^{-3}\right)\end{array}$ & & $\begin{array}{l}\text { - solo homogeneizado } \\
\text { - agregados individuais }\end{array}$ \\
\hline Teste de compressão uniaxial & & & - solo homogeneizado \\
\hline não confinada ${ }^{2}$ & pressão (Pa) & & $\begin{array}{l}\text { - agregados individuais } \\
\text { - volume estruturado de } \\
\text { solo }\end{array}$ \\
\hline Teste de compressão & & & - solo homogeneizado \\
\hline confinada ${ }^{2}$ & pressão (Pa) & $\begin{array}{l}\text { pressāo de pré-compressāo } \\
\text { (Pa) }\end{array}$ & $\begin{array}{l}\text { - volume estruturado de } \\
\text { solo }\end{array}$ \\
\hline Teste triaxial ${ }^{2}$ & pressão (Pa) & $\begin{array}{c}\text { coesão (Pa) } \\
\text { ângulo de atrito interno }\left({ }^{\circ}\right)\end{array}$ & $\begin{array}{l}\text { - solo homogeneizado } \\
\text { - agregados individuais } \\
\text { - volume estruturado de } \\
\text { solo }\end{array}$ \\
\hline Teste direto de cisalhamento ${ }^{2}$ & pressão $(\mathrm{Pa})$ & $\begin{array}{c}\text { coesão (Pa) } \\
\text { ângulo de atrito interno }\left({ }^{\circ}\right)\end{array}$ & $\begin{array}{l}\text { - solo homogeneizado } \\
\text { - agregados individuais } \\
\text { - volume estruturado de } \\
\text { solo }\end{array}$ \\
\hline
\end{tabular}

determinação indireta; ${ }^{2}$ determinaçāo direta; * conteúdo gravimétrico da água

Os penetrômetros de cone são instrumentos de medida que caracterizam a resistência do solo à penetração por um método uniforme padrão. A pressão necessária para cravar um cone circular de 30 graus até uma determinada profundidade no solo, expressa em megaPascal (MPa), é um índice da resistência do solo chamado de índice de cone (ASAE S313.3, 1999). 


\subsection{Penetrômetros}

Apesar de não haver indicações documentadas, Perumpral (1987) comenta que os penetrômetros têm sido usados desde 1846.

Os penetrômetros surgiram pela necessidade dos engenheiros de investigar a resistência à penetração ao longo do perfil do solo, por meio de ensaios chamados auscultações. Como a técnica era adaptada às condições do solo, desenvolveram-se dois grupos diferentes: os métodos estáticos e os métodos dinâmicos (Terzaghi \& Peck, 1962).

Nos métodos estáticos a haste é cravada no solo por pressão estática. Os métodos dinâmicos consistem na cravação de hastes pelo impacto de um martelo. Uma das primeiras ferramentas a utilizar o método estático de auscultação surgiu em 1917, criada pelas Ferrovias Estatais Suecas, que aperfeiçoou uma ferramenta formada de uma ponta em forma de trado, com o comprimento de $0,20 \mathrm{~m}$ e diâmetro máximo de $0,033 \mathrm{~m}$. A haste penetrava inicialmente pelo seu próprio peso, depois era carregada por estágios de até $100 \mathrm{~kg}$ e a penetração era medida em cada incremento de carga. No final, girava-se a haste no solo com todos os pesos adicionados e anotava-se a penetração para cada 50 voltas completas. Este aparelho era usado para obter informações sobre o grau de consistência da argila. Um processo semelhante foi usado em 1927 pelas Ferrovias Dinamarquesas para prever a profundidade que as estacas deveriam atingir, porém, a ponta a ser cravada no terreno tinha a forma de um pequeno tronco de pirâmide. Em 1935, o Departamento de Obras Públicas da Holanda aperfeiçoou um aparelho constituido por um cone de $60^{\circ}$ e diâmetro de $0,035 \mathrm{~m}$, ligado à extremidade inferior de uma haste de cerca $0,0159 \mathrm{~m}$ dentro de um tubo de gás de $0,019 \mathrm{~m}$. $\mathrm{O}$ cone era cravado 0,50 $\mathrm{m}$ no terreno, com a velocidade de $0,01 \mathrm{~m} / \mathrm{s}$, por um ou dois homens que aplicavam parte de seu peso a uma barra ligada perpendicularmente à extremidade superior da haste. A pressão exercida na haste era registrada por uma célula manométrica nela colocada abaixo da barra perpendicular. $A$ 
pressão exercida na haste durante cada ensaio era colocada em um gráfico em função da profundidade. Na mesma época, o Departamento Estadual de Estradas de Rodagem de Ohio, nos Estados Unidos, utilizava um aparelho com princípios dinâmicos. Consistia na cravação de uma haste com uma ponta, por meio de um martelo, anotando-se o número de golpes por $0,30 \mathrm{~m}$ de penetração. O diâmetro da ponta era, comumente, de cerca de $0,04 \mathrm{~m}$ e o peso do martelo variava entre 55 e $65 \mathrm{~kg}$. Um bate-estaca pequeno acionado por um motor de dois cilindros era usado para realizar a cravação da haste (Terzaghi \& Peck, 1962).

Em 1948, a Companhia de Engenheiros do Exército dos Estados Unidos, na Estação Experimental de Hidrovias (WES) de Vicksburg, Mississippi, desenvolveu um penetrômetro de cone de acionamento manual, de princípios estáticos, para avaliar e predizer os efeitos do tráfego e da mobilidade de veículos nas propriedades do solo. $\mathrm{O}$ aparelho penetrava até a profundidade de $0,15 \mathrm{~m}$. Desde então, versões modificadas deste penetrômetro estenderam-se a outras aplicações (Perumpral, 1987).

O princípio de funcionamento dos penetrômetros de cone da WES consiste na deformação de uma mola circular que sofre uma compressão por uma força aplicada sobre a empunhadura do aparelho. A deformação é medida por um micrômetro e é necessário se conhecer a equação de calibração baseada na Lei de Hook. Ao aplicar o aparelho no solo, anota-se a maior leitura acusada no micrômetro com a profundidade de penetração correspondente na haste, obtendo-se, portanto, o perfil de solo mais compactado ou adensado (Rípoli et al., 1985).

Numa tentativa de padronizar os testes com o penetrômetro de cone, a Sociedade Americana dos Engenheiros Agricolas (ASAE) adotou inicialmente a recomendação ASAE R313, em dezembro de 1968. Em dezembro de 1978 a recomendação foi reclassificada como norma padrão. Atualmente ela encontrase em sua terceira revisão, de fevereiro de 1999 (ASAE S313.3, 1999). 
A norma tem o propósito de estabelecer um método padrão de construção dos penetrômetros de cone de maneira a facilitar os relatórios e a interpretação dos dados do solo pelos usuários.

Para complementar a norma padrão S313.3, a ASAE adotou a prática de engenharia EP542, também em fevereiro de 1999 (ASAE EP542, 1999), com o objetivo de estabelecer métodos padrões no planejamento, na utilização e na descrição dos dados obtidos com os penetrômetros de cone. A norma e a prática de engenharia estabelecem caracteristicas de construção e procedimentos de uso dos penetrômetros de cone.

O penetrômetro de cone é definido pela norma ASAE S313.3 (1999) como um cone circular com $0,02027 \mathrm{~m}$ de diâmetro na base para solos macios $e$ $0,01283 \mathrm{~m}$ para solos duros, construido de aço inoxidável, com ângulo do vértice de $30^{\circ}$ e em cuja base se acopla uma haste de acionamento com diâmetro de $0,01588 \mathrm{~m}$ para solos macios e $0,00953 \mathrm{~m}$ de diâmetro para solos duros. A área da base é a superfície circular da secção transversal da base do cone, com $0,000323 \mathrm{~m}^{2}$ para solos macios e $0,00013 \mathrm{~m}^{2}$ para solos duros.

$O$ índice de cone é definido como a força por unidade de área da base necessária para empurrar o penetrômetro através de um pequeno incremento de deslocamento no solo. Os valores poderão ser expressos como X MPa de indice de cone (IC) na profundidade $Y$ em metros $(\mathrm{m})$, ou índice de cone médio de $X \mathrm{MPa}$ entre a profundidade de $\mathrm{Y}$ a $\mathrm{Z}$ em metros $(\mathrm{m})$ - esta última forma pode ser abreviada como $I C_{y-z}$. $O$ cone deve ser cravado no solo numa velocidade uniforme de aproximadamente $0,030 \mathrm{~m} / \mathrm{s}$. A leitura da medida é feita a partir do instante que a base do cone se encontra alinhada horizontalmente com a superficie do solo. Leituras subseqüentes devem ser feitas continuamente, ou tão freqüente quanto possivel, enquanto se mantém a velocidade de penetração constante. A norma acrescenta que os cones devem ser substituídos quando o desgaste do diâmetro da base exceder a $3 \%$, que, por conseguinte, pode afetar o índice de cone em $5 \%$. 
A Figura 2 apresenta a constituição básica de um penetrômetro de cone de acordo com a norma ASAE.

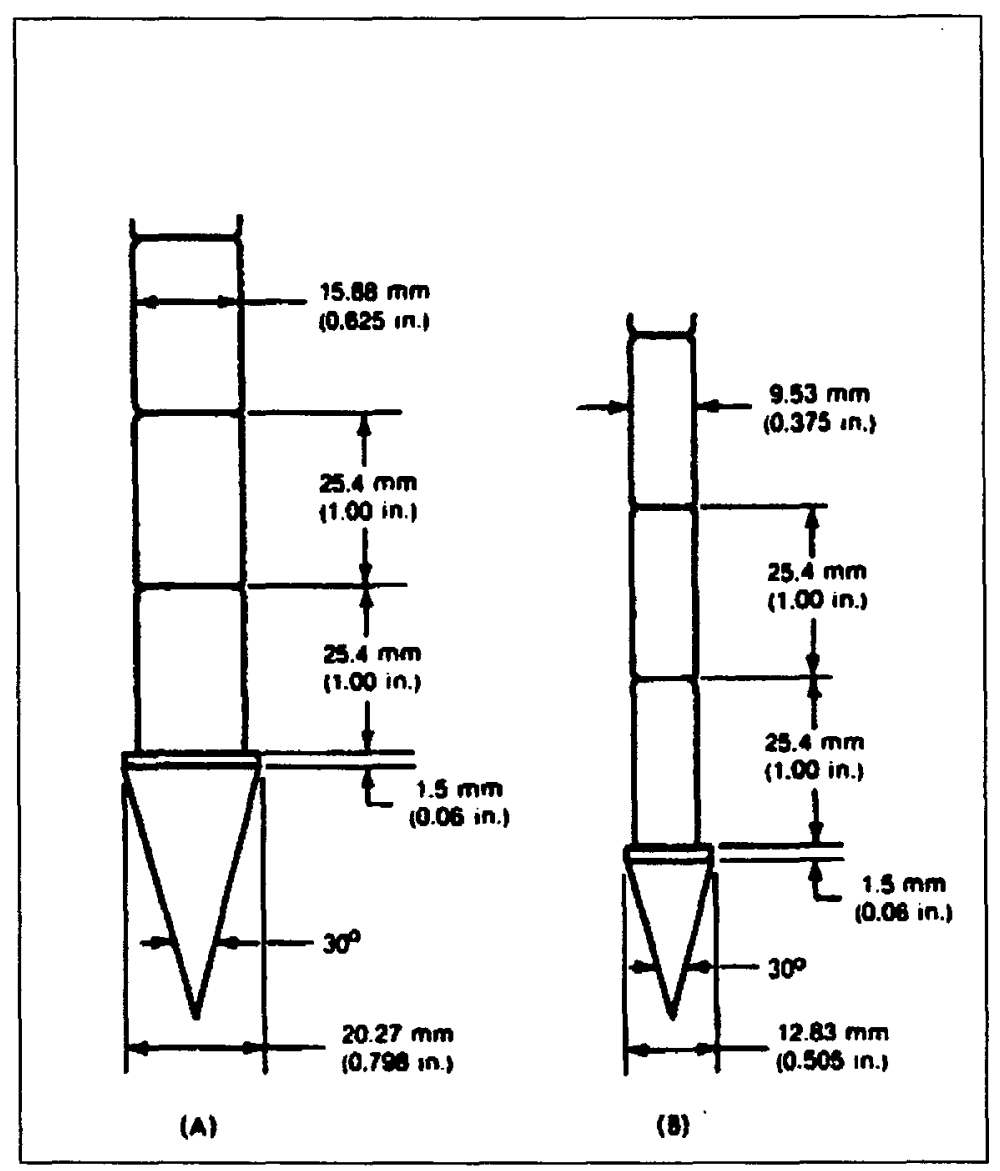

Figura 2 - Constituição básica dos penetrômetros de cone. (A) para solos macios e (B) para solos duros. (extraído de ASAE S313.3, 1999).

Os penetrômetros originais de operação manual não possuiam qualquer meio de gravar continuamente as medidas da profundidade e do índice de cone à medida que eram aplicados no solo. Terry \& Wilson (1952) resolveram este problema desenvolvendo um penetrômetro que gravava mecanicamente as medidas da profundidade e do índice de cone simultaneamente. $\mathrm{O}$ aparelho usava o movimento da haste vertical e a deflexão e compressão de uma mola para acionar uma caneta que registrava continuamente as medidas do índice de cone em função da profundidade num pequeno gráfico $X-Y$. Hendrick (1969) 
ampliou e aperfeiçoou o modelo, e Carter (1967) desenvolveu um penetrômetro similar utilizando uma mola retrátil como indicadora da profundidade. Esses penetrômetros receberam a denominação de penetrógrafos, por serem de uso e operação manual e por escreverem um gráfico ao mesmo tempo em que eram introduzidos no solo.

Este trabalho segue a classificação dos penetrômetros estabelecida pela prática de engenharia EP542 da ASAE (ASAE EP542, 1999), segundo a qual os penetrômetros são classificados em dois tipos: os penetrômetros manuais, que são forçados no solo por uma pessoa segurando a empunhadura do aparelho; e os penetrômetros mecânicos, que usualmente são montados em tratores, caminhões ou carretas e empregam potência mecânica, hidráulica ou elétrica para forçar o cone no solo, enquanto o índice de cone e a profundidade são registrados por um sistema de aquisição de dados baseado em microprocessador. Existem essencialmente duas classes de penetrômetros manuais: os instrumentos constituidos por traçadores gráficos que registram a penetração e a força sobre um gráfico à medida que o operador empurra o cone no solo, e os que registram a penetração e a força por molas ou válvulas de pressão. $\mathrm{Na}$ segunda classe estão incluídos aqueles constituídos por unidades que registram a força e a profundidade por meio de um coletor de dados eletrônico.

\subsubsection{Tipos de penetrômetros de cone manuais}

Existem quatro tipos principais de penetrômetros de cone manuais: os de mola, os de impacto, os constituídos de traçadores gráficos e os elétricos e eletrônicos. 


\subsubsection{Penetrômetros de cone manuais de mola}

São de uso e operação manual e o princípio de seu funcionamento já fora descrito anteriormente.

\subsubsection{Penetrômetros de cone manuais de impacto}

São de uso manual, porém, de acionamento dinâmico, onde a penetração é realizada pela aplicação de uma energia de impacto sobre o cone causada por uma massa que desce por uma guia. Zelenin $(1950)^{2}$, citado por Gill \& Vanden Berg (1968), reporta conclusões sobre um penetrômetro de impacto constituído por uma seta circular plana com uma área de secção transversal de $0,01 \mathrm{~m}^{2}$ para solos duros e de $0,02 \mathrm{~m}^{2}$ para solos extremamente soltos; uma massa de 2,5 kg de peso para um curso de queda livre de 0,40 m. Para este particular penetrômetro, o número de impactos para penetrar uma profundidade de $0,10 \mathrm{~m}$ era o parâmetro usado para expressar a resistência à penetração.

Stolf et al. (1983) desenvolveram um penetrômetro de impacto, modelo IAA-Planalsucar/Stolf, com uma massa de $4 \mathrm{~kg}$ de peso e um curso de queda livre de $0,40 \mathrm{~m}$, possuindo uma luva móvel para manter o aparelho na vertical sem interferir na força resultante à penetração da haste. A constituição básica deste penetrômetro segue as especificações padronizadas da ASAE.

$O$ índice de cone não pode ser obtido diretamente por estes aparelhos, visto que o impacto é causado por uma energia e não por uma força constante.

Stolf (1990) propôs a fórmula dos holandeses para estimar a resistência dinâmica do solo para o penetrômetro de impacto. Especificamente para o modelo IAA-Planalsucar/Stolf, esse autor deduziu 0 seguinte modelo matemático para estimar a resistência $R \mathrm{em} \mathrm{kgf} / \mathrm{cm}^{2}$ :

\footnotetext{
${ }^{2}$ ZELENIN, A. N. Basic physics of the theory of soil cutting. illus. Moscow. 1950. 353p.
} 


$$
R=5,6+\left(\frac{68,9}{x}\right)
$$

quando $x$ é dado em cm/impacto, ou, preferencialmente:

$$
R=5,6+(6,89 \times N)
$$

quando $N$ é dado em impactos $/ 10 \mathrm{~cm}$, ou seja, impactos $/ \mathrm{dm}$.

\subsubsection{Penetrômetros de cone manuais com traçadores gráficos}

Os penetrômetros com traçadores gráficos são mais bem elaborados que os penetrômetros de mola e os de impacto por permitirem a obtenção, não apenas de eventuais camadas diferenciadas do perfil do solo, como também do índice de cone no momento da aplicação do aparelho (Rípoli et al., 1985). Assim como os penetrômetros de mola e os de impacto, os penetrômetros com traçadores gráficos provocam substancial variabilidade dos dados pela inconsistência na velocidade de penetração. No entanto, possuem a vantagem de não serem restringidos pela altura das plantações (ASAE EP542, 1999).

Deve-se ao trabalho de Terry \& Wilson (1952), da Universidade de Cornell, o desenvolvimento do primeiro penetrômetro com traçador gráfico. $O$ aparelho utilizava dois mecanismos: um para medir a profundidade, constituído por um traçador que escrevia sobre um quadro; e o outro que media a força, constituído por uma mola. A medida da força baseava-se no fato de que a deflexão da mola era diretamente proporcional à força aplicada. Os dois mecanismos eram combinados em um de maneira que o traçador movia-se sobre o quadro realizando movimentos na direção $X$ e na direção $Y$, desenhando simultaneamente o gráfico da força em função da profundidade.

Carter (1967) desenvolveu um penetrômetro com traçador gráfico mais elaborado, constituído por um carrinho que se movia horizontalmente pela 
energia armazenada em uma mola, através de roldanas e trilhos. O carrinho suportava um pequeno ábaco, por sobre o qual uma caneta escrevia um gráfico da força em função da profundidade. O conjunto operava coaxialmente e um contrapeso, sustentado por um cabo, reposicionava o carrinho em sua posição inicial.

\subsubsection{Penetrômetros de cone manuais elétricos e eletrônicos}

Deve-se ao trabalho de Carter (1969) o desenvolvimento do primeiro penetrômetro elétrico. $O$ aparelho era constituido por uma célula de carga, um amplificador operacional e por um gerador de sinal do tipo d-c. A força para mover o penetrômetro era sentida por um anel de prova com resistências elétricas. Através de modelagem matemática entre a força e a voltagem, era possível obter a média da resistência do solo.

Prather et al. (1970) desenvolveram um penetrômetro capaz de traçar gráficos da força em função da profundidade eletronicamente. $O$ traçador gráfico era acionado por um motor que recebia sinais amplificados de uma célula de carga, com capacidade máxima de $882,6 \mathrm{~N}$, e de um potenciômetro, com capacidade máxima de deslocamento de 0,61 $\mathrm{m}$.

Anderson et al. (1980) desenvolveram na Escócia um penetrômetro eletrônico que utilizava um calculador eletrônico programável comercial capaz de registrar até 20 penetrações.

Wells et al. (1981) desenvolveram um penetrômetro eletrônico que usava um coletor de dados ("datalogger") portátil acompanhado de memórias de fitas magnéticas para aumentar a capacidade de armazenamento.

O'Sullivan et al. (1983) desenvolveram um penetrômetro eletrônico digital que utilizava um registrador de dados comercial portátil com capacidade de 64 kb (kilobites) de memória. Podia gravar até 52 pares de dados a uma profundidade máxima de $0,52 \mathrm{~m}$, com intervalo entre cada leitura de 0,01 m. 
Woodruff \& Lenker (1984) desenvolveram um penetrômetro eletrônico digital que utilizava um multiregistrador de dados capaz de armazenar de 60 a 70 penetrações de 48 leituras cada.

Morrison \& Bartek (1987) desenvolveram um penetrômetro eletrônico digital constituído por uma célula de carga e um potenciômetro de resistência variável, alojados num compartimento de alumínio, que eram interligados por um cabo padrão de 25 pinos, com 1,0 m de comprimento, a um multiregistrador de dados comercial com capacidade de 32 kb de memória.

Amaral (1994) desenvolveu um penetrômetro eletrônico portátil que utilizava um microprocessador $Z 80$ para controlar a leitura do sensor de força, constituído por uma célula de carga, e do sensor de profundidade, constituído por um potenciômetro linear. Um teclado e um pequeno monitor de cristal líquido permitiam o controle da leitura dos dados no campo. A memória RAM do sistema era capaz de armazenar 99 curvas com 200 pares de dados, que posteriormente poderiam ser transferidos a um microcomputador, via uma interface serial, para processamento e análise dos dados.

\subsubsection{Penetrômetros de cone mecânicos}

Os penetrômetros mecânicos surgiram para facilitar a operação de penetração e para que as leituras e análises dos dados não levassem muito tempo para serem obtidas. Além disto, era essencialmente impossível aos penetrômetros manuais satisfazer a norma padrão da ASAE, principalmente sobre duas perspectivas: 1) a norma determina que a velocidade de inserção seja constante; 2) que o início da coleta dos dados, a qual deve coincidir com a superfície do solo, ocorra quando a base do cone estiver rente a esta superfície. A combinação desses problemas e o requerimento adequado do número de amostras tornaram o uso dos penetrômetros manuais questionável (Clark, 1986). 
Estes aparelhos são usualmente montados em tratores, caminhonetes ou carretas e empregam potência mecânica, hidráulica ou elétrica para forçar o cone no solo, enquanto o índice de cone e a profundidade podem ser registrados por sistemas que utilizam registradores elétricos, microcomputadores ou microprocessadores.

Willford et al. (1972) desenvolveram um penetrômetro de acionamento hidráulico, com registrador de dados elétrico, acoplado em um trator. O sistema era constituído por uma célula de carga, que registrava a força de inserção; por um condicionador de sinal e por um traçador gráfico $X-Y$, que registrava a profundidade. Depois de dois anos de uso, o penetrômetro provou ser muito seguro e não apresentou qualquer problema mecânico, além de usar apenas $25 \%$ do tempo requerido para se obter dados com os penetrômetros manuais, com apenas dois homens operando.

Smith \& Dumas (1978) desenvolveram um penetrômetro montado em trator que usava para o acionamento um motor elétrico, ao invés de um cilindro hidráulico.

Com o advento dos microcomputadores, no final da década de 70 , os pesquisadores passaram a considerar inovações nos penetrômetros montados em trator e começaram a usar sistemas de instrumentação baseados em microprocessadores, os quais permitiram progressos significantes na velocidade e acurácia da coleta e análise dos dados (Clark, 1986).

Foi assim que Wilkenson et al. (1982) desenvolveram um penetrômetro montado em trator que utilizava uma unidade de controle baseada em microprocessador. $O$ aparelho era acionado pelo sistema hidráulico do trator e a unidade de controle ativava todos os movimentos dos mecanismos, além de gravar os dados em fita magnética. Uma inovação interessante introduzida neste penetrômetro foi o fato de ele possuir um transportador na estrutura que permitia movimentos laterais, mesmo estando o trator parado em uma única posição. Assim era possivel fazer uma série de amostragens de penetrações nas posições transversais e longitudinais. 
Phillips \& Perumpral (1983) desenvolveram um sistema capaz de coletar e armazenar dados da resistência à penetração de vários testes de penetrômetros de cone. Os dados eram transferidos para um computador de grande porte, através de uma porta serial, onde poderiam ser filtrados, analisados e plotados. O sistema possuía um conversor analógico-digital que controlava o sinal da força de penetração proveniente de uma célula de carga. Um microprocessador Intel de 8 bits 8085 A controlava e gerenciava a leitura dos dados que eram gravados em unidades de memória programáveis não voláteis somente para leituras (EPROM).

Riethmuller et al. (1983) desenvolveram um sistema microcomputadorizado parecido com o de Wilkenson et al. (1982), com a diferença que o sistema eletrônico não atuava nos mecanismos de movimentos, apenas na leitura e gravação dos dados. Um microcomputador Rockwell AIM 65 programado em linguagem BASIC, com sub-rotinas em linguagem de máquina, controlava a leitura, gravação e transferência dos dados do índice de cone e da profundidade do penetrômetro. $O$ dados eram gravados em fitas magnéticas $e$ posteriormente analisados pelo Sistema de Análises Estatísticas (SAS). Devese ao trabalho desses autores à confecção dos primeiros gráficos de contornos da resistência à penetração do solo.

Clark et al. (1986) desenvolveram um penetrômetro montado em trator com instrumentação e programas computadorizados capazes de desenhar mapas de contornos do índice de cone. O sistema eletrônico era constituído por um microcomputador IBM-PC com pacotes de programas com propósitos de realizarem calibração, coleta e análise dos dados, além de gerarem mapas de contornos usando um traçador gráfico digital. Uma célula de carga com capacidade de $9800 \mathrm{~N}$ (Newtons) recebia o sinal da força de penetração e um potenciômetro linear registrava a profundidade, todos conectados por interfaces ao microcomputador. Dois interruptores geravam sinais ao sistema, um para determinar quando a base do cone do penetrômetro estava rente à superfície do solo e o outro para gerar mapas topográficos do plano vertical do solo. As 
características de construção do penetrômetro seguiam a norma padrão da ASAE.

Hooks \& Jansen (1986) adaptaram um penetrômetro de cone a uma máquina comercial de amostragem de solo que era acionada pelo sistema hidráulico do trator. O aparelho era capaz de gravar os dados da resistência à penetração do perfil do solo até a profundidade de $1,12 \mathrm{~m}$. O gerenciamento das informações era feito por um sistema de aquisição de dados e por um registrador gráfico alimentados por uma fonte elétrica de 12 V DC.

Sudduth et al. (1989) adaptaram um penetrômetro hidráulico em um veículo comercial autopropelido de extensão e regulagem transversal de até $1,20 \mathrm{~m}$, com fontes de potência hidráulica e elétrica e um sistema computadorizado para aquisição de dados instalados a bordo. $O$ veículo era capaz de coletar amostras de raízes e de solo, além de dados da resistência à penetração nas próprias áreas de plantio, sem perturbar o ambiente de crescimento das plantas.

Ohmiya et al. (1993) desenvolveram um penetrômetro de acionamento elétrico sobre uma estrutura metálica que formava duas secções, uma $X$ e outra $Y$. O penetrômetro ficava montado na estrutura da secção $X$ que, por sua vez, estava montada na estrutura da secção $Y$. O penetrômetro podia ser movido lateral e longitudinalmente sobre a estrutura da secção $X$ e a estrutura da secção $Y$, formando uma área que media $1,5 \times 2,0 \mathrm{~m}$. Um computador portátil controlava os movimentos e a inserção, registrava o valor da resistência à penetração e o posicionamento do penetrômetro, gerando as coordenadas $x, y$ e $z$, o que permitia a confeç̧ão de mapas bi e tridimensionais.

No Brasil, o desenvolvimento de penetrômetros hidráulicos com fundamentação eletrônica é recente e praticamente tem procurado atender à aplicação manual ou portátil. Trabalho como o de Lins e Silva et al. (1995), que desenvolveram um penetrômetro hidráulico com sistema eletrônico de aquisição de dados, seguindo a norma padrão ASAE, tem evoluído para o melhoramento de aplicação em laboratório e campo. 
Lanças \& Santos (1998) desenvolveram um penetrômetro hidráulicoeletrônico equipado com um Sistema de Posicionamento Global Diferencial (DGPS). O penetrômetro é montado sobre uma carreta com um eixo de duas rodas pneumáticas, adaptada para ser transportada por qualquer veículo com sistema de engate. O sistema eletrônico é formado por uma célula de carga, como sensor de força; por um potenciômetro, como sensor de profundidade; e por um registrador e armazenador de dados ("micrologger"). Um microcomputador e planilha eletrônica podem efetuar as análises dos dados. Os dados são registrados de maneira automática e simultânea, uma vez que as rotinas do programa do "micrologger" permitem o início da aquisição dos dados somente quando a célula de carga capta uma força acima de $49 \mathrm{~N}$ e cessa quando a força é menor do que esse valor. As características de construção e de operação do penetrômetro seguem a norma padrão ASAE.

\subsection{Geoestatistica}

A partir dos trabalhos desenvolvidos em atividade de mineração, Georges Mathéron formalizou a teoria das variáveis regionalizadas. A geoestatística é a interpretação probabilística desta teoria (Braga, 1990).

Estudos relacionados à mineração motivaram o desenvolvimento de ferramentas estatísticas capazes de traduzir a estrutura de variabilidade espacial de um determinado atributo, como por exemplo o teor de um minério dentro de uma região, bem como permitir interpolações que levassem a boas estimativas do teor do minério em pontos não amostrados. Desta forma, seria possivel construir mapas que exibissem a distribuição do minério na região estudada, fazer estimativas de reservas, ter parâmetros para verificar viabilidade e orientar estratégias de prospecção (Ribeiro Júnior, 1995).

Diggle et al. (1998) utilizam um novo conceito denominado de "modelbased geostatistics" para descrever uma aproximação dos problemas geoestatísticos baseados na aplicação dos métodos estatísticos formais, sob 
um modelo estocástico explicitamente assumido. Programas geoestatísticos computacionais, que levam em consideração esse modelo, estão sendo disponibilizados na internet, porém, as interfaces ainda são pouco práticas para serem utilizadas como ferramentas ${ }^{3}$.

\subsection{Modelagem probabilistica e estacionaridade}

Seja uma região onde em certos pontos foram extraídas amostras e feitas medidas de variáveis de interesse. Destas amostras resultam um conjunto de dados espacialmente distribuídos, ou seja, medidas de um atributo acompanhadas de suas coordenadas. Estas coordenadas permitem o cálculo de distâncias (euclidianas) entre os pontos observados. Para cada ponto $x_{i}$ amostrado tem-se uma variável aleatória $Z$ distinta. Considera-se este conjunto de variáveis um processo estocástico, descrito da forma (Almeida \& Ribeiro Jr, 1996):

$$
\left\{Z\left(x_{i}\right): x \in D \subset R^{d}\right\}
$$

onde:

$Z$ é a variável aleatória que varia continuamente em $D$;

$x$ é a posição da variável, considerada fixa;

$D$ é a região em estudo;

$R^{d}$ é o espaço d-dimensional (d=1, 2, 3 ou 4).

Quando $d=1$, os dados estão em uma transição; para $d=2$, em um plano e para $d=3$, em um volume. Pode-se ainda considerar o tempo.

O conjunto de dados obtidos da amostragem mencionada é uma realização $\left\{z\left(x_{i}\right): x \in D \subset R^{2}\right\}$ do processo descrito em (3).

\footnotetext{
${ }^{3}$ Mais detalhes podem ser obtidos no site http://uww.maths.lancs.ac.uk/ diggle.
} 
Observa-se que o resultado da amostragem para cada variável aleatória é composto de uma única realização em cada ponto e, portanto, de cada variável, o que torna impossivel qualquer tipo de inferência sobre este processo. Isto faz com que algum tipo de estacionaridade, condizente com o problema em questão, seja assumido de forma a possibilitar estimação de ao menos os dois primeiros momentos da distribuição da variável aleatória, que em geral estão relacionados com as propriedades de interesse, tais como: média, correlação, covariância e de semivariância (Almeida \& Ribeiro Jr, 1996).

A forma de estacionaridade usualmente assumida na análise geoestatística é a chamada hipótese intrínseca e é definida pelas condições:

$$
\begin{aligned}
& E\left\{Z\left(x_{i+h}\right)-Z\left(x_{i}\right)\right\}=0 \\
& E\left\{\left[Z\left(x_{i+h}\right)-Z\left(x_{i}\right)\right]^{2}\right\}=2 \gamma(h)
\end{aligned}
$$

onde:

$E \quad$ é o valor esperado;

$Z\left(x_{i+h}\right)$ representa o ponto amostral $i$ separado por uma distância $h$;

$Z\left(x_{i}\right) \quad$ representa o ponto amostral $i$;

(h) é a semivariância que deve ser independente da posição dos pontos, sendo função apenas da distância entre eles.

Esta hipótese é um tipo de estacionaridade dos incrementos, formulada sob a variável aleatória. Existem situações mais gerais no que diz respeito à forma de estacionaridade que não serão discutidas neste trabalho e que podem ser encontradas com mais detalhes em Isaaks \& Srivastava (1989) e Cressie (1993). 


\subsubsection{Descrição e modelagem da variabilidade espacial}

Assumida a estacionaridade (hipótese intrínseca) definida nas equações (4) e (5) e considerando que a associação das variáveis em pontos distintos é maior à medida que se reduz a distância entre eles, o passo seguinte é descrever e modelar estas relações entre distâncias e associação espacial.

Várias medidas se prestam a tal descrição, tais como a autocovariância e autocorrelação, usuais na análise de séries temporais. $\mathrm{Na}$ abordagem geoestatística, a medida normalmente utilizada é a semivariância. É importante notar que, ao contrário da covariância e correlação, a semivariância é uma medida de dissimilaridade, ou seja, é maior à medida que as variáveis estão menos associadas. Esta medida exige uma hipótese de estacionaridade menos restritiva em relação às outras medidas possíveis, como por exemplo a covariância, que exige estacionaridade de segunda ordem (Ribeiro Júnior, 1995). Portanto, a semivariância pode ser utilizada em um maior número de situações, sendo definida a partir da equação (5) por:

$$
\gamma(h)=\frac{1}{2} E\left\{\left[z\left(x_{i+h}\right)-z\left(x_{i}\right)\right]^{2}\right\}
$$

Um exemplo de modelo que descreve tal comportamento é o semivariograma, dado na Figura 3 , onde $\gamma(h)$ é uma medida de dissimilaridade e $h$ a distância que separa os pontos. 


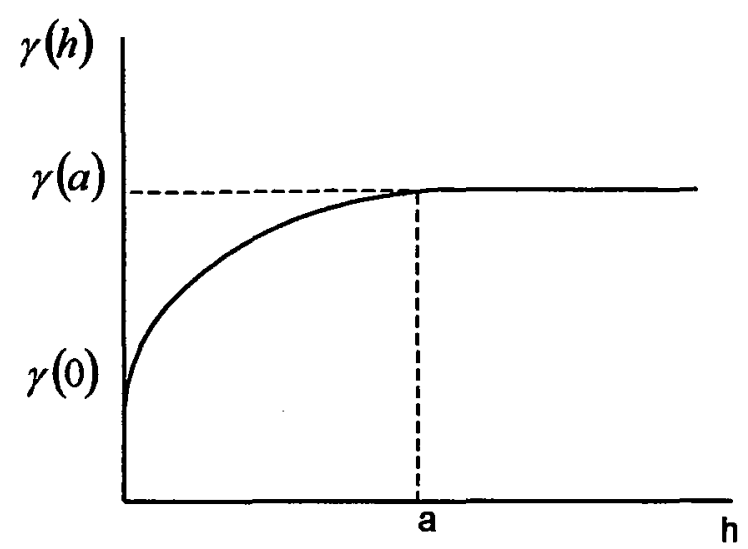

Figura 3 - Representação da associação das variáveis em pontos distintos em função da distância que as separa.

A função inicia no valor $\gamma(0)$, denominado efeito pepita ("nugget effect") e se estabiliza no valor $\gamma(a)$, que se denomina patamar total e sua respectiva distância "a" é denominada alcance ("range"). Denomina-se patamar ("sill") a quantidade dada por: $c=\gamma(a)-\gamma(0)$.

Em seu comportamento típico, o valor do semivariograma aumenta à medida que aumenta a distância de separação entre os pontos, até estabilizarse. Pode-se dizer então que o grau de dissimilaridade mantém-se constante entre os pontos com distância maior ou igual ao alcance (Almeida \& Ribeiro Júnior, 1996).

O efeito pepita revela a descontinuidade do semivariograma para distâncias menores do que a menor distância entre as amostras e que parte dessa descontinuidade pode ser devida a erros de medição ou a variabilidade a uma escala menor do que aquela amostrada, sendo impossivel quantificar o que contribui mais (Delhomme, 1976) ${ }^{4}$, citado por Vieira et al. (1983).

4 DELHOMME, J. P. Kriging in hydrosciences. Centre D'Informatique Geologique, Fontainebleau, France. 
Cressie (1993) detalha a descontinuidade revelada pelo efeito pepita $\left(c_{o}\right)$ como sendo a soma da medida da variância do erro, que ele caracteriza como $C_{M E}$, e o efeito do processo de microescala, que ele chama de ruído branco, caracterizado por $C_{M S}$, tendo-se então:

$$
c_{o}=c_{M S}+c_{M E}
$$

O estimador "clássico" do semivariograma, também dito estimador de Matheron, vem sendo largamente utilizado na literatura de geoestatística. Nada mais é do que um estimador obtido pelo método dos momentos e tem, sob a hipótese intrínseca, a desejável qualidade de não-viesado (Ribeiro Júnior, 1995). Sua expressão é:

$$
\hat{\gamma}(h)=\frac{1}{2 N(h)} \sum\left[z\left(x_{i+h}\right)-z\left(x_{i}\right)\right]^{2}
$$

onde:

$N(h)$ é o número de pares de pontos separados pela distância $h$.

Isaaks \& Srivastava (1989) consideram alguns modelos básicos de semivariogramas, os quais são os mais comumente utilizados pelos programas computacionais geoestatísticos que estão disponiveis comercialmente: 
a) modelo esférico (Esf)

$$
\gamma(h)= \begin{cases}1,5\left(\frac{h}{a}\right)-0,5\left(\frac{h}{a}\right)^{3} & \text { se } h \leq a \\ 1 & h>a\end{cases}
$$

Este modelo possui um comportamento linear nas distâncias de separação pequenas, próximas à origem, mas se achata nas distâncias maiores. A tangente na origem alcança o patamar por volta de dois terços do alcance;

b) modelo exponencial (Exp)

$$
\gamma(h)=1-\exp \left(-\frac{3 h}{a}\right)
$$

Este modelo alcança seu patamar assintoticamente, com o alcance prático " $a$ " definido como a distância na qual o valor do semivariograma está a 95\% do patamar. Como o modelo esférico, o modelo exponencial é linear nas distâncias curtas, próximas à origem, porém, apresenta uma subida mais íngreme e um achatamento mais gradual;

c) modelo Gaussiano (Gau)

$$
\gamma(h)=1-\exp \left(-\frac{3 h^{2}}{a^{2}}\right)
$$


Como o modelo exponencial, o modelo Gaussiano alcança seu patamar assintoticamente, e o parâmetro " $a$ " também é definido como o alcance prático ou a distância na qual o valor do semivariograma está a $95 \%$ do patamar. A característica marcante que distingue este modelo é o seu comportamento parabólico próximo a origem;

d) modelo linear (Lin)

$$
\gamma(h)=|h|
$$

Esse modelo não alcança seu patamar, mas aumenta linearmente com a distância $h$.

O fenômeno estudado pode ou não apresentar estruturas de variabilidade espacial diferentes, conforme a direção tomada dentro da área. Estas diferenças podem ser percebidas comparando os semivariogramas estimados para várias direções. Quando esta estrutura de dependência espacial é a mesma para todas as direções, ou seja, $h$ é considerado como escalar, o fenômeno é dito isotrópico, caso contrário considera-se $h$ um vetor e o fenômeno é dito anisotrópico (Almeida \& Ribeiro Júnior, 1996).

Os casos de anisotropia devem ser considerados na estimação das semivariâncias e ajuste do modelo (Ribeiro Júnior, 1995). Alguns programas geoestatísticos computacionais calculam automaticamente semivariogramas para várias direções, bastando apenas selecionar aquele que melhor caracteriza o fenômeno na área estudada.

Vieira (s.d) defende a posição de que não se perde nada em precisão ou em tipo de hipótese que se satisfaz se, ao invés da preocupação com a escolha do método de transformação de anisotropia, for limitada apenas a faixa de distância sobre a qual se utiliza o semivariograma. 
A indicação de periodicidade dos dados pode ser observada pelo comportamento de um semivariograma que, partindo do valor do efeito pepita, cresce bastante, além do valor do patamar, até uma determinada distância e depois cai, podendo ter flutuações abaixo do valor do patamar para pequenas distâncias (Vieira, s.d).

Fenômenos com capacidade infinita de dispersão podem ser observados pelo comportamento de um semivariograma que cresce sem limites para todos os valores de $h$ calculados. Este semivariograma indica que não há variância finita e que o tamanho do campo amostrado não foi suficiente para exibir toda a variância e é provável que exista tendência nos dados numa determinada direção (Vieira, s.d).

Barnes (1991) deduziu uma expressão sobre a relação entre a variância da amostra e o patamar do semivariograma. Ela mostra que o valor esperado da variância amostral é igual ao valor médio do semivariograma entre todos os $N^{2}$ pares de valores amostrais. Esta esperança é função da configuração geográfica dos dados e de todo o semivariograma, e não apenas de seu patamar. Em geral, se o patamar é claramente presente no gráfico do semivariograma, seu valor pode ser usado como uma estimativa da variância populacional. Porém, a variância amostral não pode ser usada como uma estimativa do patamar do semivariograma.

Escolher um modelo de semivariograma apropriado é algo que ainda guarda certo mistério. Não é um procedimento automático e requer um bom julgamento baseado na experiência e uma compreensão das limitações matemáticas da função (McBratney \& Webster, 1986).

De fato, o que se espera é que o ajuste do semivariograma seja eficiente especialmente para pequenas distâncias. As flutuações do semivariograma amostral para valores grandes de $h$ não constituem um problema sério, dado que os resultados da krigagem são pouco sensiveis aos valores do semivariograma para grandes distâncias (Samper \& Ramirez, 1990). 


\subsubsection{Krigagem}

Na maioria das vezes o interesse da análise não se limita a obtenção de um modelo de dependência espacial, desejando-se também predizer valores em pontos não amostrados. $O$ interesse, pode ser em um ou mais pontos específicos da área ou obter uma malha de pontos interpolados que permitam visualizar o comportamento da variável na região através de um mapa de isolinhas ou desenho de uma superfície. Para se obter este maior detalhamento da área em estudo é necessário um interpolador. Entre os muitos métodos de interpolação existentes pode-se citar: método poligonal, triangulação, médias locais das amostras e inverso do quadrado das distâncias. De modo geral estes interpoladores são simples e de cálculo relativamente fácil. Por outro lado, suas principais limitações são (Almeida \& Ribeiro Júnior, 1996):

- poligonal - estimativas locais descontínuas;

- inverso do quadrado das distâncias - não considera a anisotropia, não limita a vizinhança, nẳo considera a configuração da vizinhança;

- triangulação - não considera a anisotropia;

- médias locais - sensível à concentração de valores e não considera a distância entre as amostras e o ponto a ser estimado.

A proposta geoestatística de interpolação é conhecida como krigagem. Este interpolador pondera os vizinhos do ponto a ser estimado, obedecendo aos critérios de não tendenciosidade e mínima variância. Existem diversos tipos de krigagem: a simples, ordinária, universal, indicadora, probabilística, etc. A krigagem ordinária se distingue dos demais tipos por seu objetivo de minimizar a variância dos erros, por isso ela é associada com o acrônimo de B.L.U.E ("Best Linear Unbiased Estimator") ou Melhor Estimador Linear Não Viciado (Isaaks \& Srivastava, 1989). 


\subsubsection{Krigagem ordinária}

$\mathrm{Na}$ Krigagem ordinária não é necessário o conhecimento da média do atributo na região e os dados são uma realização de um processo ao menos intrinsecamente estacionário (Ribeiro Júnior, 1995)

Considerando-se a Figura 4, onde a região $D$ está contida no espaço $R^{2}$, define-se o processo espacial (Almeida \& Ribeiro Júnior, 1996):

$$
\left\{Z\left(x_{i}\right): x \in D \subset R^{2}\right\}
$$

onde em $n$ pontos $x_{i}$ são feitas medidas de uma variável $Z$. Tem-se então uma amostra de variáveis aleatórias espacialmente dependentes, ou seja, uma realizaçāo de (9): $\left\{z\left(x_{i}\right): x \in D \subset R^{2}\right\}$.

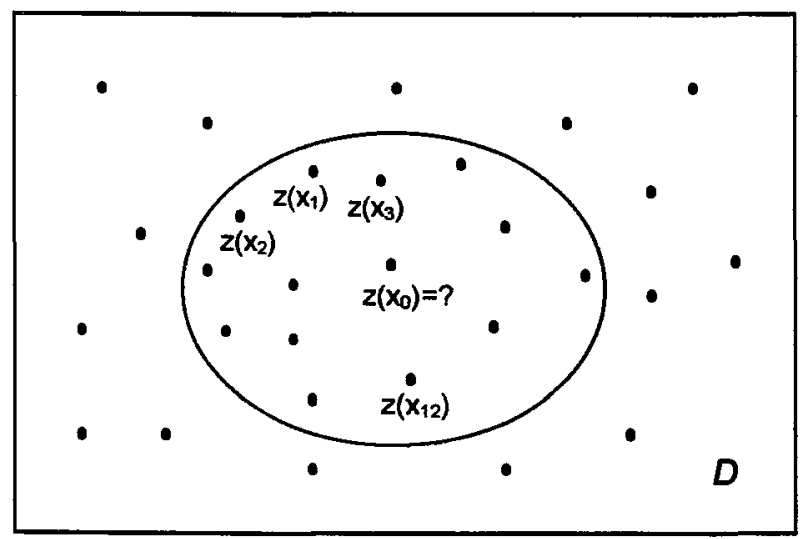

Figura 4 - Variáveis amostradas no espaço $D$.

Deseja-se então estimar $z\left(x_{0}\right)$ que é um valor desconhecido para determinada localização contida na região $D$.

Considera-se o estimador: 


$$
\hat{Z}\left(x_{0}\right)=\sum \lambda_{i} z\left(x_{i}\right)
$$

que é a função linear dos pontos conhecidos e onde os $\lambda_{i}$ 's, dados pela krigagem, são ponderadores distintos dos demais interpoladores usuais mencionados anteriormente. Distintos porque são proporcionais às "distâncias estatísticas", significando que, além de ponderar pelas distâncias euclidianas entre o ponto a ser estimado e os demais pontos conhecidos, incorporam também a estrutura de variabilidade na região de estimação. Salienta-se ainda que as distâncias consideradas não são somente as distâncias entre o ponto a ser predito e os vizinhos, mas também as distâncias entre os vizinhos. Exemplificando, supōe-se as situações representadas pelas Figuras $\mathbf{5 a}$ e $\mathbf{5 b}$, assumindo fenômenos isotrópicos.

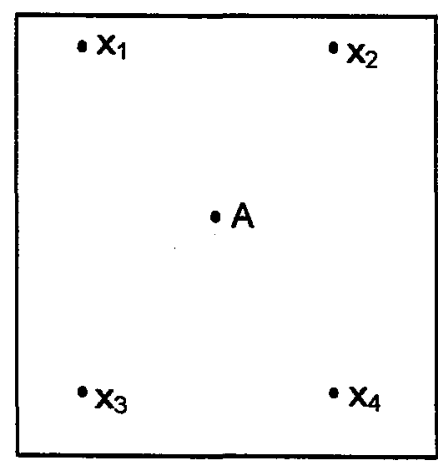

(a)

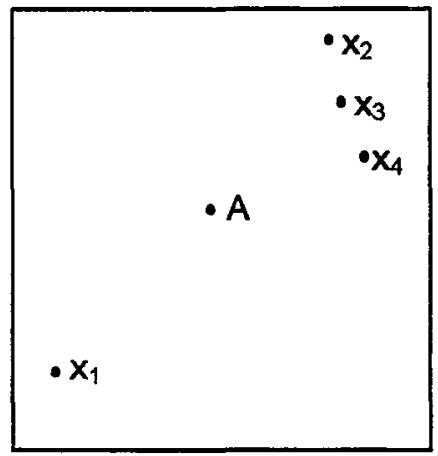

(b)

Figuras 5a e 5b - Diferentes configurações de vizinhança.

É razoável que para a Figura 5 a os pesos de cada ponto sejam semelhantes, uma vez que estão aproximadamente à mesma distância do ponto $\mathrm{A}$ e entre si. Na Figura $5 \mathrm{~b}$, nota-se um agrupamento de dados. Neste caso é razoável que o peso de $x_{1}$ seja maior que os pesos de $x_{2}, x_{3}$ e $x_{4}$, pois estes dados agrupados trazem informaçōes quase redundantes de uma mesma região. 
Esta característica deste interpolador é denominada "declustering", devendo-se ao fato do preditor considerar uma medida de associação entre os pontos $x_{i}$ da vizinhança. Normalmente, a medida de associação utilizada é a semivariância, e daí a necessidade do semivariograma e do modelo ajustado (Almeida e Ribeiro Júnior, 1996).

Considerando que o modelo adotado para o semivariograma é correto e não apresenta erros de medida, deve-se então determinar os valores de $\lambda_{i}$ que garantam as propriedades de mínima variância e não tendenciosidade.

Assumida a hipótese intrínseca, para a não tendenciosidade ser assegurada, deve-se ter:

$$
E\left[\hat{Z}\left(x_{0}\right)-Z\left(x_{0}\right)\right]=0
$$

o que implica em $\sum_{i} \lambda_{i}=1$. A variância de estimação é dada por:

$$
\operatorname{Var}\left[\hat{Z}\left(x_{0}\right)-Z\left(x_{0}\right)\right]=E\left\{\left[\hat{Z}\left(x_{0}\right)-Z\left(x_{0}\right)\right]^{2}\right\}-\left\{E\left[\hat{Z}\left(x_{0}\right)-Z\left(x_{0}\right)\right]\right\}^{2}
$$

onde o último termo é zero pela condição (11).

A variância, quando minimizada, sujeita à restrição $\sum_{i} \lambda_{i}=1$ e igualada a zero, resulta em um sistema de equações do tipo:

$$
\left\{\begin{array}{l}
\sum_{i} \hat{\lambda}_{i} \gamma\left(x_{i}, x_{j}\right)+\hat{\mu}=\gamma\left(x_{i}, x_{j}\right) \\
\sum_{i} \hat{\lambda}_{i}=1
\end{array}\right.
$$


onde:

$\gamma\left(x_{i}, x_{j}\right)$ refere-se à função de semivariância correspondente a um vetor com origem em $x_{i}$ e extremidade em $x_{j}$;

$\hat{\mu}$ é o multiplicador de Lagrange;

sob notação matricial, esse sistema de equações pode ser escrito:

$\left[\begin{array}{ccccc}\gamma_{1,1} & \gamma_{1,2} & \Lambda & \gamma_{1, n} & 1 \\ \gamma_{2,1} & \gamma_{21,2} & \Lambda & \gamma_{2, n} & 1 \\ \Lambda & \Lambda & \Lambda & \Lambda & 1 \\ \gamma_{n, 1} & \gamma_{n, 2} & \Lambda & \gamma_{n, n} & 1 \\ 1 & 1 & 1 & 1 & 0\end{array}\right]\left[\begin{array}{c}\hat{\lambda}_{1} \\ \hat{\lambda}_{2} \\ \Lambda \\ \hat{\lambda}_{n} \\ \hat{\mu}\end{array}\right]=\left[\begin{array}{c}\gamma_{1,0} \\ \gamma_{2,0} \\ \Lambda \\ \gamma_{n, 0} \\ 1\end{array}\right]$

Assim, resolvendo o sistema, tem-se a estimativa:

$$
z\left(x_{0}\right)=\sum_{i} \hat{\lambda}_{i} z\left(x_{i}\right)
$$

onde o estimador é BLUE (Melhor Estimador Linear Não Viciado).

Através de krigagem ordinária, obtém-se $\hat{z}\left(x_{0}\right)$, que é uma estimativa do valor esperado de $Z\left(x_{0}\right)$ ou $E\left[Z\left(x_{0}\right)\right]$.

Repetindo-se o processo de krigagem ordinária em vários pontos de modo a formar uma malha fina, é possível obter um mapa das estimativas na região estudada, o que facilita a interpretação quanto ao comportamento espacial da variável.

Por estimar uma média, este processo de krigagem implica numa suavização dos valores preditos para a região em estudo e não fornece uma 
estimativa da dispersão destas variáveis, já que a variância de krigagem avalia apenas a configuração da vizinhança (Almeida \& Ribeiro Júnior, 1996).

A avaliação da krigagem é realizada utilizando-se a metodologia conhecida como validação cruzada ("cross validation") que consiste em estimar os valores da variável em estudo sobre os mesmos pontos amostrados $e$ comparar os novos valores com os dados medidos (McBratney \& Webster, 1986).

\subsection{Sistema de Posicionamento Global - GPS}

O Sistema GPS-NAVSTAR (NAVigation Satellite Time And Ranging) foi desenvolvido pelo Departamento de Defesa dos Estados Unidos da América. Trata-se de um sistema militar estratégico, com enorme potencial para as aplicações civis. O setor civil passou a ter acesso a essa tecnologia a partir de meados da década de setenta e se tornou inteiramente operacional em 1993, quando universidades e instituições de pesquisa puderam, então, investigar e inclusive colaborar no aperfeiçoamento do sistema (Vettorazzi et al., 1994).

O sistema NAVSTAR é constituído por 24 satélites, sendo três de reserva. Estes satélites são especificos para o sistema GPS e estão dispostos de tal maneira que, a qualquer hora e em qualquer lugar do mundo, pelo menos quatro satélites estarão disponíveis para utilização. Para isso foram criadas seis órbitas, espaçadas de $60^{\circ}$ cada uma, onde os satélites estão posicionados a $20.200 \mathrm{~km}$ de altitude (Danna, 1994).

O princípio básico de funcionamento desta tecnologia está na triangulação dos satélites, isto é, determinando os satélites como pontos de referência é possivel localizar qualquer ponto na Terra em coordenadas (ex: lat/long) (Rocha \& Lamparelli, 1998).

O sinal do satélite é enviado via onda de rádio, sendo captado pela antena do receptor GPS. As coordenadas são calculadas utilizando-se da triangulação. A intersecção das distâncias a cada satélite utilizada no cálculo define o ponto 
onde a antena do receptor se encontra. Estas distâncias são calculadas através de equações. A maneira pela qual o GPS calcula as distâncias até o satélite depende do tipo do receptor (Rocha \& Lamparelli, 1998).

Os sistemas GPS podem ser classificados em dois grupos: o Serviço de Posicionamento Preciso (PPS) e o Serviço de Posicionamento Padrão (SPS). Para aplicações civis é utilizado o SPS (Dias et al., 1998).

Para reduzir os erros do sistema GPS, principalmente aqueles de retardo de sinal causados pela ionosfera e troposfera, foi criado o Sistema de Posicionamento Global Diferencial (DGPS). Esse sistema trabalha com um aparelho receptor extra, fixo, localizado em um ponto de coordenadas conhecidas, e com isso pode-se determinar o erro de posicionamento obtido pelo GPS. Esse erro pode ser utilizado para corrigir o posicionamento de outros aparelhos receptores que estejam em um raio de $200 \mathrm{~km}$ ao redor da base fixa. Existem diversas formas de se realizar essa correção e uma delas é através de um pós-processamento, onde os dados de posicionamento e as correções são obtidos e depois corrigidos por meio do uso de um software específico. Existe também a correção em tempo real em que os dados de posição são obtidos e instantaneamente corrigidos. Para isso, o sinal de correção da estação fixa precisa ser transmitido diretamente para os aparelhos receptores. Existe ainda a possibilidade desses dados serem transmitidos para um satélite geoestacionário e então retransmitidos para os aparelhos receptores (Dias et al., 1998).

Nos serviços de correção diferencial por satélites, estações terrestres bases de GPS calculam a correção dos dados e transmitem a um satélite geoestacionário, com órbitas diferentes dos satélites de GPS e que permanecem no mesmo ponto sobre a terra 24 horas por dia. Os satélites retransmitem a correção dos dados para a terra para serem usados em DGPS. Para receber o sinal, o usuário deve adquirir um receptor, similar ao do GPS, que possa receber o sinal de um satélite geoestacionário (Morgan \& Ess, 1997). 
O sinal de DGPS via satélite geoestacionário é continental, dirigido a qualquer usuário de GPS. No entanto, o sinal é bloqueado e disponivel aos usuários que o adquirem mediante o pagamento de uma taxa anual. No Brasil, esse tipo de serviço passou a ser disponibilizado em julho de 1997 (Molin, 2000a).

Basicamente existem duas técnicas que são aplicadas no posicionamento diferencial (Segantine, 1998):

1. transmissão de pseudodistâncias corrigidas: o receptor fixo calcula as pseudodistâncias medidas. A correção da pseudodistância para cada satélite é transmitida para o receptor do usuário;

2. transmissão dos erros de posicionamento: o método de transmissão de informações é semelhante ao descrito anteriormente, exceto que no presente caso os dados transmitidos são as coordenadas calculadas pelo receptor fixo.

\subsection{Sistema de Informação Geográfica - SIG}

O SIG é um poderoso elenco de ferramentas para colecionar, armazenar, recuperar, transformar e exibir dados espaciais referenciados ao mundo real (Burrough, 1986).

Segundo Rocha \& Lamparelli (1998), os sistemas que compõem o SIG podem ser divididos em:

- sistemas de entrada de dados: sistema de processamento digital de imagens (PDI), digitalização de mapas, sistema de posicionamento global (GPS), dados tabulares (planilhas eletrônicas) e dados estatísticos; 
- sistemas de armazenamento de dados: banco de dados espaciais (mapas digitais) e banco de dados de atributos (alfanuméricos);

- sistemas de análise de dados: sistema de análise geográfica (operações algébricas), sistema de análise estatística e sistema de gerenciamento de banco de dados (SGBD);

- sistema de saída de dados: sistema de exibição cartográfica (saída de mapas para a tela, impressora, plotter e arquivos digitais).

O SIG se apresenta, portanto, como a plataforma ideal para tratamento de dados derivados de agricultura de precisão, pois o seu conjunto de recursos possibilita uma ampla análise dos dados.

\subsection{Mapas de produtividade}

O mapa de produtividade da cultura é um dos aspectos importantes da agricultura de precisão. A observação e análise dos mapas de produtividade usualmente conduzem ao desejo de se entender os fatores que afetam a produtividade, de maneira que o gerenciamento das práticas no campo possa ser adequado para o desenvolvimento normal da planta (Clark, 1999).

Segundo Molin (2000b), mapa de produtividade é um conjunto de pontos que representa uma pequena porção da lavoura. $O$ dado mais importante é a quantidade do produto colhido em cada ponto. Os pontos são delimitados por uma área de alguns metros quadrados composta pela largura da plataforma de uma colhedora e a distância percorrida por ela entre duas leituras, normalmente de 1 a 3 segundos. A montagem do mapa nada mais é do que a plotagem de cada um desses pontos num sistema cartesiano, onde o eixo " $x$ " é a longitude $e$ o eixo " $y$ " é a latitude. Para se visualizar o mapa, basta escalonar os pontos em diferentes cores ou tons para diferentes valores de produtividade, obtidos de uma tabela de dados gerados no campo. O mapa informa a produtividade com base em produto seco, razão pela qual se deve dar ênfase à umidade do 
produto para que seja feita a transformação da umidade qualquer e variável em umidade padrão. Ainda segundo este autor, uma outra forma bastante comum de se representar mapas é através de linhas de isoprodutividade, ou seja, isolinhas que delimitam regiōes com produtividades dentro de um mesmo intervalo. Esses mapas são obtidos pelo método de interpolação entre os pontos, utilizando-se ferramentas geoestatísticas.

\subsection{Mapas do indice de cone}

Mapas do índice de cone têm sido uma ferramenta valiosa para a visualização no solo das configurações da resistência à penetração, especialmente em relação ao preparo e ao tráfego efetuados pelas máquinas (Clark et al. 1993; Clark, 1994). Esses mapas foram desenvolvidos com a suposição fundamental de que o índice de cone do solo é uma função contínua. Os estudos desses mapas mostraram que é possivel determinar a localização e o efeito do tráfego sobre a resistência do solo, uma vez que os efeitos dos rodados podem claramente ser visualizados. Através desses mapas também foi possível determinar regiões em que um subsolador foi usado para perturbar camadas duras do solo.

Clark (1999), avaliando o potencial para o desenvolvimento de mapas da resistência à penetração utilizando um penetrômetro hidráulico-eletrônico, equipado com um GPS, encontrou a necessidade de se adquirir uma grande quantidade de dados com o penetrômetro para se criar mapas acurados da resistência do solo, isto devido ao alto grau da variabilidade do índice de cone em curtas distâncias. Esses estudos também indicaram o potencial para se criar mapas do índice de cone nas entrelinhas de plantio para ajudar a explicar a variabilidade da produtividade afetada pelos rodados das máquinas.

Lanças et al. (2000) desenvolveram mapas de isocompactação utilizando um penetrômetro hidráulico-eletrônico, equipado com um sistema DGPS. Foram gerados mapas do índice de cone nas profundidades de 0 a $0,15 \mathrm{~m}, 0$ a 0,30 m 
e de 0 até a profundidade máxima alcançada pelo penetrômetro. Os mapas mostraram claramente as diferenças existentes entre as regiōes representadas pelos diversos pontos amostrais levantados na área. O sistema mostrou-se prático e flexível para ser aplicado tanto em pesquisas de campo como em grandes áreas agrícolas. 


\section{MATERIAIS E MÉTODOS}

\subsection{Caracterização das áreas experimentais}

Este trabalho faz parte de um projeto maior de monitoramento intensivo de três áreas pilotos, visando a detectar a variabilidade espacial da produtividade $e$ dos fatores de produção. São apresentadas algumas análises de duas das três áreas pilotos.

A primeira área está localizada na Faculdade de Zootecnia e de Engenharia de Alimentos da Universidade de São Paulo (USP) em Pirassununga, SP, nas coordenadas geográficas de $21^{\circ} 58^{\prime}$ de latitude sul e $47^{\circ}$ 28 ' de longitude a oeste de Greenwich, com cerca de 19 ha e altitude média de 627 metros acima do nível do mar. O clima predominante, segundo a classificação de Köppen (1948), é do tipo Cwa, temperado quente, tipo savana, com inverno seco e verão quente e chuvoso, temperatura média anual de $20,8^{\circ} \mathrm{C}$ e precipitação média anual de $1248 \mathrm{~mm}$. Dois tipos de solos foram identificados na área: uma terra roxa estruturada eutrófica, com densidade de $1,45 \mathrm{~g} / \mathrm{cm}^{3}$ e macroporosidade de 13,4\%; e um latossolo roxo eutrófico, com densidade de $1,41 \mathrm{~g} / \mathrm{cm}^{3}$ e macroporosidade de $9,6 \%$.

A área experimental de Pirassununga encontra-se sob um pivô central e vem sendo cultivada com milho, soja e sorgo deste 1997 em sistema de 
semeadura direta. O experimento nesta área foi conduzido após a colheita do milho, no ano de 1999.

A segunda área está localizada no Centro de Tecnologia da Fundação $A B C$, em Castro, $P R$, nas coordenadas geográficas $24^{\circ} 51^{\prime}$ de latitude sul e $49^{\circ}$ 55 ' de longitude a oeste de Greenwich, com cerca de 23,7 ha e altitude média de 1000 metros acima do nível do mar. O clima predominante, segundo a classificação de Köppen (1948), é do tipo Cfb, temperado propriamente dito, com temperatura média no mês mais frio abaixo dos $18^{\circ} \mathrm{C}$ (mesotérmico), com veröes frescos e temperatura média no mês mais quente abaixo dos $22^{\circ} \mathrm{C}$; sem estação seca definida e com precipitação média anual de $1690 \mathrm{~mm}$. O solo foi classificado como latossolo vermelho amarelo, com densidade de $1,29 \mathrm{~g} / \mathrm{cm}^{3}$ e macroporosidade de $14,6 \%$.

A área experimental de Castro vem sendo cultivada com milho e soja no verão e aveia e trigo no inverno, em sistema de semeadura direta deste 1985. O experimento nesta área foi conduzido após a colheita do milho, no ano de 2000.

\subsection{Caracterização do penetrômetro}

O sistema mecânico do penetrômetro foi desenvolvido e construído por Zambuzi et al. (1998), consistindo em uma estrutura tubular rígida no formato de um trapézio para ser acoplada no engate dos três pontos do trator. Um cilindro de dupla ação com $0,05 \mathrm{~m}$ de diâmetro e curso máximo de $1,0 \mathrm{~m}$ está fixado no chassi da estrutura, servindo para acionar a haste de penetração. $O$ conjunto foi construído de maneira que o trator esteja estacionado em uma posição e a haste do penetrômetro seja movida lateralmente por uma barra de rosca sem fim de $2,0 \mathrm{~m}$, acionada por um motor elétrico ligado à bateria do trator, com a chave liga-desliga próxima ao tratorista. A Figura 6 mostra a constituição básica do penetrômetro e o mesmo em funcionamento. 


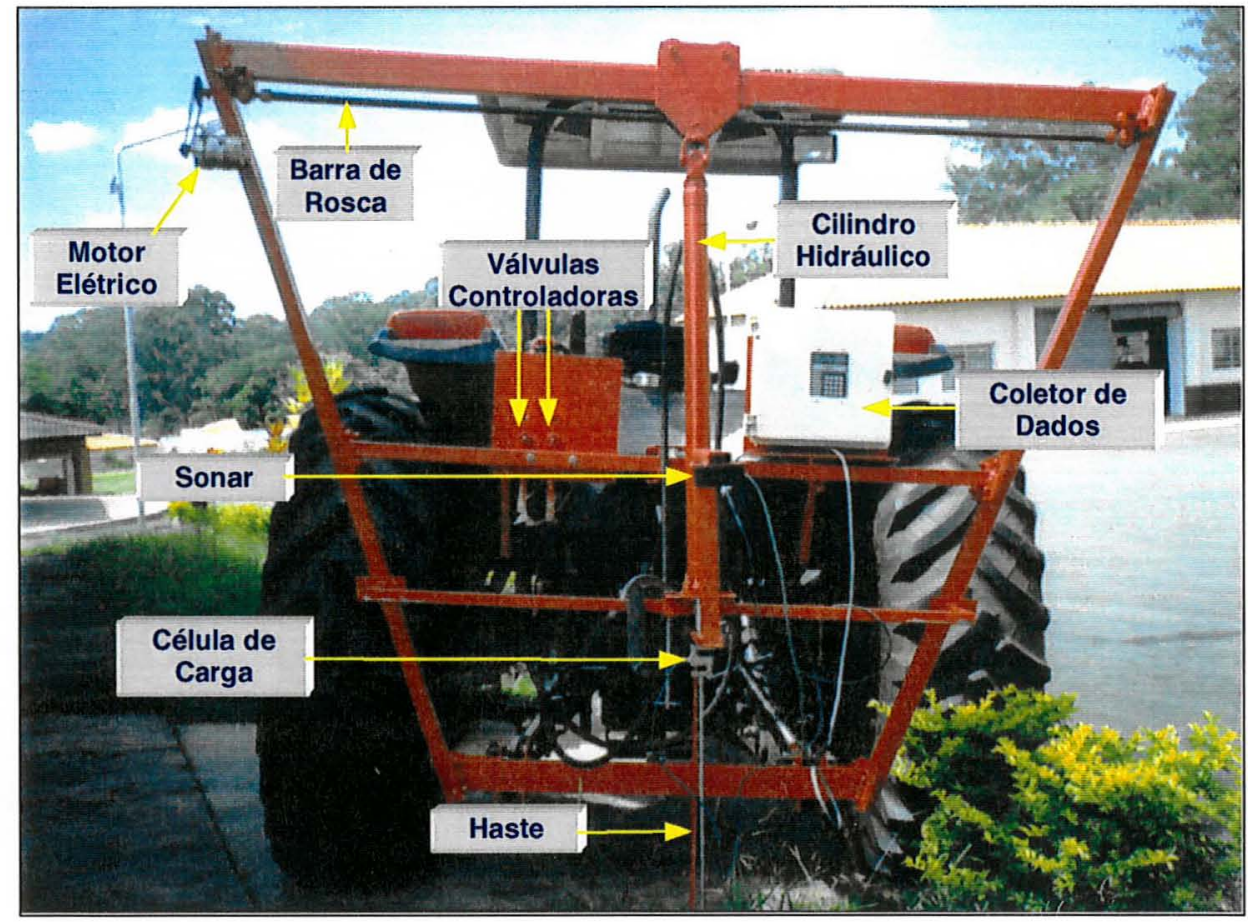

(a)

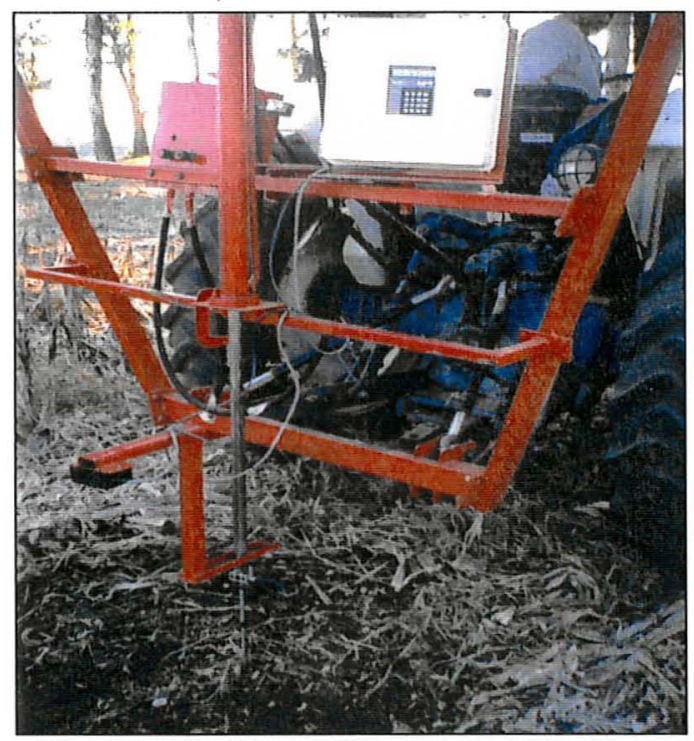

(b)

Figura 6 - Penetrômetro utilizado no trabalho mostrando as partes constituintes mais importantes (a). Penetrômetro em funcionamento no campo (b) (extraído de Silva Júnior et al., 2000). 
A potência hidráulica é fornecida pelo trator que, pelo comando da alavanca do controle remoto, permite ao tratorista controlar os movimentos de inserção e retirada da haste do solo pelo cilindro hidráulico.

O penetrômetro segue a norma padrão da ASAE (ASAE S313.3, 1999) para solos duros, com uma haste de 0,0095 $\mathrm{m}$ de diâmetro e um cone de $0,00013 \mathrm{~m}^{2}$ de área de base construídos em aço inoxidável. Para manter a velocidade de penetração constante de $0,030 \mathrm{~m} / \mathrm{s}$, independentemente da resistência encontrada no solo, regulou-se a válvula de restrição de vazão para uma rotação do motor do trator a $1600 \mathrm{rpm}$ (rotações por minuto). A fim de proteger a célula de carga instalada no sistema, uma válvula de segurança de pressão permite a leitura do índice de cone máximo de até $38 \mathrm{MPa}$, equivalente a uma força de $4903,5 \mathrm{~N}$ sobre a área da base do cone.

A força na haste é medida por uma célula de carga da marca Gefran, modelo TG61-501, com capacidade para $4903,5 \mathrm{~N}$, instalada entre a ponta do cilindro hidráulico e a haste de penetração.

Para medir a profundidade da haste, foi usado um sonar da marca Polaroid, modelo 6500, que utiliza o próprio solo como anteparo do sinal. Como esse aparelho necessita de cerca de 3,0 segundos para estabilizar o sinal, foi construída uma miniestrutura metálica para abrigá-lo $0,4 \mathrm{~m}$ acima da célula de carga.

Para a verificação da linearidade da célula de carga e do sonar, realizouse a calibração dos mesmos. Para a célula de carga, utilizou-se um sistema eletromecânico universal de tração e compressão da marca Instron, modelo 4466. Para o sonar, utilizou-se uma régua metálica para medir a profundidade, graduada em intervalos de $0,05 \mathrm{~m}$.

Tanto a célula de carga quanto o sonar são conectados nos terminais do coletor de dados, de onde são alimentados por uma bateria de 12 volts, recarregável. 


\subsubsection{Sistema de aquisição de dados}

O sistema eletrônico é composto por um coletor de dados ("datalogger"), da marca Campbell, modelo CR10X. Possui 2 Mb (megabytes) de memória, um teclado de 16 teclas, um pequeno monitor de cristal líquido e uma interface serial. Todo o conjunto fica protegido por uma caixa de plástico, fixada na estrutura metálica tubular, com movimento giratório para permitir a leitura dos dados do monitor em várias direções.

Para o desenvolvimento do programa e gerenciamento das informações, foi utilizado o pacote PC208W, do próprio fabricante do coletor de dados, que é dividido em três módulos: módulo de programação; módulo de comunicação e módulo de armazenamento de dados. Pela instrução do programa, os dados só começam a ser lidos quando a força ultrapassa $39 \mathrm{~N}$, o que equivale ao início da leitura quando a base do cone se encontra rente ao solo. Cada curva de penetração é gravada e identificada individualmente pelo programa, podendo várias delas serem geradas e armazenadas no módulo de memória. As leituras da força e da profundidade são feitas a cada meio segundo, com os registros do número da curva, da data e da hora organizados em linhas e colunas. Um contador, introduzido nas rotinas do programa, permite o incremento das curvas de penetração à medida que são determinadas no campo. O término da leitura de cada curva ocorre quando o operador pára a penetração da haste e o incremento ocorre quando é feita a sua retirada. O Apêndice 1 mostra a listagem do programa.

Após o término das medidas no campo, os dados podem ser descarregados para um microcomputador, conectado por cabo, via interface serial do coletor de dados. O próprio pacote $\mathrm{PC} 208 \mathrm{~W}$ gerencia a transferência das informações, permitindo a gravação dos dados em vários formatos de arquivos.

Para processamento dos dados obtidos, foi utilizada uma planilha eletrônica. 


\subsection{Sistema de Posicionamento Global - GPS}

Utilizou-se um GPS da marca OMNISTAR, constituído por uma antena de GPS e uma antena de DGPS, alimentado por uma bateria portátil de 12 volts, recarregável. A correção diferencial foi feita em tempo real via satélite geoestacionário, com serviço fornecido pelo próprio fabricante do GPS.

As coordenadas foram monitoradas por um microcomputador portátil, conectado com o receptor GPS, rodando um programa de caminhamento de campo ("FieldRover"). Esse programa gerava um cursor localizador que se movimentava sobre o mapa da grade à medida que o veículo se locomovia no campo. Tanto o cursor como o mapa da grade eram amostrados na tela do microcomputador.

O GPS e o microcomputador portátil foram instalados em um veículo de apoio, tipo caminhonete, para agilizar a localização e a demarcação dos pontos.

\subsection{Programas computacionais}

Para a geração das grades amostrais e dos mapas do índice de cone, bem como para auxiliar o sistema de monitoramento da produtividade, utilizouse o programa de Sistema de Informação Geográfica - SIG SStoolbox (SST Development Group, Inc.), personalizado para aplicação em agricultura de precisão.

Para as análises estatísticas descritivas e geoestatísticas, foram utilizadas a planilha eletrônica Excel (Microsoft Inc.) e o programa GS+ Geoestatistics for the Environmental Sciences (Gamma Design Software).

\subsection{Calibração do penetrômetro}

A curva de calibração da célula de carga foi obtida por ensaios de compressão em laboratório. As leituras das compressões (em Newtons), 
carregando e descarregando, no sistema eletromecânico de tração e compressão, serviram como dados de entrada e as leituras no coletor de dados (em milivolts), como dados de saída.

A curva de calibração do sonar foi obtida por ensaios de penetração e retirada da haste do penetrômetro em solo coberto. As leituras das profundidades na régua graduada (em metros), subindo e descendo a haste, serviram como dados de entrada e as leituras no coletor de dados (em milivolts), como dados de saída.

A profundidade da haste foi obtida pela seguinte relação matemática:

$$
P=1,10-\operatorname{SINAL}
$$

onde:
$P \quad$ é a profundidade $(\mathrm{m})$;
1,10 é o comprimento do conjunto haste+célula de carga+miniestrutura metálica $(\mathrm{m})$;
SINAL é a leitura do sinal no coletor de dados (m).

As curvas de calibração foram calculadas pelo método dos quadrados mínimos, proposto por Doebelin (1975).

\subsection{Caracterização das grades amostrais do índice de cone e do teor de água}

O sistema de coleta de dados utilizado para o índice de cone foi a amostragem sistemática, na qual os pontos de amostragem são localizados em intervalos regulares, formando uma grade ou malha ("grid"). As grades foram geradas pelo programa de SIG SStoolbox, que utilizou os mapas de contorno das áreas, gerados pelo programa de caminhamento de campo ("FieldRover") e 
GPS. Na área de Pirassununga, foi gerada uma grade amostral com espaçamento regular de $20 \times 20$ metros, perfazendo 444 pontos. Na área de Castro, foi gerada uma grade amostral com espaçamento regular de $25 \times 25$ metros, perfazendo 358 pontos.

A fim de liberar os equipamentos de GPS e microcomputador portátil para outras atividades do projeto, os pontos da grade amostral da área de Pirassununga foram demarcados previamente, utilizando-se estacas de madeira, sendo as sondagens com o penetrômetro feitas posteriormente. $\mathrm{Na}$ área de Castro, os pontos da grade amostral foram demarcados simultaneamente às sondagens com o penetrômetro.

Para a determinação do teor de água do solo, foram feitas amostragens aleatórias de alguns pontos das grades amostrais. $\mathrm{Na}$ área de Pirassununga foram escolhidos aleatoriamente 20 pontos e na área de Castro, 13 pontos. $A$ maior quantidade de pontos amostrais na área de Pirassununga ocorreu devido à maior desuniformidade da área, caracterizada pela presença de curvas de nivel e pela maior declividade do terreno. As Figuras 7 e 8 mostram as configurações das grades amostrais das duas áreas utilizadas no experimento. 


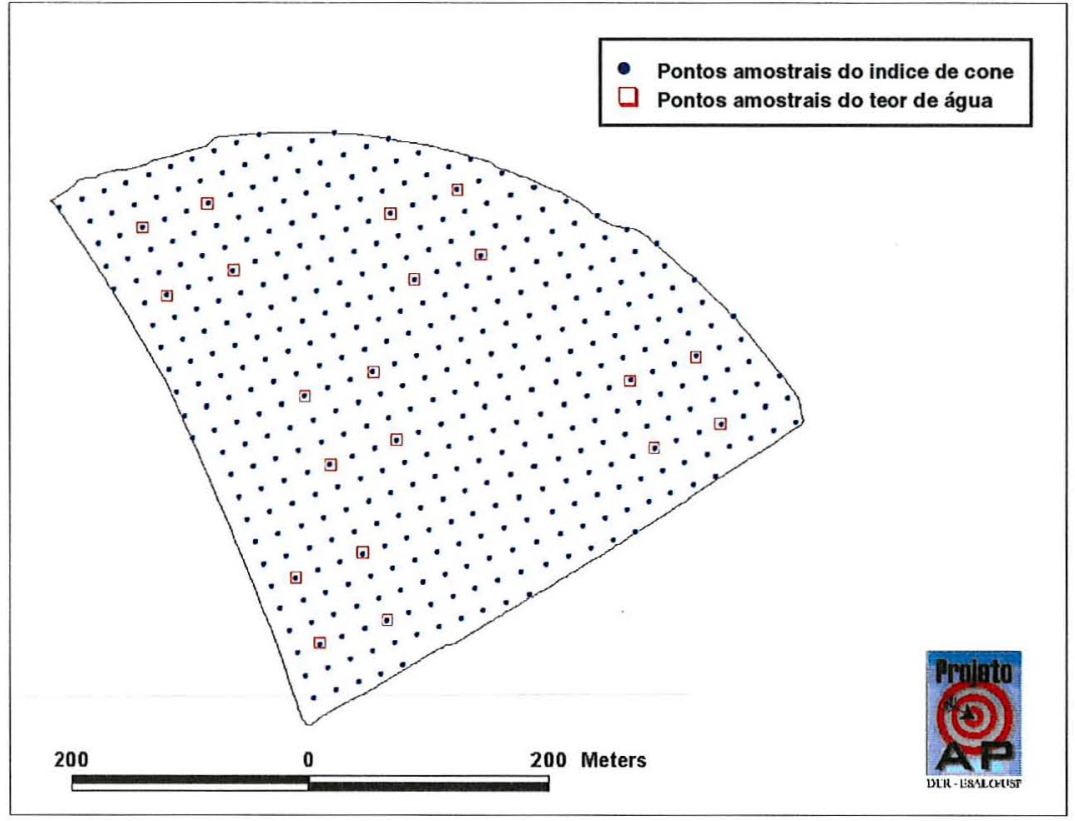

Figura 7 - Grade amostral sistemática da área de Pirassununga mostrando os pontos onde foram coletados os dados do índice de cone e do teor de água.

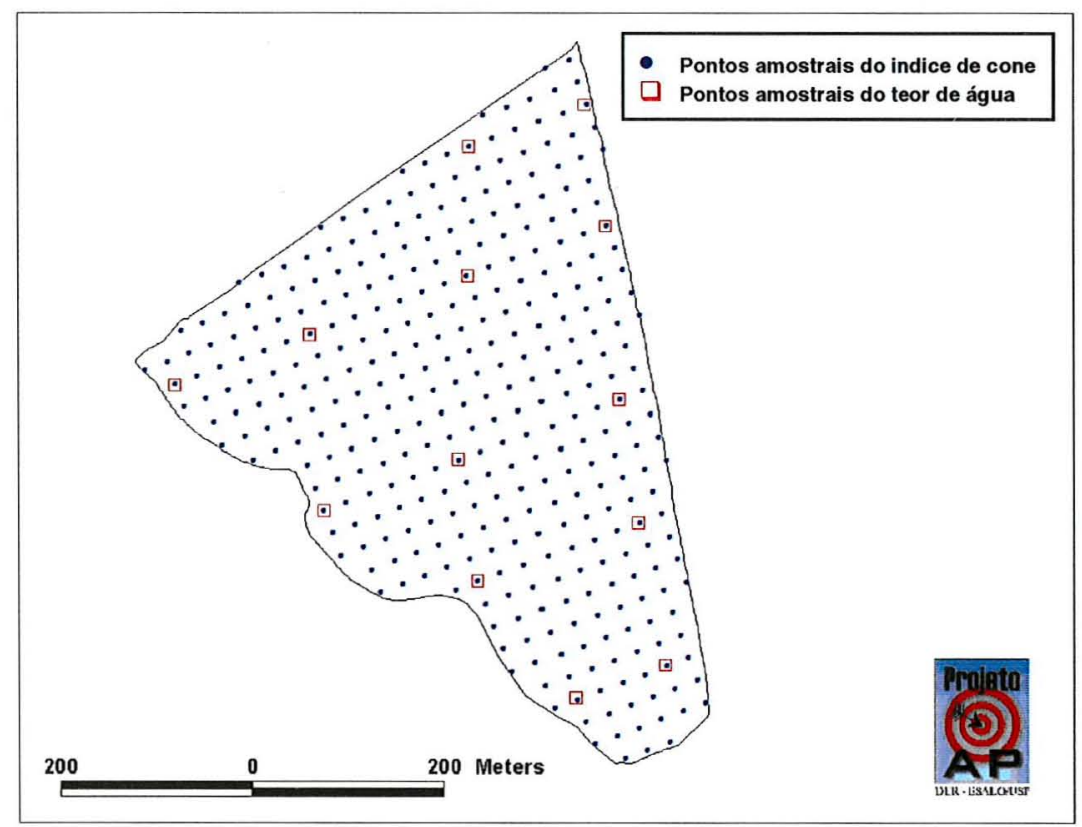

Figura 8 - Grade amostral sistemática da área de Castro mostrando os pontos onde foram coletados os dados do índice de cone e do teor de água. 
Após a determinação do índice de cone em solo seco, uma área de 150 pontos da malha amostral de Pirassununga, com cerca de 6,9 ha, foi irrigada pelo sistema de pivô central durante dois dias, para deixá-la próxima à sua capacidade de campo. Em seguida, novas sondagens foram feitas com o penetrômetro. A Figura 9 mostra a malha amostral gerada para esta análise.

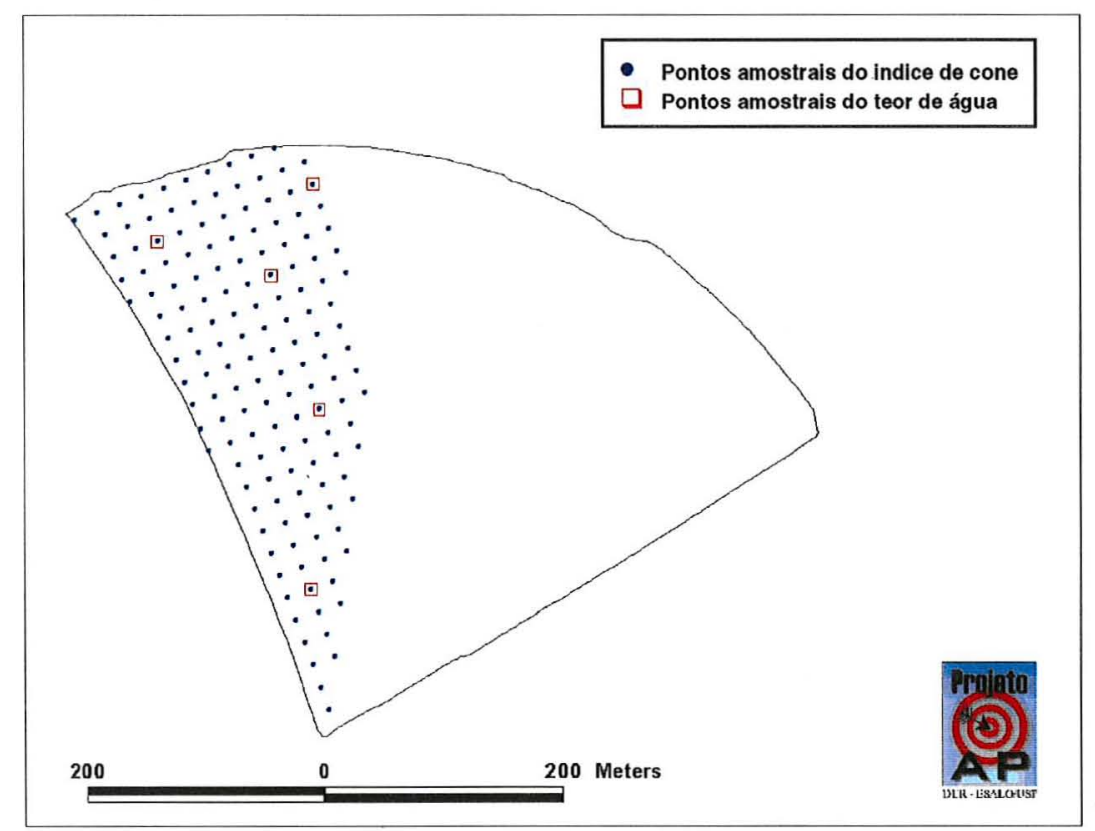

Figura 9 - Grade amostral sistemática da área de Pirassununga mostrando os 150 pontos onde foram coletados os dados do índice de cone e do teor de água, após a irrigação pelo sistema de pivô central.

\subsection{Coleta de dados do índice de cone e do teor de água}

Os dados do índice de cone foram coletados até a profundidade de 0,40 $\mathrm{m}$, sendo a leitura feita a cada meio segundo de incremento de profundidade da haste do penetrômetro. Para a análise, tomaram-se as leituras das profundidades de 0,$10 ; 0,15 ; 0,20 ; 0,25 ; 0,30 ; 0,35$ e $0,40 \mathrm{~m}$, que foram selecionadas a partir das curvas geradas pelo programa no coletor de dados. 
Os dados do teor de água foram coletados nas profundidades de $0,10 \mathrm{e}$ $0,30 \mathrm{~m}$, feitas no mesmo dia e sob as mesmas condições. Para a coleta das amostras na área de Pirassununga, utilizou-se uma máquina perfuradora de solo, equipada com uma broca medindo $0,40 \mathrm{~m}$ de diâmetro, acionada pela tomada de potência do trator. Esta solução foi encontrada porque o solo da área de Pirassununga se encontrava muito duro e seco, dificultando a retirada das amostras. Para a coleta das amostras na área de Castro, utilizou-se um trado holandês manual.

As amostras para a determinação do teor de água foram acondicionadas em recipientes hermeticamente fechados e depois colocadas no interior de um depósito térmico, que posteriormente foi levado ao laboratório. Para a determinação do teor de água, utilizou-se o método gravimétrico proposto por Brady \& Weil (1998).

No laboratório, as amostras foram primeiramente pesadas numa balança analítica, sendo os valores anotados, constituindo o peso úmido. Depois as amostras foram colocadas para secar em estufa a $105^{\circ} \mathrm{C}$ por 24 horas, sendo novamente pesadas, com valores devidamente anotados, constituindo o peso seco. $O$ teor de água foi determinado pela diferença entre o peso úmido e o peso seco da amostra, obtendo-se a relação entre gramas de água por gramas de solo seco. O teor de água das profundidades analisadas foi representado pela média dos pontos amostrados.

Os valores do teor de água e do índice de cone dos 150 pontos após a irrigação da área de Pirassununga foram comparados e analisados com os valores do teor de água e do índice de cone dos mesmos 150 pontos antes da irrigação. 


\subsection{Análise dos dados}

\subsubsection{Análise estatística descritiva}

Procedeu-se uma análise estatística descritiva para verificação do comportamento dos dados quanto às medidas estatísticas de posição e de variabilidade, bem como em relação à aderência à distribuição normal. Nestas análises, assume-se que as observações são independentes espacialmente, isto é, as variações de um lugar para outro são consideradas aleatórias, não levando em conta suas posições. Seu objetivo não foi fazer qualquer tipo de inferência, mas analisar o comportamento inicial dos dados.

Os dados foram analisados pelos momentos estatísticos: média, variância, desvio padrão, assimetria, curtose e coeficiente de variação.

A variabilidade dos dados do índice de cone foi classificada de acordo com os critérios propostos por Warrick \& Nielsen (1980), que consideram os valores do coeficiente de variação (CV) entre 17,43 e 46,48\% como de média variabilidade e os valores abaixo e acima como de baixa e alta variabilidade, respectivamente.

O comportamento da distribuição dos dados do índice de cone foi verificado pelos critérios propostos por Spiegel (1985), que sugere os valores do coeficiente de assimetria (AS) e curtose (K) próximos de 0 e 3 , respectivamente, como distribuição normal dos dados. Foram gerados gráficos de distribuição de frequência relativa dos dados do índice de cone para todas as profundidades.

\subsubsection{Análise geoestatística}

Nesta análise, o comportamento dos dados do índice de cone é associado às suas posições na região amostrada. Para identificar a estrutura de 
dependência espacial, utilizou-se a função semivariância, expressa pela equação (6).

A partir dos valores de semivariância construiu-se os semivariogramas experimentais para o conjunto de dados do índice de cone de cada profundidade, analisando os seus comportamentos nas direções $0^{\circ}, 45^{\circ}, 90^{\circ} \mathrm{e}$ $135^{\circ}$, a fim de se observar os casos de anisotropia. Os semivariogramas foram gerados pelo programa GS+ Geostatistics for the Environmental Sciences, que calculou automaticamente os semivariogramas para as direções mencionadas e ajustou o modelo teórico que melhor caracterizava o fenômeno na área estudada.

Os modelos avaliados foram o esférico, o exponencial, o gaussiano e o linear. O grau de dependência espacial foi classificado de acordo com os critérios propostos por Cambardella et al. (1994). Segundo estes autores, semivariogramas que apresentam efeito pepita menor ou igual a $25 \%$ do patamar têm forte dependência espacial. A dependência é moderada quando essa relação variar de 25 a $75 \%$ e fraca quando o efeito pepita for superior a $75 \%$ do patamar.

Os parâmetros dos modelos teóricos foram utilizados na interpolação de valores em pontos não amostrados pela técnica da krigagem ordinária, estimada por células (blocos) medindo $10 \times 10$ metros.

\subsection{Geração dos mapas do índice de cone}

Pelas aplicações sucessivas da krigagem ordinária, construíram-se os mapas do índice de cone de cada profundidade nas duas áreas, sendo calculadas as áreas dos polígonos com os valores estimados. Os mapas da área de Pirassununga foram gerados em três cenários: área total; área de 150 pontos antes da irrigação pelo sistema de pivô central e de 150 pontos após a irrigação. Os cenários das áreas de 150 pontos antes da irrigação e de 150 pontos após a irrigação foram confrontados em pares de cada profundidade, 
com o objetivo de se verificar a influência do teor de água sobre 0 índice de cone. Esses mapas foram gerados pelo programa de SIG SStoolbox.

\subsection{Geração dos mapas de produtividade}

O monitoramento da produtividade nas duas áreas foi feito por uma colhedora da marca John Deere, modelo 9510, equipada com receptor GPS, com correção diferencial em tempo real via satélite e sistema de monitoramento de produtividade "GreenStar". Na área de Pirassununga foi utilizado o mapa de produtividade da cultura do milho da safra 1999. Na área de Castro foram utilizados os mapas de produtividade da cultura da soja, safra 1999, e da cultura do milho, safra 2000. Esses dados foram coletados em uma outra etapa do projeto, que está sendo conduzido nas áreas, que visa a monitorar a variabilidade espacial da produtividade e dos fatores de produção. Os mapas foram gerados a partir dos dados brutos obtidos pelo sistema de monitoramento da produtividade ("GreenStar"), com o auxílio do programa de SIG SStoolbox.

Foram efetuadas análises de regressão lineares simples entre o índice de cone de todas as profundidades e a produtividade utilizando-se as tabelas com os dados estimados pela krigagem, que serviram de fontes para a geração dos mapas pelo programa de SIG SStoolbox. 


\section{RESULTADOS E DISCUSSÃO}

\subsection{Calibração do penetrômetro}

A Figura 10 mostra a curva de calibração encontrada para a célula de carga, bem como a equação que expressa o valor da tensão $\left(q_{0}\right)$ em função da força $\left(q_{i}\right)$ e o coeficiente de determinação $\left(R^{2}\right)$ obtido.

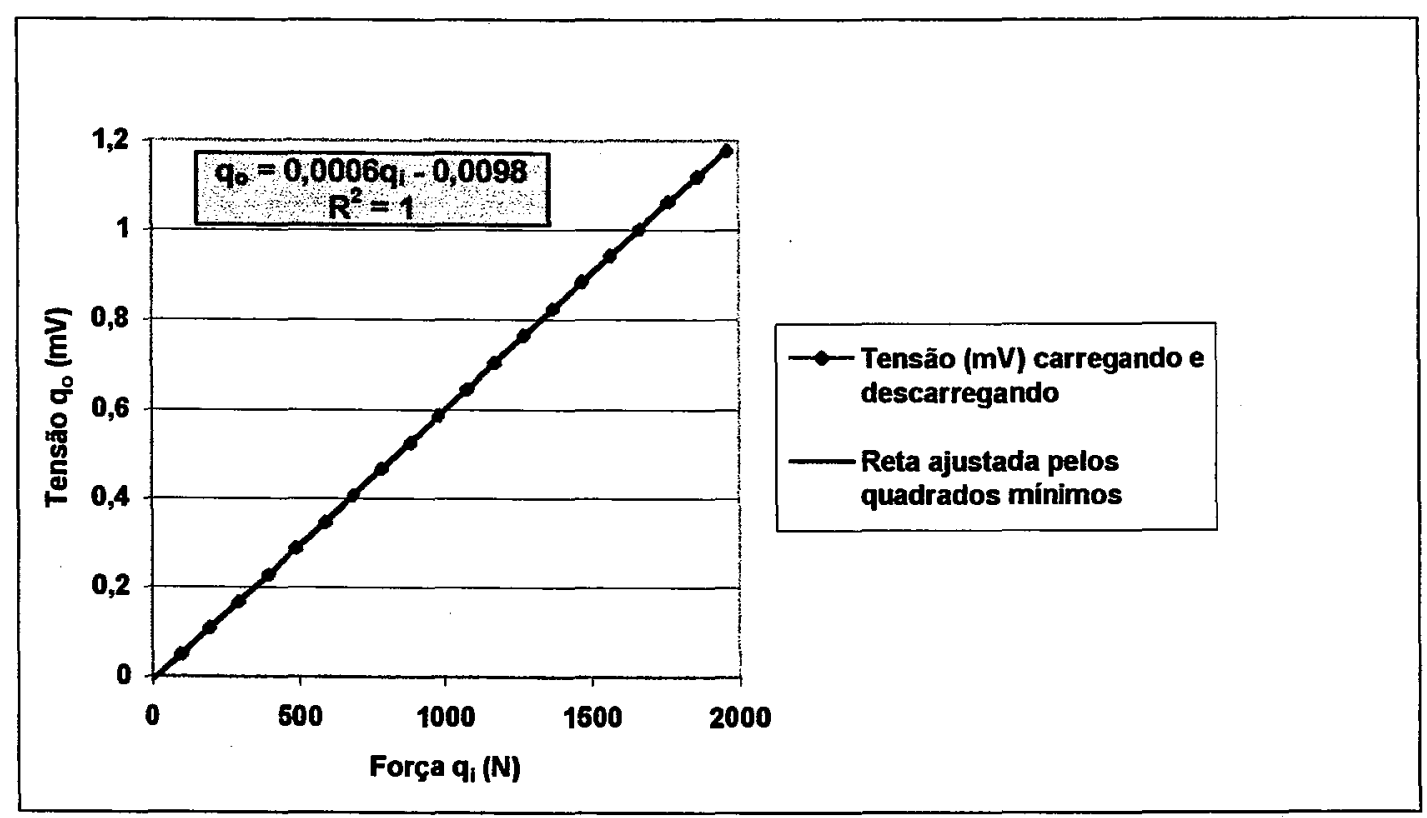

Figura 10 - Curva de calibração da célula de carga utilizada para medir a força de penetração no penetrômetro. 
A Figura 11 mostra a curva de calibração encontrada para o sonar, bem como a equação que expressa o valor da tensão $\left(q_{0}\right)$ em função da força $\left(q_{i}\right)$ e o coeficiente de determinação $\left(R^{2}\right)$ obtido.

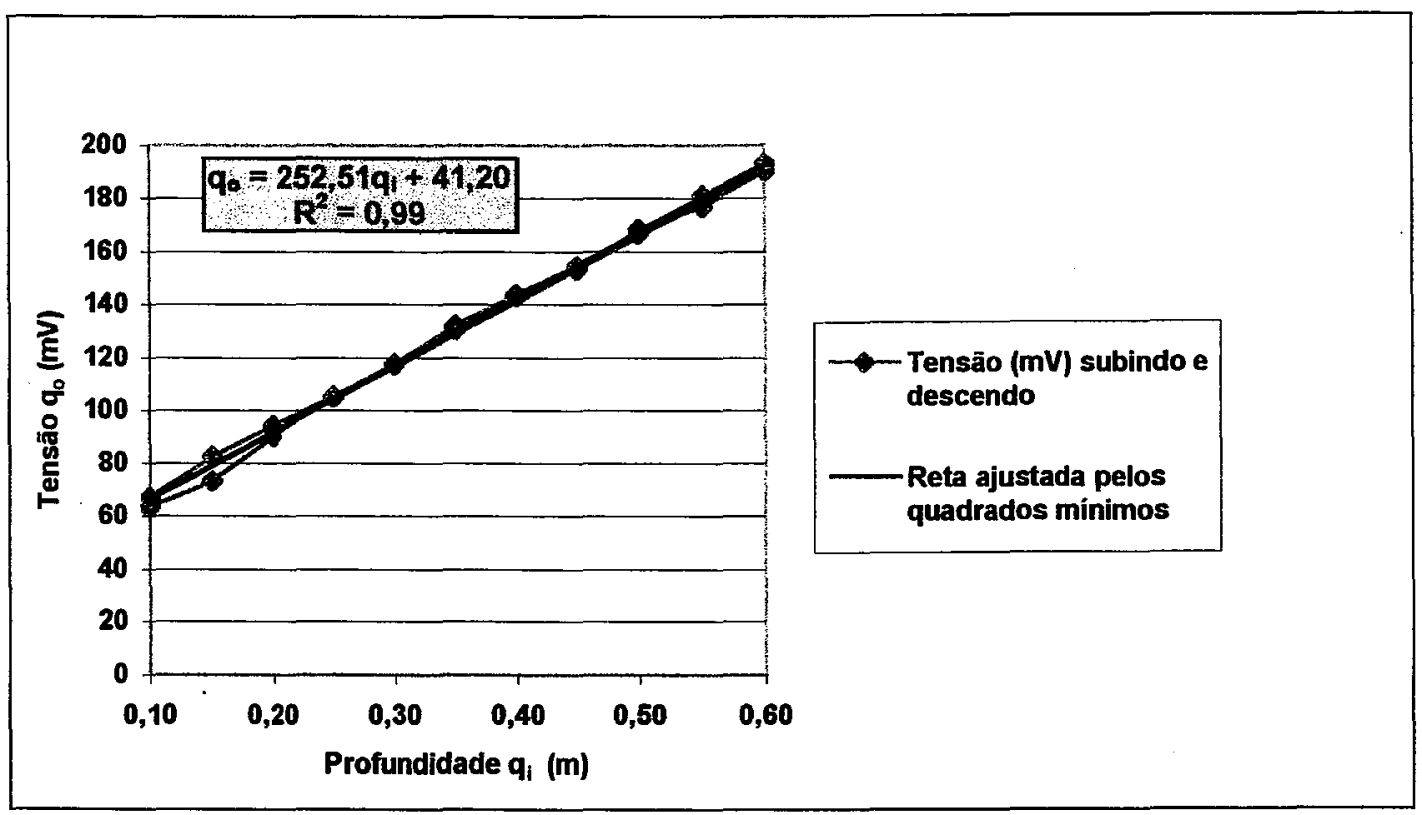

Figura 11 - Curva de calibração do sonar utilizado para medir a profundidade de penetração no penetrômetro.

Pelo valor do coeficiente de determinação encontrado para a célula de carga, observa-se uma linearidade perfeita. Os pequenos desvios observados nos ensaios do sonar ocorreram devido às interferências no sinal, derivadas das irregularidades do terreno e pela presença de restos de culturas e de outros materiais sobre o solo. No entanto, o valor do coeficiente de determinação muito próximo de 1,00 mostra que o aparelho segue um comportamento linear. Os coeficientes da reta ajustada foram inseridos nas sub-rotinas do programa de leitura de dados. 


\subsection{Análise estatística descritiva dos dados de campo}

\subsubsection{Análise estatística descritiva dos dados da área de Pirassununga}

Os momentos estatísticos dos dados do índice de cone, bem como os valores do teor de água, obtidos na área de Pirassununga, estão apresentados na Tabela 1.

Tabela 1. Momentos estatísticos dos dados do índice de cone e valores do teor de água da área de Pirassununga.

\begin{tabular}{ccccccccccc}
\hline $\begin{array}{c}\text { Profundidade } \\
(\mathrm{m})\end{array}$ & $\mathrm{N}$ & $\begin{array}{c}\text { Média } \\
(\mathrm{MPa})\end{array}$ & $\begin{array}{c}\mathrm{DP} \\
(\mathrm{MPa})\end{array}$ & $\begin{array}{c}\text { Variância } \\
(\mathrm{Mpa})\end{array}$ & $\begin{array}{c}\text { Mínimo } \\
(\mathrm{MPa})\end{array}$ & $\begin{array}{c}\text { Máximo } \\
(\mathrm{MPa})\end{array}$ & $\mathrm{AS}$ & $\mathrm{K}$ & $\begin{array}{c}\text { CV } \\
\%\end{array}$ & $\begin{array}{c}\text { Teor de Água } \\
\left({\mathrm{g} . g^{-1}}^{-1}\right.\end{array}$ \\
\hline 0,10 & 444 & 7,07 & 4,26 & 18,20 & 0,33 & 19,55 & 0,41 & $-0,71$ & 60,25 & 15,81 \\
0,15 & 444 & 7,98 & 3,48 & 12,11 & 0,89 & 21,59 & 0,58 & 0,45 & 43,61 & \\
0,20 & 444 & 7,30 & 3,06 & 9,34 & 0,86 & 19,66 & 0,73 & 0,67 & 41,92 & \\
0,25 & 444 & 6,12 & 2,80 & 7,72 & 1,27 & 17,55 & 0,91 & 0,87 & 45,75 & \\
0,30 & 444 & 4,96 & 2,40 & 5,80 & 0,36 & 15,86 & 1,14 & 1,61 & 48,39 & 18,19 \\
0,35 & 444 & 4,04 & 2,14 & 4,60 & 1,01 & 18,46 & 2,08 & 7,74 & 52,97 & \\
0,40 & 444 & 3,02 & 1,66 & 2,74 & 0,48 & 11,45 & 1,78 & 4,53 & 54,97 & \\
\hline
\end{tabular}

A Figura 12 mostra o gráfico de distribuição de frequência dos dados do índice de cone da área de Pirassununga. 


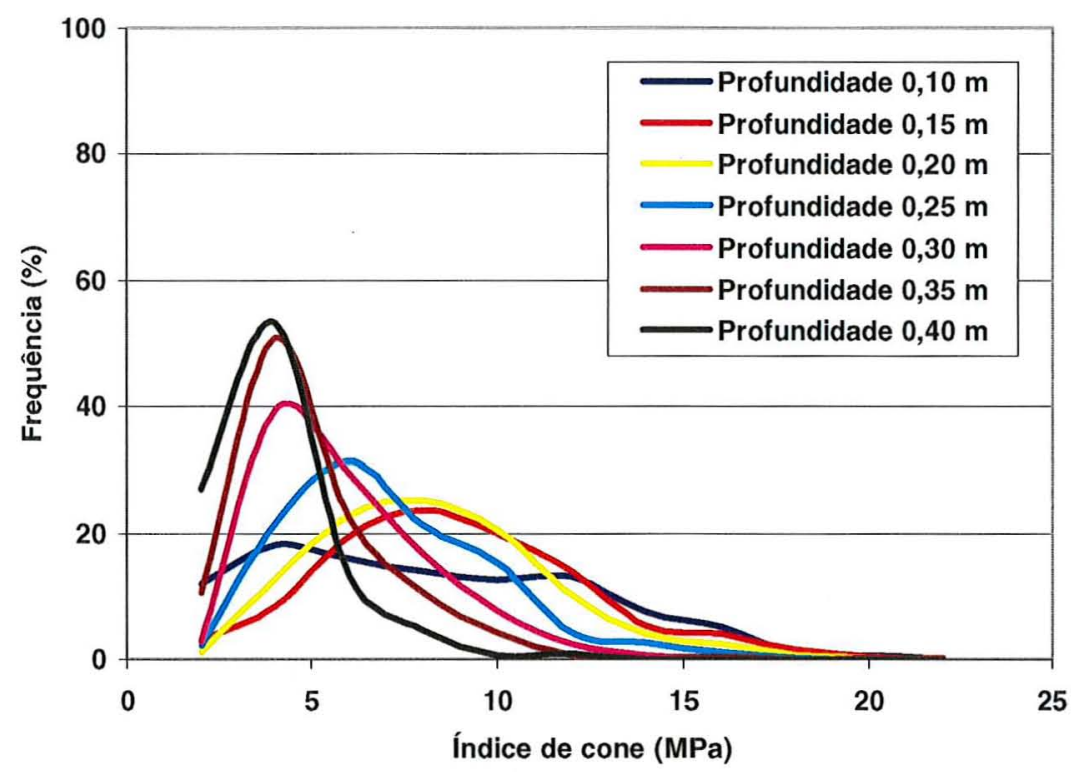

Figura 12 - Gráfico de distribuição de frequência dos dados do índice de cone da área de Pirassununga.

Os valores dos coeficientes de assimetria e curtose próximos de 0 e 3 , respectivamente, sugerem distribuição normal para os dados do índice de cone entre as profundidades de 0,10 e 0,30 m. Nas profundidades de 0,35 e 0,40 m, observa-se um desvio da normalidade.

Para todas as profundidades, a distribuição de frequência dos dados do índice de cone é assimétrica positiva, ou assimétrica à direita no gráfico de distribuição de frequência.

Pelos valores dos coeficientes de variação, segundo os critérios estabelecidos por Warrick \& Nielsen (1980), observa-se que os dados do índice de cone apresentaram alta variabilidade nas profundidades de 0,$10 ; 0,30 ; 0,35$ e $0,40 \mathrm{~m}$. As profundidades de 0,15;0,20 e 0,25 m apresentaram média variabilidade.

Pelos valores das médias, observa-se que os maiores valores do índice de cone aconteceram entre as profundidades de 0,10 e 0,20 m. 
A Figura 13 apresenta o gráfico das médias dos dados do índice de cone relacionadas com a profundidade, que constam da Tabela 1.

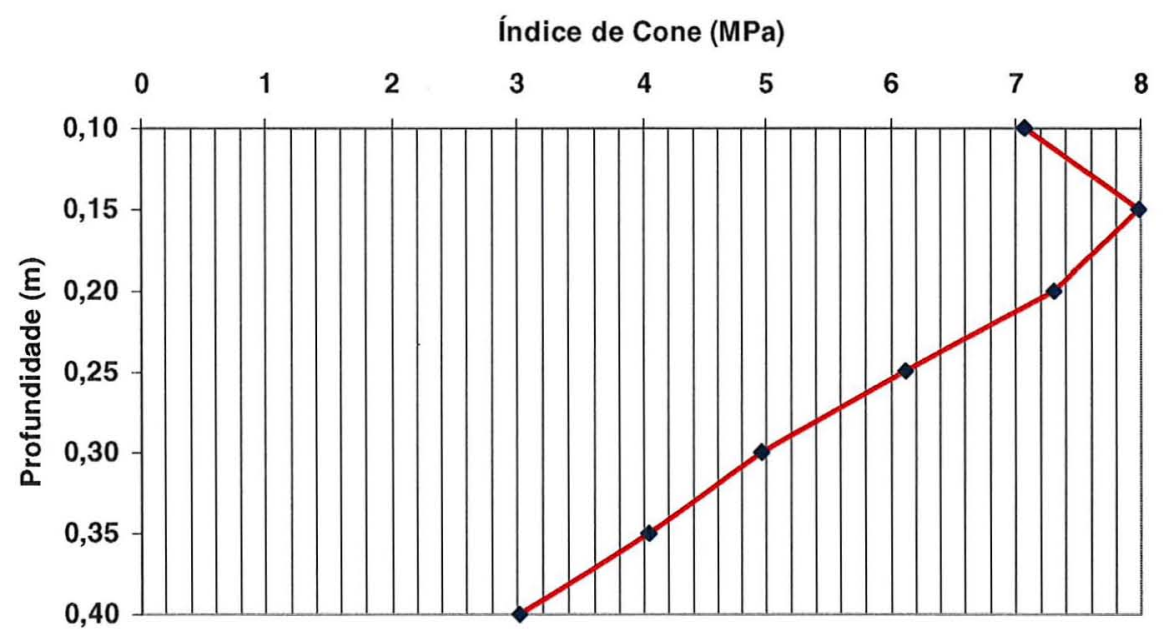

Figura 13-Gráfico do índice de cone, relacionado com a profundidade, representando a média de todos os pontos da área de Pirassununga.

Os momentos estatísticos dos dados do índice de cone, bem como os valores do teor de água dos 150 pontos antes da irrigação pelo pivô central, obtidos na área de Pirassununga, estão apresentados na Tabela 2.

A Figura 14 mostra o gráfico de distribuição de frequência dos dados do índice de cone dos 150 pontos antes da irrigação pelo pivô central da área de Pirassununga.

Os valores dos coeficientes de assimetria e curtose próximos de 0 e 3 , respectivamente, sugerem distribuição normal para os dados do índice de cone entre as profundidades de 0,10 e 0,30 m. Nas profundidades de 0,35 e 0,40 m, observa-se um desvio da normalidade.

Para todas as profundidades, a distribuição de frequência dos dados do índice de cone é assimétrica positiva, ou assimétrica à direita no gráfico de distribuição de frequência. 
Tabela 2. Momentos estatísticos dos dados do índice de cone e valores do teor de água dos 150 pontos antes da irrigação pelo pivô central da área de Pirassununga.

\begin{tabular}{|c|c|c|c|c|c|c|c|c|c|c|}
\hline $\begin{array}{l}\text { Profundidade } \\
\qquad(\mathrm{m})\end{array}$ & $\mathrm{N}$ & $\begin{array}{l}\text { Média } \\
\text { (MPa) }\end{array}$ & $\begin{array}{c}\mathrm{DP} \\
(\mathrm{MPa})\end{array}$ & $\begin{array}{c}\text { Variância } \\
\text { (MPa) }\end{array}$ & $\begin{array}{c}\text { Mínimo } \\
\text { (Mpa) }\end{array}$ & $\begin{array}{c}\text { Máximo } \\
\text { (MPa) }\end{array}$ & AS & $\mathrm{K}$ & $\begin{array}{l}\mathrm{CV} \\
\% \\
\end{array}$ & $\begin{array}{c}\text { Teor de Água } \\
\left(\mathrm{g} . \mathrm{g}^{-1}\right)\end{array}$ \\
\hline 0,10 & 150 & 5,52 & 3,85 & 14,85 & 0,62 & 16,15 & 0,80 & $-0,26$ & 69,75 & 15,39 \\
\hline 0,15 & 150 & 7,83 & 3,40 & 11,55 & 1,27 & 18,72 & 0,33 & 0,25 & 43,42 & \\
\hline 0,20 & 150 & 7,73 & 2,60 & 6,75 & 1,79 & 15,30 & 0,39 & 0,49 & 33,64 & \\
\hline 0,25 & 150 & 6,60 & 2,40 & 5,76 & 1,59 & 14,47 & 0,64 & 0,57 & 36,36 & \\
\hline 0,30 & 150 & 5,11 & 2,14 & 4,60 & 0,36 & 12,31 & 0,74 & 0,65 & 41,88 & 18,35 \\
\hline 0,35 & 150 & 4,00 & 2,06 & 4,26 & 1,01 & 18,46 & 2,77 & 15,12 & 51,50 & \\
\hline 0,40 & 150 & 2,70 & 1,21 & 1,47 & 0,53 & 10,16 & 2,28 & 9,59 & 44,81 & \\
\hline
\end{tabular}

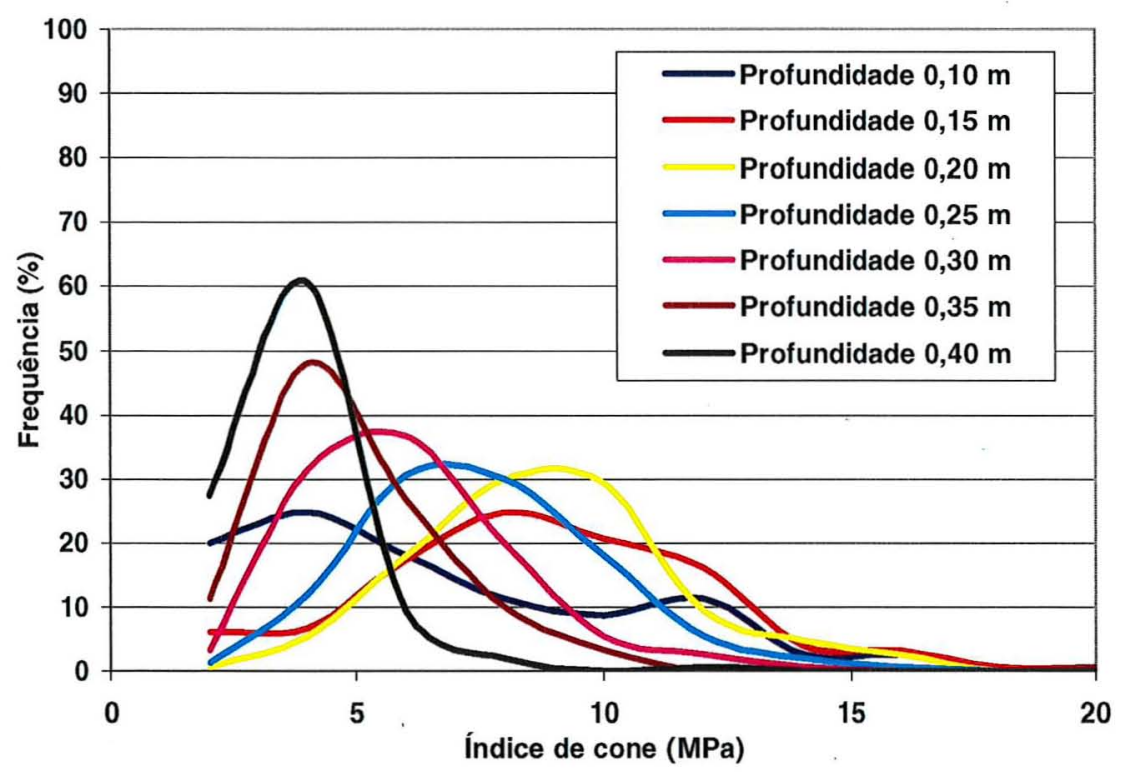

Figura 14 - Gráfico de distribuição de frequência dos dados do índice de cone dos 150 pontos antes da irrigação pelo pivô central da área de Pirassununga.

Pelos valores dos coeficientes de variação, observa-se que os dados do índice de cone apresentaram alta variabilidade nas profundidades de 0,10 e 
0,35 $\mathrm{m}$, já nas demais profundidades, os dados apresentaram média variabilidade.

Pelos valores das médias, observa-se que os maiores valores do índice de cone aconteceram nas profundidades de 0,15 e 0,20 m.

Os momentos estatísticos dos dados do índice de cone, bem como os valores do teor de água dos 150 pontos após a irrigação pelo pivô central, obtidos na área de Pirassununga, estão apresentados na Tabela 3.

Tabela 3. Momentos estatísticos dos dados do índice de cone e valores do teor de água dos 150 pontos após a irrigação pelo pivô central da área de Pirassununga.

\begin{tabular}{|c|c|c|c|c|c|c|c|c|c|c|}
\hline $\begin{array}{l}\text { Profundidade } \\
\text { (m) }\end{array}$ & $\mathbf{N}$ & $\begin{array}{l}\text { Média } \\
\text { (MPa) }\end{array}$ & $\begin{array}{c}\mathrm{DP} \\
(\mathrm{MPa})\end{array}$ & $\begin{array}{c}\text { Variância } \\
\text { (MPa) }\end{array}$ & $\begin{array}{c}\text { Mínimo } \\
\text { (MPa) }\end{array}$ & $\begin{array}{l}\text { Máximo } \\
\text { (MPa) }\end{array}$ & AS & $K$ & $\begin{array}{l}\mathrm{CV} \\
\%\end{array}$ & $\begin{array}{c}\text { Teor de Água } \\
\left(\mathrm{g} . \mathrm{g}^{-1}\right)\end{array}$ \\
\hline 0,10 & 150 & 1,60 & 0,66 & 0,44 & 0,48 & 6,46 & 2,75 & 17,99 & 41,25 & 20,03 \\
\hline 0,15 & 150 & 1,74 & 0,60 & 0,36 & 0,58 & 5,20 & 1,91 & 7,01 & 34,48 & \\
\hline 0,20 & 150 & 1,74 & 0,47 & 0,22 & 0,76 & 3,15 & 0,55 & 0,23 & 27,01 & \\
\hline 0,25 & 150 & 1,75 & 0,55 & 0,30 & 0,68 & 3,73 & 0,84 & 0,96 & 31,43 & \\
\hline 0,30 & 150 & 1,77 & 0,76 & 0,58 & 0,79 & 4,76 & 1,72 & 3,16 & 42,94 & 19,74 \\
\hline 0,35 & 150 & 1,84 & 0,98 & 0,97 & 0,44 & 6,44 & 2,07 & 4,93 & 53,26 & \\
\hline 0,40 & 150 & 2,01 & 1,01 & 1,02 & 0,60 & 6,46 & 1,70 & 3,07 & 50,25 & \\
\hline
\end{tabular}

A Figura 15 mostra o gráfico de distribuição de frequência dos dados do índice de cone dos 150 pontos após a irrigação pelo pivô central da área de Pirassununga. 


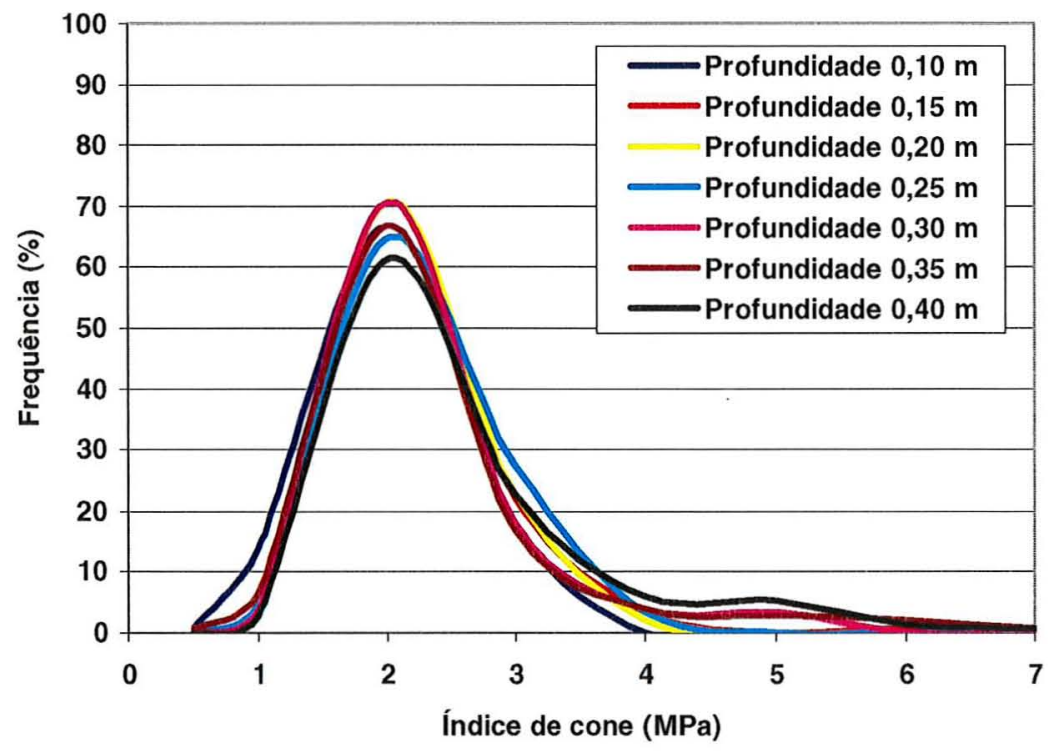

Figura 15 - Gráfico de distribuição de frequência dos dados do índice de cone dos 150 pontos após a irrigação pelo pivô central da área de Pirassununga.

O comportamento dos dados do índice de cone nas profundidades de 0,20 a 0,30 m permaneceu praticamente inalterado após a irrigação, porém, nas profundidades 0,10 e 0,15 m houve um desvio da normalidade da distribuição dos dados, como pode ser notado pelos valores dos coeficientes de assimetria e curtose. Nas profundidades de 0,35 e 0,40 m os dados apresentaram distribuição normal.

Para todas as profundidades, a distribuição de frequência dos dados do índice de cone é assimétrica positiva, ou assimétrica à direita no gráfico de distribuição de frequência.

Pelos valores dos coeficientes de variação, observa-se que os dados do índice de cone apresentaram alta variabilidade nas profundidades de 0,35 e $0,40 \mathrm{~m}$, sendo que nas demais profundidades os dados apresentaram média variabilidade. 
Pelos valores das médias, observa-se que o índice de cone permaneceu praticamente constante em todas as profundidades.

Apesar do pequeno incremento do teor de água, de $4,64 \mathrm{~g} \cdot \mathrm{g}^{-1}$ na profundidade $0,10 \mathrm{~m}$ e $1,39 \mathrm{~g} \cdot \mathrm{g}^{-1}$ na profundidade de $0,30 \mathrm{~m}$, observa-se uma considerável redução do índice de cone. Esse resultado confirma as observações de Klein et al. (1998) de que pequenas variações na condição de umidade do solo proporcionam variações acentuadas da resistência à penetração, motivo pelo qual esses autores não recomendam a determinação das sondagens quando o solo se encontra próximo à sua capacidade de campo. Para melhor visualização desse efeito, as Figuras 16 e 17 apresentam os gráficos das médias dos dados do índice de cone relacionadas com as profundidades, retiradas das Tabelas 2 e 3, respectivamente.

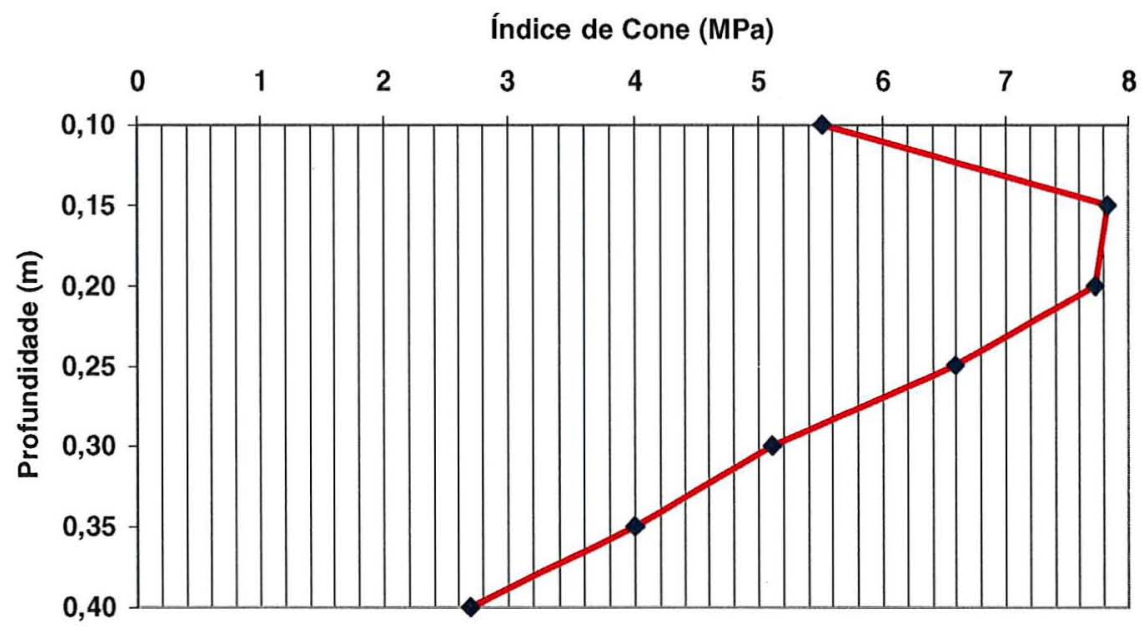

Figura 16-Gráfico do índice de cone, relacionado com a profundidade, representando a média dos 150 pontos antes da irrigação pelo pivô central da área de Pirassununga. 


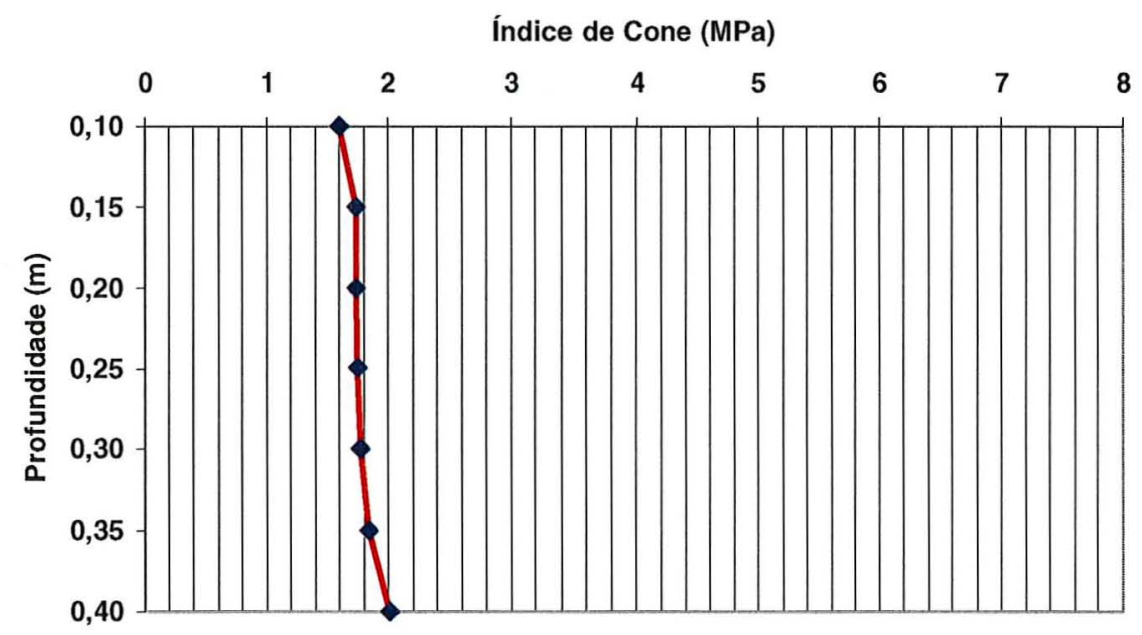

Figura 17 -Gráfico do índice de cone, relacionado com a profundidade, representando a média dos 150 pontos após a irrigação pelo pivô central da área de Pirassununga.

Como se pode observar, a área de Pirassununga apresentou um índice de cone muito elevado em todas as profundidades analisadas e nas condições de solo não irrigado. Isso sugere um manejo mais adequado, de modo a criar melhores condições à penetração das raízes, cujo crescimento pode ser reduzido se a resistência do solo atingir valores da ordem de 3,0 MPa (Miller, 1987).

Pelas análises do histórico da área de Pirassununga, observa-se que os altos valores do índice de cone nas camadas superiores do solo são atribuídos ao efeito do tráfego de máquinas. A implantação do sistema de semeadura direta na área não foi antecedida de correção física do perfil do solo. Os resultados demonstram o efeito acumulado da compactação e a formação do fenômeno conhecido como "pé-de-grade" ou "pé-de-arado".

À luz da estatística clássica, na qual as observações são consideradas aleatórias e independentes espacialmente, como os dados do índice de cone da área de Pirassununga se ajustaram próximos à distribuição normal, a média aritmética de cada profundidade pode ser considerada uma medida de 
tendência central, representativa do conjunto de dados, podendo ser utilizada no sistema de manejo do solo. Todavia, com este procedimento, o sistema poderá ser superdimensionado em alguns setores e subdimensionados em outros.

\subsubsection{Análise estatística descritiva dos dados da área de Castro}

Os momentos estatísticos dos dados do índice de cone, bem como os valores do teor de água obtidos na área de Castro estão apresentados na Tabela 4.

Tabela 4. Momentos estatísticos dos dados do índice de cone e valores do teor de água da área de Castro.

\begin{tabular}{|c|c|c|c|c|c|c|c|c|c|c|}
\hline $\begin{array}{l}\text { Profundidade } \\
\text { (m) }\end{array}$ & $\mathbf{N}$ & $\begin{array}{l}\text { Média } \\
\text { (MPa) }\end{array}$ & $\begin{array}{c}\mathrm{DP} \\
(\mathrm{MPa})\end{array}$ & $\begin{array}{c}\text { Variância } \\
\text { (Mpa) }\end{array}$ & $\begin{array}{l}\text { Mínimo } \\
\text { (MPa) }\end{array}$ & $\begin{array}{c}\text { Máximo } \\
\text { (MPa) }\end{array}$ & AS & $K$ & $\begin{array}{l}\mathrm{CV} \\
\%\end{array}$ & $\begin{array}{c}\text { Teor de Água } \\
\left(\mathrm{g} \cdot \mathrm{g}^{-1}\right)\end{array}$ \\
\hline 0,10 & 358 & 2,14 & 0,76 & 0,58 & 0,56 & 6,97 & 2,43 & 9,35 & 35,51 & 26,39 \\
\hline 0,15 & 358 & 1,87 & 0,65 & 0,43 & 0,54 & 5,96 & 2,59 & 10,86 & 34,76 & \\
\hline 0,20 & 358 & 1,76 & 0,64 & 0,41 & 0,47 & 5,41 & 2,31 & 8,14 & 36,36 & \\
\hline 0,25 & 358 & 1,76 & 0,68 & 0,46 & 0,50 & 6,21 & 2,16 & 8,14 & 38,64 & \\
\hline 0,30 & 358 & 1,84 & 0,70 & 0,47 & 0,49 & 4,72 & 1,47 & 2,93 & 38,04 & 27,03 \\
\hline 0,35 & 358 & 1,98 & 0,77 & 0,60 & 0,46 & 5,20 & 1,36 & 2,56 & 38,89 & \\
\hline 0,40 & 358 & 2,00 & 0,87 & 0,76 & 0,40 & 5,25 & 1,05 & 1,52 & 43,50 & \\
\hline
\end{tabular}

A Figura 18 mostra o gráfico de distribuição de frequência dos dados do índice de cone da área de Castro. 


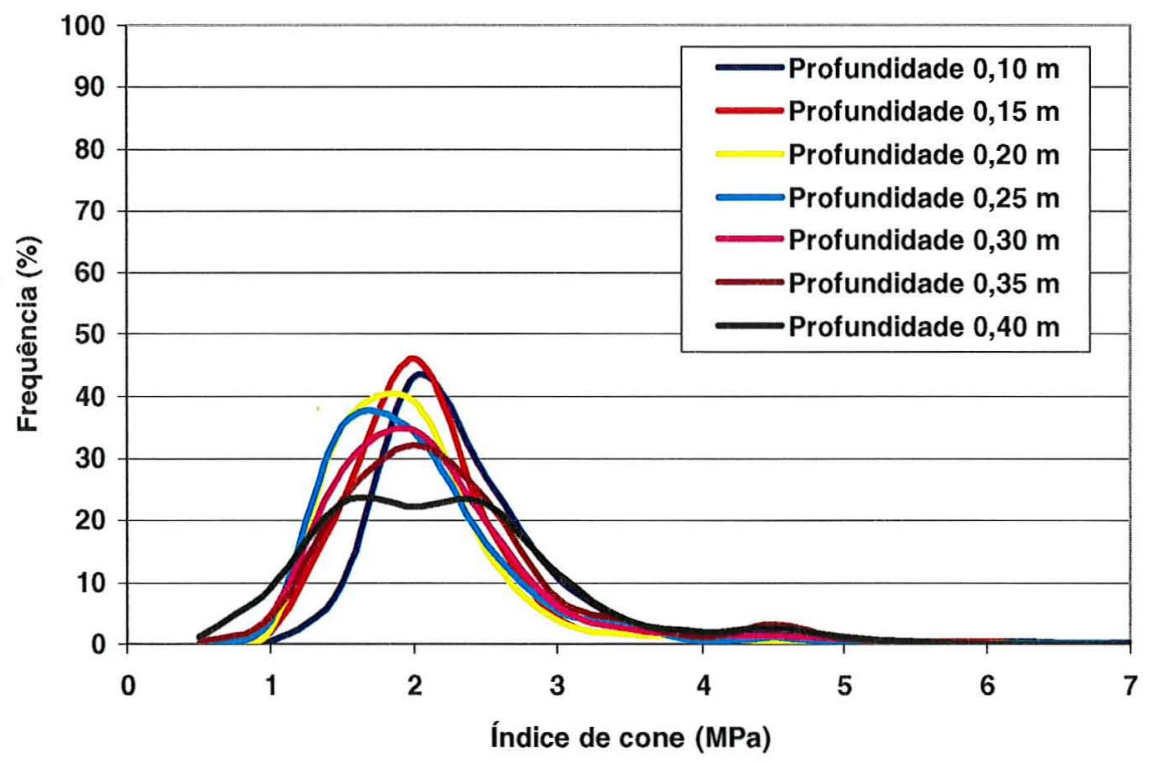

Figura 18 - Gráfico de distribuição de frequência dos dados do índice de cone da área de Castro.

Ocorreu um desvio da normalidade da distribuição dos dados nas profundidades de 0,10 a $0,25 \mathrm{~m}$, como pode ser notado pelos valores dos coeficientes de assimetria e curtose. Nas demais profundidades, os dados apresentaram comportamento próximo à distribuição normal.

Para todas as profundidades, a distribuição dos dados do índice de cone é assimétrica positiva, ou assimétrica à direita no gráfico de distribuição de frequência.

Pelos valores das médias, observa-se que o índice de cone permaneceu praticamente constante em todas as profundidades.

Pelos valores dos coeficientes de variação observa-se que os dados do índice de cone apresentaram média dispersão em todas as profundidades, permanecendo praticamente constante até a profundidade de 0,35 $\mathrm{m}$.

Os valores decorrentes do índice de cone entre as profundidades de 0,10 e 0,20 m indicam claramente o efeito do manejo da área sob semeadura direta. 
O tráfego de máquinas provoca compactação superficial sem que se evidencie o fenômeno conhecido como "pé-de-grade" ou "pé-de-arado".

A Figura 19 apresenta o gráfico das médias dos dados do índice de cone relacionadas com a profundidade, que constam da Tabela 4.

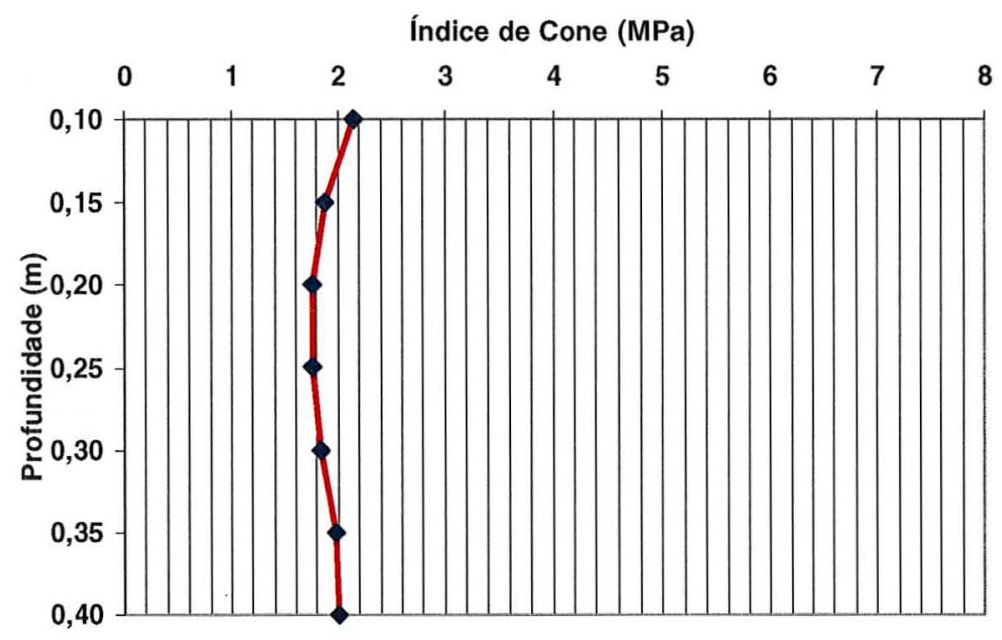

Figura 19-Gráfico do índice de cone, relacionado com a profundidade, representando a média de todos os pontos da área de Castro.

\subsection{Análise geoestatística dos dados}

Assumida a hipótese intrínseca, estimou-se a estrutura da dependência espacial através dos semivariogramas para cada profundidade nas duas áreas estudadas. Modelos isotrópicos e anisotrópicos foram considerados e avaliados pelo programa geoestatístico, que selecionou o melhor modelo pela combinação dos valores dos parâmetros que minimiza as somas dos quadrados dos resíduos ("Residual Sums of Squares - RSS"). Baseando-se neste critério, decidiu-se pelo modelo isotrópico que, se por um lado detalha menos a estrutura espacial de correlações, por outro é mais simples, uma vez que possui menor número de parâmetros (Ribeiro Júnior, 1995). 


\subsubsection{Análise geoestatística dos dados da área de Pirassununga}

Os semivariogramas experimentais, com os respectivos modelos ajustados para os dados do indice de cone das profundidades de 0,$10 ; 0,15$; 0,$20 ; 0,25 ; 0,30 ; 0,35$ e $0,40 \mathrm{~m}$ da área de Pirassununga podem ser visualizados na Figura 20.
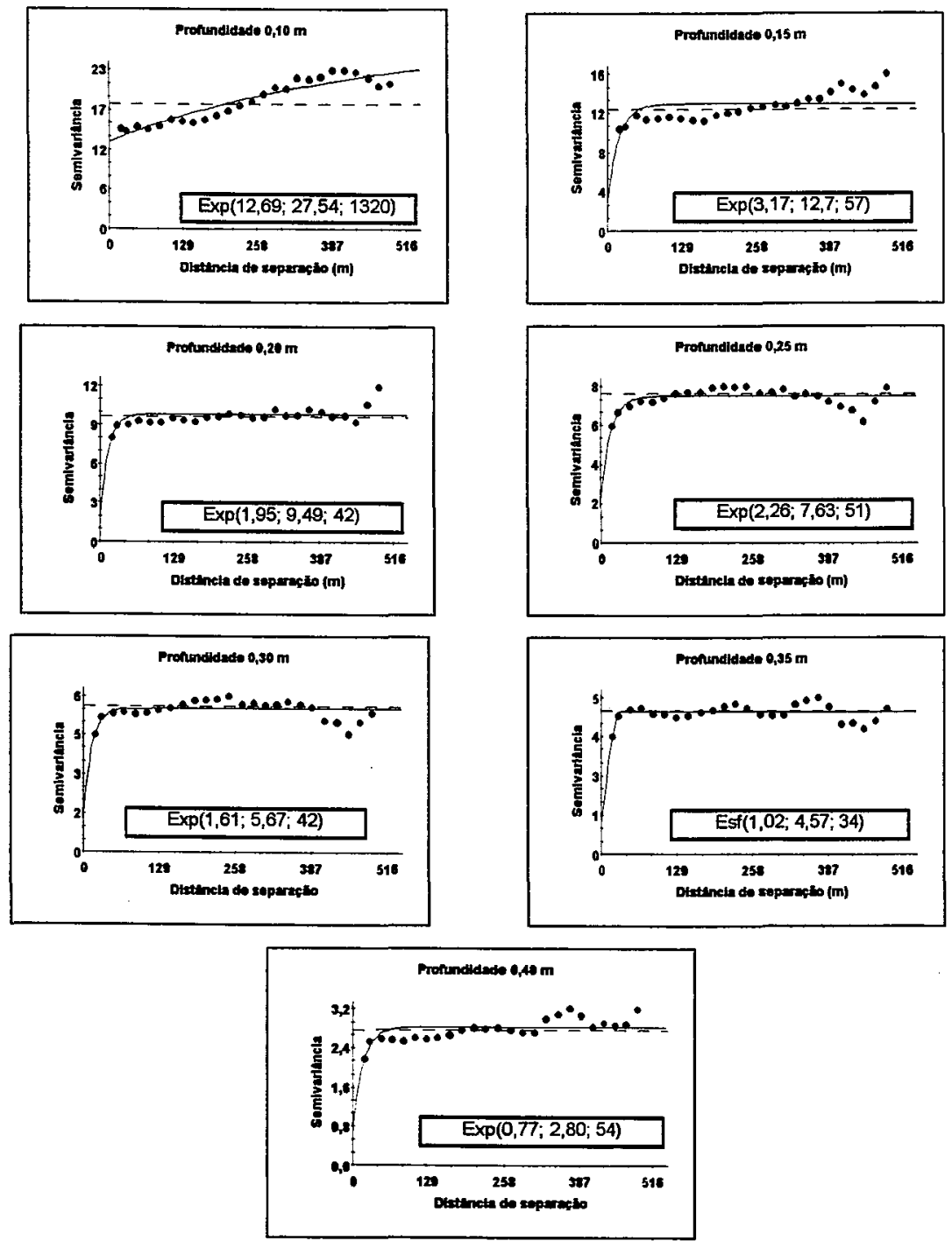

Figura 20 - Semivariogramas experimentais mostrando os modelos ajustados para os dados do índice de cone de todas as profundidades da área de Pirassununga; as linhas pontilhadas representam a variância amostral. 
Todas as profundidades apresentaram estrutura de dependência espacial do índice de cone, conforme pode ser observado pelos modelos ajustados dos semivariogramas.

A Tabela 5 mostra os parâmetros dos modelos dos semivariogramas ajustados e o efeito pepita expresso como a porcentagem do patamar.

Tabela 5. Parâmetros e modelos dos semivariogramas ajustados e o efeito pepita expresso como a porcentagem do patamar da área de Pirassununga.

\begin{tabular}{cccccc}
\hline Profundidade $(\mathrm{m})$ & ${ }^{1} \mathrm{Co}$ & ${ }^{2}(\mathrm{Co}+\mathrm{C})$ & ${ }^{3} \mathrm{Ao}(\mathrm{m})$ & $\left.{ }^{4} \mathrm{Co} / \mathrm{Co}+\mathrm{C}\right] .100$ & Modelo \\
\hline 0,10 & 12,69 & 27,54 & 1320 & 46,08 & Exp \\
0,15 & 3,17 & 12,70 & 57 & 24,96 & $\operatorname{Exp}$ \\
0,20 & 1,95 & 9,49 & 42 & 20,55 & Exp \\
0,25 & 2,26 & 7,63 & 51 & 29,62 & Exp \\
0,30 & 1,61 & 5,67 & 42 & 28,40 & Exp \\
0,35 & 1,02 & 4,57 & 34 & 22,32 & Esf \\
0,40 & 0,77 & 2,80 & 54 & 27,50 & Exp \\
\hline
\end{tabular}

As profundidades 0,$15 ; 0,20$ e $0,35 \mathrm{~m}$ apresentaram efeito pepita menor ou igual a $25 \%$ do patamar, o que, segundo os critérios propostos por Cambardella et al. (1994), indica forte dependência espacial do índice de cone. As demais profundidades apresentaram efeito pepita entre 25 e $75 \%$ do patamar, indicando moderada dependência espacial do índice de cone.

$O$ efeito pepita e o alcance da dependência espacial foram maiores na profundidade de $0,10 \mathrm{~m}$; nas demais, permaneceram praticamente constantes.

O patamaŕ e a variấncia amostral diminuíram com 0 aumento da profundidade, indicando que as propriedades do solo que afetam o índice de cone tornam-se progressivamente mais uniformes no subsolo. Moolman \& Van Huyssteen (1989), analisando geoestatisticamente a resistência do solo com um penetrômetro de cone, identificaram comportamento semelhante.

O modelo que se mostrou mais adequado para explicar a estrutura da variabilidade espacial do índice do cone foi o exponencial, para quase todas as 
profundidades, exceção apenas à profundidade de $0,35 \mathrm{~m}$, cujo modelo mais adequado foi o esférico.

Os semivariogramas experimentais com os respectivos modelos ajustados para os dados do índice de cone das profundidades de 0,$10 ; 0,15 ; 0,20 ; 0,25$; 0,$30 ; 0,35$ e 0,40 $\mathrm{m}$ dos 150 pontos antes da irrigação pelo pivô central da área de Pirassununga podem ser visualizados na Figura 21.

Todas as profundidades apresentaram estrutura de dependência espacial do índice de cone, conforme pode ser observado pelos modelos ajustados dos semivariogramas.

A Tabela 6 mostra os parâmetros dos modelos dos semivariogramas ajustados e o efeito pepita expresso como a porcentagem do patamar.

Tabela 6. Parâmetros e modelos dos semivariogramas ajustados e o efeito pepita expresso como a porcentagem do patamar dos 150 pontos antes da irrigação pelo pivô central da área de Pirassununga.

\begin{tabular}{cccccc}
\hline Profundidade $(\mathrm{m})$ & ${ }^{1} \mathrm{Co}$ & ${ }^{2}(\mathrm{Co}+\mathrm{C})$ & ${ }^{3} \mathrm{Ao}(\mathrm{m})$ & ${ }^{4}[\mathrm{Co} / \mathrm{Co}+\mathrm{C}] .100$ & Modelo \\
\hline 0,10 & 3,90 & 15,60 & 42,60 & 25,00 & Exp \\
0,15 & 2,79 & 11,48 & 35,70 & 24,30 & Exp \\
0,20 & 1,26 & 6,58 & 32,30 & 19,16 & Esf \\
0,25 & 1,09 & 5,57 & 34,30 & 19,59 & Esf \\
0,30 & 0,54 & 4,63 & 38,60 & 11,66 & Esf \\
0,35 & 0,49 & 4,02 & 28,10 & 12,18 & Esf \\
0,40 & 0,23 & 1,44 & 33,90 & 15,96 & Exp \\
\hline efeito pepita; ${ }^{2}$ patamar; ${ }^{3}$ alcance; ${ }^{4}$ efeito pepita expresso como a porcentagem do patamar.
\end{tabular}

O efeito pepita mostra alta dependência espacial do índice de cone em todas as profundidades analisadas. Observa-se que, à medida que aumenta a profundidade, o efeito pepita diminui. 

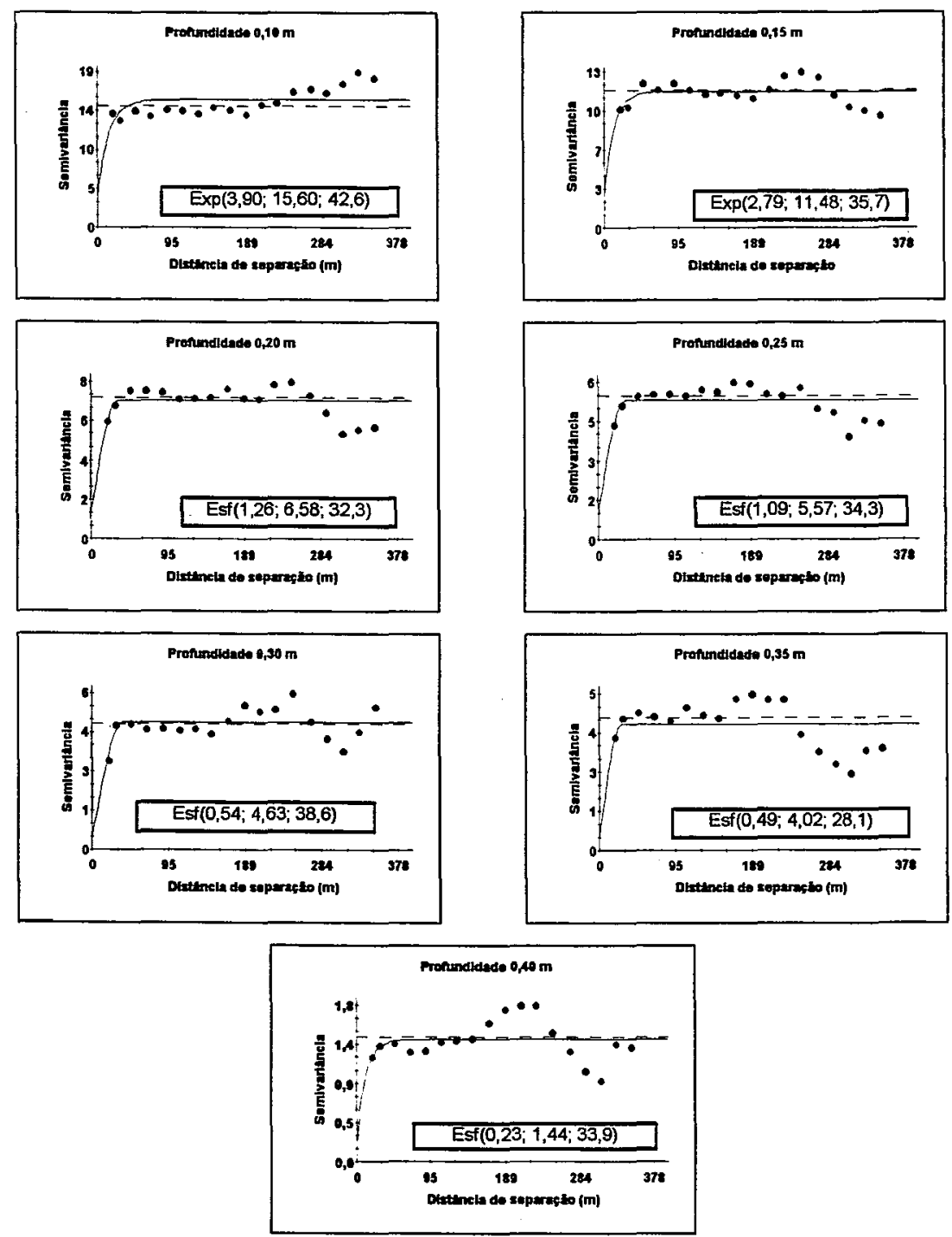

Figura 21 - Semivariogramas experimentais mostrando os modelos ajustados para os dados do índice de cone de todas as profundidades dos 150 pontos antes da irrigação pelo pivô central da área de Pirassununga; as linhas pontilhadas representam a variância amostral.

O modelo que se mostrou mais adequado para explicar a estrutura da variabilidade espacial do índice de cone nas profundidades de 0,10;0,15 e 0,40 $\mathrm{m}$ foi o exponencial, nas demais, o modelo mais adequado foi o esférico. 
Os semivariogramas experimentais com os respectivos modelos ajustados para os dados do índice de cone das profundidades de 0,$10 ; 0,15 ; 0,20 ; 0,25$; 0,$30 ; 0,35$ e 0,40 m dos 150 pontos após a irrigação pelo pivô central da área de Pirassununga podem ser visualizados na Figura 22.
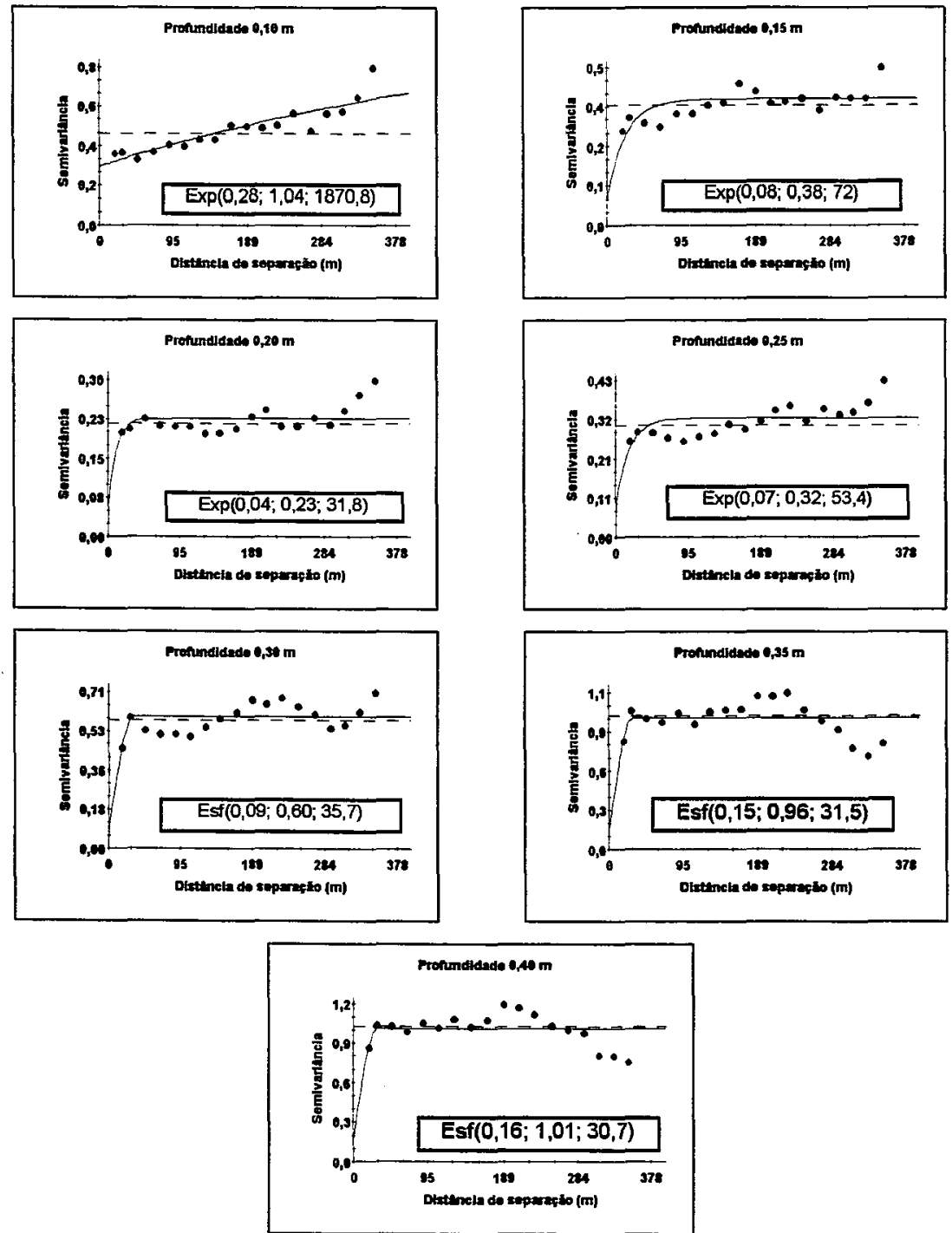

Figura 22 - Semivariogramas experimentais mostrando os modelos ajustados para os dados do índice de cone de todas as profundidades dos 150 pontos após a irrigação pelo pivô central da área de Pirassununga; as linhas pontilhadas representam a variância amostral. 
Todas as profundidades apresentaram estrutura de dependência espacial do índice de cone, conforme pode ser observado pelos modelos ajustados dos semivariogramas.

A Tabela 7 mostra os parâmetros dos modelos dos semivariogramas ajustados e o efeito pepita expresso como a porcentagem do patamar.

Tabela 7. Parâmetros e modelos dos semivariogramas ajustados e 0 efeito pepita expresso como a porcentagem do patamar dos 150 pontos após a irrigação pelo pivô central da área de Pirassununga.

\begin{tabular}{cccccc}
\hline Profundidade $(\mathrm{m})$ & ${ }^{1} \mathrm{Co}$ & ${ }^{2}(\mathrm{Co}+\mathrm{C})$ & ${ }^{3} \mathrm{Ao}(\mathrm{m})$ & ${ }^{4}[\mathrm{Co} / \mathrm{Co}+\mathrm{C}] .100$ & Modelo \\
\hline 0,10 & 0,28 & 1,04 & 1870,80 & 26,93 & Exp \\
0,15 & 0,08 & 0,38 & 72,00 & 20,88 & Exp \\
0,20 & 0,04 & 0,23 & 31,80 & 15,47 & Exp \\
0,25 & 0,07 & 0,32 & 53,40 & 21,65 & Exp \\
0,30 & 0,09 & 0,60 & 35,70 & 14,50 & Esf \\
0,35 & 0,15 & 0,96 & 31,50 & 15,29 & Esf \\
0,40 & 0,16 & 1,01 & 30,70 & 15,79 & Esf \\
\hline efeito pepita; ${ }^{2}$ patamar; ${ }^{3}$ alcance; ${ }^{4}$ efeito pepita expresso como a porcentagem do patamar.
\end{tabular}

Com exceção da profundidade de $0,10 \mathrm{~m}$, que apresentou moderada dependência espacial, todas as demais profundidades apresentaram alta dependência espacial do índice de cone.

O efeito pepita permaneceu praticamente constante em todas as profundidades analisadas, indicando que houve pouca mudança da estrutura espacial do índice de cone ao longo do perfil do solo. 0 alcance da dependência espacial da profundidade de $0,10 \mathrm{~m}$ foi elevado, nas demais, variou entre 30 e 72 metros.

0 modelo que se mostrou mais adequado para explicar a estrutura da variabilidade espacial do indice de cone entre as profundidades de 0,10 e 0,25 $\mathrm{m}$ foi o exponencial, nas demais, foi o modelo esférico. 
Os semivariogramas experimentais com os respectivos modelos ajustados para os dados do índice de cone das profundidades de 0,$10 ; 0,15 ; 0,20 ; 0,25$; 0,$30 ; 0,35$ e 0,40 m da área de Castro podem ser visualizados na Figura 23.
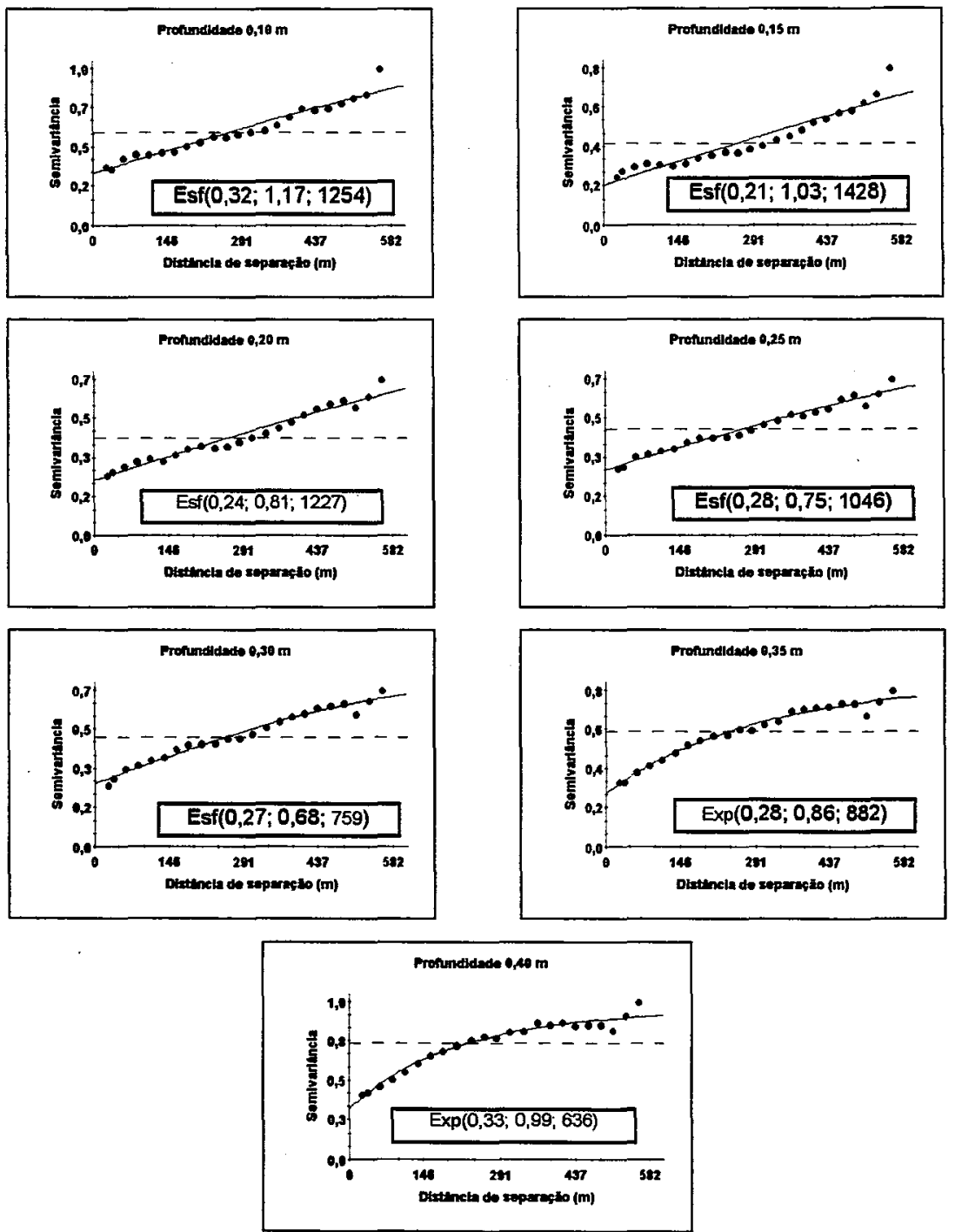

Figura 23 - Semivariogramas experimentais mostrando os modelos ajustados para os dados do índice de cone de todas as profundidades da área de Castro; as linhas pontilhadas representam a variância amostral. 
Todas as profundidades apresentaram estrutura de dependência espacial do índice de cone, conforme pode ser observado pelos modelos ajustados dos semivariogramas.

A Tabela 8 mostra os parâmetros dos modelos dos semivariogramas ajustados e o efeito pepita expresso como a porcentagem do patamar.

Tabela 8. Parâmetros e modelos dos semivariogramas ajustados e o efeito pepita expresso como a porcentagem do patamar da área de Castro.

\begin{tabular}{cccccc}
\hline Profundidade $(\mathbf{m})$ & ${ }^{1}$ Co & ${ }^{2}$ (Co $\left.+\mathbf{C}\right)$ & ${ }^{3}$ Ao $(\mathbf{m})$ & ${ }^{4}[$ Co/Co + C].100 & Modelo \\
\hline 0,10 & 0,32 & 1,17 & 1254 & 27,35 & Esf \\
0,15 & 0,21 & 1,03 & 1428 & 20,39 & Esf \\
0,20 & 0,24 & 0,81 & 1227 & 29,05 & Esf \\
0,25 & 0,28 & 0,75 & 1046 & 37,40 & Esf \\
0,30 & 0,27 & 0,68 & 759 & 39,91 & Esf \\
0,35 & 0,28 & 0,86 & 882 & 32,59 & Exp \\
0,40 & 0,33 & 0,99 & 636 & 33,50 & Exp \\
\hline efeito pepita; ${ }^{2}$ patamar; ${ }^{3}$ alcance; ${ }^{4}$ efeito pepita expresso como a porcentagem do patamar.
\end{tabular}

A profundidade de $0,15 \mathrm{~m}$ apresentou efeito pepita menor que $25 \%$ do patamar, indicando forte dependência espacial do índice de cone. As demais profundidades apresentaram efeito pepita entre 25 e $75 \%$ do patamar, indicando moderada dependência espacial do índice de cone.

O modelo que se mostrou mais adequado para explicar a estrutura da variabilidade espacial do indice do cone foi o esférico, para quase todas as profundidades, com exceção das profundidades de 0,35 e 0,40 m, para as quais, o modelo mais adequado foi o exponencial.

Os alcances da dependência espacial foram elevados em todas as profundidades analisadas e o efeito pepita permaneceu praticamente constante, indicando poucas mudanças da estrutura espacial do índice de cone ao longo do perfil do solo.

\subsection{Mapas do índice de cone da área de Pirassununga}


Os mapas do índice de cone da área total de Pirassununga, estimados pela krigagem ordinária, representados por células medindo $10 \times 10$ metros podem ser visualizados nas Figuras 24 a 30.

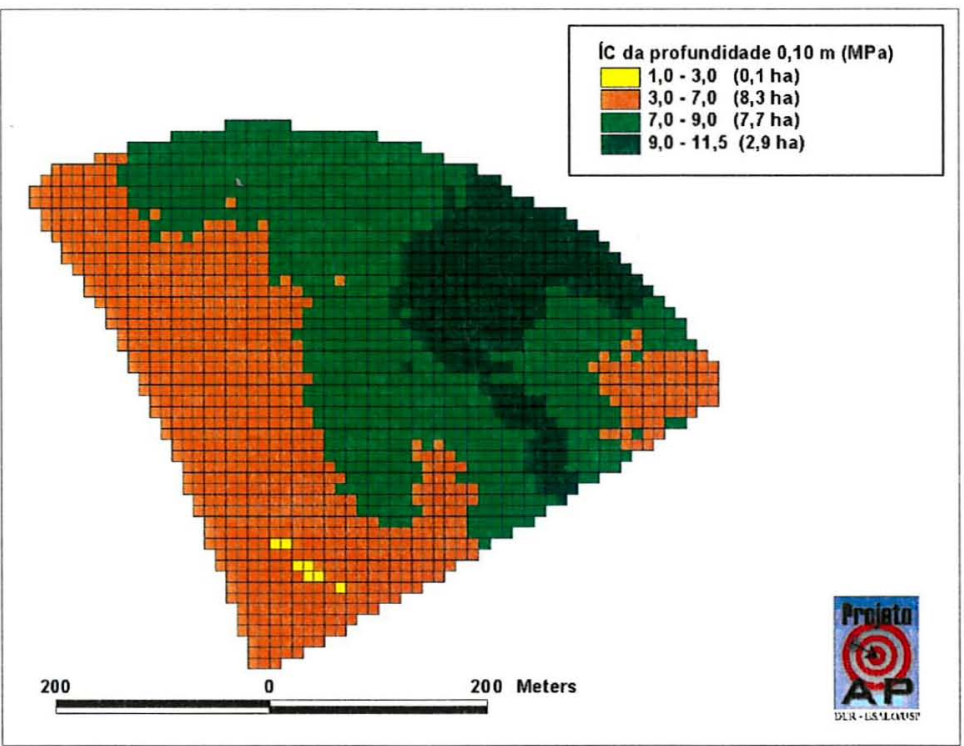

Figura 24 - Mapa do índice de cone da profundidade de 0,10 $\mathrm{m}$ da área de Pirassununga.

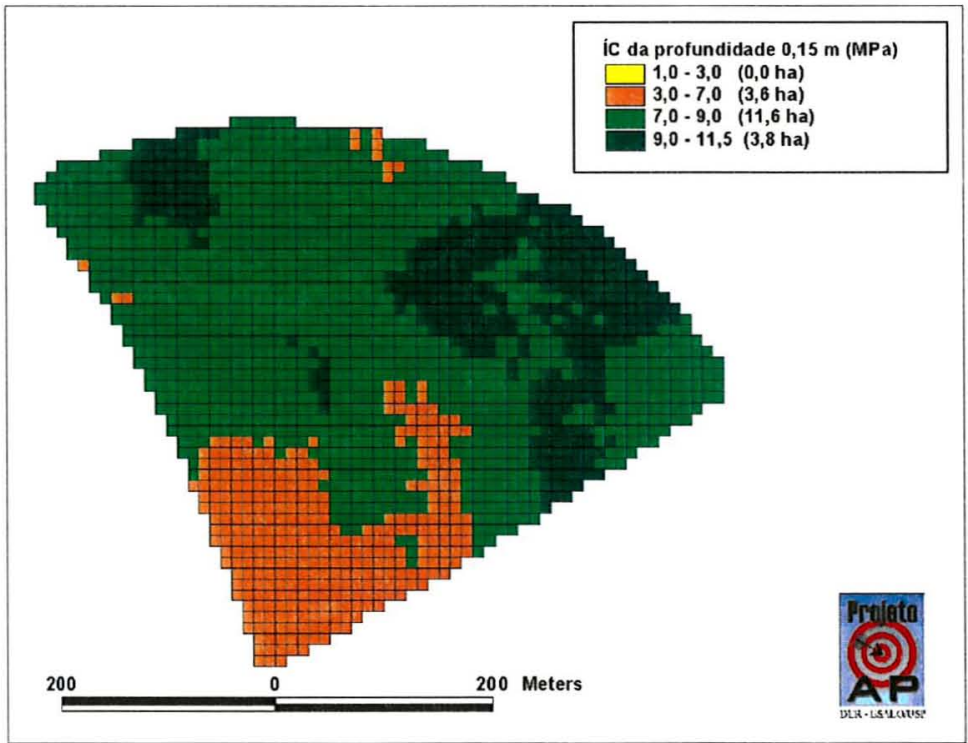

Figura 25 - Mapa do índice de cone da profundidade de 0,15 m da área de Pirassununga. 




Figura 26 - Mapa do índice de cone da profundidade de 0,20 m da área de Pirassununga.

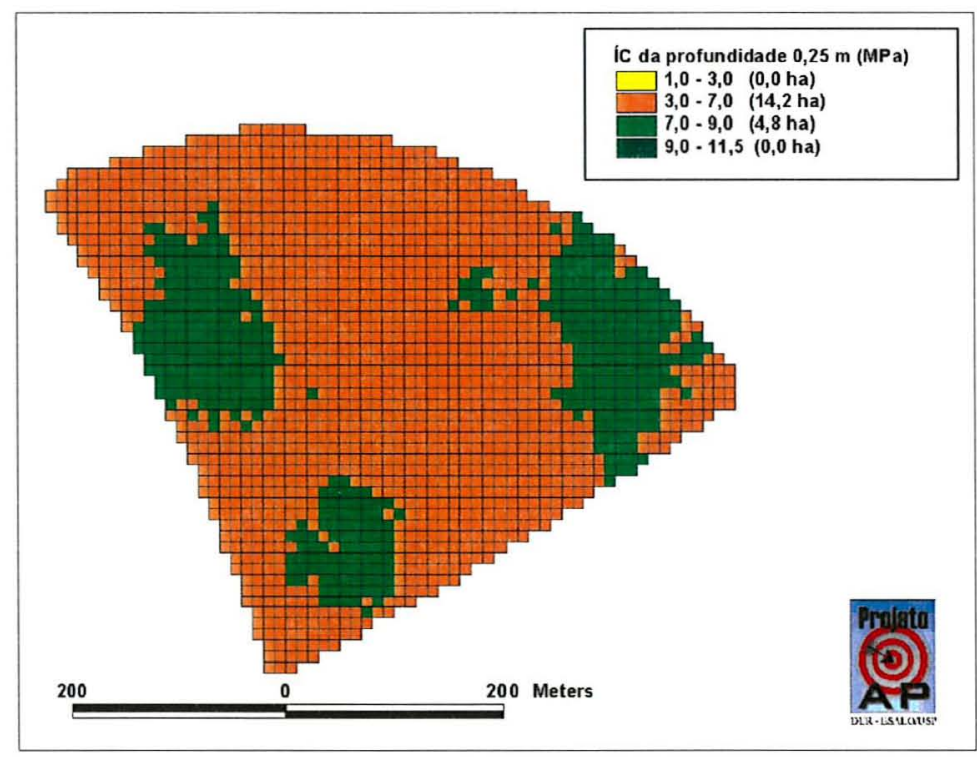

Figura 27 - Mapa do índice de cone da profundidade de 0,25 m da área de Pirassununga. 


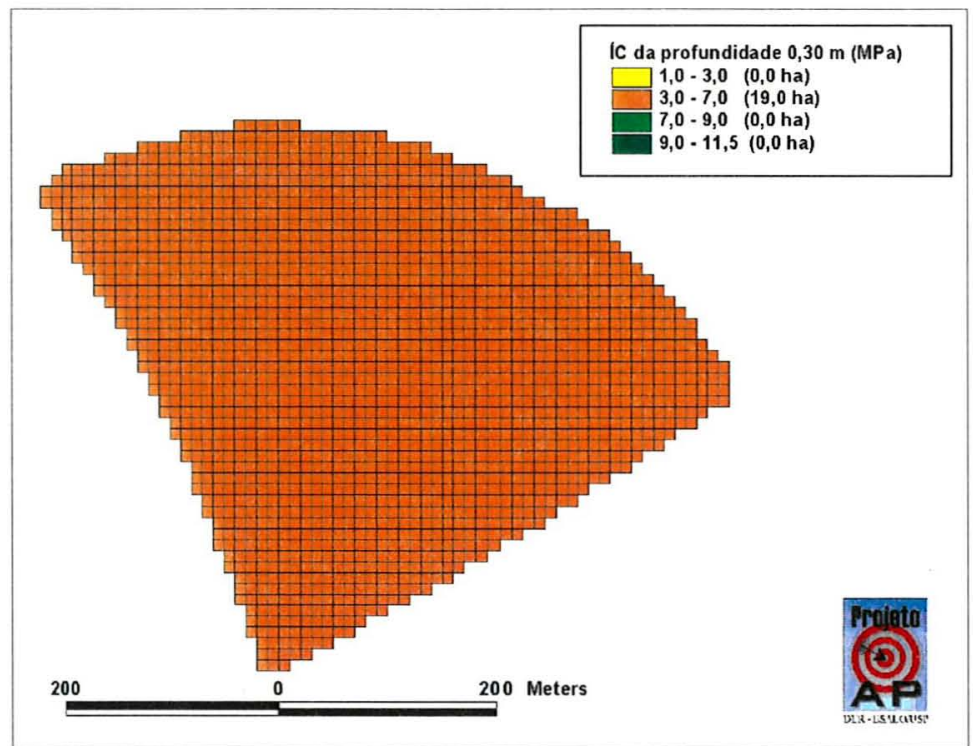

Figura 28 - Mapa do índice de cone da profundidade de 0,30 m da área de Pirassununga.



Figura 29 - Mapa do índice de cone da profundidade de 0,35 m da área de Pirassununga. 




Figura 30 - Mapa do índice de cone da profundidade de 0,40 $\mathrm{m}$ da área de Pirassununga.

Observa-se que os maiores valores do índice de cone ocorreram entre as profundidades de 0,15 e 0,30 m, com valores não-inferiores a 3,0 MPa.

Nas profundidades de 0,15 e 0,20 m, os valores do índice de cone entre 7,0 e 9,0 MPa correspondem às maiores áreas. Nas profundidades de 0,25 ; 0,30 e 0,35 m, os valores do índice de cone entre 3,0 e 7,0 MPa correspondem às maiores áreas.

As maiores áreas correspondendo aos menores valores do índice de cone ocorreram na profundidade de $0,40 \mathrm{~m}$, sendo que em metade da área os valores do índice de cone variaram de 1,0 a 3,0 MPa e na outra metade, de 3,0 a 7,0 MPa.

Em todas as profundidades analisadas, a área de Pirassununga apresentou altos valores do índice de cone, o que sugere um manejo mais adequado do solo, visando a diminuir a compactação, além de um maior controle no tráfego de máquinas.

As Figuras 31 a 37, a e b, representam os mapas do índice de cone de 150 pontos antes e após a irrigação pelo pivô central, respectivamente, da área 
de Pirassununga, estimados pela krigagem ordinária, representados por células medindo $10 \times 10$ metros.

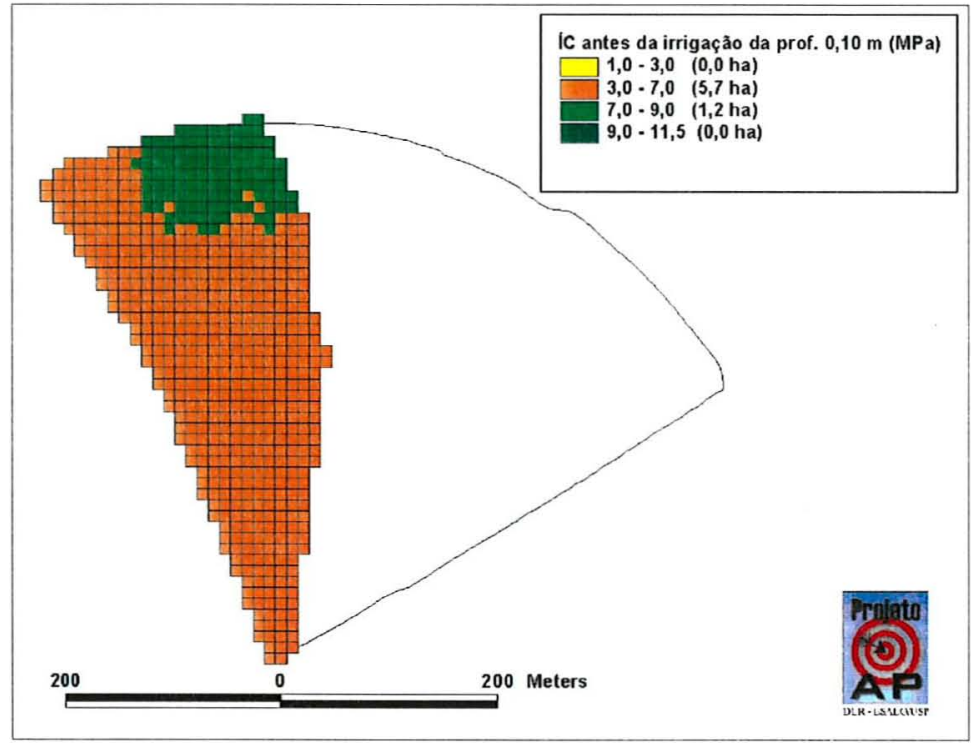

(a)

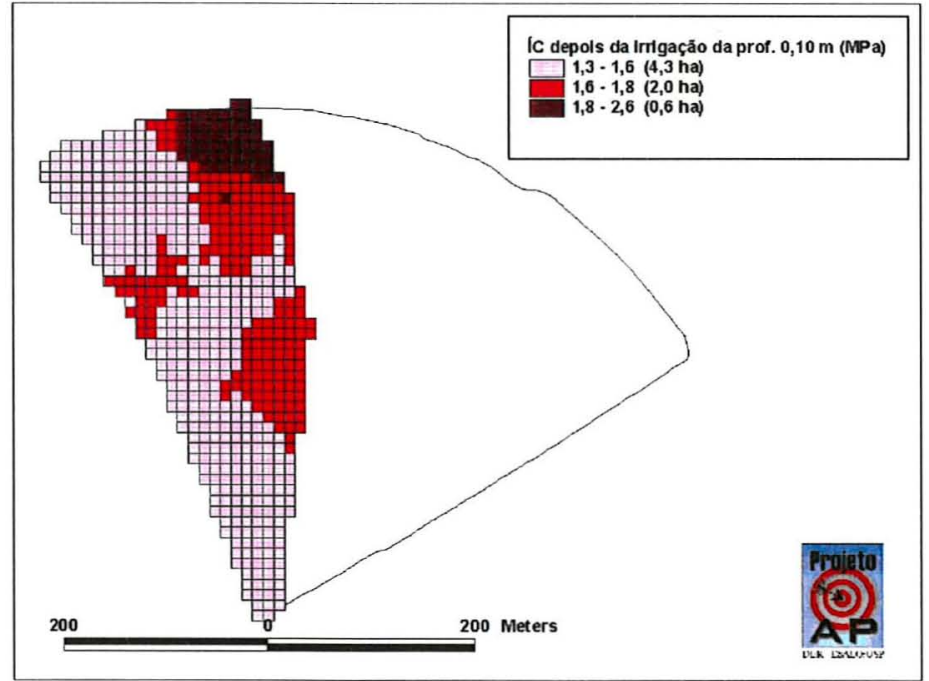

(b)

Figura 31 - Mapas do índice de cone da profundidade de $0,10 \mathrm{~m}$ de 150 pontos antes (a) e após (b) a irrigação pelo pivô central da área de Pirassununga. 


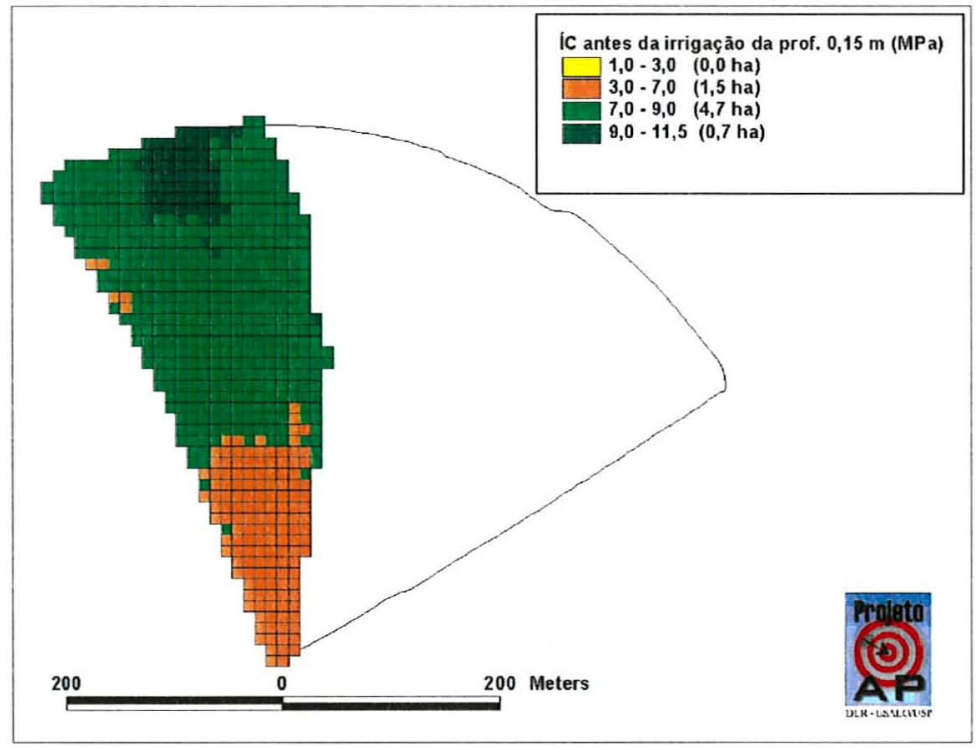

(a)

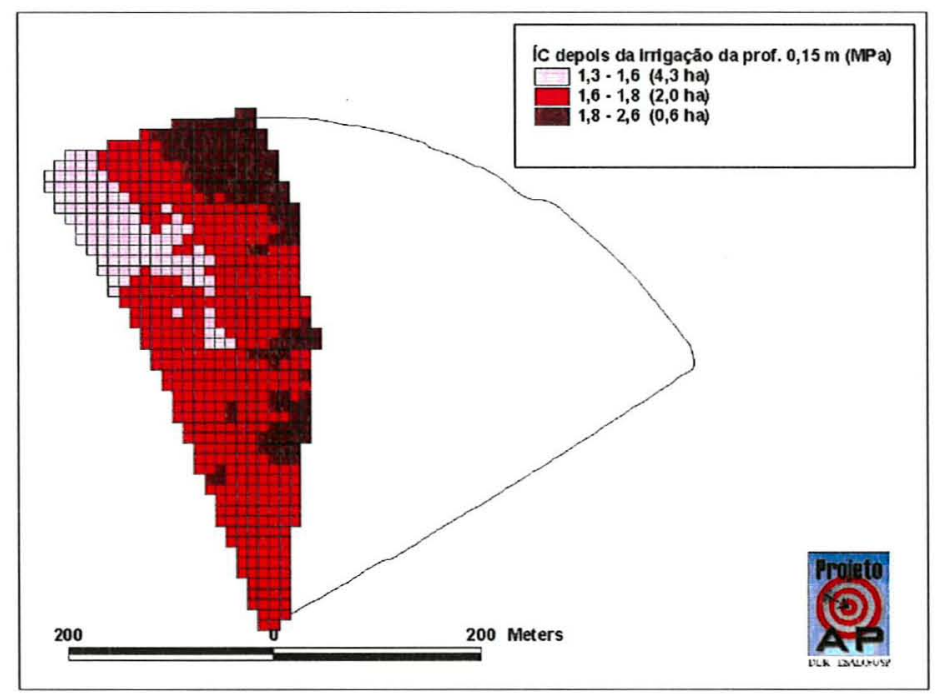

(b)

Figura 32 - Mapas do índice de cone da profundidade de $0,15 \mathrm{~m}$ de 150 pontos antes (a) e após (b) a irrigação pelo pivô central da área de Pirassununga. 


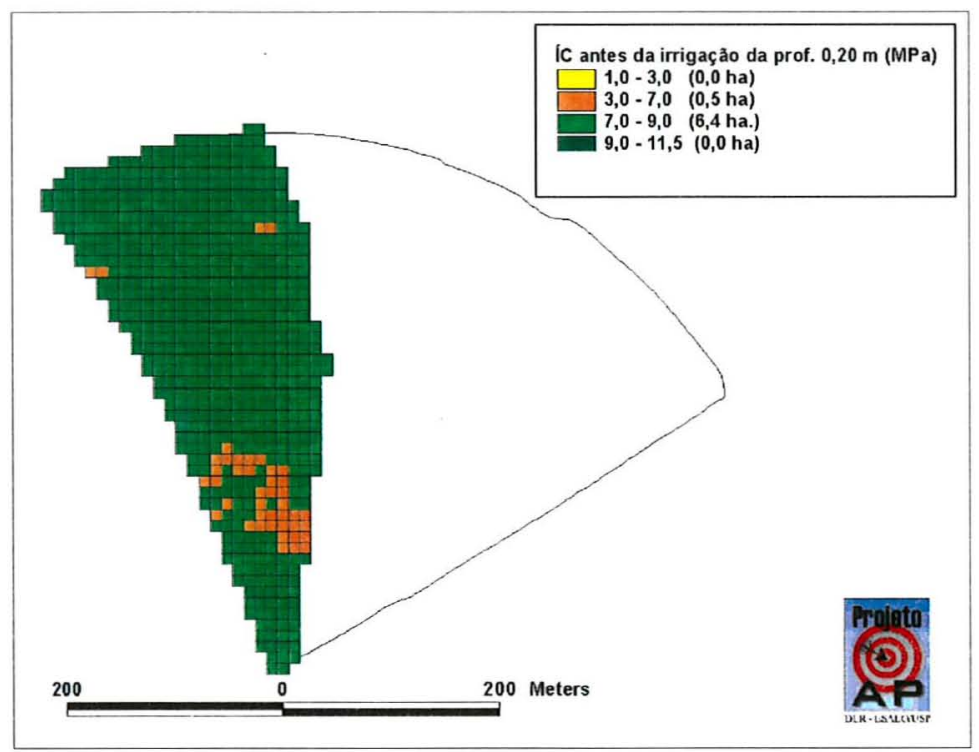

(a)

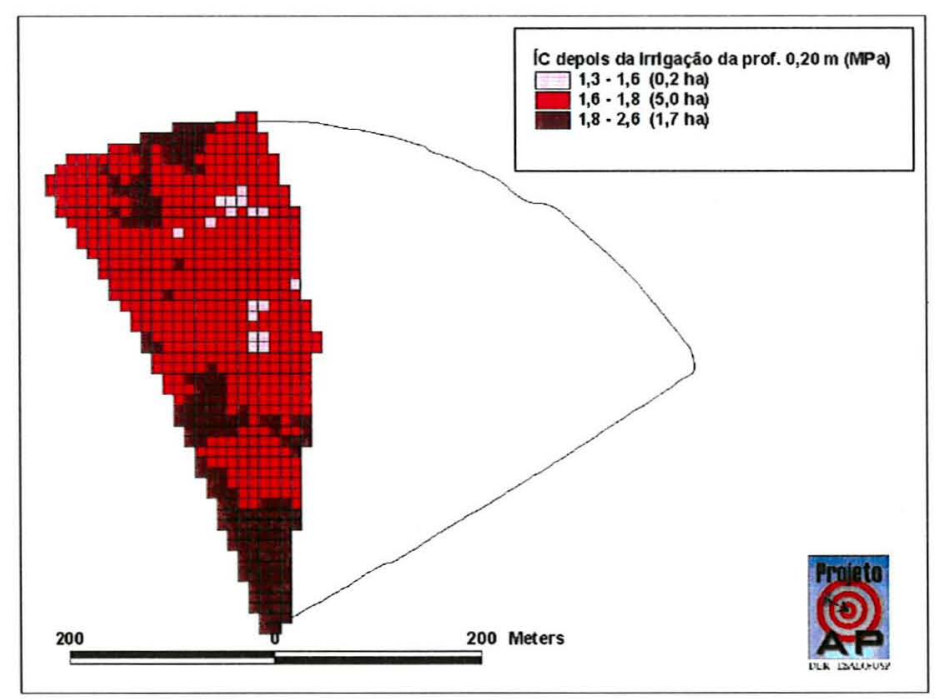

(b)

Figura 33 - Mapas do índice de cone da profundidade de 0,20 m de 150 pontos antes (a) e após (b) a irrigação pelo pivô central da área de Pirassununga. 


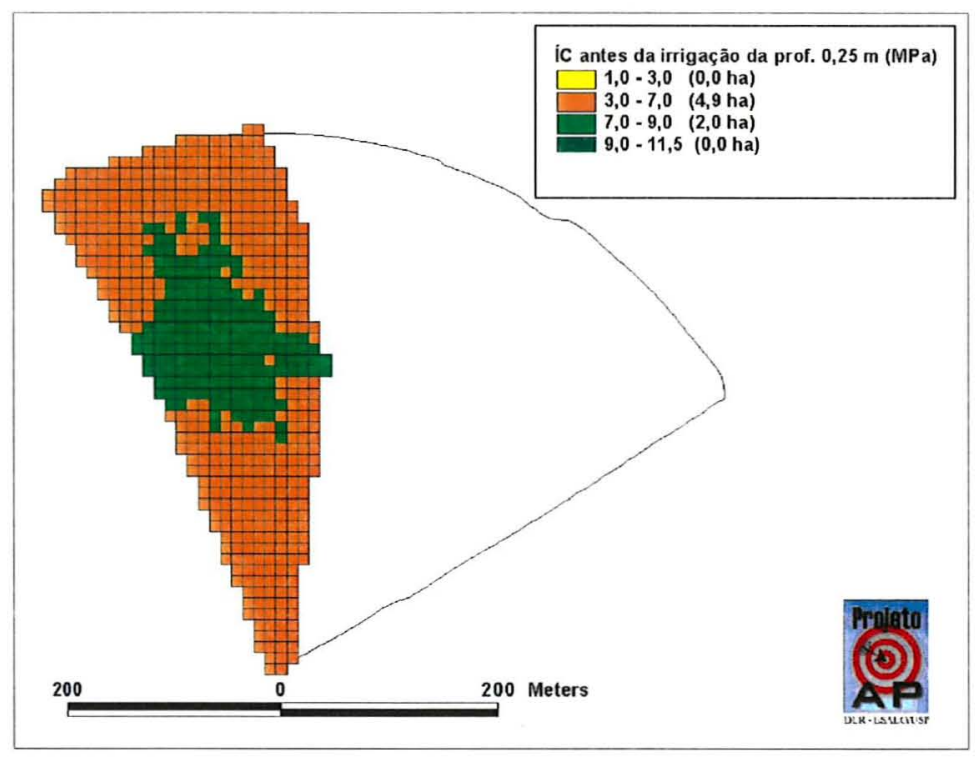

(a)

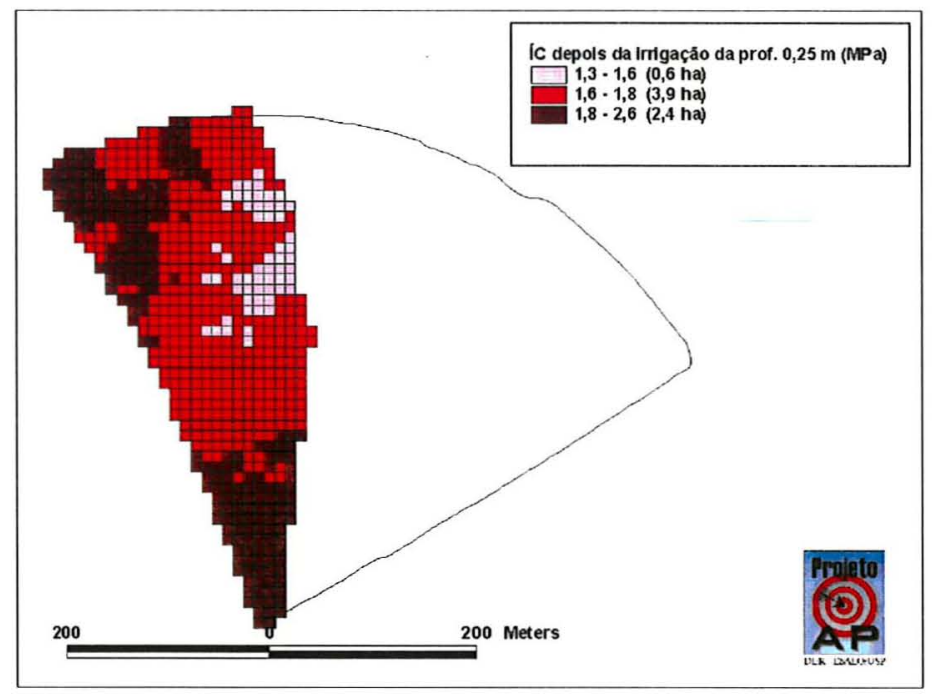

(b)

Figura 34 - Mapas do índice de cone da profundidade de 0,25 m de 150 pontos antes (a) e após (b) a irrigação pelo pivô central da área de Pirassununga. 


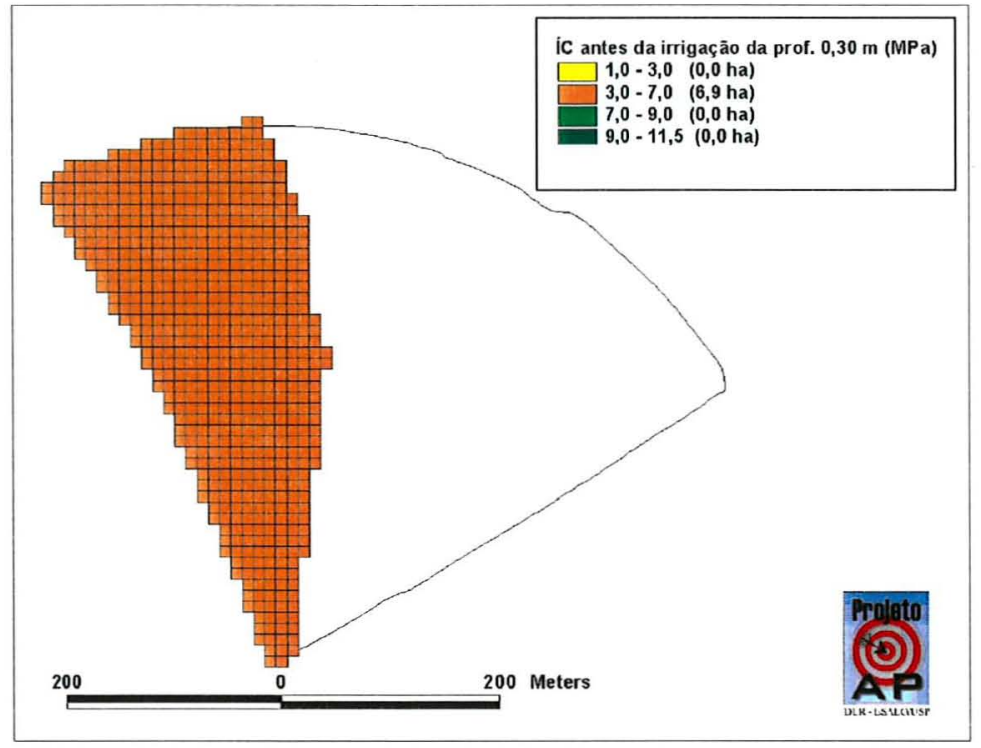

(a)

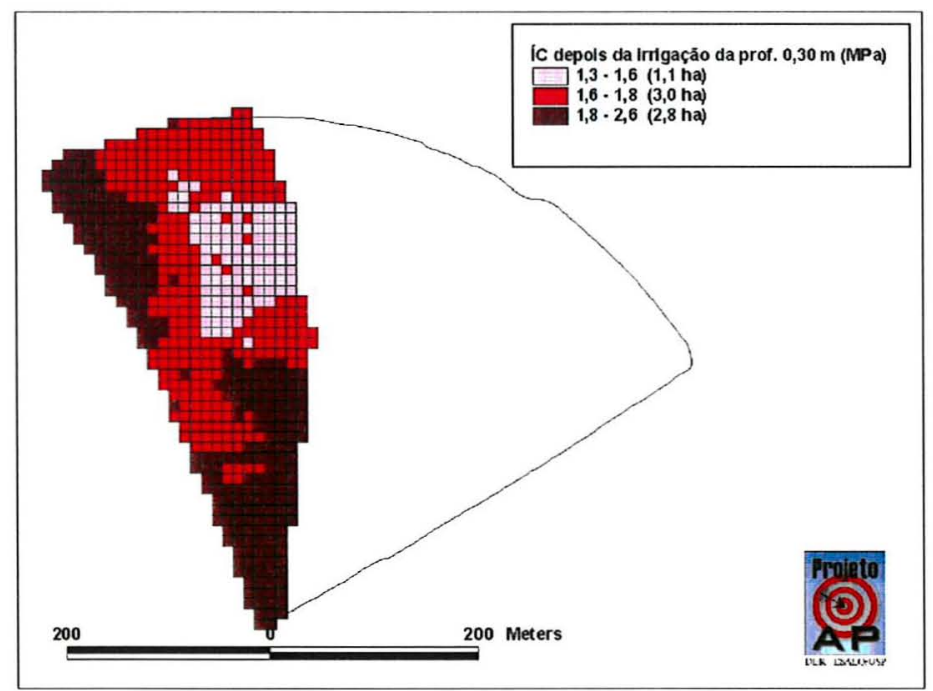

(b)

Figura 35 - Mapas do índice de cone da profundidade de $0,30 \mathrm{~m}$ de 150 pontos antes (a) e após (b) a irrigação pelo pivô central da área de Pirassununga. 


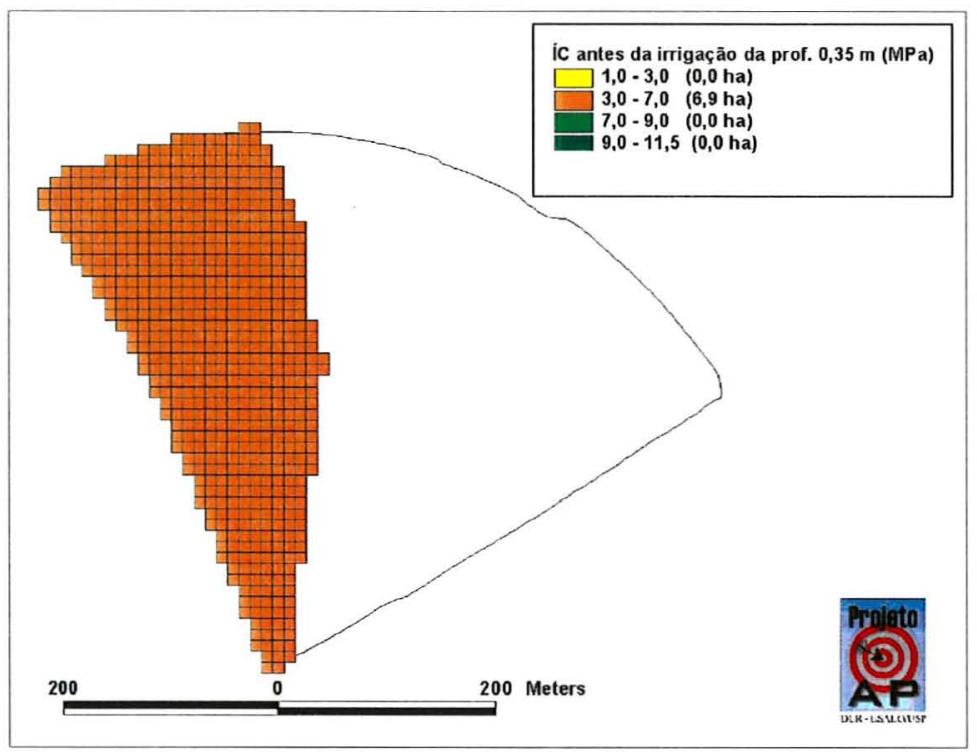

(a)

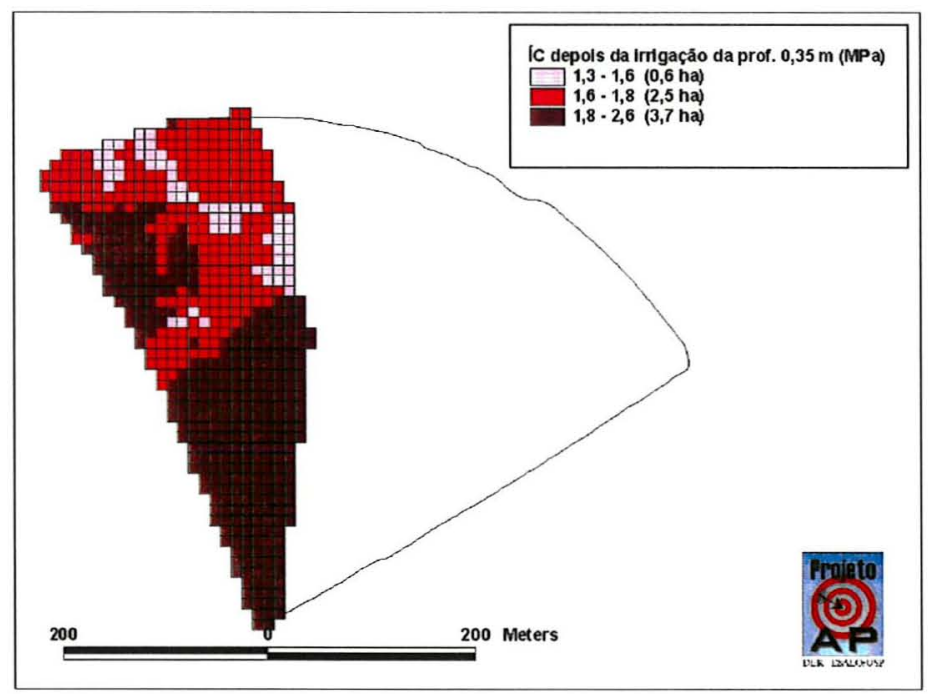

(b)

Figura 36 - Mapas do índice de cone da profundidade de 0,35 m de 150 pontos antes (a) e após (b) a irrigação pelo pivô central da área de Pirassununga. 


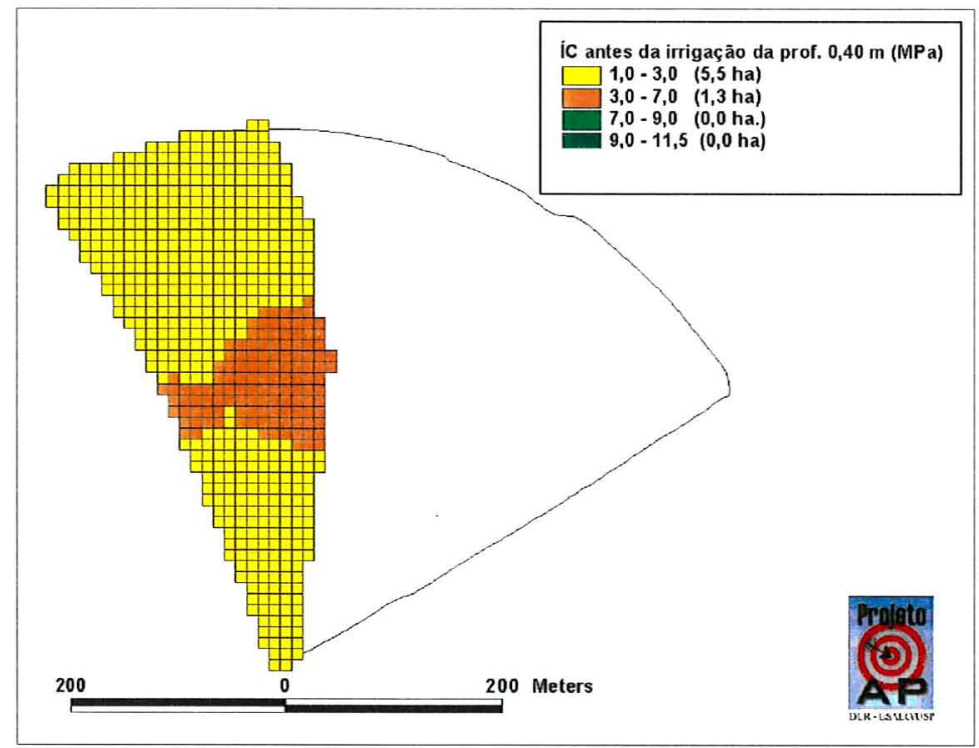

(a)

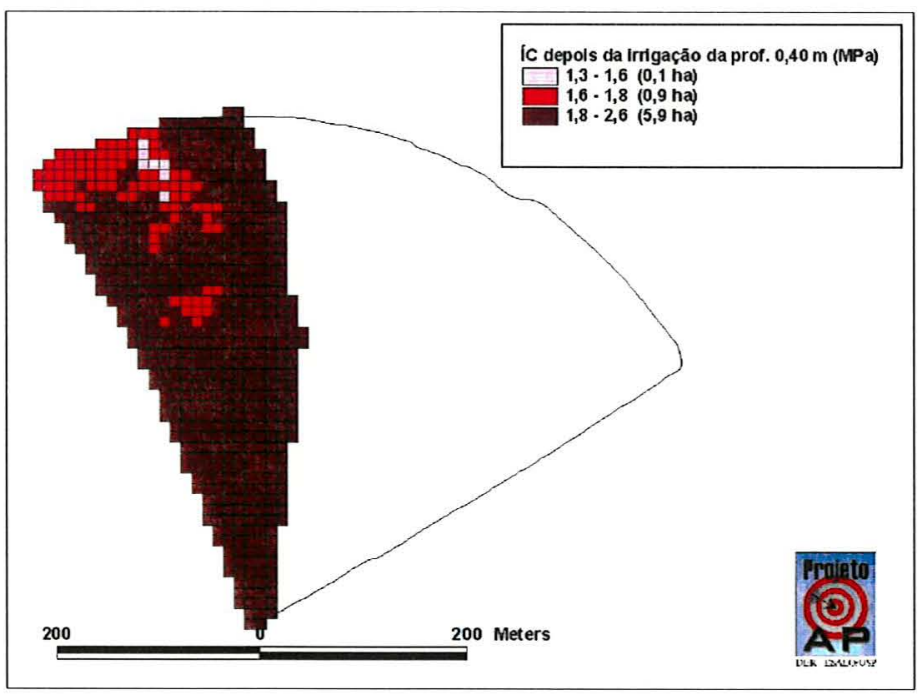

(b)

Figura 37 - Mapas do índice de cone da profundidade de 0,40 m de 150 pontos antes (a) e após (b) a irrigação pelo pivô central da área de Pirassununga.

Observa-se o efeito da irrigação sobre o índice de cone em todas a profundidades analisadas. Enquanto na área antes de ser irrigada pelo pivô central, os valores do índice de cone entre as profundidades de 0,10 e 0,35 m 
variaram de 3,0 a 11,5 MPa, após a irrigação, estes valores não ultrapassaram 2,6 $\mathrm{MPa}$, ou seja, o menor valor do índice de cone antes da irrigação corresponde praticamente ao maior valor do índice de cone após a irrigação.

$\mathrm{Na}$ condição anterior à irrigação, os valores do índice de cone entre 3,0 e 7,0 MPa correspondem às maiores áreas nas profundidades de 0,$10 ; 0,25 ; 0,30$ e 0,35 m. Após a irrigação, os valores do índice de cone entre 1,6 e 1,8 MPa correspondem às maiores áreas nas profundidades entre 0,15 e 0,30 m.

$\mathrm{Na}$ profundidade de $0,40 \mathrm{~m}$, nota-se que houve pouca alteração nos valores do índice de cone após a irrigação.

\subsection{Análises de correlação entre produtividade e índice de cone da área de Pirassununga}

O mapa de produtividade da cultura do milho, safra 1999, da área de Pirassununga, está representado na Figura 38.

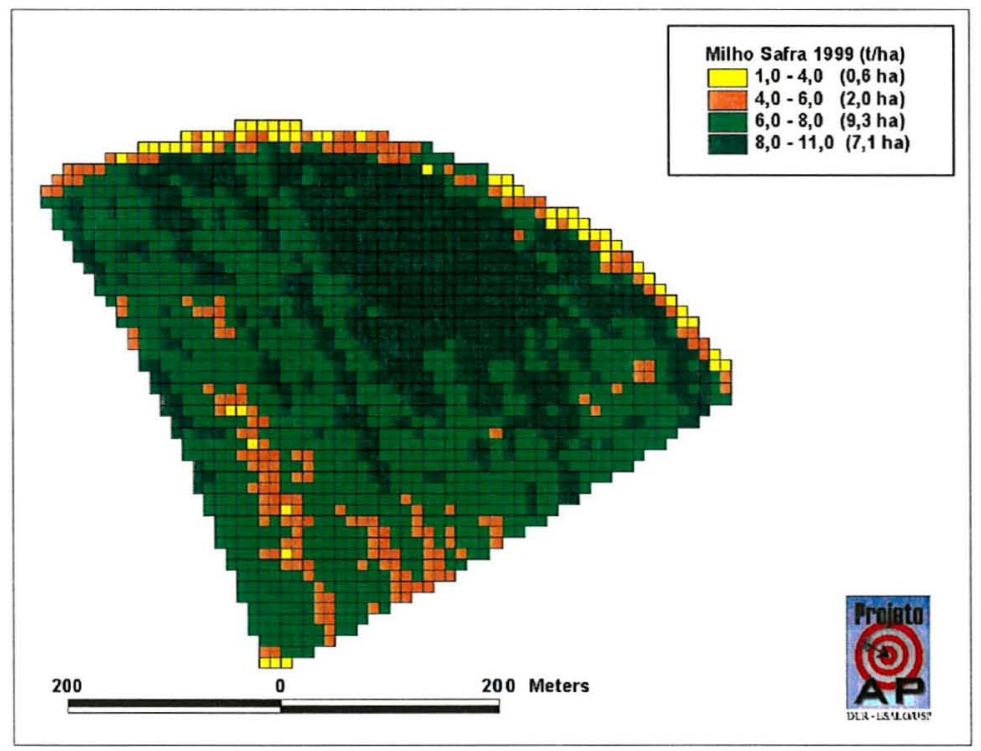

Figura 38 - Mapa de produtividade do milho, safra 1999, da área de Pirassununga. 
A análise de regressão entre o índice de cone e a produtividade do milho da área total de Pirassununga permitiu o ajuste de um modelo linear entre estas variáveis para cada profundidade analisada. Foram utilizados os valores correspondentes ao índice de cone e à produtividade de cada uma das 1827 células geradas pelo programa de SIG SStoolbox. Os resultados das análises de regressão estão representados nas Figuras 39 a 45.

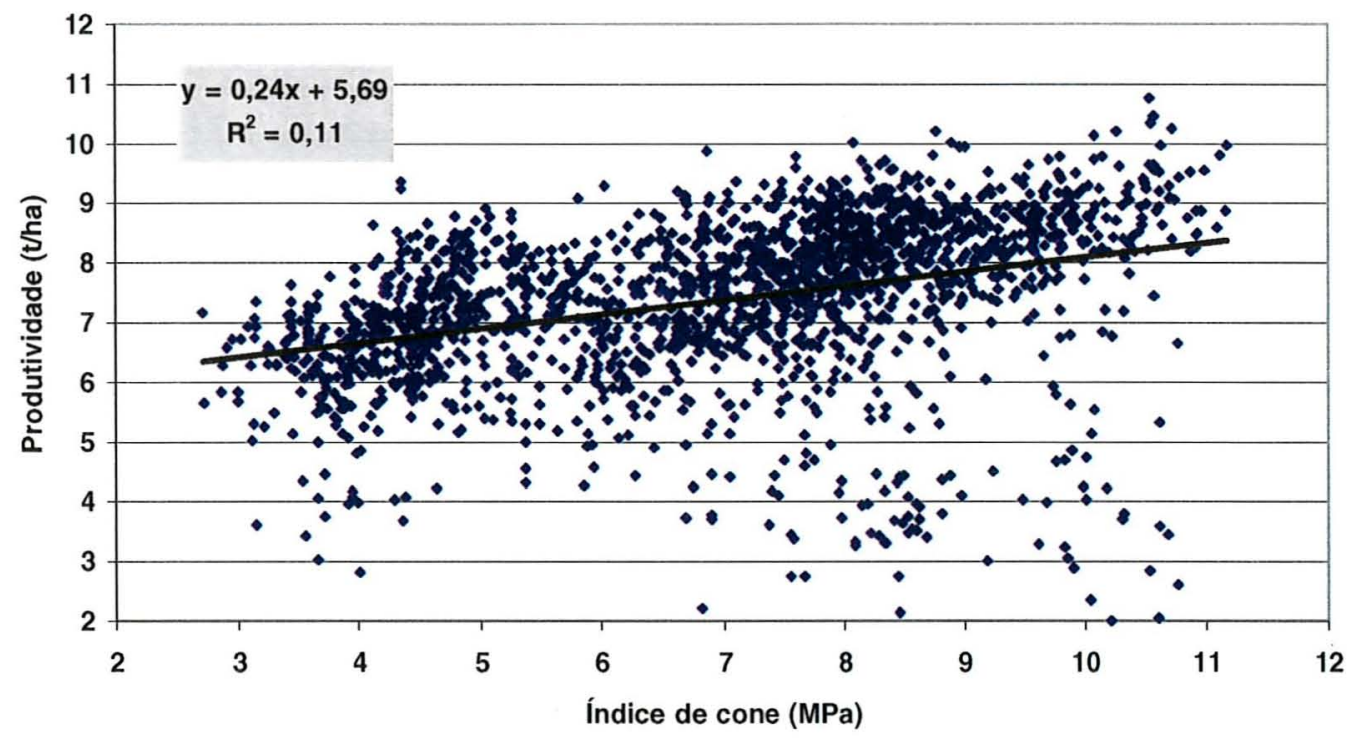

Figura 39 -Relação entre produtividade do milho e índice de cone da profundidade de 0,10 $\mathrm{m}$ da área de Pirassununga. 




Figura 40 - Relação entre produtividade do milho e índice de cone da profundidade de $0,15 \mathrm{~m}$ da área de Pirassununga.



Figura 41 - Relação entre produtividade do milho e índice de cone da profundidade de 0,20 $\mathrm{m}$ da área de Pirassununga. 


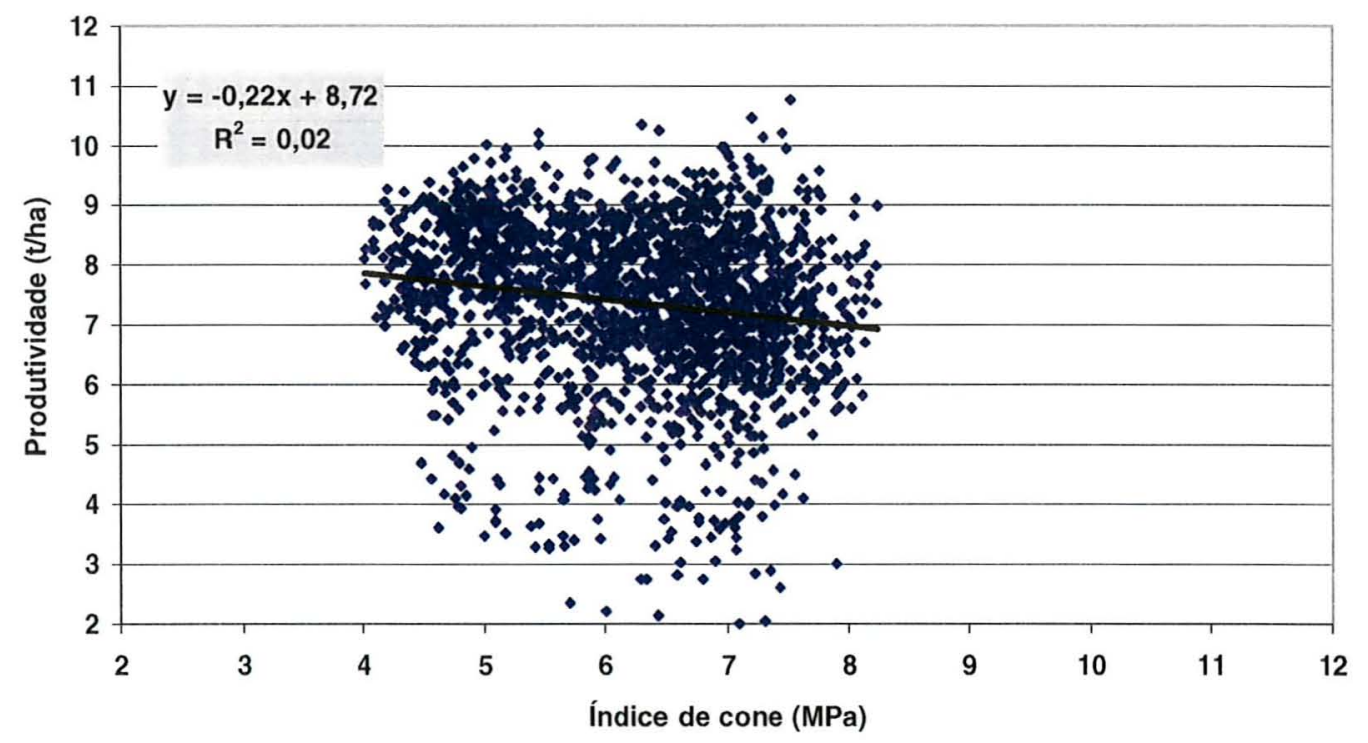

Figura 42 - Relação entre produtividade do milho e índice de cone da profundidade de 0,25 $\mathrm{m}$ da área de Pirassununga.

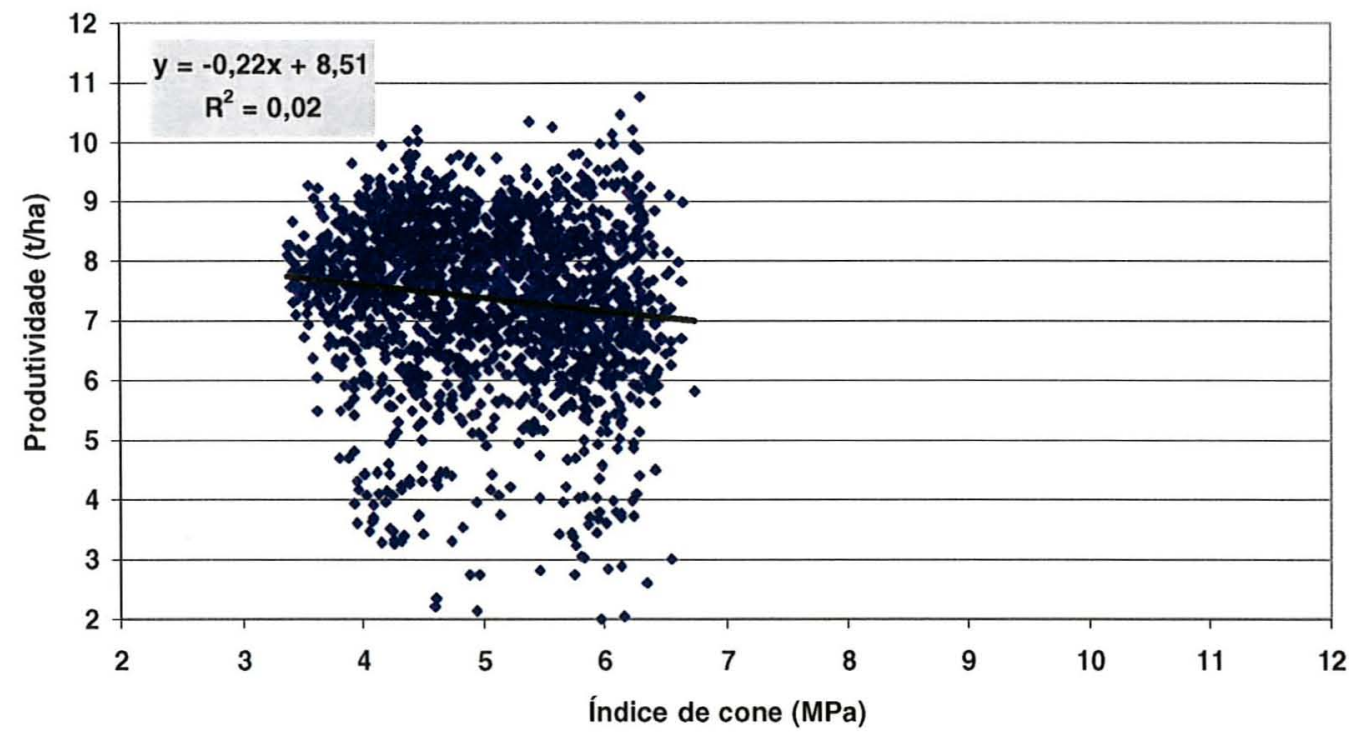

Figura 43 - Relação entre produtividade do milho e índice de cone da profundidade de 0,30 $\mathrm{m}$ da área de Pirassununga. 


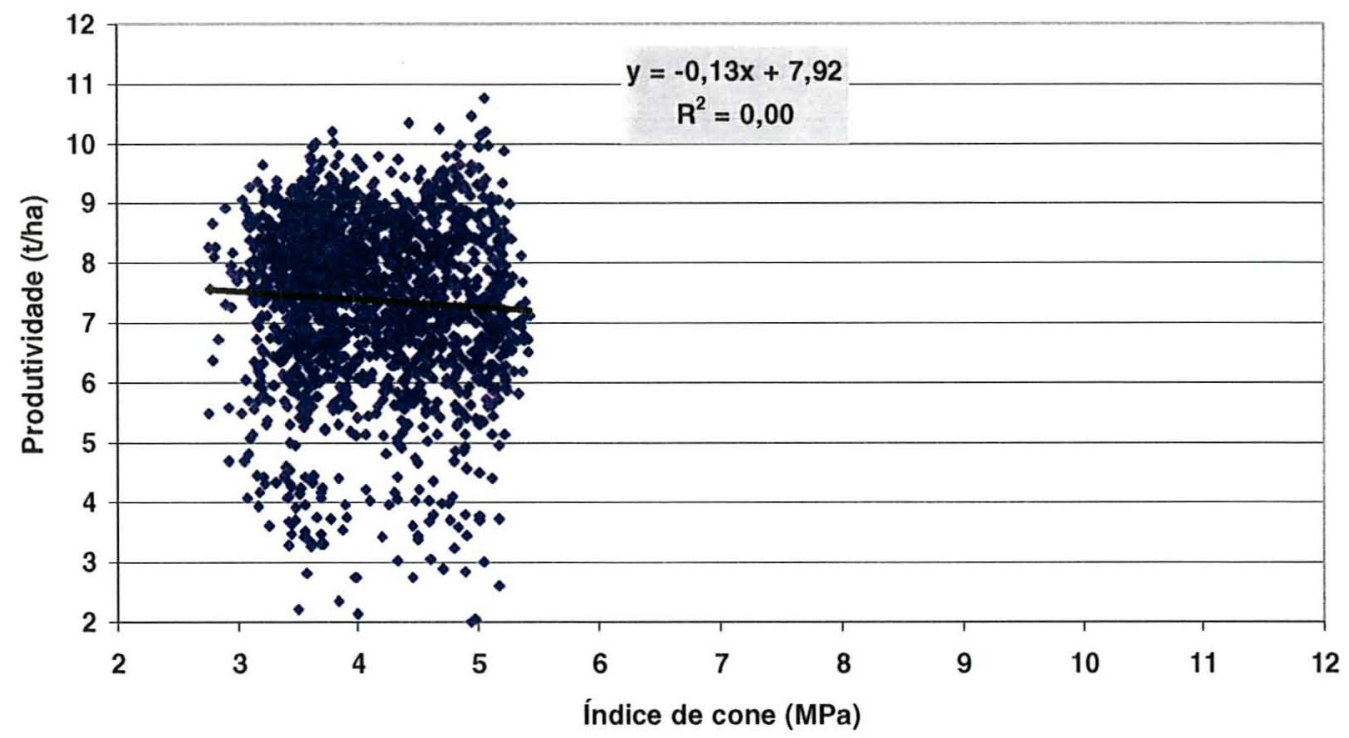

Figura 44 - Relação entre produtividade do milho e índice de cone da profundidade de 0,35 $\mathrm{m}$ da área de Pirassununga.

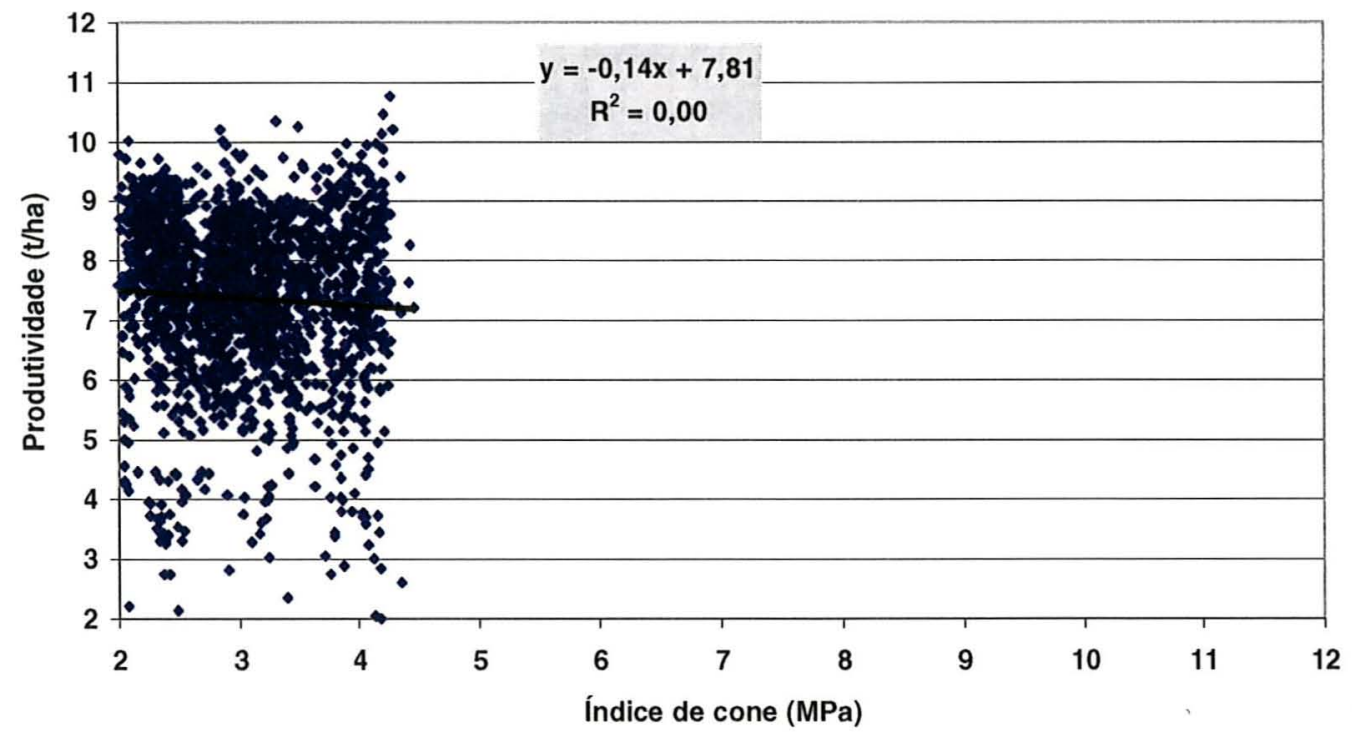

Figura 45 - Relação entre produtividade do milho e índice de cone da profundidade de 0,40 $\mathrm{m}$ da área de Pirassununga. 
Nas profundidades de 0,10 e $0,15 \mathrm{~m}$, os modelos lineares ajustados expressam uma proporcionalidade direta entre a produtividade e o índice de cone, ou seja, ocorre um aumento da produtividade com o aumento do índice de cone. Os altos valores do indice de cone nestas profundidades são atribuídos ao efeito do tráfego de máquinas. A implantação do sistema de semeadura direta na área não foi precedida por correção física do perfil do solo. Estes resultados demonstram o efeito acumulado da compactação e a formação do fenômeno conhecido como "pé-de-grade" ou "pé-de-arado". Gonçalves et al. (1998), estudando a variabilidade espacial da produtividade e da resistência à penetração em área irrigada, sob dois sistemas de preparo, identificaram comportamento semelhante.

Nas demais profundidades, verifica-se uma tendência de decréscimo da produtividade com o aumento do índice de cone, apesar dos baixos coeficientes de determinação encontrados. As maiores tendências ocorreram nas profundidades de 0,25 e 0,30 m, informando que em cada uma dessas profundidades apenas $2 \%$ da variação da produtividade é explicada pela variação do índice de cone.

\subsection{Mapas do índice de cone da área de Castro}

Os mapas do índice de cone da área de Castro, estimados pela krigagem ordinária, representados por células medindo $10 \times 10$ metros estão representados nas Figuras 46 a 52. 


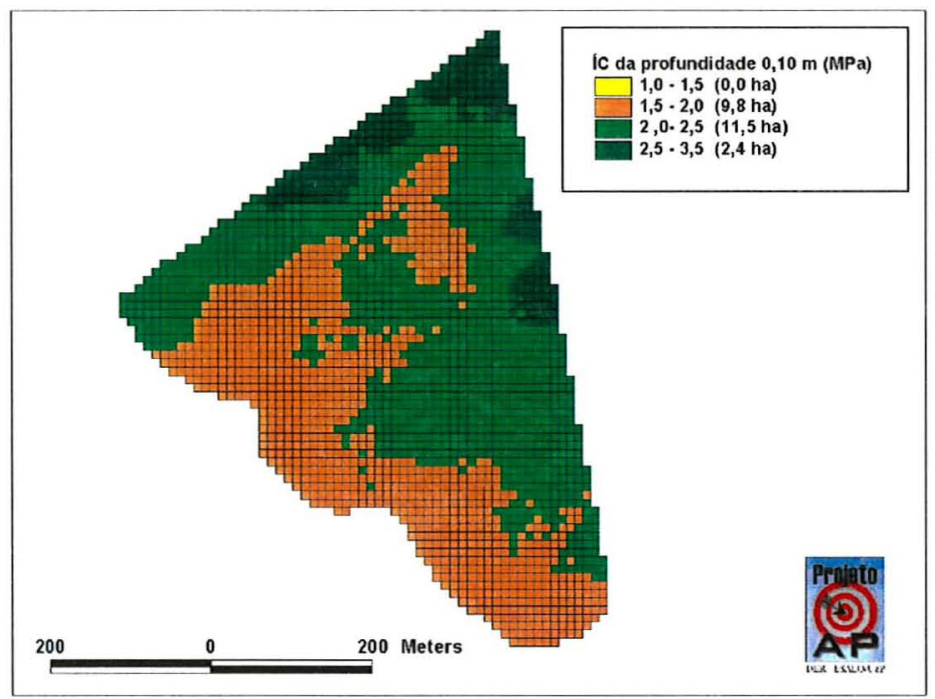

Figura 46 - Mapa do índice de cone da profundidade de 0,10 $\mathrm{m}$ da área de Castro.

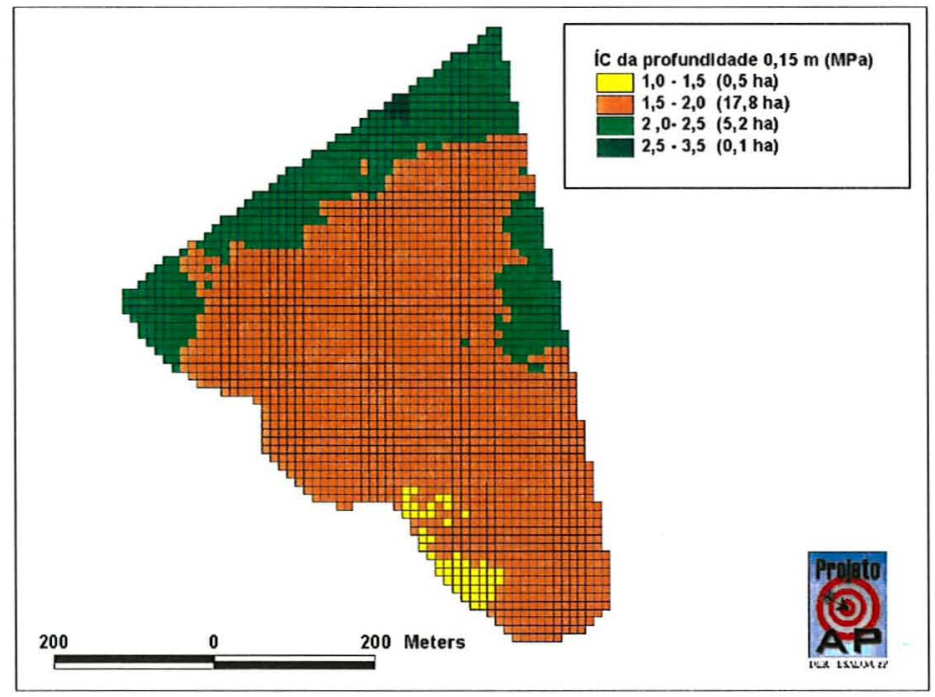

Figura 47 - Mapa do índice de cone da profundidade de 0,15 m da área de Castro. 


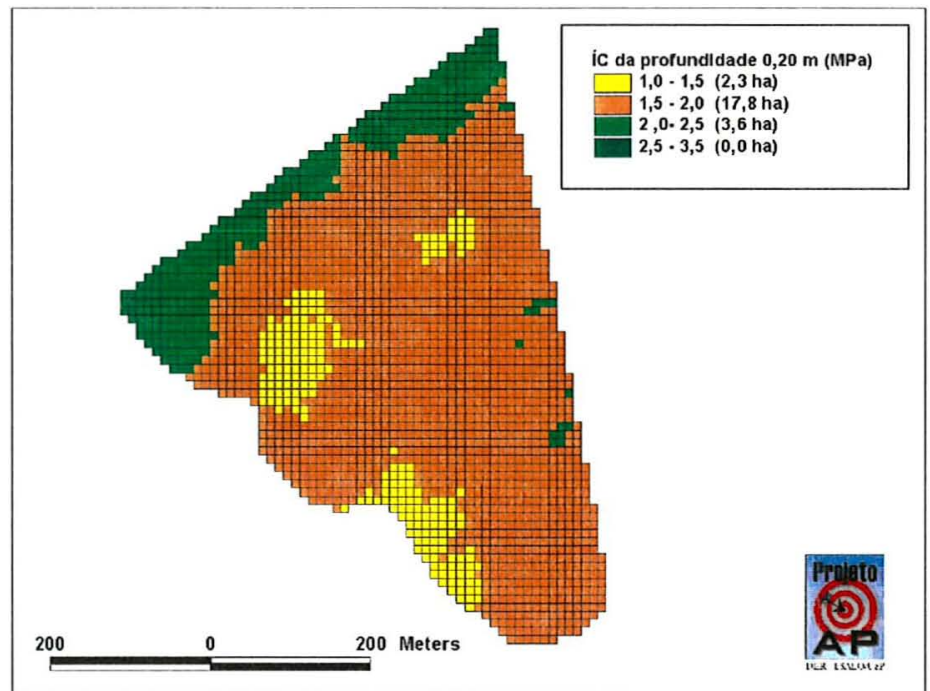

Figura 48 - Mapa do índice de cone da profundidade de 0,20 m da área de Castro.

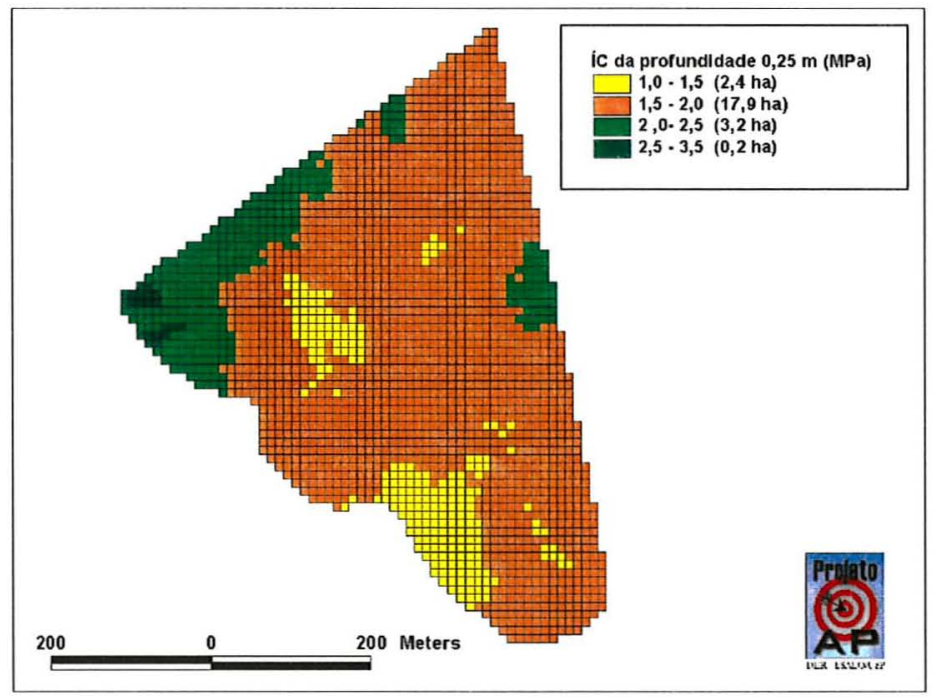

Figura 49 - Mapa do índice de cone da profundidade de 0,25 $\mathrm{m}$ da área de Castro. 


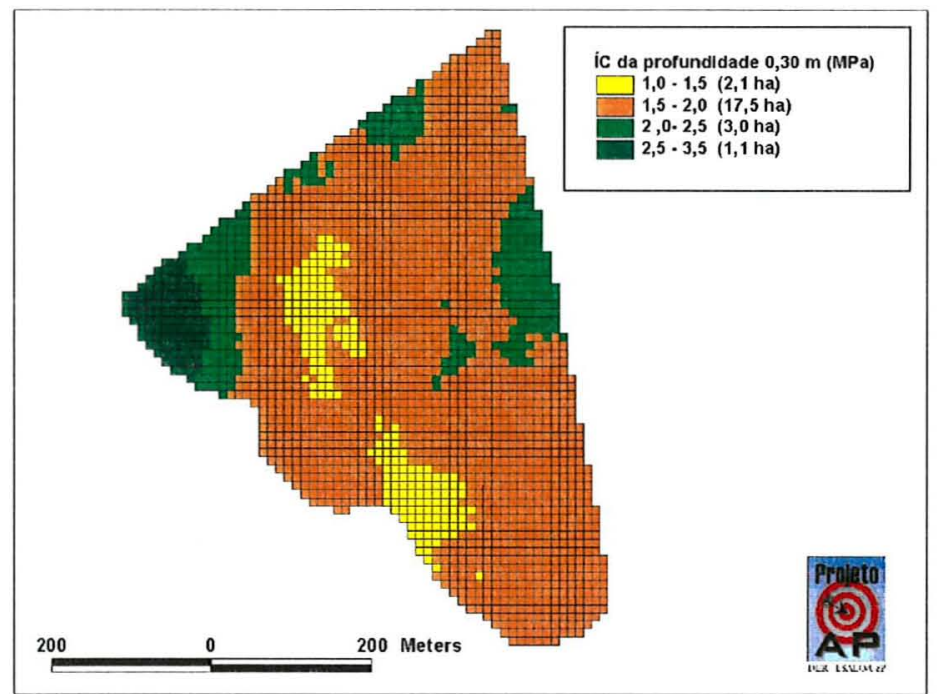

Figura 50 - Mapa do índice de cone da profundidade de 0,30 m da área de Castro.

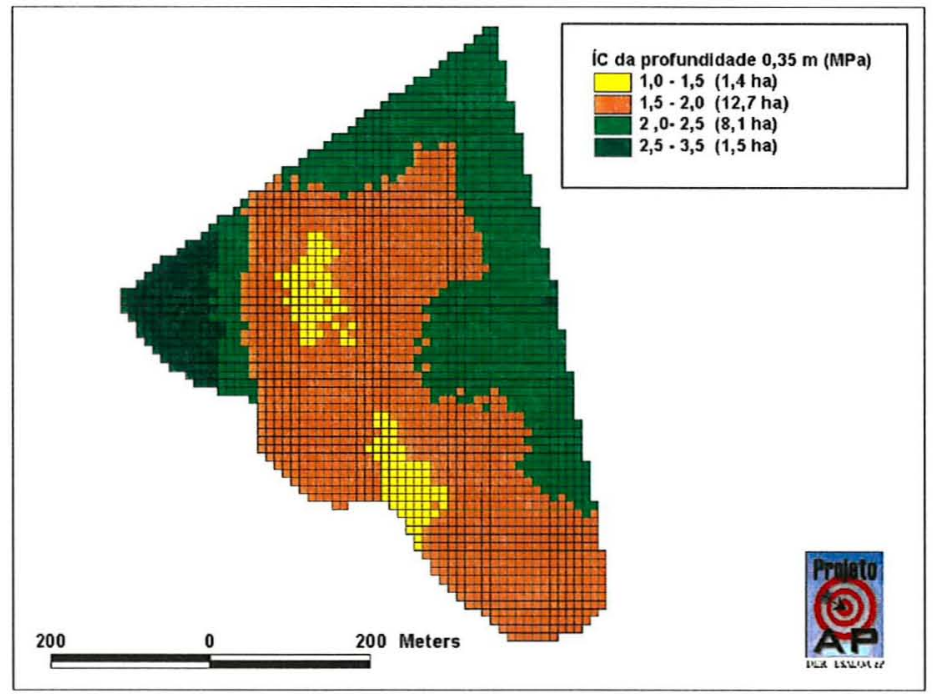

Figura 51 - Mapa do índice de cone da profundidade de 0,35 m da área de Castro. 


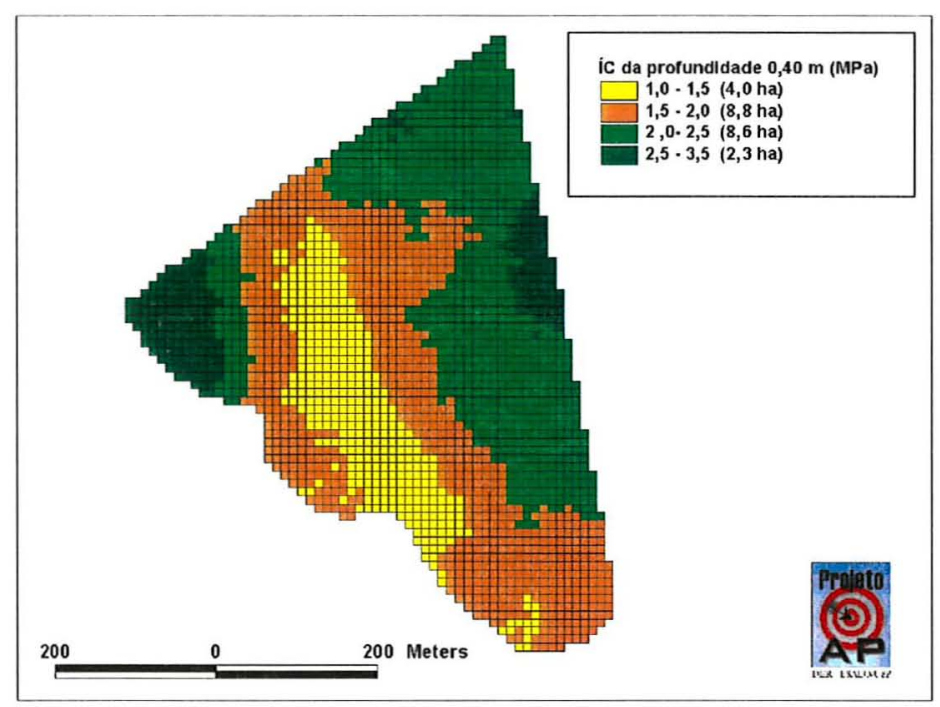

Figura 52 - Mapa do índice de cone da profundidade de 0,40 m da área de Castro.

Em todas as profundidades, os valores do índice de cone entre 1,5 e 2,5 $\mathrm{MPa}$ constituíram as maiores áreas.

Os menores valores do índice de cone ocorreram na região central da área e os maiores nas regiões de cabeceiras localizadas ao norte (parte superior do mapa), nordeste (parte direita, abaixo do mapa) e noroeste (parte esquerda, abaixo do mapa).

A região que se estende do sul (parte inferior do mapa) ao oeste (parte direita do mapa), apresentou os menores valores do índice de cone, em todas as profundidades. Os altos teores de água contribuem para os baixos valores do índice de cone observados.

Em todas as profundidades analisadas, a área de Castro apresentou baixos valores do índice de cone, necessitando de cuidados apenas nas profundidades de 0,10 a $0,15 \mathrm{~m}$. Nestes casos, uma escarificação pode melhorar as condições de compactação observadas. 
4.7 Análises de correlação entre produtividade e índice de cone da área de Castro

Os mapas de produtividade da cultura da soja, safra 1999, e da cultura do milho, safra 2000, da área de Castro, estão representados nas Figuras 53 a e b, respectivamente.

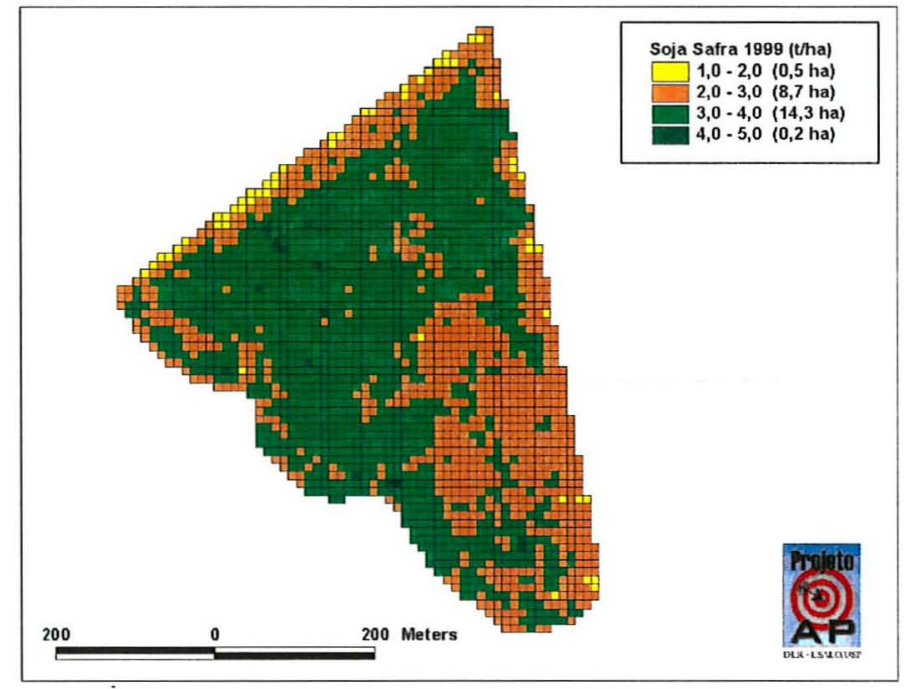

(a)

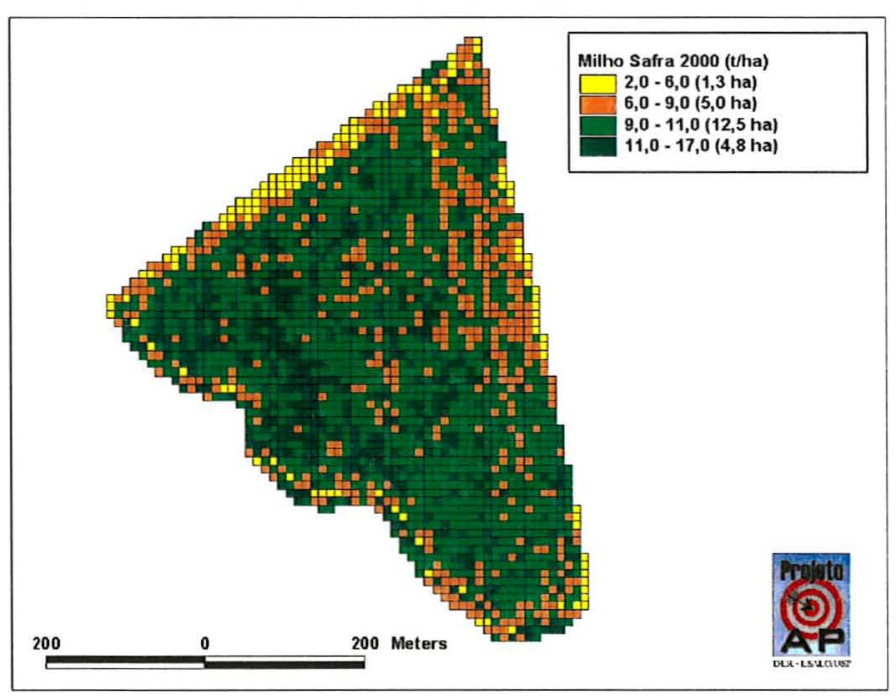

(b)

Figura 53 - Mapas de produtividade da soja, safra 1999 (a), e do milho, safra 2000 (b), da área de Castro. 
As análises de regressão entre o índice de cone e a produtividade da soja e do milho permitiram ajustes de modelos lineares entre estas variáveis, para cada profundidade analisada. Foram utilizados os valores correspondentes ao índice de cone e à produtividade de cada uma das 2301 células geradas pelo programa de SIG SStoolbox. Os resultados das análises de regressão estão representados nas Figuras 54 a 60.

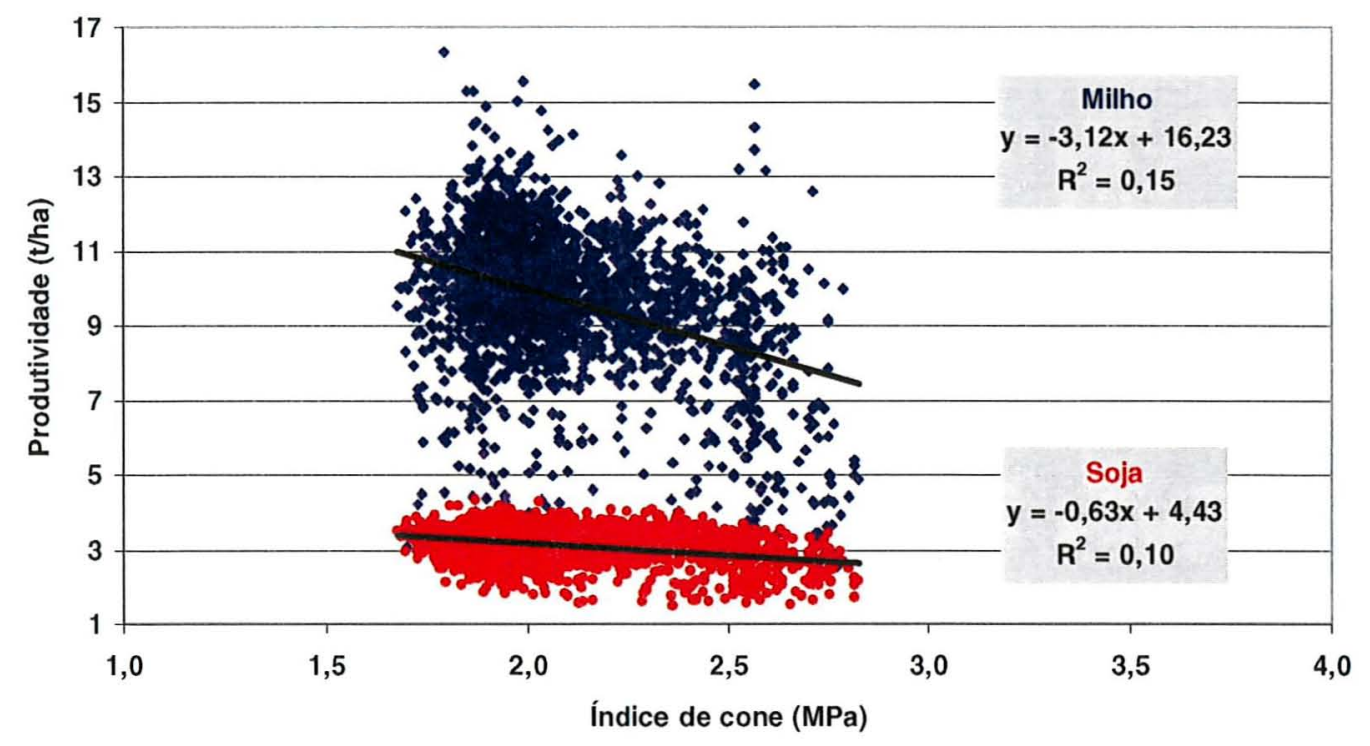

Figura 54 - Relação entre produtividade da soja e do milho e índice de cone da profundidade de $0,10 \mathrm{~m}$ da área de Castro. 


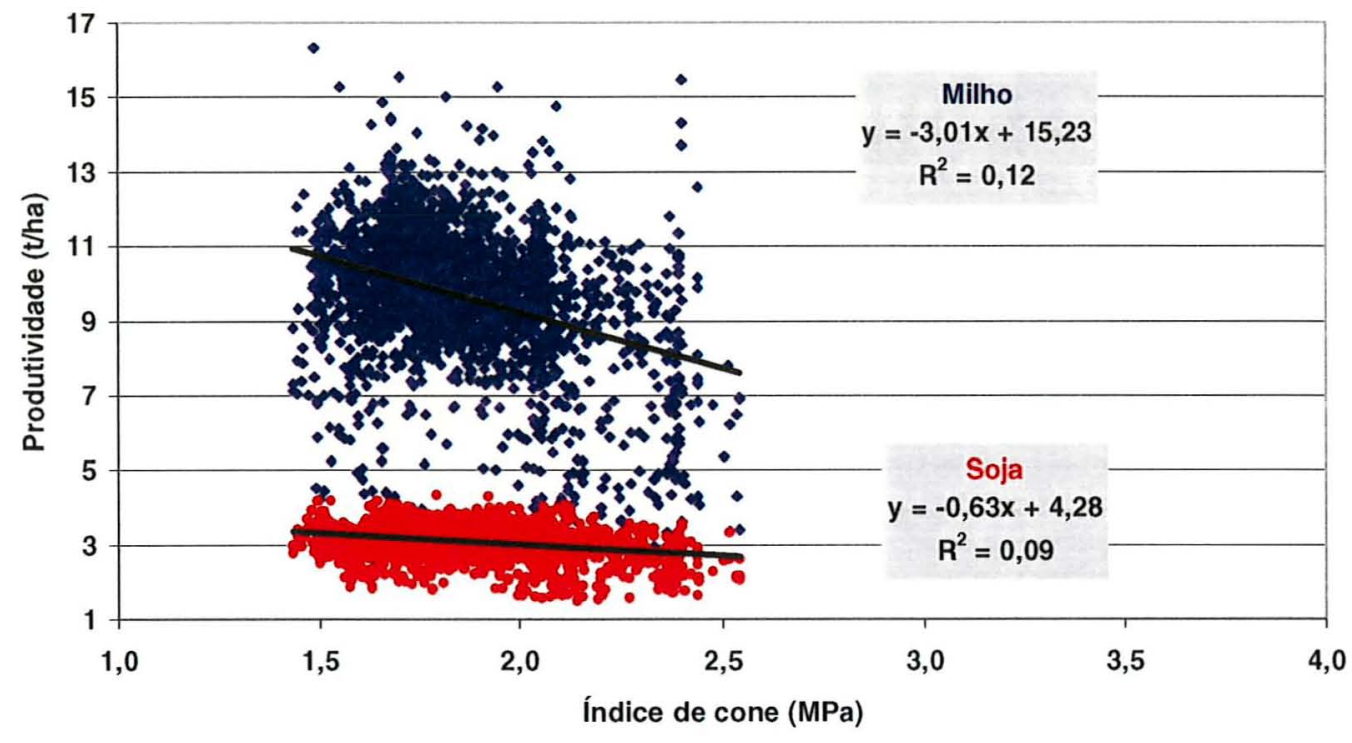

Figura 55 - Relação entre produtividade da soja e do milho e índice de cone da profundidade de 0,15 $\mathrm{m}$ da área de Castro.

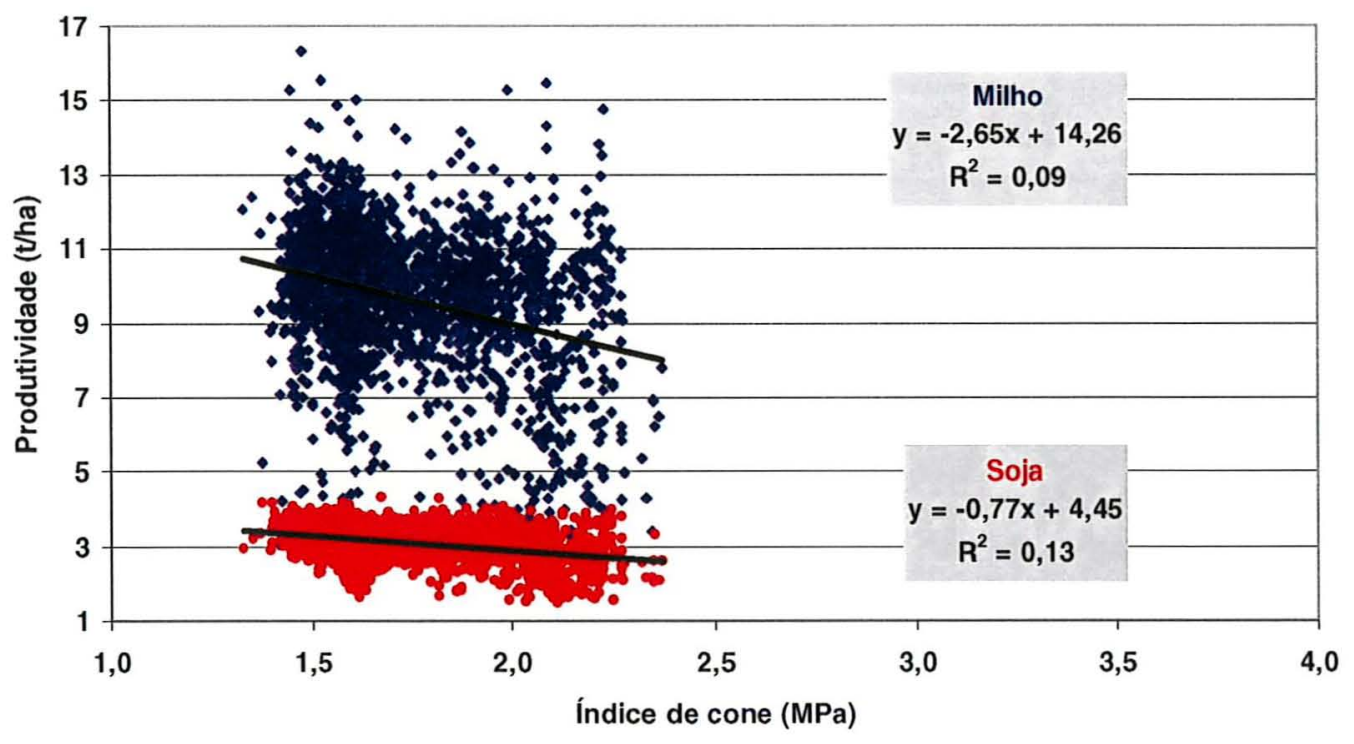

Figura 56 - Relação entre produtividade da soja e do milho e índice de cone da profundidade de 0,20 $\mathrm{m}$ da área de Castro. 


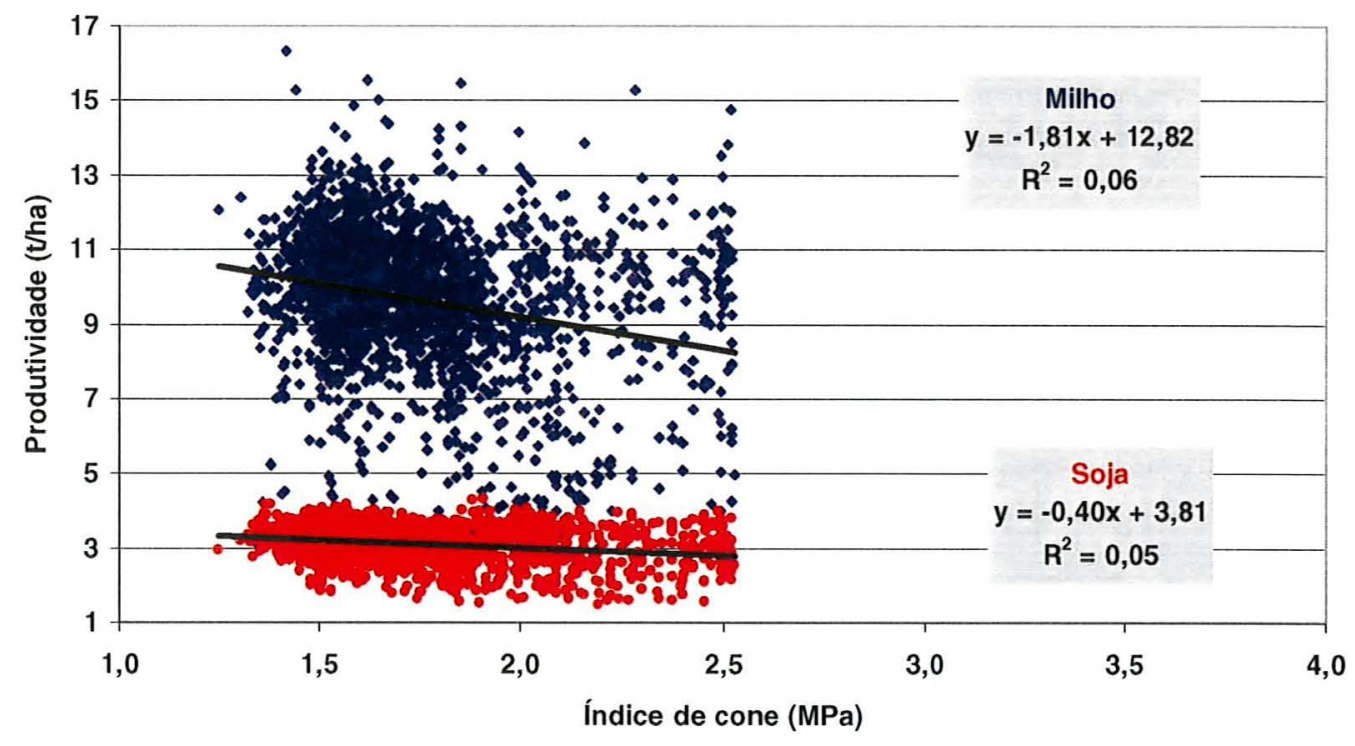

Figura 57 - Relação entre produtividade da soja e do milho e índice de cone da profundidade de $0,25 \mathrm{~m}$ da área de Castro.

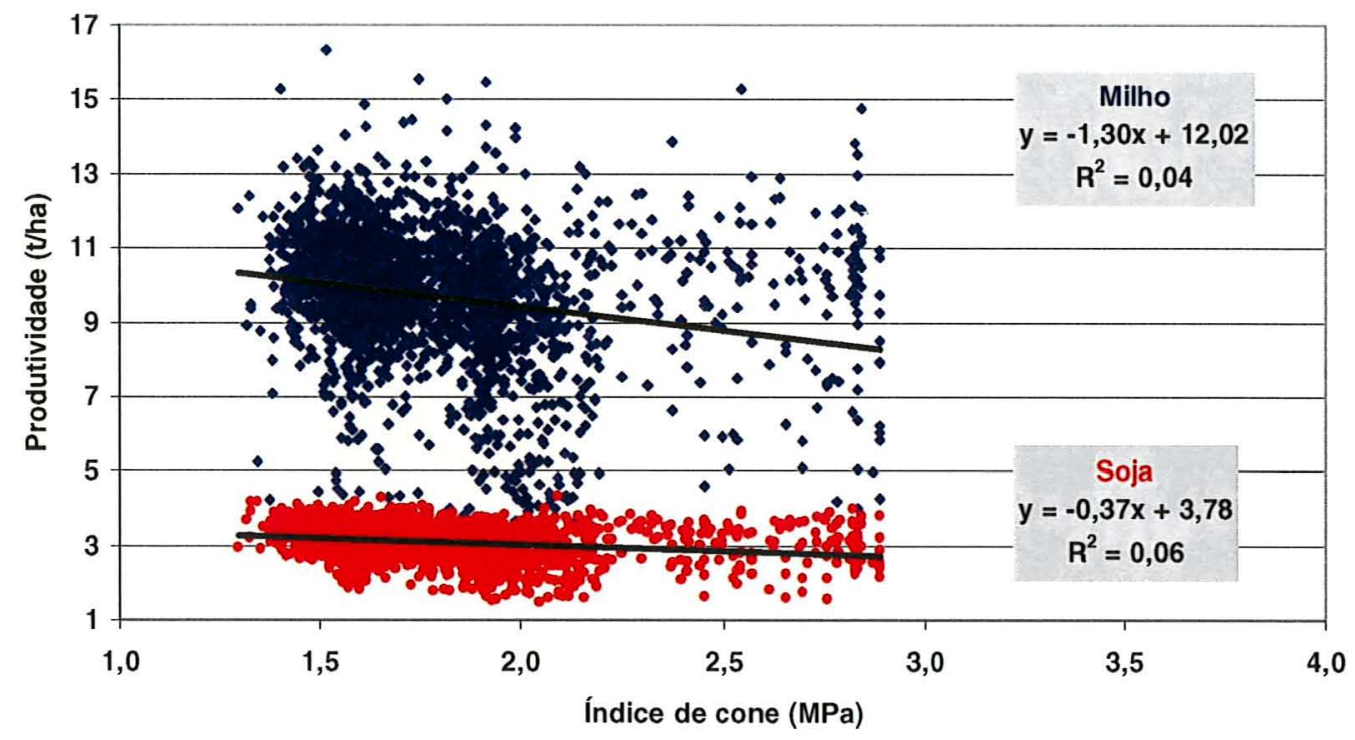

Figura 58 - Relação entre produtividade da soja e do milho e índice de cone da profundidade de 0,30 $\mathrm{m}$ da área de Castro. 


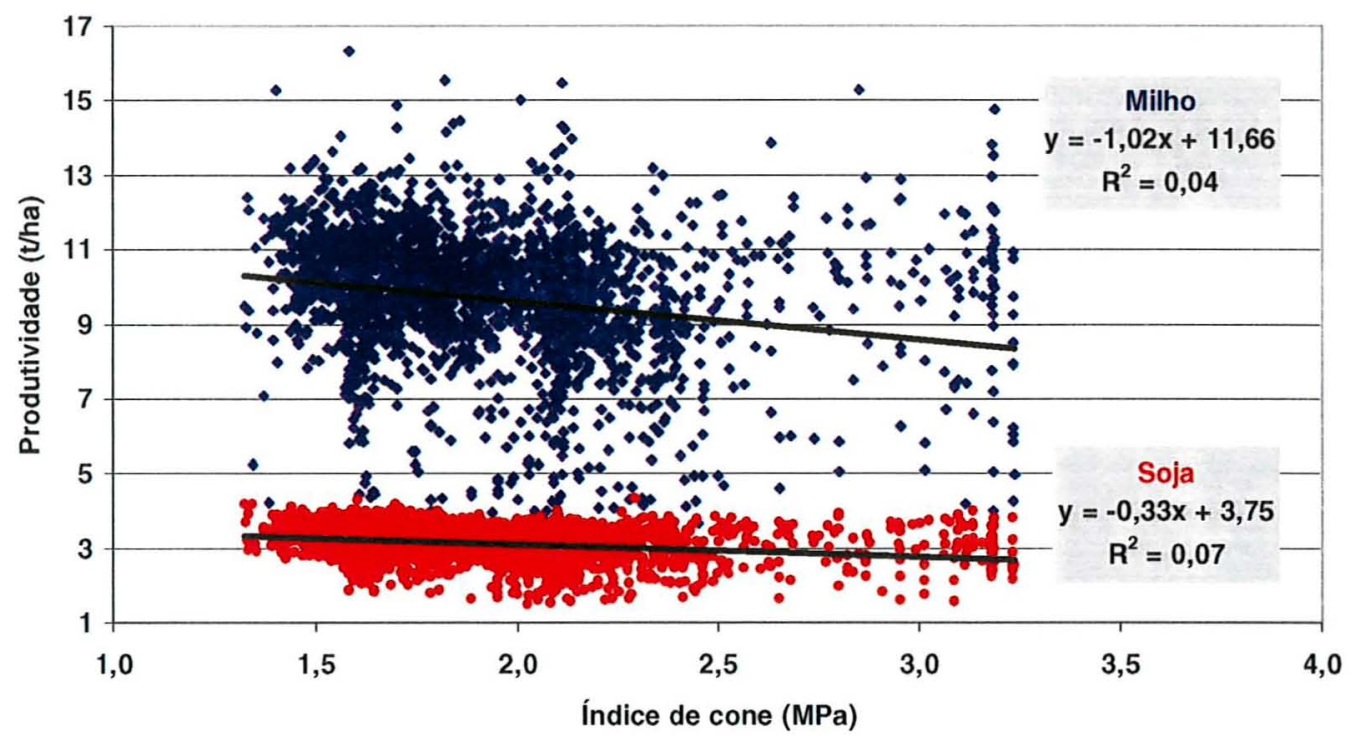

Figura 59 - Relação entre produtividade da soja e do milho e índice de cone da profundidade de 0,35 $\mathrm{m}$ da área de Castro.

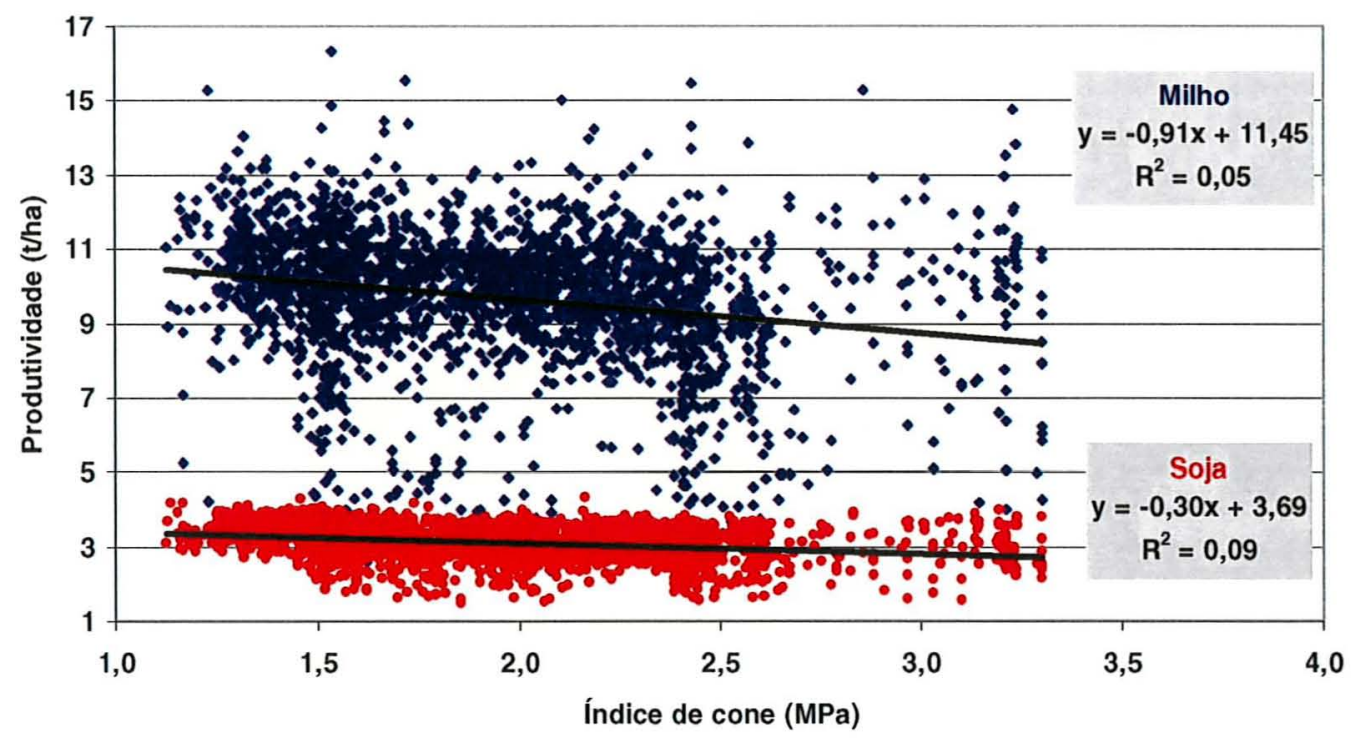

Figura 60 - Relação entre produtividade da soja e do milho e índice de cone da profundidade de 0,40 $\mathrm{m}$ da área de Castro. 
Para a cultura do milho, em todas as profundidades analisadas, verifica-se uma tendência de decréscimo da produtividade com o aumento do índice de cone. As maiores tendências ocorreram nas profundidades de 0,10 e $0,15 \mathrm{~m}$, que apresentam coeficientes de determinação $\left(R^{2}\right)$ de 0,15 e 0,12 , ou seja, uma correlação linear de 0,39 e de 0,35 , respectivamente. Estes resultados informam que $15 \%$ da variação da produtividade é explicada pela variação do índice de cone na profundidade de 0,10 $\mathrm{m}$, e $12 \%$, na profundidade de 0,15 $\mathrm{m}$. $\mathrm{Na}$ profundidade de $0,20 \mathrm{~m}$, os resultados indicam que $9 \%$ da variação da produtividade é explicada pela variação do índice de cone; $6 \%$ na profundidade de $0,25 \mathrm{~m} ; 4 \%$ nas profundidades de 0,30 e $0,35 \mathrm{~m}$ e $5 \%$ na profundidade de $0,40 \mathrm{~m}$.

Para a cultura da soja, em todas as profundidades analisadas, verifica-se uma tendência de decréscimo da produtividade com o aumento do índice de cone. As maiores tendências ocorreram nas profundidades de 0,10 e 0,20 m, informando que 10 e 13\% da variação da produtividade é explicada pela variação do índice de cone, respectivamente. Na profundidade de 0,15 m, os resultados indicam que $9 \%$ da variação da produtividade é explicada pela variação do índice de cone; $5 \%$ na profundidade de $0,25 \mathrm{~m} ; 6 \%$ na profundidade de $0,30 \mathrm{~m} ; 7 \%$ na profundidade de $0,35 \mathrm{~m}$ e $9 \%$ na profundidade de $0,40 \mathrm{~m}$.

Os resultados da análise de regressão do milho e da soja na área de Castro indicam claramente o efeito do manejo sob semeadura direta. $O$ tráfego de máquinas provoca compactação superficial sem que se evidencie o fenômeno conhecido como "pé-de-grade" ou "pé-de-arado". Estes resultados são semelhantes aos encontrados por Kayombo et al. (1986a e b), que estudaram o efeito da compactação dos rodados sobre o desenvolvimento dessas culturas em sistema de semeadura direta em um solo tropical no oeste da Nigéria.

As dependências espaciais observadas para os valores do índice de cone nas áreas de Pirassununga e Castro mostram que as análises estatísticas 
clássicas, nas quais as observações são consideradas aleatórias e independentes espacialmente e que tratam o solo como um meio homogêneo, devem ser substituídas por análises espaciais, que levam em consideração as correlações entre observações vizinhas e que tratam o solo como um meio heterogêneo. Com este procedimento, o sistema não corre o risco de ser superdimensionado em alguns setores e subdimensionado em outros. 


\section{CONCLUSÕES}

Todas as profundidades analisadas apresentaram estrutura de dependência espacial do índice de cone, sendo os alcances da área de Castro maiores do que os alcances da área de Pirassununga.

$\mathrm{Na}$ área de Pirassununga, o modelo do semivariograma que se mostrou mais adequado para explicar a estrutura da variabilidade espacial do índice do cone foi o exponencial, para quase todas as profundidades, exceção apenas à profundidade de $0,35 \mathrm{~m}$, para a qual o modelo mais adequado foi o esférico.

$\mathrm{Na}$ área de Castro, o modelo do semivariograma que se mostrou mais adequado para explicar a estrutura da variabilidade espacial do indice do cone foi o esférico, para quase todas as profundidades, com exceção das profundidades de 0,35 e $0,40 \mathrm{~m}$, para as quais o modelo mais adequado foi o exponencial.

Observou-se o efeito do teor de água sobre o índice de cone, indicando que quanto maior o teor de água, menor o valor do indice de cone.

A análise de regressão entre a produtividade do milho e o índice de cone da área de Pirassununga apresentou correlação nas profundidades de 0,25 e $0,30 \mathrm{~m}$, porém, com baixos coeficientes de determinação.

As análises de regressão entre a produtividade do milho e da soja e o indice de cone de todas as profundidades da área de Castro apresentaram 
correlações. Para a cultura do milho, a análise indicou que $15 \%$ da variação da produtividade é explicada pela variação do índice de cone na profundidade de $0,10 \mathrm{~m}$ e $12 \%$ na profundidade de $0,15 \mathrm{~m}$. Para a cultura da soja, a análise indicou que $10 \%$ da variação da produtividade é explicada pela variação do indice de cone na profundidade de $0,10 \mathrm{~m}$ e $13 \%$ na profundidade de $0,20 \mathrm{~m}$.

Os mapas do índice de cone do solo, gerados através do sistema penetrômetro de cone hidráulico-eletrônico, GPS, SIG e programas computacionais geoestatísticos, mostraram as diferenças existentes entre as regiōes representadas pelos diversos pontos amostrais levantados, permitindo a identificaçã̉o de subáreas onde o gerenciamento das práticas de campo pode ser orientado em conformidade com o grau da variabilidade desse fator. 


\section{REFERÊNCIAS BIBLIOGRÁFICAS}

ALMEIDA, C.F.P. de.; RIBEIRO JÚNIOR, P.J. Estimativa da distribuição espacial de retenção de água em um solo utilizando krigagem indicatriz. Curitiba: Departamento de Estatística, Universidade Federal do Paraná, 1996. 37p. (Relatório Técnico do Laboratório de Estatística).

AMARAL, J.R. Desenvolvimento e construção de um penetrógrafo eletrônico. Piracicaba, 1994. 103p. ilus. Dissertação (Mestre) - Escola Superior de Agricultura "Luiz de Queiroz".

AMERICAN SOCIETY OF AGRICULTURAL ENGINEERS (ASAE). Procedures for using and reporting data obtained with the soil cone penetrometer ASAE EP542. In: $46^{\text {th }}$ Edition of ASAE Standards. St. Joseph, MI. 1999. p.991-993.

AMERICAN SOCIETY OF AGRICULTURAL ENGINEERS (ASAE). Soil cone penetrometer - ASAE S313.3. In: $\mathbf{4 6}^{\text {th }}$ Edition of ASAE Standards. St. Joseph, MI. 1999. p.834.

ANDERSON, G.; PIDGEON, J.D.; SPENCER, H.B.; PARKS, R. A new handheld recording penetrometer for soil studies. Journal of Soil Science. v.31, p.279-296, 1980.

BALASTREIRE, L.A. Máquinas agrícolas. São Paulo: Manole, 1987. 307p. 
BARNES, R.J. The variogram sill and the sample variance. Mathematical Geology. v.23, n.4, p.673-678, 1991.

BILLOT, J.F.; MARIONNEAU, A. Soil compaction: Analysis of field and laboratory experiments. Proceedings of $11^{\text {th }}$ Conference International of the Soil Tillage Research Organization (ISTRO), Edinburgh, U.K., 1988. v.1. p.197-202.

BRADFOR, J.M.; FARREL, D.A.; LARSON, W.E. Effect of soil overburden pressure on penetration of fine metal probes. Soil Science Society of America Journal. v.35, p.12-15, 1971.

BRADFOR, J.M.; GUPTA, S. Soil compressibility. In: A. Klute (Ed.), Methods of Soil Analysis. Part I: Agronomy. American Society of Agronomy, Madison, WI, U.S.A., 1986, p. 479-492.

BRADY, N.C.; WEIL, R.R. The nature and properties of soils. Portland: Book News, Inc., 1998. 881p.

BRAGA, L.P.V. Geoestatística e aplicações. Rio de Janeiro. Departamento de Métodos Estatísticos, Instituto de Matemática, Universidade Federal do Rio de Janeiro. 1990. 36p.

BURROUGH, P.A. Principles of Geographical Information Systems: methods and requirements for land use planning. Clarendon Press, Oxford. 1986.

CAMBARDELLA, C.A.; MOORMAN, T.B.; NOVAK, J.M.; PARKIN, T.B.; KARLEN, D.L.; TURCO, R.F.; KONOPKA, A.E. Field-scale variability of soil properties in central lowa soils. Soil Science Society of America Journal. v. 58, n. 5, p.1501-1511, 1994.

CARTER, L.M. Integrating penetrometer provides average soil strength. Agricultural Engineering. v.50, n.10, p.618-619, 1969.

CARTER, L.M. Portable recording soil penetrometer measures soil strength profiles. Agricultural Engineering. v.48, n.6, p.348-349, 1967.

CLARK, R.L. Effect of controlled traffic on soil cone index. ASAE Paper. n.941039, 1994. 
CLARK, R.L. Evaluation of the potential to develop soil strength maps using a cone penetrometer. ASAE Paper. n.99-3109, 1999.

CLARK, R.L.; RADCLIFFE, D.E.; LANGDALE, G.W.; BRUCE, R.R. Soil strength and water infiltration as affected by paratillage frequency. Transactions of the ASAE. v.36, n.5, p.1301-1305, 1993.

CLARK, R.L.; RADCLIFFE, D.E.; TOLLNER, E.W. Microcomputer-based instrumentation and software for a tractor-mounted penetrometer. ASAE Paper. n.86-1040, 1986.

CRESSIE, N.A.C. Statistics for spatial data. New York, John Wiley \& Sons, Inc, 1993. 900p.

DANNA, P. Global Positioning System Overview. The Geographer's Craft Project, Department of Geography, University of Texas at Austin. (URL:www.utexas.edu/depts/grg/gcraft/notes/gps/gps.html). 1994.

DEXTER, A.R. Model experiments on the behavior of roots at the interface between a tilled seedbed and a compacted sub-soil. I. Effects of seedbed aggregate size an sub-soil strength on wheat roots. Plant Soil. v.95, p.123133, 1986.

DIAS JÚNIOR, M.; PIERCE, F.J. O processo de compactação do solo e sua modelagem. Revista Brasileira de Ciência do Solo. v.20, p.175-182, 1996.

DIAS, G.P.; QUEIROS, D.M. de.; MANTOVANI, E.C. Automação e instrumentação para agricultura de precisão. In: CONGRESSO BRASILEIRO DE ENGENHARIA AGRíCOLA, 27, Poços de Caldas, 1998. Anais. Viçosa: SBEA, 1998. v.1, p.71-107.

DICK, R.G. Cane transports. Developers aim for optimum high flotation, high capacity vehicle. BSES Bulletin. v.20, p.10-15, 1987.

DIGGLE, P.J.; MOYEED, R.A.; TAWN, J.A. Non-Gaussian geostatistics (with Discussion). Applied Statistics. v.47, p.299-350, 1998.

DOEBELIN, E.O. Measurement systems application and design. McGrawHill, Inc. revised edition. 1975. 
FIĖS, J.C.; STENGEL, P. Densité texturale des sols naturels. I. Méthode de mesure. Agronomie. v.1, p.651-658, 1981.

GIL, W.R. Mechanical impedance of plants by compacted soil. Transactions of the ASAE. v.4, p.238-242, 1961.

GILL, W.; VANDEN BERG, G.E. Soil dynamics in tillage and traction. Agriculture Handbook No. 316. Agricultural Research Service. United States Department of Agriculture. 1968. 511p.

GONÇALVES, A.C.A.; MATA, J.D.V.; VIEIRA, S.R.; FOLEGATTI, M.V. Variabilidade espacial de produtividade e de resistência à penetração em área irrigada, sob dois sistemas de preparo. In: BALBUENA, R.H. et al. (Eds.). Avances en el manejo del suelo y agua en la ingeniería rural latinoamericana. La Plata: Editorial de la U.N.L.P., 1998.

GUÉRIF, J. Résistance en traction des agrégats terreux: Influence de la texture, de la matière organique et de la teneur en eau. Agronomie. v.8, p.379-386, 1988.

HENDRICK, J.G. Recording soil penetrometer. Journal of Agricultural Engineering Research. 14(2): p.186-193, 1969.

HOOKS, C.L.; JANSEN, I.J. Recording cone penetrometer developed in reclamation research. Soil Science Society of America Journal. v.50, p.10-12, 1986.

HORN, R.; LEBERT, M. Soil compactability and compressibility. In: SOANE, B.D.; VAN OUWERKERK, C. (Eds.). Soil compaction in crop production. Amsterdam, Elsevier, 1994. 660p.

ISAAKS, E.H.; SRIVASTAVA, R.M. Applied Geostatistics. New York, Oxford University Press, 1989. 560p.

KAYOMBO, B.; LAL, R.; MREMA, G.C. Traffic-induced compaction in maize, cowpea and soybean production on a tropical Alfisol after ploughing and notillage: Soil physical properties. Journal of Science in Food and Agriculture, v.37, p.969-978. 1986a. 
KAYOMBO, B.; LAL, R.; MREMA, G.C. Traffic-induced compaction in maize, cowpea and soybean production on a tropical Alfisol after ploughing and notillage: Crop growth. Journal of Science in Food and Agriculture, v.37, p.1139-1154. 1986b.

KÉZDI, A. Handbook of soil mechanics. Trad. I. Lazányi. Amsterdam; New York: Elsevier Pub. Co. 1974. v.1. Soil Physics. 294p.

KLEIN, V.A.; LIBARDI, P.L.; SILVA, A.P. Resistência do solo à penetração sob diferentes condições de umidade. In: CONGRESSO BRASILEIRO DE ENGENHARIA AGRícOlA, Poços de Caldas, 27, 1998. Anais. Poços de Caldas: SBEA, 1998. v.3, p.61-63.

KÖPPEN, W.P. Climatologia, con un estudio de los climas de la tierra. Mexico: Fondo de Cultura Económica, 1948. 478p.

LANÇAS, K.P.; SANTOS, C.A. Penetrômetro hidráulico-eletrônico equipado com DGPS para avaliação da compactação do solo. In: INGENIERÍA RURAL Y MECANIZACIÓN EN EL ÁMBITO LATINOAMERICANO, La Plata, 1998. p.570-576.

LANÇAS, K.P.; CASTRO NETO, P.; NAGAOKA, A.K.; GUERRA, S.P.S. Índice de cone e mapas de isocompactação do solo agrícola obtidos com a utilização de um penetrômetro hidráulico-eletrônico e um sistema de posicionamento global diferencial (DGPS). In: BALASTREIRE, L.A. (Ed.). O estado-da-arte da agricultura de precisão no Brasil. Piracicaba, Esalq, 2000, 224p. ilus.

LEBERT, M.; HORN, R. A method to predict the mechanical strength of agricultural soils. Soil \& Tillage Research, v.19, p.274-286, 1991.

LINS E SILVA, M.L.; SVERZUT, C.B.; MANTOVANI, E.C. Desenvolvimento e utilização de um penetrógrafo hidráulico com aquisição eletrônica de dados. In: CONGRESSO BRASILEIRO DE ENGENHARIA AGRÍCOLA, 24, Viçosa, 1995. Resumos. Viçosa: SBEA, 1995. p.376.

MANICHON, H. Compactage, décompactage du sol et système de culture. C. R. Académie Agricole de France. v.74, p.43-54, 1988. 
McBRATNEY, A.B.; WEBSTER, R. Choosing functions for semi-variograms of soil properties and fitting them to sampling estimates. Journal of Soil Science. v.37, n.4, p.617-639, 1986.

MILLER, D.E. Effect of subsoiling and irrigation regime on dry bean production in the Pacific Northwest. Soil Science Society of America Journal. v.51, p.784-787, 1987.

MOLIN, J.P. Circuito Brasil de Agricultura de Precisão. Ponta Grossa, 2000a. 58p.

MOLIN, J.P. Geração e interpretação de mapas de produtividade para agricultura de precisão. In: BORÉM, A.; GIÚDICE, M.P. del; QUEIROZ, D.M. de; MANTOVANI, E.C.; FERREIRA, L.R.; VALLE, F.X.R. do; GOMIDE, R.L. (Eds.). Agricultura de precisão. Viçosa, Universidade Federal de Viçosa, 2000b. p.237-257.

MONNIER, G.; FIĖS, J.C.; STENGEL, P. Une méthode de mesure de lá densité aparrente de petits agglomérats terreux, application à l'analyse de porosité du sol. Annuel Agronomie. v.24, p.533-545, 1973.

MOOLMAN J.H.; VAN HUYSSTEEN, L. A geoestatistical analysis of the penetrometer soil strength of a deep ploughed soil. Soil \& Tillage Research, v.15, p-11-24, 1989.

MORGAN, M.; ESS, D. The precision farming guide for agriculturists. Deere \& Company, Moline, USA, 1997. 117p.

MORRISON JR, J.E.; BARTEK, L.A. Design and field evaluation of a handpushed digital soil penetrometer with two cone materials. Transactions of the ASAE. v.30, n.3, p.646-651, 1987.

O'SULLIVAN, M.F.; DICKSON, J.W.; CAMPBELL, D.J. Interpretation and presentation of cone resistance data in tillage and traffic studies. Journal of Soil Science. v.38, p.137-148, 1987.

O'SULLIVAN, M.F.; DICKSON, J.W.; HENSHALL, J.K.; ANDERSON, G. Electronic collection and storage of data from a hand-held recording soil 
penetrometer. Journal of Agricultural Engineering Research. v.28, p.175$178,1983$.

OHMIYA, K.; NOGUCHI, N.; TERAO, H. Cone Resistance measuring system for generating cone resistance distribution map. Journal of Terramechanics. v.30, n.3, p.181-190, 1993.

PERUMPRAL, J.V. Cone penetrometer - A Review. Transactions of the ASAE. v.30, n.4, p.939-944, 1987.

PHILLIPS, J.E.; PERUMPRAL, J.V. Designing a microcomputer data logger for a soil cone penetrometer. Agricultural Engineering. v.64, n.6, p.13-14, 1983.

PRATHER, O.C.; HENDRICK, J.G.; SCHAFER, R.L. An electronic handoperated recording penetrometer. Transactions of the ASAE. v.13, n.1, p.385-386,390. 1970.

RANEY, W.A.; EDMINSTER, T.W. Approaches to soil compaction research. Transactions of the ASAE. p.246-248, 1961.

RIBEIRO JÚNIOR, P.J. Métodos geoestatísticos no estudo da variabilidade espacial de parâmetros do solo. Piracicaba, 1995. 99p. ilus. Dissertação (Mestre) - Escola Superior de Agricultura "Luiz de Queiroz".

RIETMULLER, G.P.; BATCHELDER, D.G.; BLOOME, P.D. A microcomputer system for cone index measurement. Transaction of the ASAE. v.26, n.4, p.996-998,1005. 1983.

RÍPOLI, T.C.; MIALHE, L.G.; NAKAMURA, R.T.; GADANHA JÚNIOR, C.

Subsolagem e subsoladores. Piracicaba: ESALQ, 1985. 43p.

ROCHA, J.V.; LAMPARELLI, R.A. Geoprocessamento. In: CONGRESSO BRASILEIRO DE ENGENHARIA AGRÍCOLA, 27, Poços de Caldas, 1998. Anais. Viçosa: SBEA, 1998. v.1, p.1-28.

SAMPER, F.J.; RAMIREZ, J.C. Geoestatística - aplicaciones a lá hidrogeologia subterránea. Barcelona, Universitat Politècnica de Catalunya, Centro International de Métodos Numéricos en Ingenieria, 1990. $484 p$. 
SEGANTINE, P.C.L. GPS - Sistema de Posicionamento Global. São Carlos: Escola de Engenharia de São Carlos - USP. 1998. 181p.

SILVA JÚNIOR, R.L. da; AMARAL, J.R.; MOLIN, J.P. Caracterização de um penetrômetro hidráulico montado em trator com instrumentação eletrônica para aquisição de dados (compact disc). In: CONGRESSO BRASILEIRO DE ENGENHARIA AGRÍCOLA, 29, Fortaleza, 2000. Fortaleza: SBEA, 2000.

SMITH, L.A.; DUMAS, W.T. A recording soil penetrometer. Transactions of the ASAE. v.21, n.1, p.12-14,19. 1978.

SOANE, B.D.; BLACKWELL, P.S.; DICKSON, J.W.; PAINTER, D.J. Compaction by agricultural vehicles: A review. I. Soil and wheel characteristics. Soil \& Tillage Research. v.1, p.207-237, $1981 a$.

SOANE, B.D.; BLACKWELL, P.S.; DICKSON, J.W.; PAINTER, D.J. Compaction by agricultural vehicles: A review. II. Compaction under tires and other running gear. Soil \& Tillage Research. v.1, p.373-400, 1981 b.

SOANE, B.D.; OUWERKERK, V.C. Soil compaction in crop production. Amsterdam, Elsevier, 1994. 660p.

SPIEGEL, M.R. Estatística. 2. ed. São Paulo: McGraw-Hill, 1985. 454p.

STOLF, R.; FERNANDES, J.; FURLANI NETO, V. Recomendação para uso do penetrômetro de impacto modelo IAA/Planalsucar-Stolf. STAB - Açúcar, Álcool e Subprodutos. v.1, n.3, jan./fev. 1983.

STOLF, R. Fórmulas de transformação dos dados do penetrômetro de impacto em força/unidade de área. In: CONGRESSO BRASILEIRO DE ENGENHARIA AGRÍCOLA, 19, Piracicaba, 1990. Anais. Piracicaba: SBEA, 1990. v.2, p.825-836.

SUDDUTH, K.A.; HUMMEL, J.W.; LEVAN, M.A. Widespan vehicle for data collection in tillage research. Transactions of the ASAE. v.32, p.367-372, 1989.

TAYLOR, H.M.; GARDNER, H.R. Penetration of cotton seedling tap roots as influenced by bulk density, moisture content and strength of soil. Soil Science. v.96, n.3, p.153-156, 1963. 
TAYLOR, H.M.; RATLIFF, L.F. Root elongation rates of cotton and peanuts as a function of soil strength and soil water content. Soil Science. v.108, p.113$119,1969$.

TERRY, C.W.; WILSON, H.M. The Cornell soil penetrometer. Agricultural Engineering. v.33, n.7, p.425, 1952.

TERZAGHI, K.; PECK, R.B. Mecânica dos solos na prática da engenharia. Trad. de A. J. da Costa Nunes e M. de Lourdes Campos Campelo. Rio de Janeiro: Ao Livro Técnico, 1962. 659p.

TORRES, J.S.; VILLEGAS, F. Differentiation of soil compaction and cane stool damage. Sugar Cane. v.1, p.7-11, 1993.

VEPRASKAS, M.J.; MINER, G.S. Effects of subsoiling and mechanical impedance on tobacco root growth. Soil Science Society of America Journal. v.50, p.423-427, 1986.

VETTORAZZI, C.A.; ANGULO, F.R.; COUTO, H.T.Z. Sistema de Posicionamento Global - GPS. Engenharia Rural. v.5, n.2, p.61-70, 1994. VIEIRA, S.R. Uso de geoestatística em estudo de variabilidade espacial. Instituto Agronômico de Campinas. s.d. 81p.

VIEIRA, S.R.; HATFIELD, J.L.; NIELSEN, D.R.; BIGGAR, J.W. Geostatistical theory and application to variability of some agronomical properties. Hilgardia. v.51, n.3, p.1-75. 1983.

WARRICK, A.W.; NIELSEN, D.R. Spatial variability of soil physical properties in the field. In: Applications of soil physics. New York, Academic Press, 1980. $385 p$.

WELLS, L.G.; LEWIS, C.O.; DISTLER, R.J. Remote electronic acquisition of soil cone index measurement. Journal of Terramechanics. v.18, n.4, p.201207, 1981.

WILKERSON, J.B.; TOMPKINS, F.B.; WILHELM, L.R. Microprocessor-based, tractor-mounted soil cone penetrometer. ASAE Paper. n.82-5511, 1982.

WILLIFORD, J.R.; WOOTEN, O.B.; FULGHAM, F.E. Tractor mounted field penetrometer. Transactions of the ASAE. v.15, n.2, p.226-227, 1972. 
WOODRUFF, D.W.; LENKER, D.H. A handheld digital penetrometer. ASAE Paper. n.84-1038, 1984.

ZAMBUZI, P.C.; BELLIN, M.P.; MOLIN, J.P. Penetrômetro para se medir resistência do solo à penetração. In: CONGRESSO NACIONAL DE ESTUDANTES DE ENGENHARIA MECÂNICA, 5, 1998. Espírito Santo. Resumos. UFES. 1998. 
APÊNDICE 1 
Listagem do programa para coletar dados no CR10X (Coletor de Dados) ;\{CR10X\}

*Table 1 Program

01:0.5000 Execution interval (seconds)

1: Full Bridge (P6)

1:1 Reps

2: $23 \quad 25 \mathrm{mV} 60 \mathrm{~Hz}$ Rejection Range

3:3 DIFF Channel

4:1 Excite all reps w/Exchan 1

5:2500 mV Excitation

6:3 Loc [Forca]

7:0.0006 Mult

8:-0.0098 Offset

2: IF $(X<=>)$ (P89)

$1: 3 \quad X$ Loc [Forca]

$2: 3 \quad>=$

3:4 F

4: $30 \quad$ Then Do

3: $Z=F(P 30)$

1:0 $\quad F$

2:0 Exponent of 10

3:5 Z Loc [Flag 2]

4: Do (P86)

1:10 Set Output Flag High (Flag 0)

5: Resolution (P78)

1:1 High Resolution

6: Set Port(s) (P20)
1:0
C8..C5 $=$ low/low/low/low
2:1
C4..C1 = low/low/low/high

7: Pulse (P3)
1: 1
2: 1
Reps
3: 3
Pulse Channel 1
4:2
5: 252.51 Mult
6: 41.2
Loc [Posicao]
8: Set Port(s) (P20)
1:0 C8..C5 $=$ low/low/low/low
2:0 C4..C1 = low/low/low/low

High Frequency, 16 Bit, All Counts

9: Batt Voltage (P10)
1: 4
[Bateria]
10: Do (P86)
1: 10
Set Output Flag High (Flag 0) 
11: Set Active Storage Area (P80)

1:1 Final Storage Area 1

2: $10 \quad$ Array ID

12: Real Time (P77)

1:111 Day,Hour/Minute, Seconds (midnight $=0000$ )

13: Sample (P70)

1:3 Reps

2:1 Loc [Contador]

14: Else (P94)

15: IF $(X<=>F)(P 89)$

1:5 X Loc [Flag2]

2: $1=$

3: $1 \quad F$

4:0 Go to end of Program Table

16: $\mathrm{Z}=\mathrm{F}(\mathrm{P} 30)$

1:1 $\quad F$

2:0 Exponent of 10

3:5 Z Loc (Flag2]

17: IF $(X<=>$ ) (P89)

1:2 X Loc [Posicao]

2:3 >=

3: $30 \quad F$

4:30 Then Do

18: $Z=Z+1$ (P32)

1:1 Z Loc [Contador]

19: Else (P94)

20: End (P95)

21: End (P95) 
APÊNDICE 2 


\section{Áreas Experimentais}



Castro

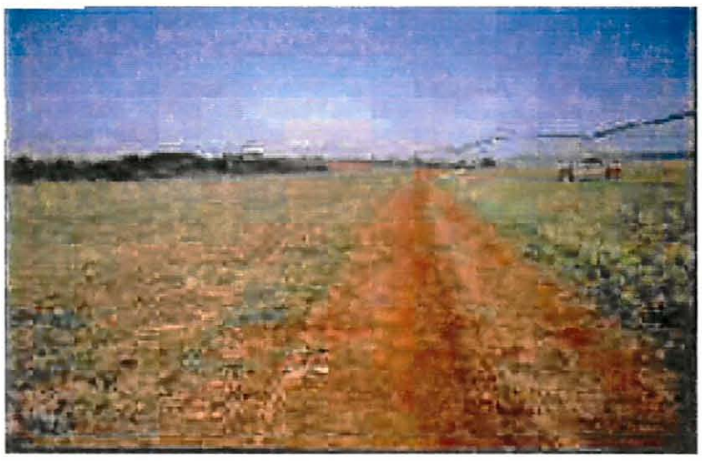

Pirassununga 
Veículo de apoio com GPS

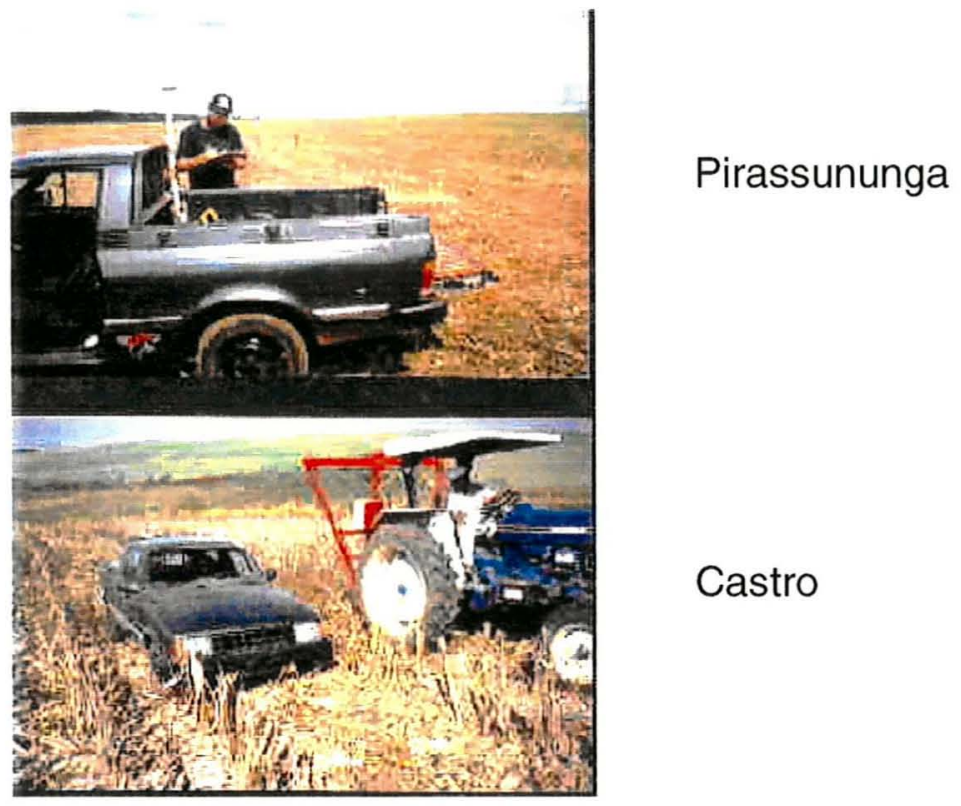

Coleta das amostras para o teor de água em Pirassununga

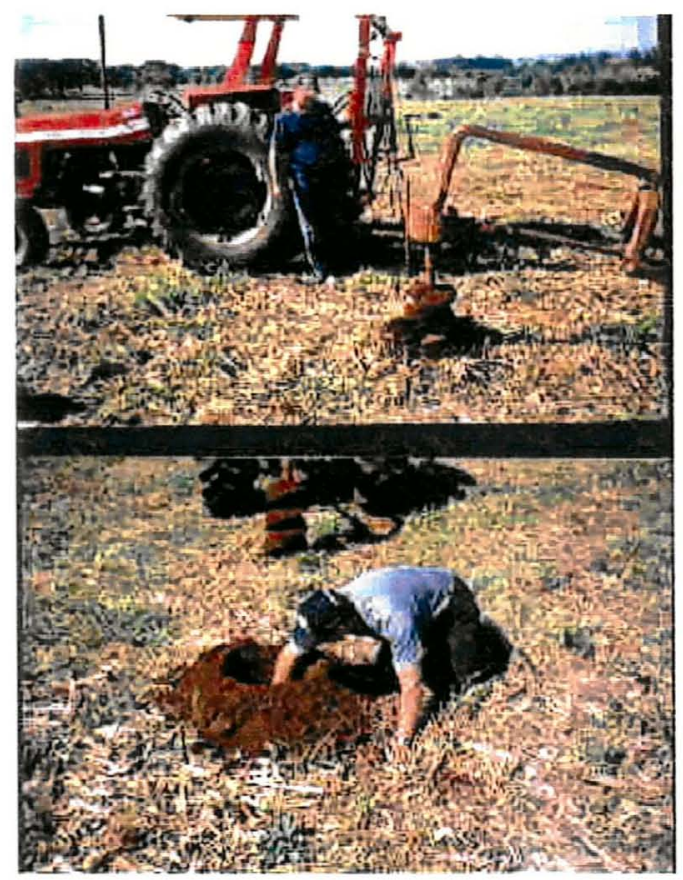


Coleta das amostras para o teor de água em Castro

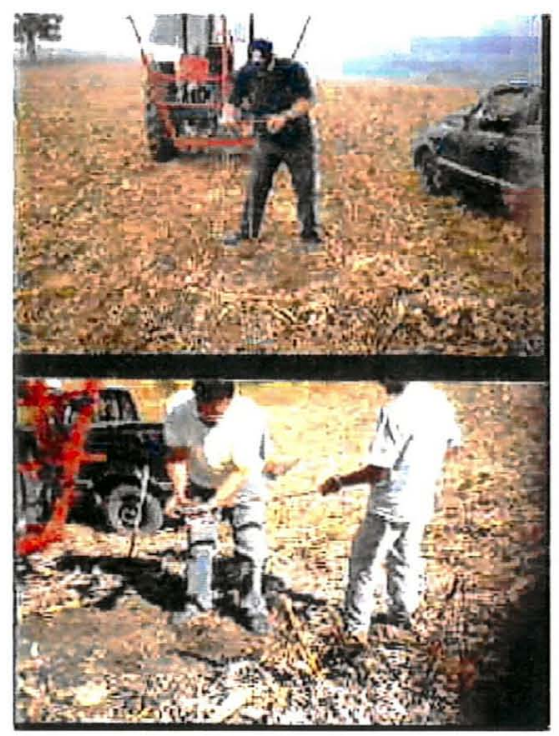




\section{APÊNDICE 3}


Dados das coordenadas e do indice de cone de todos os pontos abtidos da área de Pirassununga.

\begin{tabular}{|c|c|c|c|c|c|}
\hline alkude & & & & & \\
\hline$\frac{(\mathrm{m})}{45275,07}$ & 8672 & $\frac{0,10}{1,17}$ & 15 & & \\
\hline 245293,73 & 7568621,34 & 11,12 & 0,51 & 9.14 & 6,76 \\
\hline 45 & 75688628,46 & & & & 92 \\
\hline & 88 & 0,73 & 22 & 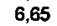 & 9,46 \\
\hline & 9 & & 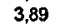 & & \\
\hline & 75686332,84 & 3,6 & 0,91 & 7, & 7,06 \\
\hline 6,57 & 68639,95 & 1 & 6,73 & & 4,81 \\
\hline & 68647,07 & 1,91 & 321 & 8,02 & 8,50 \\
\hline & 54,19 & & 1,27 & & 5,32 \\
\hline & 1,30 & 1,27 & 5,37 & 6,24 & 4,53 \\
\hline & & 8,82 & 13,67 & 2,60 & 9,98 \\
\hline & 4 & 0.70 & 1,27 & & 1,77 \\
\hline & 68682,65 & 0,80 & 1,62 & & 6,61 \\
\hline & 9,77 & 1,49 & 4,99 & & 6,30 \\
\hline & 6,89 & 1,77 & 3,03 & & 4,70 \\
\hline & & 2,86 & 7,93 & & 5,57 \\
\hline 30.70 & & & & & 7.36 \\
\hline & 75 & 2 & 38 & & 4,55 \\
\hline & & 0, & 2,1 & 7 & 6,43 \\
\hline & 80 & 0.43 & 3,64 & 4,12 & 4,37 \\
\hline & 9,91 & 1,02 & 7,03 & 8,78 & 5,33 \\
\hline & 13 & 2,0 & 3,99 &, 40 & 0.19 \\
\hline & 1,15 & & 7,05 & 9,66 & 1,97 \\
\hline & & 6,56 & 11,49 & & 4,84 \\
\hline & & 3,37 & 5,69 & 6,87 & 7,02 \\
\hline & & 3,33 & 3,06 & & 3,97 \\
\hline & & 6,57 & 3,78 & & 1,27 \\
\hline 36,61 & 75 & 3.26 & 4 & & 2,36 \\
\hline & & 9,0 & 7,96 & 4 & 3,61 \\
\hline & & 11 & 7,96 & & 3,61 \\
\hline & & 2.08 & 33 & 3 & 6,13 \\
\hline & & .07 & & 53 & 12,82 \\
\hline & 7 & 2,14 & 3,13 & 4,73 & 9,45 \\
\hline & & 5,2 & 7,64 & & \\
\hline & & 1,70 & 5,86 & 6,72 & 7,39 \\
\hline & & 2. & 6,19 & & 6,38 \\
\hline & 2 & 4,85 & 8.10 & 0,57 & 7,53 \\
\hline & & & & & 7,17 \\
\hline & 76 & 2,94 & 0,61 & & 8,16 \\
\hline & & & 8,72 & & \\
\hline & & 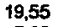 & 3,10 & 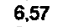 & 4,60 \\
\hline & & & 4,73 & & \\
\hline & & 9,6 & 8,21 & 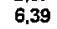 & 1,98 \\
\hline & & & & & 6,32 \\
\hline & & 4,16 & 3,43 & & 2.74 \\
\hline & & 0.73 & 6,63 & & 8,28 \\
\hline & 9 & 10,57 & 7,17 & & \\
\hline & & 4,36 & 8,69 & & 8,07 \\
\hline & & 6,8 & 7,28 & & \\
\hline & & .54 & 3.24 & & 9,89 \\
\hline & & & 12 & & \\
\hline & & 9, & 9,10 & & 6,69 \\
\hline & & 1, & 6,61 & & \\
\hline & & . & 4,86 & 6 & 6,27 \\
\hline & & & & & \\
\hline & & & 7 & 7. & 8,38 \\
\hline & & & & & \\
\hline & & & & & \\
\hline & & & & & \\
\hline & & & & & \\
\hline & & & & & \\
\hline & & 710 & 30 & & \\
\hline & & & & & \\
\hline & & 3 & & & \\
\hline & & & & & \\
\hline & & & & & \\
\hline & & & 9,25 & & \\
\hline & & & & & \\
\hline & & & & & \\
\hline & & & & & \\
\hline & & & & & \\
\hline & & & & & \\
\hline & & & & & \\
\hline & & & & & \\
\hline & & & $=80$ & & 77 \\
\hline & & & & & \\
\hline & & & & & \\
\hline & & & & & 50 \\
\hline & & & & & \\
\hline & & & & & \\
\hline & & & & & \\
\hline & & & & & \\
\hline & & & & & \\
\hline & & & & & \\
\hline & & & & & \\
\hline & & & & & \\
\hline & & & & & \\
\hline & & & & & \\
\hline & & & & & \\
\hline & & & & & \\
\hline & & & 7,62 & & 4,09 \\
\hline & & & & & \\
\hline
\end{tabular}

Dados das coordenadas e do índice de cone de todos os Pirtos obtidos da área de Pirassununga (Cont.)

$\begin{array}{lllllllll}(\mathrm{m}) & (\mathrm{m}) & 0,10 & 0,15 & 0,20 & 0,25 & 0,30 & 0,35 & 0,40\end{array}$
$\begin{array}{lllllllll}45538,74 & 7568821,15 & 10,04 & 7,23 & 6,25 & 5,83 & 4,12 & 5.37 & 5,07\end{array}$ $\begin{array}{lllllllllll}245576,18 & 756883538 & 374 & 5,13 & 4,77 & 7,03 & 6,88 & 6,36 & 4,38\end{array}$ $\begin{array}{llllllllll}445594,90 & 756884250 & 5,89 & 6,21 & 5,79 & 5,38 & 0.14 & 6,36 & 4,38\end{array}$ $\begin{array}{lllllllll}245594,90 & 756842,50 & 5,09 & 6.21 & 5,19 & 5.38 & 0.14 & 7.74 & 7.42\end{array}$

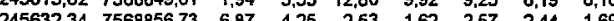

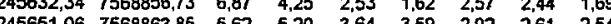
$\begin{array}{lllllllll}245651,06 & 7568863,85 & 5,62 & 5,20 & 3,64 & 3.59 & 2,92 & 2,61 & 2,54\end{array}$ $\begin{array}{llllllllll}245232,08 & 7568725,88 & 4,46 & \mathbf{5 , 4 0} & \mathbf{6 , 7 5} & \mathbf{4 , 6 2} & \mathbf{3 , 6 5} & \mathbf{4 , 4 3} & \mathbf{3 , 7 1} & \mathbf{3 , 4 9} \\ \mathbf{2 4 5 2 3 2 , 4 5}\end{array}$ \begin{tabular}{rrrrrrrrr}
245250,80 & 7568733,00 & 0,99 & 3,56 & 6,99 & 6.19 & 5,03 & 3,33 & 2.72 \\
\hline
\end{tabular} $\begin{array}{llrrrrrrr}245269,52 & 7568740,12 & 10,11 & \mathbf{7 , 6 9} & \mathbf{7 , 7 5} & \mathbf{3 , 2 0} & \mathbf{3 , 6 7} & \mathbf{2 , 8 8} & \mathbf{2 , 9 9} \\ \mathbf{2 4 5 2 8 8 , 2 4} & 7568747,24 & 1,07 & \mathbf{4 , 3 9} & \mathbf{6 , 7 7} & \mathbf{5 , 5 8} & 5,12 & \mathbf{2 , 9 5} & \mathbf{2 , 2 7}\end{array}$ $\begin{array}{lllllllll}245306,96 & 7568754,35 & 2,92 & 4,96 & 7,64 & 5,16 & 3,92 & \mathbf{2 , 8 5} & \mathbf{2 , 4 6}\end{array}$ $\begin{array}{lllllllll}245325,68 & 7568761,47 & 11,90 & 6,66 & 3,59 & 3,29 & 1,97 & 1,79 & 7,74\end{array}$ $\begin{array}{llllllllll}245344,40 & 7568768,59 & 4,85 & 10,39 & 14,22 & 14,69 & 8,47 & \mathbf{8 , 2 2} & 5,96\end{array}$ $\begin{array}{lllllllll}245363,12 & 7568775,70 & 13,80 & 14,14 & 9,46 & 6,76 & 7,03 & 4,90 & 3,64\end{array}$ $\begin{array}{llllllllll}245381,84 & 7568782,82 & 4,72 & 4,50 & 3,36 & 3,61 & 3,43 & 3,16 & 2,64\end{array}$ $\begin{array}{lllllllll}245400,55 & 7568789,94 & 11,02 & 12,67 & 10,11 & 7,93 & 4,69 & 3,07 & 3,13\end{array}$ $\begin{array}{lllllllll}245419.27 & 7568797.05 & 3,63 & 7,75 & 7,23 & \mathbf{8 , 5 3} & 4,51 & 4,82 & 4,01\end{array}$ $\begin{array}{lllllllll}245437,99 & 7568804,17 & 2,24 & 8,32 & 9,37 & 6,66 & 3,25 & 2,88 & 2,44 \\ \end{array}$ $\begin{array}{lllllllll}245456,71 & 7568811,29 & 9,10 & 5,93 & 4,15 & 2,63 & 2,57 & 1,97 & 1,54 \\ 245475,43 & 7568818,41 & 6,55 & 5,29 & 3,32 & 2,02 & 1,62 & 1,54 & 1,54\end{array}$

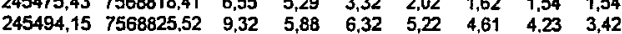
$\begin{array}{llllllllll}245494,75 & 7568825,52 & 9,32 & \mathbf{5 , 8 8} & \mathbf{6 , 3 2} & \mathbf{5 , 2 2} & \mathbf{4 , 6 1} & \mathbf{4 . 2 3} & \mathbf{3 , 4 2} \\ \mathbf{2 4 5 5 1 2 , 8 7} & \mathbf{7 5 6 8 8 3 2 , 6 4} & \mathbf{7 , 8 9} & \mathbf{4 , 7 1} & \mathbf{3 , 2 2} & \mathbf{2 , 3 6} & \mathbf{2 , 3 1} & \mathbf{2 , 2 7} & \mathbf{1 , 8 6}\end{array}$ $\begin{array}{rrrrrrrrr}245531,59 & 7568839,76 & 6,44 & 14,64 & 11,21 & 10,71 & 10,42 & 7,60 & 4,61\end{array}$ $\begin{array}{rrrrrrrrr}245531,59 & 7568839,76 & 6,44 & 14,64 & 11,21 & 10,71 & 10,42 & 7,60 & 4,61 \\ 245550,31 & 7568846,87 & 2,99 & 6,62 & 8,72 & 5,53 & 4,67 & \mathbf{3}, 17 & \mathbf{2 , 5 1}\end{array}$ $\begin{array}{rrrrrrrrr}245550,31 & 7568846,87 & 2,99 & \mathbf{6 , 6 2} & \mathbf{8 , 7 2} & \mathbf{5 , 5 3} & \mathbf{4 , 6 7} & \mathbf{3 , 1 7} & \mathbf{2 , 5 1} \\ \mathbf{2 4 5 5 6 9 , 0 3} & \mathbf{7 5 6 8 8 5 3 , 9 9} & \mathbf{1 4 , 8 9} & 12,14 & \mathbf{8 , 4 5} & \mathbf{8 , 6 6} & \mathbf{5 . 8 7} & \mathbf{3 , 0 8} & 1,99\end{array}$ $\begin{array}{rrrrrrrrr}245587,75 & 7568861,11 & 3,15 & 6,69 & 19,66 & 12,94 & 12,79 & 15,41 & 9,44\end{array}$ $\begin{array}{rrrrrrrrrr}245587,75 & 7568861,11 & 3,15 & 6,69 & 19,66 & 12,94 & 12,79 & 15,41 & 9,44 \\ 245606,46 & 7568868,22 & 11,12 & 21,59 & 15,34 & 9,58 & 5,05 & 3,11 & 2,97\end{array}$ $\begin{array}{lllllllll}245625,18 & 7568875.34 & 2,15 & 3,96 & 6,31 & 7,17 & 6,69 & 4,19 & 3,23\end{array}$ $\begin{array}{rrrrrrrrr}245643,90 & 7568882,46 & 2,97 & 5,13 & 7,82 & 6,77 & 7,11 & 7,64 & \mathbf{6 , 5 4} \\ 245662,62 & 7568889,57 & 12,51 & 10,69 & 11,24 & \mathbf{9 , 4 7} & \mathbf{6 , 6 9} & \mathbf{5 , 0 2} & \mathbf{3 , 5 0}\end{array}$ $\begin{array}{rrrrrrrrr}245662,62 & 7568889,57 & 12,51 & 10,69 & 11,24 & 9,47 & 6,69 & 5,02 & 3,50 \\ 245224,93 & 7568744,49 & 6,50 & 7,17 & 6,29 & 3,93 & 2,34 & 1,77 & 1,58\end{array}$ $\begin{array}{lllllllll}245224,93 & 7568744,49 & 6,50 & 7,17 & \mathbf{6 . 2 9} & \mathbf{3 , 9 3} & \mathbf{2 , 3 4} & \mathbf{1 , 7 7} & \mathbf{1 , 5 8} \\ \mathbf{2 4 5 2 4 3 , 6 5} & \mathbf{7 5 6 8 7 5 1 , 6 1} & \mathbf{1 1 , 2 2} & \mathbf{7 , 8 5} & \mathbf{8 , 1 0} & \mathbf{5 , 8 5} & \mathbf{3 , 8 3} & \mathbf{2 , 6 5} & \mathbf{2 , 1 6}\end{array}$ $\begin{array}{lllllllll}245262,37 & 7568758,73 & 2,04 & 6,17 & 6,12 & 5,04 & 4,35 & 3,18 & 3,74\end{array}$ \begin{tabular}{rlllrllll}
245281,09 & 7568765,85 & 1.18 & 1,55 & 9.45 & 7.88 & 6.52 & 2,33 & 2,77 \\
\hline
\end{tabular} $\begin{array}{rlllrlllll}245299,80 & 7568772,96 & \mathbf{3 , 4 2} & \mathbf{7 , 7 0} & \mathbf{1 0 , 4 2} & \mathbf{7 , 0 6} & \mathbf{4 , 5 1} & \mathbf{3 , 7 2} & \mathbf{2 , 8 7} \\ \mathbf{2 4 5 3 1 8 , 5 2} & 7568780,08 & 3,37 & \mathbf{9}, 32 & 6,83 & 6,47 & \mathbf{8}, 25 & 5,89 & \mathbf{2} 86\end{array}$ $\begin{array}{lllllllll}245337.24 & 7568787.20 & 5,81 & 6,56 & 7,03 & \mathbf{9 . 8 3} & \mathbf{5 , 5 0} & \mathbf{5 , 4 9} & \mathbf{4 , 5 9}\end{array}$ $\begin{array}{lllllllll}245355,96 & 7568794,31 & 12,82 & 9,45 & 5,99 & 5,50 & 4,27 & 4,51 & 4,06\end{array}$ $\begin{array}{llllllllll}245374,68 & 7568801,43 & 8,47 & 5,63 & 5.11 & 5,74 & \mathbf{6 . 0 5} & \mathbf{5 . 4 4} & 4,95\end{array}$ $\begin{array}{lllllllll}245393,40 & 7568808,55 & 7,62 & \mathbf{5 , 7 8} & \mathbf{2 , 9 2} & \mathbf{2 , 8 8} & \mathbf{2 , 4 2} & \mathbf{2 , 4 3} & \mathbf{2 , 9 8}\end{array}$ $\begin{array}{lllllllll}245393,40 & 7568808,55 & 7,62 & 5,78 & 2,92 & 2,88 & 2,42 & 2,43 & 2,98 \\ 245412,12 & 7568815,66 & \mathbf{5 , 7 1} & \mathbf{5 , 0 5} & \mathbf{6 , 3 7} & \mathbf{4 , 4 2} & \mathbf{3 , 3 8} & \mathbf{4 3 2} & \mathbf{3}, 24\end{array}$ $\begin{array}{rrrrrrrrr}245430,84 & 7568822,78 & 11,19 & 7,32 & \mathbf{4 , 4 4} & \mathbf{4 , 4 3} & \mathbf{3 , 3 8} & \mathbf{4 , 3 2} & 3,24 \\ \mathbf{2 4} & \mathbf{2 , 3 0} & \mathbf{2 , 1 9} & \mathbf{1 , 9 4}\end{array}$ $\begin{array}{rrrrrrrrrr}245430,84 & 7568822,78 & 11,19 & 7,32 & 4,44 & 3,38 & 2,30 & 2,19 & 1,94 \\ \mathbf{2 4 5 4 4 9 , 5 6} & \mathbf{7 5 6 8 8 2 9 , 9 0} & \mathbf{6 , 7 1} & \mathbf{6 , 8 7} & \mathbf{5 , 5 4} & \mathbf{4 , 5 2} & \mathbf{3 , 2 8} & \mathbf{2 , 2 2} & 1,56\end{array}$ $\begin{array}{lllllllll}245468,28 & 7568837,01 & 9,73 & 7,32 & 8,46 & \mathbf{4 , 5 2} & 3,28 & 2,22 & 1,56 \\ & \mathbf{4}, 12 & 3,14 & \mathbf{2 , 2 5}\end{array}$ $\begin{array}{llllllllll}245468,28 & 7568837,01 & 9,73 & \mathbf{7 , 3 2} & \mathbf{8 , 4 6} & \mathbf{6 , 6 0} & \mathbf{4 , 1 2} & \mathbf{3 , 1 4} & \mathbf{2 , 2 5} \\ \mathbf{2 4 5 4 8 7 , 0 0} & \mathbf{7 5 6 8 8 4 4 , 1 3} & \mathbf{7 , 0 0} & \mathbf{8 , 0 7} & \mathbf{8 , 2 7} & \mathbf{8 , 3 5} & \mathbf{7 , 9 4} & \mathbf{7 , 7 7} & \mathbf{5 , 5 2}\end{array}$ $\begin{array}{llllllllll}\mathbf{2 4 5 4 8 7 , 0 0} & \mathbf{7 5 6 8 8 4 4 , 1 3} & \mathbf{7}, 00 & \mathbf{8 , 0 7} & \mathbf{8 , 2 7} & \mathbf{8 , 3 5} & \mathbf{7 , 9 4} & \mathbf{7 , 7 7} & \mathbf{5 , 5 2} \\ \mathbf{2 4 5 5 0 5 , 7 1} & \mathbf{7 5 6 8 8 5 1 , 2 5} & \mathbf{7 , 9 5} & \mathbf{5 , 3 8} & \mathbf{4 , 4 5} & \mathbf{3 , 5 0} & \mathbf{2 , 5 1} & \mathbf{2 , 0 8} & \mathbf{1 , 1 1}\end{array}$ $\begin{array}{rlrrrrrrr}245524,43 & 7568858,37 & 6,08 & 6,17 & 6,33 & 2,53 & 3,09 & 5.28 & 5,02 \\ 245543,15 & 7568865,48 & 14,22 & 17,60 & 10,63 & 11,03 & 6,13 & 3,82 & 1,92\end{array}$ $\begin{array}{rrrrrrrrrr}245543,15 & 7568865,48 & 14,22 & 17,60 & 10,63 & 11,03 & 6,13 & 3,82 & 1,92 \\ 245561,87 & 7568872,60 & 2,04 & 3,98 & 14,51 & 12,71 & 9,66 & 6,88 & 6,58\end{array}$ $\begin{array}{llllllllll}245580,59 & 7568879,72 & 4,37 & 9,04 & 8,70 & 9,51 & 8,07 & 8,56 & 7,43\end{array}$ $\begin{array}{llllllllll}245599,31 & 7568886,83 & 15,33 & 10,84 & 4,31 & 4,16 & 2,68 & \mathbf{2 , 5 5} & \mathbf{2 , 6 7}\end{array}$ \begin{tabular}{rrrrrrrrr}
245618,03 & 7568893,95 & 3,33 & 5,98 & 12,72 & 10,91 & 9,74 & 5,61 & 4,45 \\
\hline
\end{tabular} $\begin{array}{lllllllll}245636,75 & 7568901,07 & 17,25 & 15,37 & 9,24 & \mathbf{8 , 6 3} & 7,18 & \mathbf{4 , 8 6} & \mathbf{3 , 7 4} \\ \mathbf{2 4 5 2 1 7} 77 & 7568763,11 & 3,77 & 11,96 & 6,19 & 4,05 & 3,52 & 2,18 & 1,85\end{array}$ $\begin{array}{rrrrrrrrrr}245236,49 & 7568770,22 & 1,08 & 7,76 & 7,96 & 7,94 & 4,28 & \mathbf{3 , 4 1} & \mathbf{2 , 0 9}\end{array}$ $\begin{array}{lllllllll}245255,21 & 7568777,34 & 6,75 & 4,36 & 2,01 & 2,45 & 1,83 & 1.91 & 1,98\end{array}$ $\begin{array}{lllllllll}245273,93 & 7568784,46 & 0,62 & 1,86 & 4,92 & 7,38 & 4,03 & \mathbf{2 , 5 2} & \mathbf{2 , 4 2}\end{array}$ $\begin{array}{lllllllll}245292,65 & 7568791,57 & 2,49 & 4,44 & 4,04 & 3,22 & 2,38 & 2,06 & 4,00\end{array}$ $\begin{array}{rrrrrrrrrr}245311,37 & 7568798,69 & 7,95 & 5,36 & 4,42 & 3,68 & 3,31 & 2,68 & 2,41 \\ 245330,09 & 7568805,81 & 11,58 & 14,86 & 14,91 & 11,02 & 7,96 & \mathbf{4 , 1 2} & 3,96\end{array}$ $\begin{array}{rrrrrrrrr}245330,09 & 7568805,81 & 11,58 & 14,86 & 14,91 & 11,02 & 7,96 & 4,12 & 3,96 \\ 245348,81 & 7568812,92 & 4,21 & 3,45 & 2,93 & 2,24 & 2,52 & 2,34 & 1,20\end{array}$ $\begin{array}{llrllllll}245348,81 & 7568812,92 & 4,21 & 3,45 & 2,93 & 2,24 & 2,52 & 2,34 & 1,20 \\ 245367,53 & 7568820,04 & 11,98 & 9,13 & 5,22 & 4,24 & 3,33 & 2,82 & 2,68\end{array}$ $\begin{array}{rrrrrrrrr}245387,53 & 7568820,04 & 11,98 & 9,13 & \mathbf{5 , 2 2} & \mathbf{4 . 2 4} & \mathbf{3 , 3 3} & \mathbf{2 , 8 2} & \mathbf{2 , 6 8} \\ \mathbf{2 4 5 3 8 6 , 2 5} & \mathbf{7 5 6 8 8 2 7 , 1 6} & 9,07 & \mathbf{6 , 4 1} & \mathbf{4 , 5 6} & \mathbf{2 , 0 1} & 1,98 & \mathbf{1 , 4 2} & \mathbf{1 , 1 3}\end{array}$ $\begin{array}{lllllllll}245404,96 & 75688834,27 & 3,66 & \mathbf{3 , 4 5} & \mathbf{4 , 5 6} & \mathbf{2 , 0 1} & 1,98 & \mathbf{1 , 4 2} & 1,13 \\ \mathbf{2 4 5 4 7} & \mathbf{4 , 0 9} & \mathbf{2 , 1 5} & \mathbf{2 , 4 9}\end{array}$ $\begin{array}{lllllllll}245423,68 & 7568841.39 & 4,10 & 4,46 & 3,41 & 2,46 & 2,49 & 1,99 & 1,00\end{array}$ $\begin{array}{rlrrrrrrrr}245442,40 & 7568848,51 & 11,76 & 9,70 & \mathbf{8 , 2 1} & \mathbf{5 , 0 5} & \mathbf{3 , 8 3} & \mathbf{7 , 9 1} & \mathbf{1 1 , 4 5} \\ \mathbf{2 4 5 4 6 1 , 1 2} & \mathbf{7 5 6 8 8 5 5 , 6 3} & \mathbf{1 2 , 7 7} & \mathbf{1 0 , 7 5} & 11,40 & \mathbf{8}, 11 & 7,24 & \mathbf{4}, 99 & \mathbf{4}, 36\end{array}$ $\begin{array}{llllllllll}245479,84 & 7568862,74 & 13,34 & 13,61 & 11,40 & \mathbf{9 , 0 1} & \mathbf{5 , 2 0} & \mathbf{3 , 3 9} & \mathbf{2 , 7 4}\end{array}$ $\begin{array}{lllrrrrrr}245498,56 & 7568869,86 & 8,80 & 9,67 & 5,69 & 4,51 & 5,16 & 4,39 & 4,15\end{array}$ \begin{tabular}{rlrrrrrrr}
245517,28 & 7568876,98 & 18,27 & 15,79 & 13,95 & 8,77 & 6,39 & 4,88 & 3,28 \\
\hline
\end{tabular} \begin{tabular}{rlllllllll}
245536,00 & 7568884,09 & 4,14 & 7,89 & 11,99 & 9,61 & $\mathbf{5 , 0 4}$ & $\mathbf{1 , 8 4}$ & 1,85 \\
\hline
\end{tabular} $\begin{array}{rrrrrrrrr}245554,72 & 7568891,21 & 3,53 & 9,47 & 15,21 & 12,47 & 8,59 & \mathbf{5 , 6 1} & 4,12 \\ 245573,44 & 7568898,33 & 4,50 & 8,08 & 5,56 & 4,27 & \mathbf{3 , 1 9} & \mathbf{2 , 1 2} & \mathbf{2 , 0 5}\end{array}$ $\begin{array}{lllllllll}245592,16 & 7568905,44 & 10,44 & 9,77 & \mathbf{7 , 3 3} & \mathbf{8 , 2 4} & \mathbf{7 , 9 3} & \mathbf{4 , 3 5} & \mathbf{3 , 0 7}\end{array}$ $\begin{array}{lllllllll}245610,87 & 7568912,56 & 1,56 & 3,10 & 3,74 & 3,08 & 2,13 & 1,95 & 1,60\end{array}$ $\begin{array}{llllllllll}245629,59 & 7568919,68 & 12,91 & 11,96 & 10,05 & 7.76 & 6,70 & 4,05 & 3,81\end{array}$ $\begin{array}{llllllllll}\mathbf{2 4 5 2 1 0 , 6 2} & \mathbf{7 5 6 8 7 8 1 , 7 2} & \mathbf{8 , 2 0} & \mathbf{4 , 7 4} & \mathbf{7 , 1 7} & \mathbf{6 , 2 5} & \mathbf{5 , 4 2} & \mathbf{4 , 7 5} & \mathbf{3 , 2 2}\end{array}$ $\begin{array}{rllrrrrrr}245229,34 & 7568788,83 & 2,85 & 10,48 & 7,35 & \mathbf{8 , 1 3} & \mathbf{4 , 4 8} & \mathbf{4 , 0 2} & \mathbf{3 , 2 2} \\ \mathbf{2 4}, 14\end{array}$ $\begin{array}{rrrrrrrrr}245229,34 & 7568788,83 & 2,85 & 10,48 & 7,35 & 8.13 & 4,78 & 3,02 & 2,14 \\ 245248,06 & 7568795,95 & 4,66 & 9,47 & 6,17 & 4,08 & 2,61 & 1,99 & 2,25\end{array}$ $\begin{array}{lllllllll}245248,06 & 7568795,95 & 4,66 & 9,47 & 6,17 & 4,08 & 2,61 & 1,99 & 2,25 \\ 245266,78 & 7568803,07 & 1,78 & 3,30 & 6,16 & 3,95 & 2,45 & 2,11 & 1,72\end{array}$

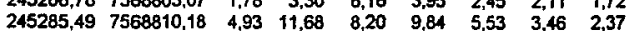
$\begin{array}{llllllllll}245285,49 & 7568810,18 & 4,93 & 11,68 & \mathbf{8 , 2 0} & \mathbf{9 , 8 4} & \mathbf{5 , 5 3} & \mathbf{3 , 4 6} & \mathbf{2 . 3 7} \\ \mathbf{2 4 5 3 0 4 , 2 1} & \mathbf{7 5 6 8 8 1 7 , 3 0} & \mathbf{7 . 4 9} & 11,60 & \mathbf{7 , 8 2} & \mathbf{5 , 7 7} & \mathbf{6 , 9 1} & \mathbf{6 , 5 8} & \mathbf{4 , 7 3}\end{array}$ $\begin{array}{lllllllll}245322,93 & 7568824,42 & 7,71 & 7,18 & 7,76 & 5,88 & \mathbf{3 , 1 2} & 6,58 & 4,73 \\ 2,94 & 2,72\end{array}$ $\begin{array}{lllllllll}245341,65 & 7568831,53 & 5,94 & 8,25 & 6,37 & 4,48 & 4,70 & 3.75 & 3,45 \\ 245360,37 & 7568938,65 & 7,76 & 4,01 & 3,52 & 3,83 & 4,22 & 3,31 & 3.23\end{array}$ $\begin{array}{lllllllll}\mathbf{2 4 5 3 6 0 , 3 7} & \mathbf{7 5 6 8 8 3 8 , 6 5} & \mathbf{7 , 7 6} & \mathbf{4 , 0 1} & \mathbf{3 , 5 2} & \mathbf{3 , 8 3} & \mathbf{4 , 2 2} & \mathbf{3 , 3 1} & \mathbf{3 , 2 3} \\ \mathbf{2 4 5 3 7 9 , 0 9} & \mathbf{7 5 6 8 8 4 5 , 7 7} & \mathbf{5 , 9 2} & \mathbf{3 , 7 3} & \mathbf{4 , 8 8} & \mathbf{3 , 5 2} & \mathbf{2 , 7 0} & \mathbf{2 , 8 6} & \mathbf{3 , 1 3}\end{array}$ $\begin{array}{lllllllll}245397,81 & 7568852,88 & 8.54 & 6.32 & 4,29 & 3,09 & 2,95 & 1,83 & 1,00\end{array}$ $\begin{array}{llllllllll}245416,53 & 7568860,00 & 12,45 & 10,51 & 8,21 & 4.83 & 4,53 & 2,76 & 2,12\end{array}$ \begin{tabular}{lllllllll}
245435,25 & 7568867,12 & 7,39 & 4,39 & 3,82 & 2,99 & 2,85 & 2,67 & 1.66 \\
245453,97 & 7568874,24 & 4,78 & 7,94 & 4,03 & 2.10 & 3,95 & 3,92 & 2.57 \\
\hline
\end{tabular} 
Dados das coordenadas e do índice de cone de todos os pontos obtidos da área de Pirassununga (Cont.)

\begin{tabular}{|c|c|c|c|c|c|c|c|c|}
\hline artifude & onglide & & & Protu & ndildade & s (m) & & \\
\hline (m) & (m) & 0,10 & 0,15 & 0,20 & 0,25 & 0,30 & 0,35 & 0,40 \\
\hline & & 10,52 & 8,55 & 8,19 & 5,78 & 3,74 & 3,01 & 2,39 \\
\hline 245491,41 & 7568888,47 & 10,33 & 11,83 & 7,01 & 4,01 & 3,38 & 2,70 & 2,73 \\
\hline & 5.59 & 9.43 & 9.05 & 6,94 & 5,57 & 4,46 & 3,21 & 2,55 \\
\hline 28,84 & 7568902,70 & 5,77 & 9,45 & 9,41 & 6,68 & 6,79 & 5,11 & 4,87 \\
\hline & 7568 & 11,50 & 6,28 & 3,69 & 2,88 & 2,22 & 1,82 & 1,38 \\
\hline 36,28 & 7568916,84 & 3,16 & 8,81 & 17,61 & 9,21 & 6,12 & 4.94 & 3,75 \\
\hline & 7568924,05 & 6,75 & 12,20 & 11,86 & 8,94 & 4,20 & 2,51 & 3,89 \\
\hline 245603,72 & 7568931,17 & 5,28 & 6,67 & 3,64 & 3,90 & 4,33 & 3,43 & 3,03 \\
\hline 245622,44 & 7568938,29 & 14,40 & 19.35 & 10,89 & 6,77 & 7,46 & 5,01 & 3,93 \\
\hline 33,46 & 7568800,33 & 11,78 & 14,20 & 12,10 & 8,06 & 10,67 & 8,42 & 6,16 \\
\hline 245222,18 & 7568807,44 & 1,36 & 1,93 & 5,53 & 7,00 & 6,85 & 5.22 & 4,37 \\
\hline 245240,90 & 14,56 & 7,39 & 5,87 & 3.52 & 2,77 & 2,08 & 1,90 & 2,09 \\
\hline 245259,62 & 7568821,68 & 1,29 & 5,06 & 8,98 & 9,05 & 9,00 & 4,25 & 2,93 \\
\hline 245278,34 & 7568828,79 & 1,17 & 1,90 & 9,08 & 6,92 & 6,04 & 4.83 & 5,02 \\
\hline 245297,06 & 7568835.91 & 11,05 & 17,63 & 14,19 & 9,47 & 8,14 & 6,08 & 3,52 \\
\hline 245315.78 & 7568843,03 & 8,87 & 6,30 & 4,34 & 4,30 & 3,65 & 2,95 & 2,23 \\
\hline 245334,50 & 7568850,14 & 4,61 & 3,77 & 3,67 & 2,72 & 2,35 & 2,29 & 1,73 \\
\hline 245353,22 & 7568857,26 & 14,14 & 14,22 & 7.76 & 6,26 & 4,98 & 4,23 & $\mathbf{3 , 5 3}$ \\
\hline 245371.94 & 7568864,38 & 4,82 & 5,28 & 5,78 & 5,67 & 5,05 & 4,54 & 3,40 \\
\hline 245390,65 & 7568871,49 & 4,67 & 5,47 & 4,69 & 4,03 & 3,17 & 3.01 & 2,94 \\
\hline 245409,37 & 7568878,61 & 6,13 & 7,20 & 5,33 & $3,+3$ & 2,74 & 2,69 & 1,18 \\
\hline 245428,09 & 7568885,73 & 5,15 & 7,12 & 11,77 & 11,68 & 10,28 & 8.06 & 6,22 \\
\hline 245446,81 & 7568892,84 & 14,44 & 12,03 & 8,03 & 4,55 & 3,14 & 2,56 & 2,30 \\
\hline 245 & 7568899,96 & 4,23 & 8,04 & 6,90 & 4,85 & 3,39 & 3,31 & 2,81 \\
\hline & 7568907,08 & 6,80 & 4,38 & 3,83 & 3,48 & 3.08 & 2.69 & 1.16 \\
\hline 2.97 & 4.20 & 1,51 & 4,91 & 4,27 & 4,86 & 4,26 & 3,53 & 2,78 \\
\hline 245521,69 & 7568921,31 & 4,87 & 4,55 & 9,92 & 8,61 & 6,47 & 4,51 & 3,35 \\
\hline 245540,41 & 7568928,43 & 13.29 & 10,05 & 8,04 & B.12 & 6,51 & 5,48 & 3,95 \\
\hline 245559.13 & 7568935,55 & 15,33 & 16,65 & 11,76 & 9,97 & 8,45 & 5,97 & 6,53 \\
\hline 245577,85 & 7568942,66 & 3,13 & 9,93 & 7,54 & 5,65 & 3,26 & 3,05 & 3,10 \\
\hline 245596,56 & 7568949,78 & 10,82 & 9,86 & 6,87 & 6,45 & 7.44 & 7,16 & 5,28 \\
\hline 2451 & 7568 & 2.37 & 6,04 & 5,92 & 5,93 & 6,88 & 4,15 & 3,45 \\
\hline 245215,03 & 7568826,05 & 8,81 & 12,43 & 13,94 & 11,53 & 10,69 & 4,50 & 4,05 \\
\hline 245233,75 & 33,17 & 3,34 & 7,08 & 5,22 & 3,25 & 2,92 & 2,42 & 1,91 \\
\hline 245252,47 & 7568840.29 & 1,15 & 1,32 & 1,79 & 9,01 & 12,31 & 6,73 & 3,13 \\
\hline 245271,19 & 67,40 & 4,88 & 18,72 & 14,76 & 14,47 & 9,58 & 5.27 & 2,18 \\
\hline 245289,90 & 7568 & 8,56 & 12,55 & 8,44 & 6,75 & 5,92 & 3,80 & 3,23 \\
\hline 245308,62 & 61,64 & 9,14 & 10,87 & 5,80 & 4,91 & 3,75 & 3,26 & 2,83 \\
\hline 245327,34 & 3.75 & 9,95 & 12,02 & 8,06 & 5,97 & 4,87 & 4.34 & 3,81 \\
\hline 245346,06 & 75,87 & 9,66 & 8,69 & 5.42 & 3,82 & 2,79 & 1.91 & 1,47 \\
\hline 2453 & 756 & 9,10 & 8,71 & 9,31 & 6,00 & 4,12 & 3,47 & 2,08 \\
\hline 245383,50 & 7568890,10 & 5,16 & 7,87 & 6,71 & 4,66 & 3,49 & $\uparrow .41$ & 1,07 \\
\hline 245 & & 9,48 & 8,59 & 7,04 & 5,46 & 3,14 & 2,52 & 2,01 \\
\hline 245420,94 & 7568904,34 & 13,78 & 10,66 & 7,04 & 5,60 & 4,10 & 3,17 & 3,73 \\
\hline 245 & 7568 & 9,07 & 7,12 & 9,53 & 7.07 & 4,35 & 3,49 & 2,98 \\
\hline 245458.38 & 7568918,57 & 11,39 & 8,46 & 7,31 & 4,61 & 3,12 & 2,96 & 2,79 \\
\hline 245 & 5,69 & 10,98 & 10,87 & 12,58 & 7,07 & 6,39 & 4,90 & 4,03 \\
\hline 245495,81 & 7568932,81 & 7,57 & 8,91 & 6,57 & 4,12 & 4,07 & 3,76 & 3.22 \\
\hline & 9.92 & 12,50 & 7,94 & 6,33 & 7,80 & 8,80 & 8,91 & 7,14 \\
\hline 2456 & 7568947,04 & 7,85 & 2,91 & 2,48 & 2,87 & 2,33 & 2.34 & 1,68 \\
\hline & 7568954,16 & 15,45 & 16,88 & 11,00 & 7,76 & 5.55 & 3,77 & 3,56 \\
\hline 2455 & 7568961,27 & 18,91 & 13,94 & 11,12 & 12,96 & 9,89 & 8,60 & 4,91 \\
\hline 245589,41 & 7568968,39 & 14,13 & 12,75 & 8,97 & 19,43 & 8,28 & 7.04 & 5,01 \\
\hline 2451 & 756 & 1.47 & 1,90 & 4,66 & 3,69 & 3,68 & 3,39 & 2,63 \\
\hline 2451 & 7568 & 1,96 & 7,48 & 9,87 & 7,10 & 5,96 & 6,66 & 4,20 \\
\hline 2452 & 756 & 11,75 & 11,93 & 8,60 & 5,06 & 3,70 & 2,70 & 2.44 \\
\hline 245226,59 & 1,78 & 1,07 & 5,46 & 7.02 & 3.94 & 2.49 & 2,32 & 1,76 \\
\hline 245 & 3,90 & 2,69 & 4,95 & 8,77 & 6,94 & 4,66 & 3,66 & 2,09 \\
\hline 2452 & 756 & 5,23 & 7,96 & 12,23 & 10,03 & 10,66 & 18.46 & 10,16 \\
\hline 245 & 756 & 7,35 & 10.71 & 12,45 & 8,18 & 6,87 & 6,40 & 4,46 \\
\hline 2453 & 30,25 & 5,60 & 5,78 & 5,94 & 4,48 & 3,87 & 3.20 & 3,09 \\
\hline 2453 & 756 & 9,13 & 6,35 & 3,58 & 3,01 & 2,24 & 2.32 & 1,45 \\
\hline 245 & 4,48 & 8,08 & 5,89 & 4,70 & 4,02 & 4,42 & 3,97 & 1,67 \\
\hline 2453 & 1.60 & 10,68 & $\mathbf{9 , 5 4}$ & 6.71 & 3,39 & 2,07 & 1,92 & 1,67 \\
\hline 245376,35 & 7568 & 10,15 & 7,46 & 6,00 & 2,56 & 2,10 & 2.04 & 1,81 \\
\hline & & 13,60 & B,98 & 7,82 & 5,60 & 3,70 & 3,46 & 2,31 \\
\hline 245 & 75 & 14,99 & 13,69 & 12,46 & 12,58 & 14,13 & 7,94 & 6,99 \\
\hline & & 17,29 & 14,90 & 6,12 & 4,57 & 6,95 & 4,59 & 3,16 \\
\hline & 756 & 15,20 & 12,42 & 9,46 & 5,80 & 3,45 & 3.76 & 3,40 \\
\hline & & 14,64 & 11,67 & 10,10 & 8,53 & 7,25 & 6,59 & 5,43 \\
\hline & 756 & 11,56 & 8,10 & 7,40 & 7,38 & 7,18 & 6.95 & 6,67 \\
\hline & & 5.15 & 7,81 & 8,13 & 9,76 & 9,85 & 6,21 & 5,87 \\
\hline 245 & 7568965,65 & 7,70 & 5,10 & 8,89 & 6,70 & 4,95 & 3.07 & 1,35 \\
\hline & & 10,93 & 12,34 & 10,31 & 10,16 & 9,44 & 8,62 & 6,58 \\
\hline & 756 & 3.8 & 5,45 & 4,48 & 6,73 & 9,51 & 7,03 & 4,49 \\
\hline & & 4,25 & 6,93 & 6,18 & 7,84 & 5,26 & 4,50 & 3.52 \\
\hline & & 1.65 & 9,49 & 8,51 & 8,91 & 5,93 & 4,48 & 2,60 \\
\hline 72 & 363,27 & 1,67 & 10,67 & 10,04 & 8,68 & 6,13 & 4,31 & 2,65 \\
\hline 245 & 756 & 5,96 & 7,16 & 8.21 & 7,34 & 6,36 & 4,16 & 2,90 \\
\hline & 7.51 & 1,87 & 7,71 & 6,82 & 5,68 & 3,30 & 3,18 & 2.26 \\
\hline & & 2.79 & 7,13 & 6,22 & 9,96 & 7,81 & 6,39 & 5,88 \\
\hline 245 & 7568 & 3,31 & 8,91 & 8,62 & 6,5 & 4,95 & 3,71 & 2.88 \\
\hline & & 6.65 & 9.69 & 8,14 & 5.40 & 4,77 & 5,04 & 4,25 \\
\hline & & 2,65 & 6,56 & 7,13 & 4,90 & 2,77 & 2,53 & 1,40 \\
\hline & & 5,07 & 6,78 & 6,20 & 4,87 & 3,76 & 3.55 & 1,42 \\
\hline & & 6.46 & 9,19 & 3,46 & 4,37 & 7,72 & 8,36 & 3,63 \\
\hline & & 9,31 & 5,83 & 3,79 & 2,64 & 2,32 & 1,61 & 0,83 \\
\hline 387,91 & 38934,44 & 5,51 & 14,61 & 10,41 & 5,02 & 4,81 & 3,11 & 2,12 \\
\hline
\end{tabular}

Dados das coordenadas e do índice de cone de todos os pontos obtidos da área de Pirassununga (Cont.)

$\begin{array}{ccccccccc}\text { Latk) } & \text { (m) } & 0,10 & 0,15 & 0,20 & 0,25 & 0,30 & 0,35 & 0,40\end{array}$ $\begin{array}{lllllllll}245425,35 & 7568948,68 & 3,49 & 3,09 & 4,27 & 5.00 & 8,77 & 8,19 & 6,15\end{array}$ $\begin{array}{llllllllll}245444,07 & 7568955,79 & 14,91 & 15,55 & 11,51 & 12,79 & 8,84 & 6,81 & 2,07\end{array}$

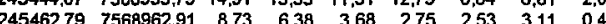

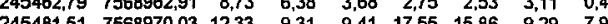
$\begin{array}{lllllllll}245481,51 & 7568970.03 & 12,33 & 9,31 & 9,41 & 17,55 & 15.06 & 9,29 & 7,95\end{array}$ $\begin{array}{llllllllll}245518,94 & 7568984,26 & 10,33 & 9,31 & 5,44 & 4,48 & 3,88 & 3,39 & 1,50\end{array}$ $\begin{array}{llllllllll}245537,66 & 7568991,38 & 6,28 & 10,69 & 3,63 & 6,36 & 6,40 & 7,04 & 8,41\end{array}$ $\begin{array}{lllllllll}245556,68 & 7568998,49 & \mathbf{1 5}, 14 & \mathbf{1 1 . 8 4} & \mathbf{7}, 37 & \mathbf{5}, 35 & \mathbf{3}, 74 & \mathbf{2} 59 & 1,95\end{array}$ $\begin{array}{lllllllll}245156,13 & 7568867,65 & 4,36 & 7,72 & 7,55 & 5,91 & 5,14 & 3,35 & 2,72\end{array}$ $\begin{array}{lllllllll}245156,13 & 7568867,65 & 4,36 & 7,72 & 7,55 & 5,91 & 5,14 & 3,35 & 2,72 \\ 245174,84 & 7568874,77 & 6,49 & 8,43 & 9,69 & 13,64 & 9,43 & 9,15 & 4,30\end{array}$ $\begin{array}{rllrrrrrr}245174,84 & 7568874,77 & \mathbf{6 , 4 9} & \mathbf{8 , 4 3} & \mathbf{9 , 6 9} & \mathbf{1 3 , 6 4} & \mathbf{9 , 4 3} & \mathbf{9 , 1 5} & 4,30 \\ \mathbf{2 4 5 1 9 3 , 5 6} & \mathbf{7 5 6 8 8 8 1 , 8 8} & \mathbf{4 , 4 9} & \mathbf{1 1 , 4 2} & \mathbf{8 , 1 6} & \mathbf{7 , 9 0} & \mathbf{8 , 4 3} & \mathbf{5 , 8 1} & 4,01\end{array}$ $\begin{array}{lllllllll}245212,28 & 7568889,00 & 6,72 & 11,50 & 10,90 & 8,29 & 7,81 & 6,69 & 4,09\end{array}$ $\begin{array}{lllllllll}245231,00 & 7568896,12 & 2,06 & 8,49 & 8,48 & 5,95 & 4,18 & 2,16 & 1,80\end{array}$

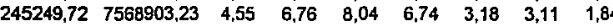
$\begin{array}{rrrrrrrrr}245268,44 & 7568910,35 & 10,12 & 11,05 & 8,47 & 5,07 & 3,16 & 2,24 & 1,46\end{array}$ $\begin{array}{lllllllll}245287,16 & 7568917,47 & 5,28 & 6,62 & 5,05 & 4,92 & 3,79 & 4,03 & 3,37\end{array}$ $\begin{array}{lllllllll}\mathbf{2 4 5 3 0 5 , 8 8} & \mathbf{7 5 6 8 9 2 4 , 5 8} & \mathbf{8 , 5 0} & 7,05 & 5,37 & \mathbf{5 , 1 8} & \mathbf{4 , 0 7} & 3,58 & \mathbf{3 , 4 2}\end{array}$ $\begin{array}{llllllllll}245324,60 & 7568931,70 & 3,38 & 7,93 & 8,64 & 4,47 & 5,40 & 4,60 & 2,36 \\ \mathbf{2} 45343,32 & 7568938,82 & 5,17 & 7,71 & 5,37 & 4,68 & 2,83 & 2,90 & 2,46\end{array}$ $\begin{array}{lllllllll}245362,04 & 7568945,93 & 7,15 & 5,34 & 3,64 & 2,59 & 2,59 & 2,76 & 1,70\end{array}$ $\begin{array}{lllllllll}245380,76 & 7568953,05 & 5,18 & 7,42 & 6,22 & 4,32 & 3,63 & 3,57 & 2,94\end{array}$ $\begin{array}{lllllllll}\mathbf{2 4 5 3 9 9 , 4 7} & \mathbf{7 5 6 8 9 6 0 , 1 7} & 10,43 & \mathbf{5 , 9 1} & \mathbf{4 , 5 5} & \mathbf{3 , 2 3} & \mathbf{2 , 4 7} & \mathbf{1 , 9 4} & 1,09\end{array}$ $\begin{array}{lllllllll}245418,19 & 7568967,28 & 10,46 & 10,26 & 9,10 & 7,95 & 7,10 & 6,94 & 5,36\end{array}$ $\begin{array}{rrrrrrrrr}245418,19 & 7568967,28 & 10,46 & 10,26 & 9,10 & 7,95 & 7,10 & 6,94 & 5,30 \\ \mathbf{2 4 5 4 3 6 , 9 1} & \mathbf{7 5 6 8 9 7 4 , 4 0} & \mathbf{3 , 5 8} & \mathbf{3 , 6 8} & \mathbf{3 , 8 0} & \mathbf{3}, 73 & 3,07 & \mathbf{3}, 13 & 3,00\end{array}$ $\begin{array}{rrrrrrrrr}245455,63 & \mathbf{7 5 6 9 9 8 4}, \mathbf{5 2} & \mathbf{1 5 , 9 0} & \mathbf{1 6 , 3 1} & \mathbf{1 7 , 5 8} & \mathbf{1 4 , 8 4} & 9,89 & \mathbf{8}, 56 & \mathbf{7 , 8 9}\end{array}$ $\begin{array}{rrrrrrrrr}245474,35 & 7568988,64 & 10,80 & 8,80 & 7,14 & 5,24 & 3,46 & 3,62 & 3,42\end{array}$ \begin{tabular}{rrrrrrrrr}
245493,07 & 7568995,75 & 5,18 & 9,02 & 10,54 & 6,28 & 2,55 & 1,46 & 1,42 \\
\hline
\end{tabular} $\begin{array}{llrrrrrrr}245511,79 & 7569002,87 & 14,47 & 12,54 & 6,28 & 4,21 & 2,86 & 2,48 & 1,90\end{array}$ $\begin{array}{llllllllll}245530,51 & 7569009,99 & 10,82 & 7,78 & 5,09 & 3,56 & 2,86 & 2,76 & 2,30\end{array}$ $\begin{array}{lllllllll}245148,97 & 7568886,26 & 7,70 & 7,46 & 9,54 & \mathbf{5 , 1 8} & 3,35 & 3,30 & 2,04 \\ \mathbf{2 4 5 1 6 7 , 6 9} & 7588893,38 & 1,71 & 3,55 & 9,78 & 7,00 & 6,69 & 5,81 & 4,11\end{array}$ $\begin{array}{llllllllll}\mathbf{2 4 5 1 6 7 , 6 9} & 7588893,38 & 1,71 & 3,55 & 9,78 & 7,00 & 6,69 & 5,81 & 4,11 \\ \mathbf{2 4 5 1 8 6 , 4 1} & \mathbf{7 5 6 8 9 0 0 , 4 9} & 5,64 & 8,09 & 6,99 & 4,67 & 3.01 & \mathbf{2 , 4 9} & 1,78\end{array}$ $\begin{array}{rlrrrrrrr}245186,41 & \mathbf{7 5 6 8 9 0 0 , 4 9} & 5,64 & 8,09 & 6,99 & \mathbf{4 , 6 7} & \mathbf{3 , 0 1} & \mathbf{2 , 4 9} & 1,78 \\ \mathbf{2 4 5 2 0 5 , 1 3} & \mathbf{7 5 6 8 9 0 7 , 6 1} & \mathbf{3 , 4 6} & \mathbf{1 0 , 9 7} & \mathbf{1 0 , 4 5} & \mathbf{1 3 , 5 7} & \mathbf{7 , 5 0} & \mathbf{6 , 3 7} & \mathbf{2 , 4 1}\end{array}$ $\begin{array}{llllllllll}245223,85 & 7568914,73 & 1,60 & 1,27 & 6,39 & 8,23 & 5,69 & 4,80 & 3,68\end{array}$ $\begin{array}{lllllllll}245242.57 & 7568921.84 & 10,38 & 9,30 & 7,66 & 6,77 & 4,03 & 2,53 & 1,62\end{array}$ $\begin{array}{llllllllll}\mathbf{2 4 5 2 6 1 , 2 9} & \mathbf{7 5 6 8 9 2 8 , 9 6} & \mathbf{1 , 2 2} & \mathbf{7 , 3 5} & \mathbf{8 , 8 0} & \mathbf{6 , 8 6} & \mathbf{7 , 7 4} & \mathbf{4 , 5 9} & \mathbf{2 , 7 3}\end{array}$ $\begin{array}{lllllllll}245280,01 & 7568936,08 & 12,95 & 11,22 & 5,96 & 5,06 & 4,56 & 4,11 & 3,66\end{array}$ $\begin{array}{lllllllll}245298,72 & 7568943,19 & 8,82 & 8,39 & 5,91 & 4,26 & 3,85 & 2,10 & 1,60\end{array}$ $\begin{array}{lllllllll}\mathbf{2 4 5 3 1 7 , 4 4} & \mathbf{7 5 6 8 9 5 0 , 3 1} & 12,87 & 9,37 & 5,52 & 3,94 & 3,03 & 3,48 & 2,34\end{array}$ $\begin{array}{lllllllll}245336,16 & 7568957,43 & 8,00 & 8,48 & 4,96 & 1,79 & 2,40 & 2,65 & 2,33\end{array}$ $\begin{array}{rlrlllllll}\mathbf{2 4 5 3 5 4 , 8 8} & \mathbf{7 5 6 8 9 6 4 , 5 4} & 10,56 & \mathbf{9 , 5 3} & \mathbf{6 , 7 6} & \mathbf{5 , 4 0} & \mathbf{3 , 4 0} & \mathbf{2 , 6 5} & \mathbf{2 , 3 3} \\ \mathbf{3}, 12 & \mathbf{2 , 6 9}\end{array}$ $\begin{array}{lllllllll}245354,88 & 7568964,54 & 10,56 & \mathbf{9 , 5 3} & \mathbf{6 , 7 6} & \mathbf{5 , 4 0} & \mathbf{3 , 8 0} & \mathbf{3 , 1 2} & 2,69 \\ \mathbf{2 4 5 3 7 3 , 6 0} & \mathbf{7 5 6 8 9 7 1 , 6 6} & 10,40 & \mathbf{7 , 0 9} & \mathbf{4 , 7 9} & \mathbf{3 , 8 9} & \mathbf{4 , 4 3} & \mathbf{2 , 4 9} & \mathbf{2 , 0 2}\end{array}$ $\begin{array}{rrrrrrrrrr}245373,60 & 7568971,66 & 10,40 & 7,09 & 4,79 & 3,89 & 4,43 & 2,49 & 2,02 \\ 245392,32 & 7568978,78 & 9,05 & 14,21 & 8,66 & 4,32 & 5,22 & \mathbf{4 , 2 7} & 2,23\end{array}$ $\begin{array}{rrrrrrrrr}245392,32 & 7568978,78 & 9,05 & 14,21 & 8,66 & 4,32 & 5,22 & 4,27 & 2,23 \\ 245411,04 & 7568985,89 & 7,45 & 12,05 & 11,26 & 12,66 & 12,34 & 10,28 & 7,03\end{array}$ $\begin{array}{rrrrrrrrr}245411,04 & 7568985,89 & 7,45 & 12,05 & 11,26 & 12,66 & 12,34 & 10,28 & 7,03 \\ 245429,76 & 7568993,01 & 15,00 & 8,32 & 7,76 & 4,85 & 3,29 & 2,90 & 2,34\end{array}$ $\begin{array}{rrrrrrrrr}245429,76 & 7568993,01 & 15,00 & 8,32 & 7,76 & 4,85 & 3,29 & 2,90 & 2,34 \\ 245448,46 & 7569000,13 & 6,52 & 7,33 & 6,12 & 3,97 & 3,47 & 3,32 & 3,11\end{array}$ $\begin{array}{llllllllll}245448,46 & 7569000,13 & 6,52 & 7,33 & 6,12 & 3,97 & 3,47 & 3,32 & 3,11 \\ \mathbf{2 4 5 4 6 7 , 2 0} & \mathbf{7 5 6 9 0 0 7 , 2 5} & \mathbf{6 , 4 6} & \mathbf{5 , 0 3} & \mathbf{4 , 1 1} & \mathbf{3 , 2 9} & \mathbf{3 , 5 6} & \mathbf{3 , 9 6} & 3,86\end{array}$ $\begin{array}{lllllllll}245485,92 & 7569014,36 & 13,80 & 10,73 & 7,90 & 5,70 & 5,61 & 3,59 & 2,77\end{array}$ $\begin{array}{lllllllll}\mathbf{2 4 5 5 0 4 , 6 3} & \mathbf{7 5 6 9 0 2 1 , 4 8} & 11,78 & \mathbf{7 , 9 2} & \mathbf{5 , 2 5} & \mathbf{5 , 3 0} & \mathbf{4 , 7 6} & \mathbf{4 , 2 4} & \mathbf{2 , 6 6}\end{array}$ $\begin{array}{lllllllll}245141,82 & 7568904,87 & 2,19 & 2,16 & 3,72 & 4,35 & 3,21 & 8,47 & 3,44\end{array}$

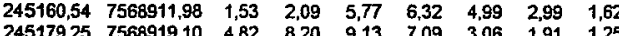
$\begin{array}{rlllllllll}245197,97 & 7588926,22 & \mathbf{8 , 1 5} & \mathbf{1 1 , 1 6} & \mathbf{1 0 , 3 1} & \mathbf{9 , 4 3} & \mathbf{6 , 7 6} & \mathbf{6 , 5 4} & \mathbf{3 , 7 2}\end{array}$ $\begin{array}{llllllllll}245216,69 & 7568933,34 & 2,54 & 7,16 & 14,86 & 11,64 & 7,49 & 6,50 & 3,57\end{array}$ $\begin{array}{lllllllll}245235,41 & 7568940,45 & 3,16 & 5,70 & 8,44 & 7,77 & 5,97 & 4,64 & 2,06\end{array}$ $\begin{array}{lllllllll}\mathbf{2 4 5 2 5 4 , 1 3} & \mathbf{7 5 6 8 9 4 7 , 5 7} & \mathbf{9 , 7 4} & \mathbf{9 , 6 1} & \mathbf{4 , 3 5} & \mathbf{4 , 6 8} & 3,94 & 2,62 & 1,93\end{array}$ $\begin{array}{rllllllll}245272,85 & 7568954,69 & 7,16 & 8,30 & 7,90 & 4,28 & 3,37 & 2,37 & 1,54\end{array}$ $\begin{array}{lllllllllllll}245291,57 & 756891,80 & 2,43 & 9,62 & 10,06 & 7,43 & 5,61 & 5,03\end{array}$ $\begin{array}{llllllllll}245310,29 & 756808,92 & 7,23 & 6,18 & 4,72 & 4,09 & 3,06 & 2,24 & 1,68\end{array}$ $\begin{array}{llllllllll}245329,01 & 7568976,04 & 6,27 & 5.00 & 3,22 & 2.10 & 1,76 & 1,66 & 1,02\end{array}$ $\begin{array}{llllllllll}245347,73 & 7568983,15 & 2,67 & 7,54 & 8,19 & 3,96 & 7,34 & 7,00 & 4,39 \\ \mathbf{2 4 5 3 6 6 , 4 5} & 7568990,27 & 2,99 & 8,34 & 5,69 & 4,97 & 3,21 & 3,06 & 1,51\end{array}$ $\begin{array}{lllrllllll}245385,17 & 7568997,39 & 13,01 & 11,70 & 8,03 & 6,96 & 5,02 & 3,70 & 3,01\end{array}$ $\begin{array}{lllllllll}245403,88 & 7569004,51 & 10,35 & 8,95 & 7,65 & 4,06 & \mathbf{2 , 1 8} & \mathbf{1 , 8 3} & 1,61\end{array}$ $\begin{array}{lllllllll}245422,60 & 7569011,62 & 16,58 & 10,29 & 5,81 & 3,06 & 2,18 & 1,83 & 1,61 \\ & \mathbf{7} & \mathbf{2}, 91 & \mathbf{2 3 8} & 1,81\end{array}$ $\begin{array}{rrrrrrrrr}245422,60 & 7569011,62 & 16,58 & 10,29 & 5,81 & 3,16 & 2,91 & 2,38 & 1,81 \\ 245441,32 & 7569018,74 & 9,48 & 6,28 & 3,38 & 3,04 & 4,35 & 3,31 & 2,38\end{array}$ $\begin{array}{rrrrrrrrrr}\mathbf{2 4 5 4 4 1 , 3 2} & \mathbf{7 5 6 9 0 1 8 , 7 4} & \mathbf{9 , 4 8} & \mathbf{6 , 2 8} & \mathbf{3 , 3 8} & \mathbf{3 , 0 4} & \mathbf{4 , 3 5} & \mathbf{3 , 3 1} & \mathbf{2 , 3 8} \\ \mathbf{2 4 5 4 6 0 , 0 4} & \mathbf{7 5 6 9 0 2 5 , 8 6} & \mathbf{1 3 , 8 9} & \mathbf{1 1 , 1 0} & \mathbf{9 , 0 6} & \mathbf{5 , 4 0} & \mathbf{4 , 4 2} & 3,84 & \mathbf{2 , 7 5}\end{array}$ $\begin{array}{llllllllll}245478,76 & 7569032,97 & 7,39 & 8.79 & 9,19 & 4,17 & 2,77 & 2,30 & 1,54\end{array}$ $\begin{array}{lllllllll}245134,66 & 7568923,48 & 1,27 & 7,33 & 7,43 & 7,08 & 3,51 & 2,58 & 1,66\end{array}$ $\begin{array}{llllllllll}\mathbf{2 4 5 1 5 3 , 3 8} & \mathbf{7 5 6 8 9 3 0 , 5 9} & \mathbf{1 , 4 4} & \mathbf{5 , 8 8} & \mathbf{6 , 9 1} & \mathbf{5 , 9 4} & \mathbf{4 , 8 7} & \mathbf{3 , 5 2} & \mathbf{2 , 4 5}\end{array}$

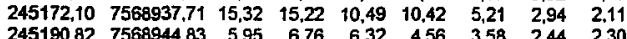
$\begin{array}{llllllllll}245190,82 & 7568944,83 & 5,95 & 6,76 & 6,32 & 4,56 & 3,58 & 2,44 & 2,30\end{array}$ $\begin{array}{lllllllll}245209,54 & 7568951,95 & 3,13 & 8,01 & 8,42 & 5,65 & 5,00 & 3,13 & 2,05\end{array}$ $\begin{array}{lllllllll}245228,26 & 7568959,08 & 3,99 & 11,88 & 8,30 & 6,90 & 4,24 & 3,00 & 2,06\end{array}$ $\begin{array}{llllllllll}245246,98 & 7568966,18 & 4,3 \dagger & 8,90 & 7,02 & 5,22 & 4,28 & 3,76 & 3,30\end{array}$ \begin{tabular}{lllllllll}
245284,41 & 7568980,41 & 8,03 & 8,86 & 7,41 & 7,08 & 4,21 & 3,72 & 2,87 \\
\hline
\end{tabular} $\begin{array}{lllllllll}245284,41 & 756890,41 & 8,03 & 8,86 & 7,53 & 5,66 & 4,80 & 4,60 & 3,07\end{array}$ $\begin{array}{llllllllll}245303,13 & 7568987,53 & 7,07 & 5,75 & 3,48 & 2,64 & 1,84 & 1,87 & 1,1\end{array}$ $\begin{array}{lllrlllll}245321,85 & 7558994,65 & 9,36 & 10,20 & 7,87 & 4,44 & 3,03 & 2,54 & 1,96\end{array}$ $\begin{array}{llllllllll}245340,57 & 7569001,76 & 9.68 & 5.39 & 3,70 & 6.89 & 7,93 & 7.18 & 3,01\end{array}$ $\begin{array}{lllllllll}245359,29 & 7569008,88 & 8,52 & 4,19 & 3,41 & 3,01 & 2,42 & 1,44 & 0,58\end{array}$ $\begin{array}{lllllllll}245378,01 & 7569016,00 & 7,57 & 5,80 & 4,03 & 3,43 & 1,39 & 2,12 & 0,57\end{array}$ $\begin{array}{lllllllll}245396,73 & 7569023,11 & 11,29 & 9,75 & 8,41 & 5.43 & 3,87 & 2,34 & 1,83\end{array}$ $\begin{array}{lllllllll}245415,45 & 7569030,23 & 14,90 & 8,46 & 4,52 & 3,05 & 2,67 & 2,57 & 1,43\end{array}$ $\begin{array}{rrrrrrrrr}245434,17 & 7569037,35 & 0,86 & 5,08 & 5,44 & 4,73 & 3,50 & 2,87 & 2,71\end{array}$ \begin{tabular}{rrrrrrrrr}
245452,89 & 7569044,47 & 13.93 & 15,88 & 10,62 & 7,69 & 4,71 & 3,75 & 3,44 \\
$\mathbf{2 4 5 1 2 7 , 5 1}$ & $\mathbf{7 5 6 8 9 4 2 , 0 9}$ & 2,65 & $\mathbf{8 , 1 8}$ & 8,66 & 8,21 & 6,89 & 5,17 & 2,90 \\
\hline
\end{tabular} 
Dados das coordenadas e do indice de cone de todos os pontos obtidos da área de Pirassununga (Cont.)

\begin{tabular}{|c|c|c|c|c|c|c|c|c|}
\hline \multirow{2}{*}{$\begin{array}{l}\text { Laffitudo } \\
\text { (m) }\end{array}$} & \multicolumn{3}{|c|}{ Longitude ndidades (m) } & & & & & \\
\hline & & & & & & & & \\
\hline & 68949,20 & 2,91 & 5,44 & 3,09 & 7,05 & 3,99 & 2.92 & 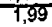 \\
\hline & 6,32 & 39 & 7,15 & 6,66 & 4,24 & & & \\
\hline & & 62 & 2,25 & 6,53 & B, 03 & 7.92 & 04 & \\
\hline & & 31 & 6,70 & 7,52 & 0.09 & & & \\
\hline &, 67 & 2,32 & 9,34 & 9,60 & 7,04 & 4,70 & & \\
\hline & & 95 & 8,04 & 4,81 & 02 & & & \\
\hline & & 6.11 & 4.75 & 4,94 & 4.40 & 2,79 & & \\
\hline & & 7,69 & 7,16 & 5,99 & 4,99 & 4,78 & & \\
\hline & 14 & 12,95 & 11,19 & 7,17 & 5,11 & 3,98 & & \\
\hline & & 12.32 & 2,00 & 1,77 & & & & \\
\hline & & 8,99 & 1,67 & 7,90 & 8,10 & 10,59 & & \\
\hline & & 7,07 & 8,27 & 5,18 & 3,46 & 45 & & \\
\hline & & 5,99 & 7,28 & 7,80 & 12,56 & & & \\
\hline & & 2,59 & 4,67 & 3,72 & 36 & & & \\
\hline & & 1,07 & 2,46 & 3,40 & $7 ?$ & & & \\
\hline & & 2.92 & 2,49 & 1,91 & 1,75 & & & \\
\hline & & & 8,09 & 8,24 & 6,05 & & & \\
\hline & & 2,89 & 5,79 & 7,58 & 8,43 & & & \\
\hline & & 1,22 & 6,93 & 7,91 & & & & \\
\hline & & 5,73 & 11,38 & 35 & & & & \\
\hline & & 5,48 & 5.03 & & & & & \\
\hline & & 1.19 & 1,91 & & & & & \\
\hline & & 5,23 & 6,05 & 7,61 & 5,19 & & & \\
\hline & & 1,87 & & 5,07 & & & & \\
\hline & & 4,60 & 8,22 & 11,18 & 13,00 & & & \\
\hline & & 5.75 & 8,95 & 4,37 & & & & \\
\hline & 75 & 12.66 & 11.06 & 13,36 & 10,04 & & & \\
\hline & & 5,40 & 6,58 & 4,49 & & & & \\
\hline & & 1,04 & 50 & 6,80 & & & & \\
\hline & & 5.14 & & & & & & \\
\hline & & 6,87 & & 3,92 & & & & \\
\hline & & 7,43 & 4,89 & 3,96 & & & & \\
\hline & & 4,1 & 4.24 & 4,21 & & & & \\
\hline & & & 4,46 & 3,63 & & & & \\
\hline & & $\mathbf{9}, 53$ & 10,96 & 8,72 & & & & \\
\hline & & 2,64 & 4.23 & 7,38 & 6 & & & 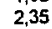 \\
\hline & & 2,49 & 38 & & & & & \\
\hline & & 6,15 & 5,98 & 03 & & & & \\
\hline & & & & & & & & \\
\hline & & 44 & 56 & 9,19 & & & & \\
\hline & & & & & & & & \\
\hline & & & & & & & & \\
\hline & & & & & & & & \\
\hline & & 5. & 4,11 & 3,08 & & & & \\
\hline & & & & & & & & \\
\hline & & 6,95 & 6,94 & & & & & \\
\hline & & & & & & & & \\
\hline & & & & & & & & \\
\hline & & & & & & & & \\
\hline & & & & & & & & \\
\hline & & .47 & & & & & & \\
\hline & & 3,19 & & & & & & \\
\hline & & & & 20 & & & & 1 \\
\hline & & & & & & & & \\
\hline & & & & & & & & 1.0 \\
\hline & & & & & & & & \\
\hline & & & & & & & & \\
\hline & & & & & & & & \\
\hline & & & & & & & & \\
\hline & & & & & & & & \\
\hline & & & & & & & & \\
\hline & & & & & & & & \\
\hline & & & & & & & & \\
\hline & & & & & & & & \\
\hline & & & & & & & & \\
\hline & & & & & & & & \\
\hline & & & & & & & & \\
\hline & & & & & & & & \\
\hline & & & & & & & & \\
\hline & & & & & & & & \\
\hline & & & & & & & & \\
\hline & & & & & & & & \\
\hline & & & & & & & & \\
\hline & & in, & & & & & & \\
\hline & & & & & & & & \\
\hline & & & & & & & & \\
\hline & & & & & & & & \\
\hline & & & & & & & & \\
\hline & & & 11 & & & & & \\
\hline & & & & & & & & \\
\hline & & & & & & & & \\
\hline & & & & & & & & \\
\hline & & & & & & & & 2,3 \\
\hline & & & & & & 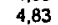 & a & \\
\hline
\end{tabular}


Dados das coordenadas e do índice de cone de todos os 150 pontos antes da irrigaçăo pelo pivo central obtidos da área de Pirassununga.

\begin{tabular}{|c|c|c|c|c|c|c|c|}
\hline $\begin{array}{l}\text { atifude } \\
\text { (m) }\end{array}$ & ongituda & & & rof & $\mathrm{da}$ & & \\
\hline 5260,70 & $(m)$ & 3,00 & 43 & $\frac{0,20}{70,5}$ & 0,25 & $\frac{0,30}{5,49}$ & 9 \\
\hline & & & 1,38 & 4,66 & & & \\
\hline & & & & 4,73 & 9,45 & 8,46 & \\
\hline & & & & & & & \\
\hline & & & & & & & \\
\hline & & & & & & & \\
\hline & & & 9,72 & 9,24 & $6,5 t$ & 5,69 & 38 \\
\hline & & & 7,32 & 8,63 & & & $2 \boldsymbol{E}$ \\
\hline & & 3,16 & $\gamma$ & 11,80 & 10,50 & 11,00 & 38 \\
\hline & & & 5,70 & 8,20 & 7,34 & 0,36 & \\
\hline & & & 5,40 & 6,75 & 4,62 & 68 & 6,59 \\
\hline & 75 & & 3,56 & 6,99 & 6,19 & 5,03 & 3,33 \\
\hline & & & 7,69 & 7,75 & 3,20 & & \\
\hline & & & 4,39 & 6,77 & 55 & & \\
\hline & & & & & & & \\
\hline & & & 7,85 & 8,10 & 5,85 & 83 & 65 \\
\hline & & & 6,17 & 6,12 & 5,04 & & 18 \\
\hline & & 1,18 & 55 & 9,45 & 7,88 & & 33 \\
\hline & & & 11,96 & 6.19 & 4,05 & 52 & 2,18 \\
\hline & & 08 & 7,76 & 7,96 & 7,94 & & 3,41 \\
\hline & & 6,7 & 4,36 & 201 & 2,45 & 1,83 & 1,91 \\
\hline & & $0 \approx$ & 1,86 & & $\overline{7,38}$ & & \\
\hline & & & 4,44 & 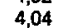 & & & \\
\hline & & & 4 & & 6 & & \\
\hline & & 2,8 & 10 & 7,3 & 8,13 & 4 & 02 \\
\hline & & 4,6 & 9,4 & 6,17 & 4,08 & & 99 \\
\hline & & $i_{1}$ & 3 & 6,16 & 3,95 & 2,45 & 11 \\
\hline & & & 1,68 & 8,20 & 9,84 & 5,53 & 46 \\
\hline & & 78 & 14,20 & 12,10 & 8,06 & 10,67 & 1,42 \\
\hline & & 1,36 & 1,93 & 5,53 & 7,00 & 6,85 & 5,2 \\
\hline & & $7-1$ & 587 & & & & \\
\hline & & 4 & & is & & & \\
\hline & & & & 9,08 & & & \\
\hline & & & 17,63 & 14,19 & 9,47 & 8,14 & 08 \\
\hline & & & 6,04 & 5,92 & 5,93 & 6,88 & 15 \\
\hline & & & 2,43 & 13,94 & 11,53 & 10,69 & 50 \\
\hline & & 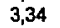 & 7,08 & 5,22 & 3,25 & 2,92 & 2,42 \\
\hline & & 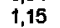 & 1, & & & &  \\
\hline & & 4 & 18,72 & 14,76 & 14,47 & 9 & \\
\hline & & 8 & 12,55 & & 6,75 & & \\
\hline & & & & 4 & & & \\
\hline & & & & 9,87 & & & 6 \\
\hline & & & 11,93 & 8,60 & 5,06 & & 2 \\
\hline & & & 5,46 & 7,02 & 3,94 & & 2 \\
\hline & & & 4 & 8,77 & & & \\
\hline & & 5,23 & 7,96 & 12,23 & 10,03 & & \\
\hline & & & & & & & \\
\hline & & & & & & & \\
\hline & & & & & & & \\
\hline & & & & & & & \\
\hline & & & 10 & 10, & & & \\
\hline & & & & & & & \\
\hline & & 1,8 & 7 & & & & \\
\hline & & & 7 & & & & \\
\hline & & & & & & & \\
\hline & & & & & & & \\
\hline & & & & & & & \\
\hline & & & & & & & \\
\hline & & & & & & & \\
\hline & & & & & & & \\
\hline & & & & & & & \\
\hline & & & 6,76 & & & & \\
\hline & & & & & & & \\
\hline & & & & & & & \\
\hline & & & & & & & \\
\hline & & & & & & & \\
\hline & & & & & & & \\
\hline & & & & & & & \\
\hline & & & & & & & \\
\hline & & & & & & & \\
\hline & & & & & & & \\
\hline & & & & & & & \\
\hline & & & & & & & \\
\hline & & & & & & & \\
\hline & & & & & & & \\
\hline & & & & & & & \\
\hline & & & & & & & \\
\hline & & & & & & & \\
\hline & & & & & & & \\
\hline & & & & & & & \\
\hline & & & & & & & \\
\hline & & & & & & & 3,5 \\
\hline & & & & & & & \\
\hline & & & & & & & \\
\hline & & & & 42 & 5 & & 3 \\
\hline & & 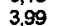 & 100 & & & & 3 \\
\hline & & & & & & & $=$ \\
\hline & & & & & & & 3,7 \\
\hline & & & & & 66 & 4,80 & 4 \\
\hline & & & & 00 & 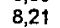 & 09 & \\
\hline
\end{tabular}

Dados das coordenadas e do indice de cone de todos os 150 pontos antes da irrigaçáo pelo pivó central obtidos da área de Pirassununga (Cont.)

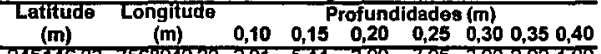
245146,23 7568949,20 2,97 5,44 3,09 7,05 3,99 2,92 1,99 $\begin{array}{lllllllll}245164,95 & 7568956,32 & 2,39 & 7,15 & 6,66 & \mathbf{4 , 2 4} & 2,71 & 1,95 & 1,88 \\ 245183,66 & 7568963,44 & 1,62 & 2,25 & 6,53 & \mathbf{8 , 0 3} & 7,92 & 6,04 & 4,08\end{array}$ $\begin{array}{lllllllllll}245202,38 & 7568970,56 & 10,31 & 6,70 & 7,52 & 10,09 & 6,48 & 4,14 & 2,61\end{array}$ $\begin{array}{lllllllll}245221,10 & 7568977,67 & 2,32 & 9,34 & 9,60 & 7,04 & 4,70 & 3,88 & 2,79\end{array}$ $\begin{array}{lllllllll}245239,82 & 7568984,79 & 10,95 & 8,04 & 4,81 & 8,02 & 5,80 & 4,37 & 3,01\end{array}$

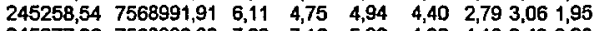
$\begin{array}{lllllllll}245277,26 & 7568999,02 & 7,69 & 7,16 & 5,99 & 4,99 & 4,18 & 3,43 & 2,90\end{array}$ $\begin{array}{lllllllll}245101,63 & 7568953,58 & 4,44 & 8,09 & 8,24 & 6,05 & 3,85 & 2,76 & 1,70\end{array}$ $\begin{array}{lllllllll}245101,63 & 7568953,58 & 4,44 & \mathbf{8 , 0 9} & \mathbf{8 , 2 4} & \mathbf{6 , 0 5} & \mathbf{3 , 8 5} & \mathbf{2}, 76 & 1,70 \\ \mathbf{2 4 5 1 2 0 , 3 5} & 7568960,70 & \mathbf{2 , 8 9} & \mathbf{5 , 7 9} & \mathbf{7 , 5 8} & \mathbf{8 , 4 3} & 1,84 & \mathbf{2}, 05 & 3,55\end{array}$ $\begin{array}{lllllllll}245120,35 & 7568960,70 & 2,89 & 5,79 & 7,58 & 8,43 & 1,84 & 2,05 & 3,55 \\ 245139,07 & 7568967,81 & 1,22 & 6,93 & 7,91 & 5,77 & 5,76 & 3,22 & 1,91\end{array}$ $\begin{array}{ccccccccc}245139,07 & 7568967,81 & 1,22 & 6,93 & 7,91 & 5,77 & 5,76 & 3,22 & 1,91 \\ 245157,79 & 7568974,93 & 15,73 & 11,38 & 10,35 & 8,75 & 5,87 & 4,04 & 3,01\end{array}$ $\begin{array}{lllllllll}245157,79 & 7568974,93 & 15,73 & 11,38 & 10,35 & 8,75 & 5,87 & 4,04 & 3,01 \\ 245176,51 & 7568982,05 & 5,48 & 15,03 & 13,24 & 9,94 & 7,96 & 5,38 & 3,07\end{array}$ $\begin{array}{lllllllll}245176,51 & 7568982,05 & 5,48 & 15,03 & 13,24 & 9,94 & 7,96 & 5,38 & 3,07 \\ 245195,23 & 7568989,17 & 1,19 & 1,91 & 2,96 & 4,93 & 7,35 & 5,83 & 1,97\end{array}$ $\begin{array}{lllllllll}245213,95 & 7568996,28 & 5,23 & 6,05 & 7,61 & 5,19 & 3,44 & 2,23 & 1,04\end{array}$ $\begin{array}{llllllllll}245232,67 & 7569003,40 & 1,87 & 3,06 & 5,07 & 4,02 & 4,41 & 1,01 & 1,38\end{array}$ $\begin{array}{llllllllll}245251,39 & 7569010,52 & 4,60 & 8,22 & 11,18 & 13,00 & 8,50 & 6,33 & 2,97\end{array}$ $\begin{array}{lllllllll}245270,11 & 7569017,63 & 5,75 & 8,95 & 4,37 & 3,52 & 2,72 & 1,42 & 1,37\end{array}$ $\begin{array}{lllllllll}245094,48 & 7568972,19 & 2,27 & 4,46 & 3,63 & 3,28 & 3,22 & 2,80 & 1,99\end{array}$ $\begin{array}{lllllllll}245113,20 & 7568979,31 & 9,53 & 10,96 & 8,72 & 5,19 & 3,84 & 1,47 & 1,03\end{array}$ $\begin{array}{lllllllll}245131,92 & 7568986,43 & 2,64 & 4,23 & 7,38 & 6,09 & 5,15 & 3,18 & 2,35 \\ 245150,64 & 7568993,54 & 2,49 & 5,38 & 8,41 & 6,88 & 5,17 & 6,30 & 3,35\end{array}$

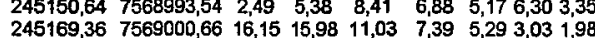
$\begin{array}{lllllllll}245169,36 & 7569000,66 & 16,15 & 15,98 & 11,03 & 7,39 & 5,29 & 3,03 & 1,98 \\ 245188,07 & 7569007,78 & 10,08 & 10,33 & 8,36 & 5,76 & 6,20 & 6,73 & 3,82\end{array}$ $\begin{array}{lllllllllll}245206,79 & 7569014,89 & 11,44 & 12,56 & 9,19 & 4,63 & 5,37 & 4,47 & 2,77\end{array}$ $\begin{array}{lllllllllllll}245225,51 & 7569022,01 & 4,56 & 11,04 & 15,30 & 10,38 & 3,69 & 2,43 & 1,58\end{array}$

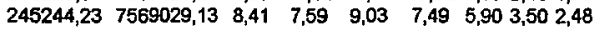
$\begin{array}{lllllllll}245262,95 & 7569036,24 & 6,64 & 3,78 & 2,73 & 1,62 & 1,27 & 1,23 & 0,53\end{array}$

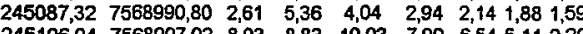

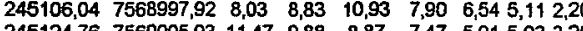
$\begin{array}{llllllllll}245124,76 & 7569005,03 & 11,47 & 9,88 & 8,87 & 7,47 & 5,91 & 5,03 & 3,26\end{array}$ $\begin{array}{llllllllll}245143,48 & 7569012,15 & 3,19 & 8,95 & 8,48 & 7,02 & 5,86 & 4,37 & 2,36\end{array}$ $\begin{array}{llllllllll}245162,20 & 7569019,27 & 8,14 & 9,66 & 10,20 & 9,72 & 5,82 & 5,15 & 2,17\end{array}$ $\begin{array}{lllllllll}245180,92 & 7569026,39 & 4,12 & 13,72 & 12,03 & 8,03 & 6,19 & 3,67 & 2,80\end{array}$ $\begin{array}{lllllllll}245199,64 & 7669033,60 & 11,63 & 9,05 & 5,85 & 4,84 & 3,53 & 3,27 & 2,05\end{array}$

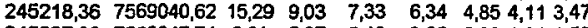
$\begin{array}{llllllllll}245237,08 & 7569047,74 & 6,61 & 5,97 & 5,18 & 3,66 & 2,38 & 1,81 & 1,55\end{array}$

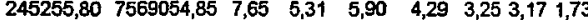
$\begin{array}{lllllllll}245080,17 & 7569009,41 & 0,85 & 3,90 & 4,26 & 3,83 & 2,78 & 1,78 & 1,00\end{array}$ $\begin{array}{lllllllll}245098,89 & 7569016,53 & 7,70 & 11,50 & 8,80 & 6,20 & 6,58 & 5,45 & 2,20\end{array}$ $\begin{array}{lllllllllll}245117,61 & 7569023,64 & 2,18 & 4,54 & 6,94 & 4,92 & 6,55 & 4,73 & 2,65\end{array}$ $\begin{array}{lllllllll}245136,33 & 7569030,76 & 9,41 & 7,62 & \mathbf{8}, 90 & \mathbf{7}, 92 & 6,55 & 4,73 & 2,65 \\ \mathbf{2 4}, 30 & \mathbf{5}, 00 & 2,36\end{array}$ $\begin{array}{lllllllll}245136,33 & 7569030,76 & 9,41 & 7,62 & 8,90 & 7,09 & 6,30 & 5,00 & 2,36 \\ 245155,05 & 7569037,88 & 9,77 & 11,12 & 10,96 & 9,39 & 6,17 & 3,77 & 1,49\end{array}$

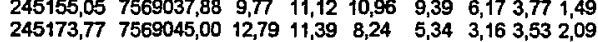
$\begin{array}{llllllllll}245192,48 & 7569052,11 & 5,57 & 12,72 & 6,81 & 5,66 & 3,79 & 3,05 & 2,64\end{array}$ $\begin{array}{llllllllll}245211,20 & 7569059,23 & 13,12 & 11,30 & 7,72 & 6,12 & 4,36 & 4,59 & 3,43\end{array}$ $\begin{array}{llllllllll}245229,92 & 7569066,35 & 6,67 & 14,26 & 12,53 & 8,89 & 5,40 & 3,63 & 2,51\end{array}$

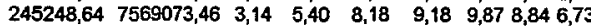
$\begin{array}{lllllllll}245054,30 & 7569020,90 & 3,95 & 6,18 & 4,24 & 3,34 & 4,27 & 3,69 & 1,82\end{array}$ $\begin{array}{lllllllll}245073,01 & 7569028,02 & 3,92 & 4,48 & 2,16 & 1,59 & 1,16 & 1,13 & 0,96\end{array}$ $245091,73 \quad 7569035,14 \quad 9,95 \quad 8,21 \quad 6,94 \quad 4,02 \quad 2,711,911,46$ $\begin{array}{lllllllll}245091,73 & 756903,14 & 9,95 & 8,21 & 6,94 & 4,02 & 2,71 & 1,91 & 1,46 \\ 245248,64 & \mathbf{7 5 6 9 0 7 3 , 4 6} & 3,14 & \mathbf{5 , 4 0} & \mathbf{8 , 1 8} & \mathbf{9 , 1 8} & \mathbf{9 , 8 7} & \mathbf{8}, 84 & 6,73\end{array}$

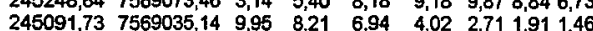
$\begin{array}{lllllllll}245091,73 & 7569035,14 & 9,95 & 8,21 & \mathbf{6 , 9 4} & \mathbf{4 , 0 2} & \mathbf{2 , 7 1} & \mathbf{1 , 9 1} & 1,46 \\ \mathbf{2 4 5 1 1 0 , 4 5} & \mathbf{7 5 6 9 0 4 2 , 2 5} & \mathbf{3 , 4 1} & \mathbf{7 , 4 3} & \mathbf{8 , 3 5} & \mathbf{5 , 6 2} & \mathbf{4 , 3 0} & \mathbf{3}, 25 & \mathbf{2}, 16\end{array}$

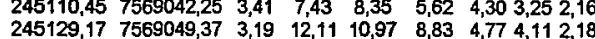
$\begin{array}{lllllllll}245129,17 & 7569049,37 & 3,19 & 12,11 & 10,97 & 8,83 & 4,77 & 4,11 & 2,18 \\ 245147,89 & 7569056,49 & 10,39 & 8,56 & 7,80 & 5,58 & 3,56 & 2,40 & 1,67\end{array}$ $\begin{array}{llllllllll}245166,61 & 7569063,61 & 5,38 & 7,67 & 5,17 & 3,79 & 3,66 & 1,85 & 1,72\end{array}$ $\begin{array}{llllllllll}245185,33 & 7569070,72 & 10,64 & 7,78 & \mathbf{5 , 4 4} & \mathbf{3}, 74 & \mathbf{3}, 07 & \mathbf{2}, 80 & \mathbf{2}, 39\end{array}$

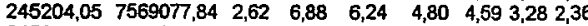
$\begin{array}{lllllllll}245222,77 & 7569084,96 & 14,15 & 11,07 & 8,28 & 6,44 & 4,83 & 3,92 & 2,14\end{array}$ 
Dados das coordenadas e do índice de cone de todos os 150 pontos apos a irrigaçăo pelo pivó central obtidos da área de Pirassununga.

\section{Latitưde Longitude Profundidades (m)}

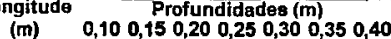
(m) $\quad(m) \quad 0,100,150,200,250,300,350,40$

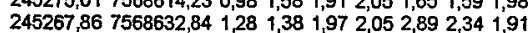
$\begin{array}{lllllllll}245267,86 & 7568632,84 & 1,28 & 1,38 & 1,97 & 2,05 & 2,89 & 2,34 & 1,91 \\ 245260,70 & 7568651,44 & 1,51 & 1,20 & 1,36 & 2,56 & 1,75 & 1,78 & 1,69\end{array}$ $\begin{array}{lllllllll}245260,70 & 7568651,44 & 1,51 & 1,20 & 1,36 & 2,56 & 1,75 & 1,78 & 1,69 \\ 245279,42 & 7568658,56 & 0,58 & 1,15 & 1,68 & 1,49 & 1,77 & 1,99 & 1,69\end{array}$ $\begin{array}{llllllllll}245279,42 & 7568658,56 & 0,68 & 1,15 & 1,68 & 1,49 & 1,77 & 1,99 & 1,69 \\ 245253,55 & 7568670,06 & 0,93 & 1,68 & 1,46 & 3,03 & 1,67 & 1,77 & 1,90\end{array}$ $245272,27 \quad 7568677,17 \quad 1,311,442,47 \quad 2,123,292,262,89$ $245246,397568688,670,992,013,071,381,201,511,64$ $\begin{array}{lllllllll}245265,11 & 7568695,78 & 2,63 & 2,72 & 1,95 & 2,47 & 1,67 & 1,53 & 1,49\end{array}$

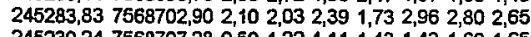

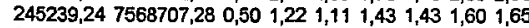
$245257,967568714,391,702,642,163,734,323,392,20$

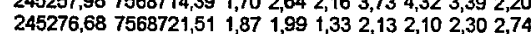
$245232,087568725,881,021,430,862,291,380,981,16$ $245250,80 \quad 7568733,0000,68 \quad 1,13 \quad 1,72 \quad 2,00 \quad 1,45 \quad 1,331,35$


245288,24 7568747,24 1,14 1,50 1,70 2,08 2,13 3,80 4,29 $245224,93 \quad 7568744,491,36 \quad 1,631,58 \quad 1,891,46 \quad 1,401,35$ $245243,65 \quad 7568751,61 \quad 1,54 \quad 1,52 \quad 2,491,911,73 \quad 1,94 \quad 1,97$ $\begin{array}{lllllllll}245262,37 & 7568758,73 & 1,04 & 2,48 & 2,24 & 2,20 & 2,20 & 2,07 & 3,19\end{array}$ $2452817,777568763,110,841,871,671,431,631,531,45$

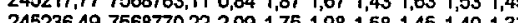
(1, 1,33 $245255,21 \quad 7568777,34 \quad 2,342,13 \quad 1,73 \quad 1,45 \quad 1,47 \quad 1,291,44$ $245273,937568784,461,881,771,261,151,191,351,66$

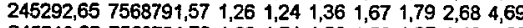
$245210,627568781,721,691,711,581,53 \quad 1,27 \quad 1,42 \quad 1,68$ $245229,347568788,830,690,84 \quad 1,541,070,901,071,18$ $245248,067568795,951,801,71,1,902,203,085,145,09$ 245266,78 $7568803,07 \quad 0,76 \quad 1,501,170,93 \quad 1,091,081,32$ $245285,49 \quad 7568810,18 \quad 1,7 \dagger 1,31 \quad 1,190,82 \quad 1,992,842,10$ $245203,46 \quad 7568800,33 \quad 1,23 \quad 1,381,79 \quad 1,52 \quad 1,42 \quad 1,78 \quad 3,65$ $245222,18 \quad 7568807,44,03 \quad 1,75 \quad 1,47,1,151,12,1,141,18$ $245240,907568814,562,612,743,032,984,214,172,57$ $\begin{array}{lllllllllllll}245240,90 & 7568814,56 & 2,61 & 2,74 & 3,03 & 2,98 & 4,21 & 4,17 & 2,57 \\ 245259,62 & 7568821,68 & 1,22 & 3,28 & 2,11 & 2,24 & 1,53 & 1,77 & 1,83\end{array}$ $\begin{array}{lllllllllll}245259,62 & 7568821,68 & 1,22 & 3,28 & 2,11 & 2,24 & 1,53 & 1,77 & 1,83 \\ 245278,34 & 7568828,79 & 2 & 28 & 2,03 & 1,51 & 211 & 2,12 & 1,93 & 1,88\end{array}$ $\begin{array}{llllllllll}245278,34 & 7568828,79 & 2,98 & 2,03 & 1,51 & 2,11 & 2,12 & 1,93 & 1,88 \\ 245297,06 & 7568835,91 & 2,84 & 2,51 & 2,10 & 1,78 & 2,37 & 2,12 & 1,99\end{array}$ $\begin{array}{lllllllll}246297,06 & 7568835,91 & 2,84 & 2,51 & 2,10 & 1,78 & 2,37 & 2,12 & 1,99 \\ 245196,31 & 7568818,93 & 1,73 & 2,05 & 2,06 & 2,39 & 2,64 & 2,59 & 3,15\end{array}$ $245215,037568826,05 \quad 1,03 \quad 1,15 \quad 1,66 \quad 1,41$ t,58 2,52 2,80 $\begin{array}{lllllllllll}245233,75 & 7568833,17 & 1,62 & 1,71 & 1,19 & 1,20 & 0,82 & 1,56 & 2,37\end{array}$ $\begin{array}{lllllllll}245252,47 & 7568840,29 & 2,17 & 2,16 & 2,61 & 2,44 & 2,22 & 2,75 & 2,50\end{array}$ $245271,197568847,402,251,482,173,014,76 \quad 6,44 \quad 4,79$ $245289,907568854,52 \quad 1,001,34 \quad 1,44 \quad 1,47 \quad 1,34 \quad 1,62 \quad 1,82$ $245170,447568830,431,381,592,432,653,72 \quad 2,692,50$ $245189,15 \quad 7668337,641,32,382,322,142,34 \quad 1,682,42$ $\begin{array}{llllllllll}245189,15 & 7668837,64 & 1,32 & 2,38 & 2,32 & 2,14 & 2,34 & 1,68 & 2,42 \\ 245207,87 & 7568844,66 & 1,36 & 1,27 & 1,94 & 1,13 & 1,24 & 1,01 & 1,00\end{array}$ $\begin{array}{llllllllll}245207,87 & 7568844,66 & 1,36 & 1,27 & 1,94 & 1,13 & 1,24 & 1,01 & 1,00 \\ 245226,59 & 7568851,78 & 1,53 & 1,32 & 1,34 & 1,23 & 0,79 & 1,15 & 1,17\end{array}$ $\begin{array}{llllllllll}245226,59 & 7568851,78 & 1,53 & 1,32 & 1,34 & 1,23 & 0,79 & 1,15 & 1,17 \\ 245245,31 & 7568858,90 & 1,34 & 1,36 & 1,90 & 1,28 & 1,35 & 1,62 & 1,98\end{array}$ $\begin{array}{lllllllllll}245245,31 & 7568858,90 & 1,34 & 1,36 & 1,90 & 1,28 & 1,35 & 1,62 & 1,98 \\ 245264,03 & 7568866,01 & 1,55 & 1,47 & 1,31 & 1,88 & 3,07 & 3,18 & 4,27\end{array}$ $245282,757568873,132,512,68 \quad 2,04 \quad 1,31 \quad 1,141,221,05$ $245301,477568880,252,701,811,511,151,101,011,59$ $245163,287568849,042,201,481,852,062,694,896,46$ $245182,007568856,150,601,45 \quad 1,901,711,21 \quad 0,820,98$ $245200,727568863,271,762264,871,931,311771,06$ 245219,44 7568870 39 1,46, $1791,061,75,07,751,02$ $24573816756887751,1,881,721,871,091,071,751,22$

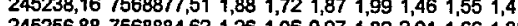
$1,661,86$

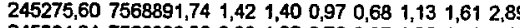
$\begin{array}{llllllllll}245294,31 & 7568898,86 & 0,90 & 1,02 & 0,76 & 0,87 & 1,26 & 1,28 & 1,49\end{array}$ $\begin{array}{llllllllll}245156,13 & 7568867,65 & 2,11 & 1,46 & 1,35 & 1,23 & 1,56 & 1,92 & 2,15\end{array}$

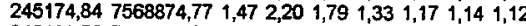

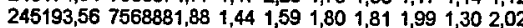
$245212,287568889,001,22,561,491,151,662,01,65$ $245231,007568896,121,262,111,401,441,29+041,44$ $245249,72 \quad 7568903,230,62 \quad 0,81 \quad 1,18 \quad 1,311,48 \quad 2,463,05$ $245268,447568910,352,113,532,71221 \quad 1,13 \quad 1,151,19$ $\begin{array}{llllllllll}245287,16 & 7568917,47 & 1,26 & 1,56 & 1,68 & 2,04 & 1,56 & 0,57 & 1,51\end{array}$ $\begin{array}{lllllllll}245287,16 & 7568917,47 & 1,26 & 1,56 & 1,68 & 2,04 & 1,56 & 0,57 & 1,51 \\ 245148,97 & 7568886,26 & 2,23 & 3,06 & 1,98 & 2,65 & 2,95 & 1,92 & 1,66\end{array}$ $\begin{array}{llllllllllllll}245148,97 & 7568886,26 & 2,23 & 3,06 & 1,98 & 2,65 & 2,95 & 1,92 & 1,66 \\ 245167,69 & 7568893,38 & 1,16 & 1,20 & 1,71 & 1,92 & 2,25 & 2,64 & 2,79\end{array}$ $\begin{array}{llllllllllll}245167,69 & 7568893,38 & 1,16 & 1,20 & 1,71 & 1,92 & 2,25 & 2,64 & 2,79 \\ 245186,41 & 7568900,49 & 1,78 & 1,59 & 1,85 & 2,15 & 1,42 & 1,48 & 1,37\end{array}$ $\begin{array}{llllllllll}245186,41 & 7568900,49 & 1,78 & 1,59 & 1,85 & 2,15 & 1,42 & 1,48 & 1,37 \\ 245205,13 & 7568907,61 & 1,37 & 1,05 & 1,45 & 4,51 & 1,73 & 1,27 & 1,07\end{array}$ $245223,85 \quad 7568914,73 \quad 1,341,201,48 \quad 1,42 \quad 1,231,331,64$ $245242,577568921,841,90,1,73,1,441,28,772,492,81$ $\begin{array}{lllllllllll}245261,29 & 7568928,96 & 1,41 & 2,26 & 2,04 & 2,02 & 1,68 & 1,67 & 1,70\end{array}$ $245280,017568936,084,682,301,974,75+221,381,75$ $245141,827568904,872001,351,291,521,640,441,68$ $245160,547568911,981,491,38,292,021,640,441,68$ 245179,25 75689

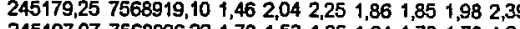
$245197,977508926,221,701,531,651,641,78 \quad 1,701,21$ 245216,69 7568933,34 1,48 $1,732,04 \quad 1,36 \quad 1,661,932,41$ $\begin{array}{lllllllll}245235,41 & 7568940,45 & 2,03 & 1,90 & 1,77 & 1,92 & 1,87 & 1,99 & 2,07\end{array}$ 245254,13 7568947,57 $1,46 \quad 1,02 \quad 1,48 \quad 1,17 \quad 1,17 \quad 1,391,73$ $245272,857568954,691,692,022,091,591,772,82 \quad 2,82$ 245134,66 7568923,48 1,92 1,52 2,51 $1,67 \quad 1,431,531,78$ $245153,387568930,591,48+371,27+12+511190,99$ $245172,107568937,711,721,891,481,261,281,141,07$ $245190,827568944830,741561,241,301,050,951,37$ $245209547568951,952951,9$ $\begin{array}{lllllllllll}245209,54 & 7568951,95 & 2,95 & 1,98 & 2,79 & 2,48 & 1,94 & 2,03 & 1,63\end{array}$ $\begin{array}{lllllllll}245228,26 & 7568959,06 & 1,36 & 1,78 & 1,52 & 1,13 & 1,20 & 1,58 & 2,04 \\ 245246,98 & 7568966,18 & 1,37 & 1,33 & 1,19 & 1,19 & 1,04 & 1,19 & 1,26\end{array}$ \begin{tabular}{lllllllll}
245246,98 & 7568966,18 & 1,37 & 1,33 & 1,19 & 1,19 & 1,04 & 1,19 & 1,26 \\
245265,70 & 7568973,30 & 2,30 & 2,46 & 2,30 & 1,63 & 2,49 & 1,22 & 1,39 \\
\hline
\end{tabular}
Dados das coordenadas e do indice de cone de todos os 150 pontos após a irrigaçăo pelo pivó central obtidos da área de Pirassununga (Cont.)

\section{(m) Longitude 0 Profundidades (m)}

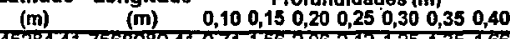

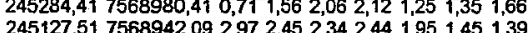
$245146,23.7558949,20 \quad 1,36 \quad 1,161,451,643,595,074,13$ $245164,957568956,321,671,251,641,12 \quad 1,574,24 \quad 4,91$ $245183,667568963,44 \quad 1,812,012,472,11 \quad 1,61 \quad 1,26 \quad 1,34$ $245202,387568970,562,26 \quad 1,090,97 \quad 1,791,841,481,51$ $245221,107568977,67 \quad 1,68 \quad 1,942,17 \quad 1,56 \quad 1,42 \quad 1,84 \quad 1,79$ $245239,827568984,791,92 \quad 1,691,42 \quad 1,23 \quad 2,231,68 \quad 3,90$ $245258,547568991,911,74$ 1,15 $1,511,24 \quad 1,07 \quad 1,252,01$ $245277,267568999,02,891,761,321,27,0151,321,65$ $245101,637568953,580,9800871,313,524,265,123,85$ $\begin{array}{lllllllllll}245101,63 & 7568953,58 & 0,98 & 0,87 & 1,31 & 3,52 & 4,26 & 5,12 & 3,85\end{array}$ $245139,07 \quad 7568967,81$ 1,68 2,09 1,74 2,16 1,87 1,51 1,47 $245157,797568974,931,291,731,792,012,003,094,02$ $245476,547558982,05 \quad 1,271,28 \quad 1,26 \quad 1,99 \quad 1,52 \quad 1,44 \quad 1,06$ $245195,237568989,17 \quad 1,491,861,73 \quad 2,01 \quad 1,501,751,95$ $\begin{array}{lllllllll}245213,95 & 7568996,28 & 1,36 & 1,46 & 1,10 & 2,65 & 2,16 & 2,74 & 2,79\end{array}$ $245232,67 \quad 7569003,401,45 \quad 1,87 \quad 1,701,330,952,41 \quad 2,35$ $245251,397569010,522,102,04 \quad 1,791,881,751,602,11$ $245270,117569017,632,122,014,641,882,52 \quad 0,791,90$ $24509414756072,102,127,01,041,082,520,791,90$ $245094,487568972,1927,1,62,01,01,631,73,1,251,59$ $245113,207568979,31 \quad 1,43 \quad 1,77 \quad 2,00 \quad 1,74 \quad 1,451,56 \quad 1,79$ $245131,927568986,431,221,231,051,240,910,941,07$ $245150,647568993,540,97 \quad 1,091,73 \quad 1,612,23 \quad 1,24 \quad 1,20$ $245169,367569000,660,63 \quad 1,51$ 1,95 $1,891,701,371,33$ $245188,07 \quad 7569007,781,591,351,481,641,301,131,29$ $245206,797569014,891,371,461,151,691,381,161,24$ $245225,517569022,011,912,691,641,22 \quad 1,030,951,07$

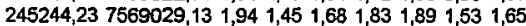
$245262,957569036,24 \quad 1,64 \quad 1,31 \quad 1,020,96 \quad 1,04 \quad 1,22 \quad 1,15$ $245087327568990800,70058,02,731,0903,11$ $245106,047568997,921,931,852,17,163,663,624,17$ $\begin{array}{lllllllllll}245106,04 & 7568997,92 & 1,93 & 1,85 & 2,17 & 2,16 & 3,66 & 3,62 & 4,17 \\ 245124,76 & 7569005,03 & 0,48 & 1,04 & 1,18 & 1,40 & 1,17 & 1,03 & 1,34\end{array}$ $\begin{array}{llllllllll}245124,76 & 7569005,03 & 0,48 & 1,04 & 1,18 & 1,40 & 1,17 & 1,03 & 1,34 \\ 245143,48 & 7569012,15 & 1,93 & 1,22 & 2,08 & 2,43 & 2,02 & 1,40 & 1,31\end{array}$ $\begin{array}{lllllllll}245143,48 & 7569012,15 & 1,93 & 1,22 & 2,08 & 2,43 & 2,02 & 1,40 & 1,31 \\ 245162,20 & 7569019,27 & 1,50 & 1,40 & 1,81 & 1,68 & 1,96 & 1,58 & 1,43\end{array}$ $\begin{array}{lllllllllll}245162,20 & 7569019,27 & 1,50 & 1,40 & 1,81 & 1,68 & 1,96 & 1,58 & 1,43\end{array}$

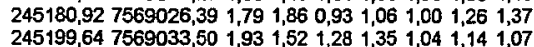
$245218,367569040,621,601,991,601,241,051,321,36$ $245237,08 \quad 7569047,742,192,251,991,77 \quad 2,812,84 \quad 3,02$ $245255,807569054,852,121,951,591,571,481,482,12$ $245080,177569009,411,901,761,641,58 \quad 1,401,411,71$ $245098,897569016,531,72 \quad 1,251,601,67 \quad 1,501,061,62$ $245098,897569016,531,721,251,601,671,501,061,62$ $\begin{array}{lllllllllll}245117,61 & 7569023,64 & 1,30 & 1,76 & 2,49 & 2,27 & 2,66 & 2,69 & 3,04\end{array}$ $\begin{array}{lllllllll}245136,33 & 7569030,76 & 0,82 & 0,94 & 1,69 & 1,57 & 1,31 & 1,13 & 1,10 \\ 245155,05 & 7569037,88 & 1,39 & 3,61 & 3,15 & 3,20 & 2,25 & 1,97 & 1,84\end{array}$ $\begin{array}{lllllllllll}245155,05 & 7569037,88 & 1,39 & 3,61 & 3,15 & 3,20 & 2,25 & 1,97 & 1,84 \\ 245173,77 & 7569045,00 & 1,23 & 2,59 & 2,12 & 2,08 & 2,24 & 1,97 & 2,05\end{array}$ $\begin{array}{lllllllllll}245173,77 & 7569045,00 & 1,23 & 2,59 & 2,12 & 2,08 & 2,24 & 1,97 & 2,05 \\ 245192,48 & 7569052,11 & 1,59 & 1,68 & 1,40 & 0,96 & 1,02 & 1,26 & 1,06 \\ 245211,20 & 7569059,23 & 1,25 & 2,05 & 1,84 & 1,45 & 1,31 & 1,03 & 1,03\end{array}$ $245211,207569059,23 \quad 1,252,051,841,451,311,031,03$ $245229,927569066,351,393,552,592,84 \quad 4,324,995,09$ $245248,64 \quad 7569073,46 \quad 1,861,851,26 \quad 1,28 \quad 2,08 \quad 2,123,50$ $245054,307569020,901,591,40 \quad 1,61 \quad 1,501,07 \quad 0,710,60$ $245073,01 \quad 7569028,02 \quad 1,451,48 \quad 0,940,680,850,910,88$ $245091,737569035,14,1801,441,321,191,181,081,14$

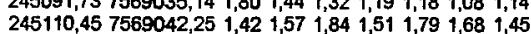
$245129,177569049,37,782,452,53,652,713,022,63$ $245147,897569056,49$ 1,52 $1,47 \quad 1,861,73 \quad 1,47 \quad 1,502,01$ $245166,617569063,61 \quad 1,852,171,771,911,57 \quad 2,202,29$ $245185,337569070,722,851,921,621,361,531,632,08$ $245204,057569077,841,822,192,602,901,661,401,40$ 245222,77 7569084,96 6,46 5,20 2,64 2,06 1,94 1,88 2,48 
Dados das coordenadas e do indice de cone de todos os pontos obtidos da área de Castro

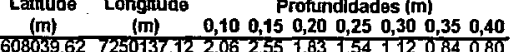

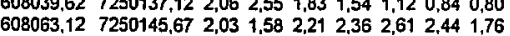
$\begin{array}{llllllllll}608086,60 & 7250154,22 & 1,67 & 1,38 & 1,61 & 1,79 & 2,13 & 1,46 & 1,36\end{array}$ $\begin{array}{lllllllllll}608007,58 & 7250152,06 & 1,23 & 1,02 & 0,96 & 1,19 & 1,39 & 1,45 & 0,76\end{array}$ $\begin{array}{lllllllll}608031,07 & 7250160,61 & 0,57 & 0,75 & 1,22 & 1,69 & 2,12 & 2,16 & 2,34\end{array}$ $\begin{array}{llllllllll}608054,56 & 7250169,16 & 1,67 & 1,60 & 1,20 & 1,75 & 1,70 & 1,58 & 1,21\end{array}$ $\begin{array}{lllllllllll}608078,06 & 7250177,72 & 1,82 & 1,86 & 1,98 & 1,65 & 1,63 & 1,60 & 1,29\end{array}$ $\begin{array}{lllllllllll}608101,55 & 7250186,26 & 2,77 & 2,40 & 1,68 & 1,63 & 1,99 & 1,82 & 2,13\end{array}$

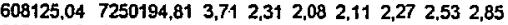
$607999,03 \quad 7250175,56 \quad 1,25+, 02+, 53 \quad 1,21 \quad 1,22 \quad 1,04 \quad 1,21$ $\begin{array}{llllllllll}608022,53 & 7250184,10 & 2,30 & 1,79 & 1,79 & 1,69 & 1,77 & 1,87 & 1,98\end{array}$ $608046,01 \quad 7250192,65 \quad+86 \quad 1,881,962,18 \quad 154 \quad 1,72 \quad 1,94$

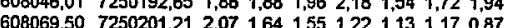
$6000.9072501,21,07,04,54,221,131,170,87$ $1,381,581,19$ $\begin{array}{lllllllllll}608116,49 & 7250218.30 & 1,62 & 0.90 & 1.94 & 0,94 & 2,11 & 2,46 & 2,69\end{array}$ $\begin{array}{lllllllllll}607966,98 & 7250190,49 & 2,20 & 1,60 & 1,78 & 1,68 & 1,65 & 2,67 & 1,44\end{array}$ $\begin{array}{llllllllll}607990,48 & 7250199,05 & 1,75 & 1,68 & 1,71 & 1,73 & 2,12 & 2,02 & 1,61\end{array}$ $\begin{array}{llllllllll}608013,97 & 7250207,60 & 2,11 & 1,75 & 1,66 & 1,52 & 1,53 & 1,51 & 1,65\end{array}$ 608037,46 7250216,14 1,65 1,25 1,79 1,45 1,37 1,50 0,96 $\begin{array}{llllllllll}608060,96 & 7250224,70 & 1,70 & 1,23 & 1,20 & 0,88 & 0,87 & 0,95 & 0,94\end{array}$

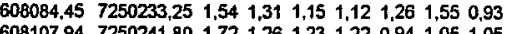
$608107,94 \quad 7250241,80 \quad 1,72 \quad 1,26 \quad 1,23 \quad 1,22 \quad 0,94 \quad 1,05 \quad 1,05$ $\begin{array}{llllllllll}607958,44 & 7250213,98 & 2,59 & 1,75 & 1,35 & 1,15 & 1,17 & 1,35 & 1,45\end{array}$

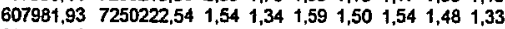
$\begin{array}{lllllllllllllll}608005,42 & 7250231,09 & 2,27 & 1,87 & 1,89 & 2,00 & 2,05 & 2,47 & 3,03\end{array}$ $\begin{array}{llllllllll}608028,91 & 7250239,64 & 1,89 & 1.36 & 1,43 & 1,27 & 1,06 & 0.51 & 1,14\end{array}$ $608052,40 \quad 7250248,191,861,962,081,72 \quad 1,491,491,48$ $\begin{array}{llllllllll}6008075,90 & 7250256,74 & 2,08 & 1,61 & 1,19 & 1,36 & 1,84 & 2,16 & 2,89\end{array}$ $\begin{array}{lllllllllll}608099.39 & 7250265.29 & 2.10 & 1.72 & 1.52 & 1.26 & 1.27 & 1.54 & 0.96\end{array}$

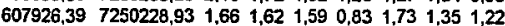
$\begin{array}{lllllllll}60794988 & 7250237,48 & 1,16 & 1,27 & 1,29 & 1,26 & 116 & 1,55 & 1,24\end{array}$ $607973,38 \quad 7250246,032331,681,872,26 \quad 16 \quad 1,551,24$ $607973,387250246,032,331,681,872,102.091,981,79$ $\begin{array}{lllllllllll}607996,87 & 7250254,58 & 1,62 & 1,70 & 1,55 & 1,91 & 1,89 & 2,00 & 2,30\end{array}$ $\begin{array}{llllllllllllll}608020,36 & 7250263,13 & 2,01 & 1,35 & 1,32 & 1,38 & 1,54 & 1,58 & 1,89\end{array}$ $\begin{array}{lllllllll}608043,86 & 7250271,69 & 2,23 & 1,93 & 1,98 & 2,04 & 2,21 & 2,29 & 2,20\end{array}$ $608067,34 \quad 7250280,23 \quad 1,66 \quad 1,83 \quad 1,34 \begin{array}{lllllll}1,21 & 1,05 & 1,31 & 1,66\end{array}$ $\begin{array}{llllllllllll}608090,84 & 7250288,78 & 1,92 & 1,36 & 1,27 & 1,29 & 1,53 & 1,93 & 2,28\end{array}$ $\begin{array}{llllllllll}607917,85 & 7250252,42 & 1,17 & 1,11 & 0,85 & 0,57 & 1,18 & 0,94 & 1,23\end{array}$ $\begin{array}{lllllllllll}607941,34 & 7250260,97 & 1,25 & 1,00 & 1,56 & 1,23 & 1,20 & 1,49 & 1,03 \\ 607964,82 & 7250269,53 & 2,16 & 1,35 & 1,41 & 1,23 & 1,58 & 1,67 & 1,65\end{array}$ $\begin{array}{llllllllll}607988.32 & 7250278,07 & 1,59 & 1.51 & 1.45 & 1,31 & 1,59 & 1,86 & 2,23\end{array}$ $\begin{array}{lllllllllll}608011,81 & 7250286,62 & 2,25 & 1,93 & 1,53 & 1,46 & 1,30 & 1,46 & 1,53\end{array}$ $\begin{array}{llllllllllll}608035,30 & 7250295,18 & 1,71 & 1,67 & 1,60 & 2,03 & 2,07 & 2,77 & 2,68\end{array}$ $\begin{array}{lllllllllll}608058,80 & 7250303,73 & 2,51 & 1,90 & 1,48 & 1,50 & 1,75 & 1,92 & 2,32\end{array}$ $\begin{array}{lllllllllll}608082,29 & 7250312,27 & 1,81 & 1,51 & 1,45 & 1,72 & 1,74 & 2,70 & 2,63\end{array}$ $\begin{array}{llllllllllll}608105,78 & 7250320,83 & 2,44 & 2,21 & 2,93 & 3,46 & 2,74 & 2,62 & 1,71\end{array}$ $\begin{array}{llllllllllll}607909,29 & 7250275,91 & 2.08 & 1.68 & 1.17 & 1,20 & 1,13 & 1,15 & 1,32\end{array}$ $\begin{array}{lllllllllll}607932,78 & 7250284,46 & 1,60 & 1,58 & 1,51 & 1,52 & 1,17 & 1,08 & 0,95\end{array}$ $\begin{array}{llllllllllll}607958,28 & 7250293,02 & 1,54 & 1,40 & 1,26 & 1,10 & 0,97 & 1,08 & 0,91\end{array}$ $\begin{array}{lllllllllll}607979.77 & 7250301,57 & 2.16 & 2,01 & 1,69 & 1,93 & 2,34 & 2,37 & 2,49\end{array}$ $\begin{array}{llllllllll}608003,27 & 7250310,11 & 2,68 & 1,71 & 1,74 & 1,33 & 1,30 & 1,68 & 1,49\end{array}$ $\begin{array}{llllllllllllll}608026,75 & 7250318,67 & 2,45 & 2,29 & 2,08 & 2,05 & 2,35 & 2,26 & 2,47\end{array}$ $\begin{array}{lllllllll}608050,24 & 7250327,22 & 1,94 & 2,40 & 2,19 & 1,57 & 1,87 & 2,29 & 2,70\end{array}$ $\begin{array}{llllllllllll}608073,74 & 7250335,76 & 2,25 & 2,32 & 1,49 & 1,21 & 1,64 & 1,88 & 2,15\end{array}$ $\begin{array}{llllllllll}608097,23 & 7250344,32 & 2,34 & 1,95 & 5,02 & 4,37 & 3,79 & 4,02 & 1.55\end{array}$ $\begin{array}{lllllllll}607900,74 & 7250299,41 & 1,74 & 1,02 & 1,14 & 1,14 & 1,20 & 1,46 & 1,41 \\ 607924,23 & 7250307,95 & 1,44 & 0,59 & 1,39 & 1,35 & 1,59 & 1,89 & 0,83\end{array}$ $\begin{array}{lllllllll}607924,23 & 7250307,95 & 1,44 & 0,59 & 1,39 & 1,35 & 1,59 & 1,89 & 0,83 \\ 607947,72 & 7250316,51 & 1,56 & 2,06 & 1,64 & 1,34 & 1,66 & 1,53 & 0,84\end{array}$ $\begin{array}{lllllllll}607947,72 & 7250316,51 & 1,56 & 2,06 & 1,64 & 1,34 & 1,66 & 1,53 & 0,94 \\ 607971,22 & 7250325,06 & 1,91 & 2,17 & 2,61 & 2,27 & 2,23 & 2,18 & 2,41\end{array}$ $\begin{array}{lllllllll}607971,22 & 7250325,06 & 1,91 & 2,17 & 2,61 & 2,27 & 2,23 & 2,18 & 2,41 \\ 607994,71 & 7250333,61 & 2,21 & 1,25 & 1,27 & 1,09 & 0,94 & 1,00 & 1,34\end{array}$ $\begin{array}{lllllllll}607994,71 & 7250333,61 & 2,21 & 1,25 & 1,27 & 1,09 & 0,94 & 1,00 & 1,34 \\ 608018,20 & 7250342,16 & 1,85 & 1,64 & 1,24 & 1,14 & 1,01 & 1,18 & 1,20\end{array}$ $\begin{array}{llllllllll}608041,70 & 7250350,71 & 1,42 & 1,95 & 1,60 & 1,50 & 1,49 & 1,77 & 2,42\end{array}$ $608065,19 \quad 7250359,26 \quad 1,82 \quad 1,45 \quad 1,45 \quad 1,41 \quad 1.48 \quad 1,701,89$ $\begin{array}{lllllllllllll}608088,68 & 7250367,81 & 2,51 & 2,22 & 3,23 & 2,41 & 2,07 & 2,26 & 2,63\end{array}$ $\begin{array}{lllllllllll}607868,70 & 7250314,35 & 1,79 & 1,65 & 1,53 & 1,62 & 1,37 & 1,45 & 1,33\end{array}$ $\begin{array}{llllllllll}607892,19 & 7250322,90 & 1,16 & 1,34 & 1,09 & 0,83 & 0,80 & 0,72 & 0,70\end{array}$ $\begin{array}{lllllllllll}607915,69 & 7250331,45 & 1,70 & 1,60 & 1,27 & 1,33 & 1,41 & 1,52 & 1,34\end{array}$ $\begin{array}{llllllllllllllll}607939.18 & 7250340,00 & 1,54 & 1,36 & 1,39 & 1,37 & 1,23 & 1,30 & 1,22\end{array}$ $\begin{array}{lllllllllllllllll}607962,67 & 7250348,55 & 1,42 & 1,33 & 1,21 & 1,16 & 1,38 & 1,56 & 2,00\end{array}$ $\begin{array}{lllllllllll}607986,16 & 7250357,10 & 2,44 & 1,85 & 2,08 & 2,36 & 1,72 & 1,87 & 2,12\end{array}$ $\begin{array}{llllllllllll}608009,65 & 7250365,65 & 2,31 & 1,88 & 1,53 & 1,20 & 1,08 & 1,15 & 1,28\end{array}$ $608033,14 \quad 7250374,20 \quad 1,65 \quad 1,58 \quad 2,19 \quad 1,54 \quad 1,791,97 \quad 2,20$ $\begin{array}{lllllllll}608056,64 & 7250382,75 & 2,93 & 2,27 & 2,05 & 1,36 & 1,59 & 2,14 & 2,58\end{array}$ $\begin{array}{llllllllllll}608080,13 & 7250391,31 & 1,63 & 1,81 & 1,80 & 1,73 & 2,28 & 2,59 & 2,71\end{array}$ $\begin{array}{lllllllllllll}607789,67 & 7250312,19 & 2,48 & 2,01 & 2,22 & 2,12 & 2,54 & 3,04 & 2,67\end{array}$ $\begin{array}{lllllllll}607789,67 & 7250312,19 & 2,48 & 2,01 & 2,22 & 2,12 & 2,54 & 3,04 & 2,67 \\ 607813,17 & 7250320,74 & 1,32 & t, 05 & t, 10 & 1,20 & 1,15 & 1,43 & t, 42\end{array}$ $\begin{array}{lllllllll}607813,17 & 7250320,74 & 1,32 & 1,05 & 1,10 & 1,20 & 1,15 & 1,43 & 1,42 \\ 607836,66 & 7250329,29 & 1,69 & 1,69 & 1,23 & 1,62 & 2,13 & 2,01 & 1,45\end{array}$ $\begin{array}{lllllllll}607836,66 & 7250329,29 & 1,69 & 1,69 & 1,23 & 1,62 & 2,13 & 2,01 & 1,45 \\ 607860,14 & 7250337,84 & 2,09 & 1,16 & 0,92 & 1,04 & 1,11 & 1,09 & 0,73\end{array}$ $\begin{array}{lllllllll}607860,14 & 7250337,84 & 2,09 & 1,16 & 0,92 & 1,04 & 1,11 & 1,09 & 0,73 \\ 607883,64 & 7250346,39 & 1,64 & 1,39 & 1,14 & 1,10 & 0,97 & 0,90 & 0,97\end{array}$ $\begin{array}{lllllllll}607883,64 & 7250346,39 & 1,64 & 1,39 & 1,14 & 1,10 & 0,97 & 0,90 & 0,97 \\ 607907,13 & 7250354,94 & 2,08 & 1,95 & 1,65 & 2,02 & 1,90 & 2,06 & 1,80\end{array}$ $\begin{array}{llllllllll}607930,62 & 7250363,50 & 1,98 & 1,99 & 1,59 & 1,20 & 1,16 & 1,03 & 0.97\end{array}$ $\begin{array}{lllllllll}607954.12 & 7250372,04 & 1,82 & 1,47 & 1,65 & 1,52 & 1,94 & 1,95 & 2,38\end{array}$ $607977.61 \quad 7250380,592,16 \quad 1,47 \quad 1,161,231,301,56 \quad 1,91$ $\begin{array}{llllllllll}608001,10 & 7250389,15 & 2,03 & 2,37 & 2,47 & 2,05 & 2,65 & 3,62 & 3,95\end{array}$ $\begin{array}{lllllllllll}608024,60 & 7250397,69 & 2,44 & 2,46 & 1,63 & 1,94 & 1,44 & 1,68 & 2,01\end{array}$ $\begin{array}{lllllllllll}608048,08 & 7250406,24 & 1,89 & 1,18 & 1,52 & 1,46 & 1,72 & 2,06 & 1,94\end{array}$ $\begin{array}{llllllllllll}608071,57 & 7250414,80 & 2,63 & 2,13 & 2,01 & 2,31 & 2,45 & 2.98 & 2,58\end{array}$ $\begin{array}{llllllllll}607781,12 & 7250335,69 & 2,07 & 1,94 & 2,38 & 2,02 & 2,89 & 2,76 & 3,22\end{array}$ 607828.11 7250352,78 $1,741,461,041,060,960,95 \quad 0,52$ $607851,607250361,341051.561371,161,040,050,84$

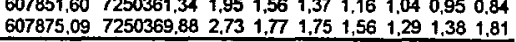

Dados das coordenadas e do indice de cone de todos os pontos obtidos da área de Castro (Cont.)

axturo Longitude

(m)

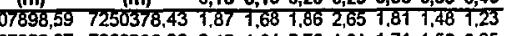
$\begin{array}{lllllllll}607922,07 & 7250386,99 & 2,42 & 1,84 & 2,76 & 1,91 & 1,71 & 1,56 & 0,95\end{array}$ $\begin{array}{llllllllll}607945,56 & 7250395,53 & 2,32 & 2,23 & 1,85 & 1,66 & 2,00 & 2,41 & 3,17\end{array}$ $\begin{array}{lllllllll}607969,06 & 7250404,08 & 2,25 & 2,13 & 1,48 & 1,31 & 1,53 & 1,40 & 1,39\end{array}$ $\begin{array}{lllllllll}607992,55 & 7250412,64 & 0,56 & 0,54 & 0,52 & 0,50 & 0,49 & 0,46 & 0,45\end{array}$ $\begin{array}{lllllllll}608016,04 & 7250421,19 & 2,30 & 1,65 & 1,45 & 1,37 & 1,41 & 1,83 & 1,74\end{array}$ $\begin{array}{llllllllll}608039,54 & 7250429,73 & 1.81 & 1,83 & 1,26 & 1,14 & 1,57 & 1,63 & 1,68\end{array}$ $\begin{array}{lllllllll}608063,03 & 7250438,29 & 1,68 & 2,49 & 2,02 & 1,41 & 1,65 & 1,89 & 1,42\end{array}$ $\begin{array}{lllllllll}608086,52 & 7250446,84 & 2.14 & 1,69 & 1,39 & 1,33 & 1,55 & 2,30 & 2,35\end{array}$

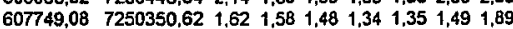
$607772.57 \quad 7250359,18 \quad 2,491,561,40 \quad 1,57 \quad 1,631,96 \quad 2,68$ $607796,06 \quad 7250367,732101,941,792,262,392,842,81$ $60781955 \quad 7250376,27 \quad 1,92,520,911,030,910,840,78$


$\begin{array}{llllllllllll}607843,05 & 7250384,83 & 2,27 & 1,60 & 1,50 & 1,34 & 1,42 & 1,40 & 1,14\end{array}$ $\begin{array}{llllllllllll}607866,54 & 7250393,38 & 2,35 & 1,29 & 1.45 & 1,55 & 1,47 & 1,42 & 1,21\end{array}$ $\begin{array}{lllllllllll}6 & 07890 & 7250401,92 & 2,96 & 2,37 & 1,73 & 2,24 & 2,30 & 2,18 & 1,66\end{array}$ 607913,53 7250410,46 2,58 1,78 1,71 1,58 $1,391,090,91$ $\begin{array}{lllllllllll}607937,02 & 7250419,03 & 3,14 & 1,78 & 1,77 & 1,82 & 2,13 & 2,54 & 2,42\end{array}$ $607960,517250427,57$ 607984,01 7250436,13 $3.12 \quad 2,442,37 \quad 3,11 \quad 3,55 \quad 4,43 \quad 5,22$ $\begin{array}{lllllllll}608007,49 & 7250444,68 & 1,93 & 1,58 & 1,43 & 1,54 & 2,03 & 2,47 & 2,56\end{array}$ $\begin{array}{llllllllllll}608030,98 & 7250453,23 & 1,64 & 1,47 & 1,36 & 1,28 & 1,75 & 2,04 & 1,94\end{array}$ $\begin{array}{lllllllllll}608054,48 & 7250461,78 & 3,29 & 2,35 & 2,88 & 2,30 & 2,09 & 1,71 & 1,86\end{array}$ $608077,97 \quad 7250470,33 \quad 1,15 \quad 1,56 \quad 1,86 \quad 1,96 \quad 2,86 \quad 3,21 \quad 3,79$ $\begin{array}{llllllllll}607740,53 & 7250374,11 & 1,85 & 1,69 & 1,58 & 1,86 & 1,90 & 2,11 & 2,17\end{array}$ $\begin{array}{lllllllllll}607764,02 & 7250382.67 & 1,36 & 1,27 & 1,40 & 1,69 & 2,06 & 2.01 & 1,39\end{array}$ $\begin{array}{llllllllll}607787,51 & 7250391,22 & 1,52 & 1,43 & 1,79 & 1,60 & 1,68 & 2,01 & 1,67\end{array}$ $\begin{array}{llllllllll}607811,01 & 7250399,76 & 1,84 & 1,84 & 1,65 & 1,26 & 1,23 & 1,11 & 1,04\end{array}$ $\begin{array}{llllllllll}607834,50 & 7250408,32 & 1,63 & 1,95 & 2,16 & 2,31 & 1,32 & 1,40 & 1,06\end{array}$ $\begin{array}{lllllllllll}607857,98 & 7250416,87 & 1,96 & 1,88 & 1,60 & 1,22 & 1,39 & 1,46 & 1,42\end{array}$ $607881,48 \quad 7250425,422052,152012062,192001,90$ $607801,487250425,422,052,152,012,062,192,001,90$ $\begin{array}{lllllllll}607904,97 & 7250433.97 & 3.28 & 1.93 & 0,53 & 2,24 & 2,22 & 2,41 & 2.18\end{array}$ $\begin{array}{lllllllll}607928,46 & 7250442,52 & 2,50 & 2,28 & 2,16 & 2,34 & 2,24 & 2,28 & 2,39\end{array}$ $\begin{array}{lllllllll}607951,96 & 7250451,07 & 2,30 & 1,63 & 1,32 & 1,23 & 1,24 & 1,44 & 1,52\end{array}$

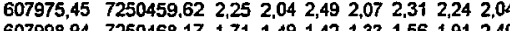
$607998,94 \quad 7250468,17 \quad 1,711,491,42 \quad 1,33 \quad 1,56 \quad 1,91 \quad 2,40$ $\begin{array}{lllllllllll}608022,44 & 7250476,72 & 1,78 & 1,41 & 1,60 & 1,61 & 1,45 & 1,57 & 1,78\end{array}$ $\begin{array}{llllllllllll}608045,93 & 7250485,28 & 3.22 & 2,01 & 1,88 & 1.47 & 1.37 & 2,17 & 2,22\end{array}$ $608069,42 \quad 7250493,822,632,531,221,541,002,772,56$ $\begin{array}{llllllllll}607731,97 & 7250397,61 & 1,84 & 1,49 & 1,49 & 1,32 & 0,74 & 1,10 & 1,19\end{array}$ $\begin{array}{llllllllll}607755,47 & 7250406,16 & 1.92 & 1,87 & 1,36 & 1,55 & 1,55 & 1,63 & 1,41\end{array}$ $607778,96 \quad 7250414,71 \quad 1,46 \quad 1,40 \quad 1,22 \quad 1,32 \quad 1,60 \quad 1,76 \quad 0,49$ $\begin{array}{lllllllllll}607802,45 & 7250423,26 & 1,71 & 2,00 & 1,97 & 1,87 & 1,97 & 1,44 & 1,3\end{array}$ $\begin{array}{lllllllllll}607825,95 & 7250431,81 & 1,98 & 1,38 & 1,33 & 1,25 & 1,20 & 1,38 & 1,20\end{array}$ $\begin{array}{llllllllllll}607849,44 & 7250440,36 & 2,04 & 1,70 & 1,45 & 1,24 & 1,15 & 1,13 & 0,94\end{array}$ $\begin{array}{llllllllll}607872,93 & 7250448,91 & 1,46 & 1,34 & 1,96 & 1,95 & 1,98 & 2,13 & 1,01\end{array}$ $607896,43 \quad 7250457,46 \quad 1,85 \quad 1,641,641,77 \quad 1,55 \cdot 1,44 \quad 1,31$ $\begin{array}{lllllllllll}607919,91 & 7250466,01 & 1,89 & 2,03 & 1,42 & 1,40 & 1,70 & 1,88 & 2,11\end{array}$

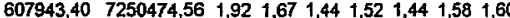
$\begin{array}{lllllllllll}607966,90 & 7250483,12 & 2,69 & 2,62 & 2,38 & 1,81 & 2,33 & 2,59 & 2,72\end{array}$ $6079939725049166 \quad 1,941,151,471,651,77 \quad 2022,53$ $608013,80 \quad 7250500,21 \quad 2,372,092,401,051,77 \quad 2,022,53$ $\begin{array}{llllllllll}608013,88 & 7250500,21 & 2,37 & 2,89 & 2,18 & 1,86 & 1,28 & 2,11 & 2,70\end{array}$ $\begin{array}{llllllllll}608037,38 & 7250508,77 & 2,25 & 1,29 & 2,22 & 1,66 & 1,68 & 2,09 & 2,37\end{array}$ $\begin{array}{llllllllll}608060,87 & 7250517,32 & 4,21 & 3,17 & 2,78 & 3,09 & 2,57 & 2,86 & 2,33\end{array}$ $\begin{array}{llllllllll}607723,43 & 7250421,10 & 1,64 & 1,36 & 1,04 & 1,11 & 1,48 & 1,47 & 0,40\end{array}$ $607746,927250429,86 \quad 2,41 \quad 1,551,591,601,53 \quad 1,76 \quad 1,82$ $607770,42 \quad 7250438,20 \quad 2,11,4,451,942,251,681,990,94$ $\begin{array}{lllllllllll}607793,90 & 7250446,75 & 3,42 & 2.36 & 1,73 & 1,60 & 1,48 & 1,40 & 1,16\end{array}$

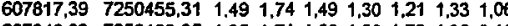
$\begin{array}{lllllllllll}607840,89 & 7250463,85 & 1,95 & 1,71 & 1,60 & 1,56 & 1,73 & 1,95 & 2,10\end{array}$ $\begin{array}{llllllllll}607864,38 & 7250472,40 & 1,81 & 1,84 & 1,54 & 1,64 & 1,65 & 1,82 & 2,02\end{array}$ $607887,87 \quad 7250480,96 \quad 1,70 \quad 1,37 \quad 1,31,1,38 \quad 1,53 \quad 1,781,69$ $\begin{array}{lllllllll}607911,37 & 7250489,50 & 1,95 & 1,85 & 1,96 & 2,12 & 2,65 & 3,04 & 3,27\end{array}$ $\begin{array}{lllllllllll}607934,86 & 7250498,05 & 2.52 & 2,44 & 2,12 & 2,72 & 2,14 & 2,16 & 2,12\end{array}$ $\begin{array}{llllllllll}607958,35 & 7250506,61 & 2,22 & 1,71 & 1,74 & 1,58 & 2,18 & 2,14 & 1,44\end{array}$ $607981,85 \quad 7250515,16 \quad 1,89 \quad 1,601,96 \quad 2,213,603,34 \quad 2,51$ $608005,34 \quad 7250523,702,82 \quad 2,62 \quad 2,23 \quad 2,131,94 \quad 1,962,63$ $\begin{array}{lllllllll}608028,82 & 7250532,26 & 2,46 & 2,40 & 1,73 & 1,71 & 2,01 & 255 & 2,75\end{array}$ $608052,31 \quad 7250540,812,362,502,581,752,20233 \quad 31$ $607714,877250444,591,641,501101,941,641,811,01$ $607714,87 \quad 7250444,591,641,591,101,941,641,81 \quad 1,91$ $\begin{array}{lllllllllll}607738,37 & 7250453,15 & 1,83 & 1,65 & 1,48 & 1,67 & 1,53 & 1,60 & 1,43\end{array}$ $607761,86 \quad 7250461,69 \quad 1,86 \quad 1,87 \quad 1,74 \quad 1,702,00 \quad 2,10 \quad 2,0$ 607785,36 7250470.24 1,82 2,25 1,70 1,87 2,02 1,77 2,08 607008,05 7250478,00 $2,221,771,911,681,531,44 \quad 1,20$ 60732,34 7250487.35 1,95 1,50 1,31 1,21 1,34 1,36 1,04 $607556,83 \quad 7250495,891,841,612,192,262,141,991,79$ $\begin{array}{llllllllll}607879,32 & 7250504,45 & 1,82 & 1,34 & 0,97 & 1,02 & 1,15 & 1,16 & 1,49\end{array}$ $\begin{array}{lllllllllll}607902,81 & 7250513,00 & 2,09 & 2,03 & 1,62 & 2,20 & 2,93 & 2,61 & 3,05\end{array}$ $\begin{array}{llllllllllllll}607926,30 & 7250521,54 & 1,51 & 2,23 & 1,77 & 1,92 & 2,40 & 2,60 & 2,52\end{array}$ $\begin{array}{lllllllll}607949,80 & 7250530,10 & 2,34 & 1,30 & 1,58 & 1,35 & 1,35 & 1,45 & 1,36\end{array}$ $\begin{array}{llllllllllll}607973,29 & 7250538,65 & 2,89 & 2,37 & 2,10 & 1,90 & 2,03 & 1,80 & 2,39\end{array}$ $\begin{array}{lllllllllllll}607996,78 & 7250547,20 & 2,69 & 2,72 & 2,74 & 3,26 & 2,67 & 2,89 & 2,95\end{array}$ $608020,28 \quad 7250555,75 \quad 1,61 \quad 1.75 \quad 1,77 \quad 1,50 \quad 1,791.892,00$ $\begin{array}{llllllllll}608043,77 & 7250564,30 & 2,37 & 2,03 & 2,47 & 3,40 & 2.67 & 2,49 & 1,93\end{array}$ $\begin{array}{llllllllll}607659,34 & 7250450,98 & 1,95 & 1,83 & 2,07 & 2,23 & 2,45 & 2,48 & 2,02\end{array}$ $607682847250459.541221 .451711,98212238194$ 607706,32 7250468.08 $2.01 \quad 1,92 \quad 1,52 \quad 1,712,112,362,16$ $607729817250476,641,601371090900,800760,03$ $607753,317250485,19,67,231,151,39,1,441,641,45$ 6077761250485,19 1.67 1,23 $1.151,391.44 \quad 1,64 \quad 1,45$ $607800297250502,2927,011,261,170,990,910,75$ \begin{tabular}{lllllllll}
607800,29 & 7250502,29 & 2,27 & 2,01 & 1,29 & 0,97 & 1,13 & 1,04 & 0,86 \\
607823,79 & 7250510,84 & 1,87 & 1,30 & 1,07 & 0,91 & 1,17 & 1,13 & 0,97 \\
\hline
\end{tabular} 
Dados das coordenadas e do indice de cone de todos os pontos obtidos da área de Castro (Cont. Lattudo Longltude Profundldades (m)

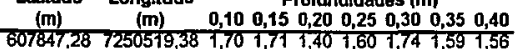

$\begin{array}{llllllllllll}607870,77 & 7250527,94 & 1,89 & 1,74 & 1,47 & 1,47 & 1,72 & 1,78 & 1,79\end{array}$ $\begin{array}{lllllllll}607894,27 & 7250536,49 & 2,31 & 1,96 & 1,62 & 1,64 & 1,96 & 2,25 & 2,03\end{array}$ $\begin{array}{llllllllll}607917,76 & 7250545,04 & 1,88 & 1,78 & 1,87 & 1,49 & 1,67 & 2,07 & 1,99\end{array}$ $607941,24 \quad 7250553,591,381,60+38+23 \quad 1,251,561,55$ $607964,747250562,14 \quad 1781,79 \quad 1,591,811992,13 \quad 2,60$ 607988 23 7250570,69 2062,78 1,80 $2521,032,132,60$ $\begin{array}{lllllllll}607988,23 & 7250570,69 & 2,06 & 2,48 & 1,88 & 2,52 & 1.93 & 2,19 & 2,39\end{array}$ $\begin{array}{lllllllll}608011,72 & 7250579,24 & 1,46 & 1,39 & 1,18 & 1,33 & 1,35 & 1,64 & 2,50\end{array}$ $\begin{array}{lllllllll}608035,22 & 7250587,79 & 2,87 & 2,38 & 2,18 & 3,06 & 2,04 & 1,72 & 1,69\end{array}$ $\begin{array}{llllllllll}608058,74 & 7250596,34 & 6,16 & 3,17 & 1,83 & 2,92 & 4,08 & 4,76 & 4,93\end{array}$ $\begin{array}{llllllllll}607627,30 & 7250465,93 & 2,34 & 2.06 & 2,55 & 3,14 & 3,99 & 4,79 & 5,25\end{array}$ $\begin{array}{lllllllllll}607650,79 & 7250474,47 & 1,21 & 1,71 & 1,79 & 2,25 & 2,08 & 2,41 & 2,03\end{array}$ $\begin{array}{lllllllllllll}607674,28 & 7250483,03 & 2,09 & 1,64 & 1,75 & 2,14 & 2,02 & 2,03 & 1,63\end{array}$ $\begin{array}{llllllllllll}607697,78 & 7250491,58 & t, 63 & 1,36 & 1,54 & 1,81 & 2,14 & 2,25 & 2,19\end{array}$ $\begin{array}{lllllllllll}607721,27 & 7250500,13 & 2,18 & 1,84 & 1,41 & 1,46 & 1,58 & 1,67 & 1,43\end{array}$ $\begin{array}{llllllllllll}607744,76 & 7250508,68 & 1,73 & 1.58 & 0,47 & 1,27 & 1.84 & 1,95 & 2,00\end{array}$

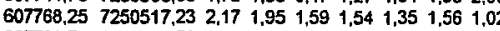
$\begin{array}{lllllllllll}607791,74 & 7250525,78 & 1,84 & 1,53 & 1,78 & 1,82 & 1,60 & 1,68 & 1,32\end{array}$ $\begin{array}{lllllllllll}607815,23 & 7250534,33 & 2,21 & 1,39 & 1,36 & 1.25 & 1,21 & 1,28 & 1,01\end{array}$ $\begin{array}{lllllllllll}607638,73 & 7250542,88 & 1,71 & 1,07 & 1,65 & 1,69 & 1,80 & 2,01 & 1,63\end{array}$ $\begin{array}{lllllllll}607862,22 & 7250551,43 & 2,33 & 1,97 & 1.51 & 1,56 & 1.63 & 1,79 & 2,11\end{array}$ $\begin{array}{lllllllllllll}607885,71 & 7250559,98 & 2,38 & 2,18 & 1,64 & 1,77 & 1,91 & 2,27 & 1,96\end{array}$ $\begin{array}{llllllllllll}607909,21 & 7250568,53 & 1,47 & 1,37 & 1,27 & 1,25 & 1,19 & 1,36 & 1,62\end{array}$ $\begin{array}{lllllllllllll}607932,70 & 7250577,09 & 1,94 & 1.71 & 1,50 & 1,82 & 1,78 & 1,95 & 2,63\end{array}$

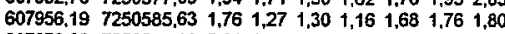
$\begin{array}{llllllllllll}607979,69 & 7250594,18 & 2,01 & 1,42 & 1,11 & 0,89 & 1,15 & 1,34 & 1,64\end{array}$ $\begin{array}{llllllllllllll}608003.18 & 7250602,74 & 1.68 & 1.50 & 1,43 & 1,40 & 1,74 & 2.33 & 2,89\end{array}$ $\begin{array}{lllllllllllll}608026.67 & 7250611,28 & 2,70 & 1,58 & 1,71 & 1,72 & 1,90 & 2,33 & 2,17\end{array}$ $\begin{array}{lllllllll}608050,15 & 7250619,83 & 3,42 & 3,19 & 2,44 & 2,88 & 3,26 & 4,17 & 4,45 \\ 607618.74 & 7250489,42 & 1,54 & 1,75 & 2,17 & 2,80 & 3,40 & 3,93 & 4,14\end{array}$ $\begin{array}{llllllllll}607618.74 & 7250489,42 & 1,54 & 1,75 & 2,17 & 2,80 & 3,40 & 3,93 & 4,14 \\ 607642,24 & 7250497,96 & 2,65 & 3,01 & 3,01 & 2,98 & 3,17 & 3,43 & 3,52\end{array}$ $\begin{array}{lllllllllll}607665,73 & 7250506,52 & 1,66 & 1,77 & 1,66 & 2,09 & 2,47 & 2,35 & 2,41\end{array}$ $\begin{array}{llllllllll}607689,22 & 7250515,07 & 2,07 & 2,01 & 1,60 & 1,62 & 1,65 & 1,90 & 1,88\end{array}$ $\begin{array}{llllllllll}607712,72 & 7250523,63 & 1,90 & 1,95 & 1,39 & 1,15 & 1,16 & 1,22 & 1,42\end{array}$ $\begin{array}{llllllllllll}607736,21 & 7250532,17 & 2,30 & 1,87 & 1,79 & 1,85 & 2,03 & 2,30 & 2,55\end{array}$ $\begin{array}{lllllllllllll}607759.70 & 7250540,72 & 1,92 & 1,66 & 1,83 & 1,93 & 1,70 & 1,86 & 1,54\end{array}$ $\begin{array}{lllllllllll}607783,20 & 7250549,28 & 2,28 & 1,89 & 1,55 & 1,09 & 1,28 & 1,32 & 1,24\end{array}$ $\begin{array}{lllllllllll}607806,69 & 7250557,82 & 1,83 & 1,60 & 1,28 & 1.11 & 1.00 & 0.91 & 0,82\end{array}$ $\begin{array}{lllllllllllll}607830.18 & 7250566,37 & 2.51 & 1.61 & 1,35 & 1,50 & 1,57 & 1,48 & 1,59\end{array}$ $\begin{array}{llllllllll}607853,67 & 7250574,93 & 1,96 & 2,15 & 2,30 & 1,83 & 1,81 & 1,85 & 1,74\end{array}$ $\begin{array}{llllllllll}607877,16 & 7250583,47 & 3,39 & 2,62 & 1.88 & 2.02 & 2.17 & 2,58 & 2,87\end{array}$ $\begin{array}{llllllllll}607900,65 & 7250592,02 & 2.40 & 2.60 & 1,78 & 1,70 & 1,67 & 1,87 & 1.90\end{array}$ $607924,14 \quad 7250600,58 \quad 1,95 \quad 1,76 \quad 1,801,78 \quad 2,07 \quad 2,051,78$ $\begin{array}{llllllllllll}607947,64 & 7250609,12 & 1,92 & 2,06 & 1,61 & 1,54 & 1,76 & 2,23 & 2,32\end{array}$ $\begin{array}{lllllllllll}607971.13 & 7250617,67 & 1,59 & 1,78 & 1,34 & 1,29 & 1,59 & 1,79 & 1,88\end{array}$ $\begin{array}{lllllllllllll}607994,62 & 7250626,23 & 2,29 & 2,09 & 1,58 & 1,38 & 2,02 & 2,50 & 2,65\end{array}$ $\begin{array}{llllllllll}607994,62 & 7250626,23 & 2,29 & 2,09 & 1,58 & 1,38 & 2,02 & 2,50 & 2,65 \\ 60.018,12 & 7250634,78 & 2.60 & 1,46 & 1,06 & 1,49 & 1,51 & 1,64 & 2,10\end{array}$ $\begin{array}{llllllllll}608041,61 & 7250643,32 & 2,87 & 1,92 & 2,33 & 2,66 & 2,94 & 3,30 & 3,81\end{array}$ $\begin{array}{lllllllll}608041,61 & 7250643,32 & 2,87 & 1,92 & 2,33 & 2,66 & 2,94 & 3,30 & 3,81 \\ 607586,74 & 7250504,36 & 3,08 & 3,39 & 3,26 & 3,86 & 4,16 & 4,18 & 4,60\end{array}$ $\begin{array}{llllllllllll}607610,20 & 7250512,91 & 2,38 & 2,52 & 2,57 & 2,72 & 3,26 & 4,01 & 4,33\end{array}$ $\begin{array}{lllllllll}607610,20 & 7250512,91 & 2,38 & 2,52 & 2,57 & 2,72 & 3,26 & 4,01 & 4,33 \\ 607633,69 & 7250521,46 & 1,44 & 1,72 & 1,90 & 1,75 & 2,25 & 2,36 & 1,88\end{array}$ $\begin{array}{lllllllll}607633,69 & 7250521,46 & 1,44 & 1,72 & 1,90 & 1,75 & 2,25 & 2,36 & 1,88 \\ 607657,19 & 7250530,01 & 1,77 & 1,98 & 1,72 & 1,88 & 1,84 & 1,94 & 1,23\end{array}$ $\begin{array}{llllllllll}607657.19 & 7250530,01 & 1,77 & 1,98 & 1,72 & 1,88 & 1,84 & 1,94 & 1,23 \\ 607680,68 & 7250538,56 & 2,42 & 2,23 & 1,92 & 2,26 & 2,34 & 2,49 & 2,63\end{array}$ $\begin{array}{llllllllllll}607704,16 & 7250547,12 & 1,54 & 2,09 & 1,53 & 1,51 & 1,53 & 1,56 & 1,63\end{array}$

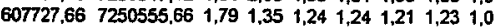
$\begin{array}{lllllllllll}607751.15 & 7250564,21 & 1,82 & 1.97 & 1,86 & 1,77 & 1,52 & 1,61 & 1,35\end{array}$ $\begin{array}{llllllllllll}607774,64 & 7250572,77 & 1,77 & 1,66 & 1,55 & 1,38 & 1,40 & 1,40 & 1,30\end{array}$ $\begin{array}{llllllllllll}607798,14 & 7250581,31 & 1,99 & 1,77 & 1,72 & 1,40 & 1,19 & 1,11 & 1,02\end{array}$

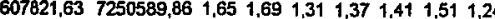
$\begin{array}{llllllllll}607845,12 & 7250598,42 & 2,44 & 1,85 & 2,42 & 2,05 & 1,82 & 1,69 & 2,00\end{array}$ 607868,61 $7250606,97 \quad 2,51 \quad 1,49 \quad 1,40 \quad 1.511,691.822,13$

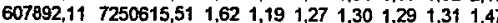
$607915,60 \quad 7250624,07 \quad 1,771,42 \quad 1,22 \quad 1,351,101,52 \quad 198$ $607939,097250632,62 \quad 2,17 \quad 1,67 \quad 1,351,421,611,621,90$ $607962587250641,161,48+381,541,391,291,621,90$ $607986,07 \quad 7250649,72,44,311,541,391,291,48 \quad 1,79$ $\begin{array}{llllllllll}607986,07 & 7250649,72 & 2,44 & 2,31 & 1,64 & 1,53 & 1,56 & 1,42 & 2,09\end{array}$ $\begin{array}{llllllllllllllll}608009,56 & 7250658,27 & 2,02 & 0,77 & 0,71 & 0,83 & 0,87 & 1,37 & 1,42\end{array}$ $\begin{array}{lllllllll}608033,06 & 7250666,82 & 1,72 & 1,75 & 2,13 & 2,60 & 2,62 & 3,07 & 3,48\end{array}$ $\begin{array}{llllllllll}607578,15 & 7250527,86 & 1,15 & 1,65 & 1,84 & 2,11 & 2,56 & 3,47 & 4,14\end{array}$ $607601,647250536,401,772,02$ 2,50 2,61 2,55 $2,682,50$ $\begin{array}{lllllllllll}607625.14 & 7250544,95 & 1,73 & 2,15 & 2,38 & 2,57 & 3,06 & 3,77 & 4,30\end{array}$ $\begin{array}{llllllllll}607648,63 & 7250553,51 & 1,57 & 1,34 & 1,43 & 1,91 & 1.88 & 2,27 & 2,30\end{array}$ $\begin{array}{lllllllllllll}607672,12 & 7250562,05 & 2,61 & 0,96 & 1,85 & 2,06 & 2,04 & 2,31 & 2,20\end{array}$ $\begin{array}{lllllllllll}607695,62 & 7250570,61 & 1,38 & 1,36 & 1,25 & 1,37 & 1,36 & 1,37 & 1,25\end{array}$ $\begin{array}{lllllllllll}607749,11 & 7250579,16 & 1,88 & 1,52 & 1,52 & 1,58 & 1.68 & 2,01 & 2,22\end{array}$ $\begin{array}{lllllllllllll}607742,60 & 7250587,70 & 1,95 & 1,28 & 1,71 & 1,71 & 1,79 & 1,36 & 1,25\end{array}$ $\begin{array}{llllllllll}607766,09 & 7250596,26 & 2,77 & 2,15 & 2,13 & 2,19 & 1,27 & 1,20 & 1,13\end{array}$

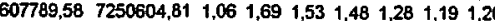
$\begin{array}{lllllllllll}607813,07 & 7250613,35 & 1,71 & 1,57 & 1,73 & 1,75 & 1,80 & 2,09 & 2,17\end{array}$ 607836,57 7250621.91 194 1.65 $1,93 \quad 1,781,84 \quad 1,481,42$ $\begin{array}{lllllllll}607860,06 & 7250630,46 & 1,96 & 1,86 & 1,71 & 1,69 & 1,82 & 2,11 & 2,75\end{array}$ $607883,557250639,01 \quad 1,90 \quad 1,64+400,98 \quad 0,800,920,54$ $607907,05 \quad 7250647,56$ 1,27 1,54 1,38 $1,31 \quad 0,400,92 \quad 0,54$ $607930.547250656,11,84$ 1,99 $1,77,261,481,401,43$ $\begin{array}{llllllllllll}607930,54 & 7250656,11 & 1,84 & 1,99 & 1,77 & 2,26 & 2.31 & 2,37 & 2,03\end{array}$ $\begin{array}{llllllllll}607977,53 & 7250673,21 & 2,43 & 2,78 & 2,16 & 2,20 & 2,34 & 2,73 & 2,04\end{array}$ $\begin{array}{lllllllll}607977,53 & 7250673,21 & 2,43 & 2,78 & 2,16 & 2,20 & 2.31 & 2,73 & 2,04 \\ 608001,02 & 7250681,76 & 2,86 & 1,92 & 1,14 & 1,37 & 1,33 & 1,54 & 1,98\end{array}$ $\begin{array}{lllllllll}608001,02 & 7250681,76 & 2,86 & 1,92 & 1,14 & 1,37 & 1,33 & 1,54 & 1,98 \\ 608024,51 & 7250690,31 & 3,60 & 3,55 & 3,04 & 3,21 & 3,51 & 4,47 & 4,79\end{array}$

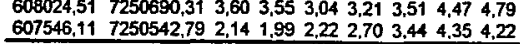

Dados das coordenadas e do índice de cone de todos os pontos obtidos da área de Castro (Cont.)

catlfude Longlfude Profundildades (m)

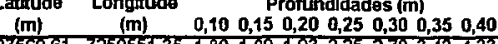

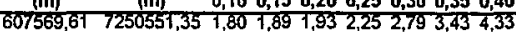
$\begin{array}{lllllllllll}607593,09 & 7250559,90 & 1,65 & 1,56 & 1,45 & 1,81 & 2,33 & 2,46 & 2,33\end{array}$ $\begin{array}{llllllllllll}607616,58 & 7250568,44 & 1,69 & 2,18 & 2,43 & 2,41 & 2,85 & 3.72 & 2,85\end{array}$ $\begin{array}{lllllllllll}607640,08 & 7250577,00 & 1,43 & 1,65 & 2,06 & 2,02 & 2,23 & 2,28 & 2,47\end{array}$ $607663,57 \quad 7250585,55 \quad 1,41,401,64 \quad 1,82 \quad 2,001,28 \quad 1,57$ 607687,0 $7250594101,992,15,041,02 \quad 2,001,991,57$ $\begin{array}{llllllllll}607710,56 & 725060,10 & 1,99 & 2,15 & 2,22 & 1,67 & 1,73 & 1,67 & 1,84\end{array}$ $\begin{array}{llllllllll} & \end{array}$ $\begin{array}{llllllllll} & \end{array}$ $\begin{array}{llllllllll}60757,54 & 7250619,75 & 1,67 & 1,19 & 1,06 & 1,02 & 1,04 & 1,17 & 0.47\end{array}$ $\begin{array}{lllllllll}607781.04 & 7250628.30 & 1,30 & 1,42 & 1,47 & 1,17 & 1,48 & 1,66 & 1,57\end{array}$ $\begin{array}{lllllllll}607804,53 & 7250636,85 & 2,28 & 2,13 & 1,79 & 2,39 & 2,54 & 2,18 & 2,06\end{array}$ $\begin{array}{llllllllllll}607828,02 & 7250645,40 & 1,98 & 1,40 & 1,22 & 1,46 & 1,16 & 1,13 & 1,11\end{array}$

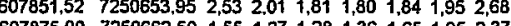
$\begin{array}{llllllllll}607875,00 & 7250662,50 & 1,55 & 1,27 & 1,28 & 1,36 & 1,65 & 1,95 & 2,37\end{array}$ $\begin{array}{llllllllll}607898,49 & 7250671,05 & 1,60 & 1,69 & 1,26 & 1,21 & 1,26 & 1,13 & 0,89\end{array}$ $\begin{array}{llllllllllll}60792 t, 99 & 7250679,60 & 1,45 & 1,19 & 1,51 & 1,83 & 1,84 & 1,94 & 1,74\end{array}$ $\begin{array}{lllllllllll}607945,48 & 7250688,15 & 1,43 & 1,76 & 1,37 & 1,74 & 1,83 & 2,09 & 1,95\end{array}$ $\begin{array}{lllllllllll}607968.97 & 7250696,71 & 1,96 & 2,14 & 1,33 & 1,47 & 1,46 & 1,69 & 1,38\end{array}$ $\begin{array}{lllllllllll}607992,46 & 7250705,25 & 2,43 & 2,24 & 1,59 & 1,73 & 1,82 & 1,93 & 2,49\end{array}$ $\begin{array}{llllllllllll}608015,96 & 7250713,80 & 4,11 & 2,71 & 2,32 & 2,82 & 3,17 & 3,28 & 3,17\end{array}$ $\begin{array}{lllllllll}607584,55 & 7250583,39 & 3,78 & 3,72 & 3,78 & 4,06 & 4,72 & 4,96 & 4,67\end{array}$ $\begin{array}{lllllllll}607608,04 & 7250591,93 & 3,29 & 2,25 & 2,45 & 2,67 & 2,87 & 3,17 & 3,47\end{array}$ $607631.537250600,492362272.633243 .574 .074,14$ $\begin{array}{llllllllll}607631,53 & 7250600,49 & 2,36 & 2.27 & 2,63 & 3,24 & 3,57 & 4,07 & 4,14\end{array}$ $\begin{array}{lllllllll}607655,03 & 7250609,04 & 1,67 & 1,88 & 2,21 & 2,09 & 2,47 & 2,55 & 2,14\end{array}$ $\begin{array}{lllllllllll}607678,51 & 7250617,58 & 1,76 & 1,36 & 1,27 & 1,32 & 1,29 & 1,38 & 1,22\end{array}$ $\begin{array}{llllllllll}607702,00 & 7250626,14 & 1,77 & 1,69 & 1,46 & 1,70 & 1,69 & 1,94 & 1,93\end{array}$ $\begin{array}{llllllllll}607725,50 & 7250634,69 & 1,90 & 1,85 & 2,03 & 1,66 & 1,61 & 1,30 & 1,20\end{array}$ $\begin{array}{llllllllll}607748,99 & 7250643,25 & 2,02 & 1,59 & 1,41 & 1,29 & 1,06 & 1,08 & 0.75\end{array}$ $\begin{array}{llllllllll}607772,40 & 7250651,79 & 2,30 & 1,80 & 1.37 & 1,24 & 1,10 & 1,16 & 1,03\end{array}$ $\begin{array}{llllllllll}607795,98 & 7250660,34 & 1,77 & 1,40 & 1,32 & 1,52 & 1,58 & 1,94 & 2,20\end{array}$ $\begin{array}{llllllllllll}607819,47 & 7250668,90 & 1,95 & 1,27 & 1,09 & 1,09 & 0,94 & 0,89 & 0,75\end{array}$ $\begin{array}{lllllllllll}607842,96 & 7250677,44 & 1,95 & 1,62 & 1,42 & 1,53 & 1,84 & 2,54 & 2,74\end{array}$ $\begin{array}{llllllllll}607866,45 & 7250685,99 & 2,02 & 2,43 & 2,12 & 1,78 & 1,98 & 1,96 & 2,45\end{array}$ $\begin{array}{lllllllllll}607889,95 & 7250694,55 & 1,66 & 1,51 & 1,52 & 1,07 & 1,22 & 1,62 & 1,76\end{array}$ $\begin{array}{lllllllllll}607913,44 & 7250703,09 & 2.58 & 2,36 & 1,69 & 1,94 & 2,13 & 2,39 & 3,17\end{array}$ $\begin{array}{llllllllll}607936,93 & 7250711,64 & 2,69 & 1,81 & 2,23 & 2,39 & 2,56 & 2,54 & 2,27\end{array}$ $\begin{array}{llllllllll}607960,43 & 7250720,20 & 2,91 & 1,61 & 1,62 & 1,84 & 2,22 & 2,44 & 2,40\end{array}$

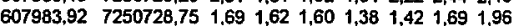
$\begin{array}{llllllllll}608007,40 & 7250737,29 & 2,12 & 1,82 & 1,03 & 1,44 & 1,63 & 1,97 & 2,29\end{array}$ $\begin{array}{lllllllll}607846,47 & 7250632.53 & 3.04 & 2,18 & 2.88 & 2.99 & 3.43 & 3.61 & 4,20\end{array}$ $607669,97 \quad 7250641,093,402,492,42 \quad 2,251,992,281,59$ $607693,46 \quad 7250649,63 \quad 4,443,903,166,21 \quad 4,114,093,69$ 607716,957250658 $\begin{array}{lllllllllll}607716,95 & 7250658,18 & 2,96 & 4,01 & 4,90 & 5,32 & 4,04 & 3,02 & 2,71\end{array}$ $\begin{array}{llllllllll}607740,45 & 7250666,74 & 2,68 & 2,06 & 2,08 & 1,99 & 1,80 & 1,56 & 1,37\end{array}$ $\begin{array}{lllllllll}607763,93 & 7250675,28 & 2,44 & 2,39 & 2,22 & 2,26 & 2,04 & 1,93 & 1,48\end{array}$ $\begin{array}{lllllllllll}607787,42 & 7250683,83 & 1,50 & 1,53 & 1,45 & 1,52 & 1,50 & 1,54 & 1,20\end{array}$ $\begin{array}{lllllllllll}607810,91 & 7250692,39 & 1,96 & 1,66 & 1,69 & 1,30 & 1,02 & 0,98 & 0,97\end{array}$ $\begin{array}{llllllllllll}607834,41 & 7250700,94 & 3.28 & 2.46 & 1,76 & 1,90 & 2.28 & 2,33 & 2,95\end{array}$ $\begin{array}{lllllllllll}607857,90 & 7250709,48 & 2,58 & 2,15 & 2,07 & 2,57 & 2,38 & 2,58 & 2,79\end{array}$ $\begin{array}{lllllllllll}607881,39 & 7250718,04 & 1,68 & 1,51 & 1,17 & 1,20 & 1,13 & 1,53 & 1,37\end{array}$ $\begin{array}{llllllllllll}607904,89 & 7250726.59 & 2,30 & 2,09 & 1,94 & 2,03 & 2,32 & 2,39 & 3,02\end{array}$

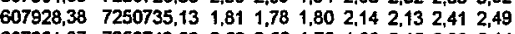
$\begin{array}{llllllllllll}607951,87 & 7250743,69 & 2,63 & 2,56 & 1,79 & 1,89 & 2,15 & 2,33 & 2,14\end{array}$ $\begin{array}{llllllllllll}607975,37 & 7250752,24 & 1,13 & 1,03 & 1,15 & 1,26 & 1,34 & 1,46 & 1,98\end{array}$ $\begin{array}{llllllllll}607998,86 & 7250760,78 & 1,87 & 1,42 & 1,43 & 1,10 & 1,27 & 1,66 & 1,70\end{array}$ $\begin{array}{llllllllllll}608022,35 & 7250769,34 & 2,60 & 1,62 & 1,23 & 1,26 & 1,53 & 1,92 & 2,36\end{array}$

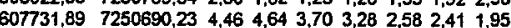
$\begin{array}{lllllllllll}607755,38 & 7250698,78 & 4,27 & 2.95 & 2.57 & 2.02 & 2,03 & 1,92 & 1,73\end{array}$ $607778,88 \quad 7250707,32 \quad 3,37 \quad 1,74 \quad 1,632,42 \quad 2,59277 \quad 2,55$ $\begin{array}{llllllllllll}607802,37 & 7250715,88 & 5,07 & 3,79 & 3,16 & 2,34 & 2,01 & 1,98 & 1,86\end{array}$ $\begin{array}{llllllllll}607825,86 & 7250724,43 & 2,02 & 1,48 & 1,51 & 1,73 & 1,87 & 231 & 2,03\end{array}$ $607849,36 \quad 7250732,97 \quad 1,50$ $\begin{array}{llllllll} & \\ 1,50 & 1,57 & 1,54 & 1,43 & 1,27 & \mathbf{1}, 56 & 2,03\end{array}$ $\begin{array}{lllllllllll}607872,04 & 7250741,53 & 2.05 & 1,40 & 1,75 & 1,47 & 1,50 & 1,74 & 2,10\end{array}$ $\begin{array}{lllllllllll}607896,33 & 7250750,08 & 1,57 & 1,35 & 1,37 & 0,95 & 1,14 & 1,36 & 1,68\end{array}$ $\begin{array}{lllllllll}6070 & 1,50\end{array}$ $\begin{array}{llllllllll}607943,32 & 7250767,18 & 1,89 & 2.07 & 1,62 & 1,51 & 1,62 & 1,77 & 1,95\end{array}$ $\begin{array}{llllllll} & \end{array}$ $\begin{array}{lllllllll}607990,30 & 7250784,28 & 1,66 & 2,20 & 1,36 & 1,40 & 1,60 & 2,04 & 3,02\end{array}$ $\begin{array}{llllllllll}608013.80 & 7250792.83 & 2,47 & 2,11 & 1,62 & 1,69 & 1,92 & 1,98 & 2,12\end{array}$


$\begin{array}{lllllllllll}607840,80 & 7250756,47 & 3.76 & 3,85 & 3,77 & 3,65 & 4,52 & 4,12 & 4,11\end{array}$ $\begin{array}{lllllllllllll}607864,30 & 7250765,02 & 2,05 & 1,46 & 1,77 & 1,51 & 1,53 & 1,75 & 1,86\end{array}$

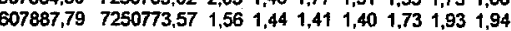
$\begin{array}{llllllllllll}607911,28 & 7250782.12 & 2,41 & 2.26 & 1,70 & 1,28 & 1,30 & 1,34 & 1,43\end{array}$ $\begin{array}{lllllllllll}607934,77 & 7250790,68 & 1,46 & 2,00 & 1,59 & 1,57 & 1,99 & 1,92 & 2,37\end{array}$ $\begin{array}{llllllllll}607958,27 & 7250799,22 & 1,84 & 1,81 & 3,98 & 2,52 & 2,33 & 2,49 & 2,31\end{array}$ $\begin{array}{llllllllll}607981.76 & 7250807.77 & 1,14 & 1,66 & 1,85 & 2,37 & 2,29 & 2,61 & 3,02\end{array}$ $\begin{array}{lllllllll}608005,25 & 7250816,33 & 2,21 & 1,98 & 2,02 & 1.84 & 1,89 & 1,91 & 2,48\end{array}$ $607902,73 \quad 7250805,615,705,534,32 \quad 3,023,223,433,73$ $607926,227250814,175,685,144,364,094,20,437,73$

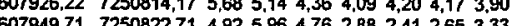
$\begin{array}{llllllllll}607949.71 & 7250822,71 & 4,92 & 5,96 & 4,76 & 2,88 & 2,41 & 2,65 & 3,33\end{array}$ $\begin{array}{llllllllllll}607973,21 & 7250831,26 & 1,82 & 1,67 & 1,35 & 1,55 & 1,72 & 2,15 & 2,38\end{array}$ $\begin{array}{lllllllll}607996,70 & 7250839,82 & 2,91 & 1,82 & 1,88 & 1,78 & 1,98 & 1,79 & 2,12\end{array}$ \begin{tabular}{llllllllll}
607964,65 & 7250854,75 & 4,31 & 2,88 & 2,13 & 1,66 & 1,62 & 1,84 & 2,36 \\
607988,14 & 7250863,31 & 3,68 & 3.16 & 2,67 & 2,18 & 1,95 & 2,18 & 2.71 \\
\hline
\end{tabular} 